University of Rhode Island

DigitalCommons@URI

Open Access Dissertations

1988

\title{
A PHYSICO-CHEMICAL STUDY OF THE COMPLEXATION OF CYCLODEXTRINS WITH PHARMACEUTICAL SUBSTANCES
}

Francois A. Menard

University of Rhode Island

Follow this and additional works at: https://digitalcommons.uri.edu/oa_diss

\section{Recommended Citation}

Menard, Francois A., "A PHYSICO-CHEMICAL STUDY OF THE COMPLEXATION OF CYCLODEXTRINS WITH PHARMACEUTICAL SUBSTANCES" (1988). Open Access Dissertations. Paper 184.

https://digitalcommons.uri.edu/oa_diss/184

This Dissertation is brought to you for free and open access by DigitalCommons@URI. It has been accepted for inclusion in Open Access Dissertations by an authorized administrator of DigitalCommons@URI. For more information, please contact digitalcommons-group@uri.edu. 


\title{
A PHYSICO-CHEMICAL STUDY \\ OF THE COMPLEXATION OF CYCLODEXTRINS WITH PHARMACEUTICAL SUBSTANCES
}

\section{$B Y$}

FRANCOIS A. MENARD

A DISSERTATION SUBMITTED IN PARTIAL FULFILLMENT OF THE REQUIREMENTS FOR THE DEGREE OF DOCTOR OF PHILOSOPHY

IN

PHARMACEUTICAL SCIENCES

\author{
UNIVERSITY OF RHODE ISLAND
}




\section{DOCTOR OF PHILOSOPHY DISSERTATION \\ OF}

FRANCOIS A. MENARD

\section{Approved :}

Dissertation Committee

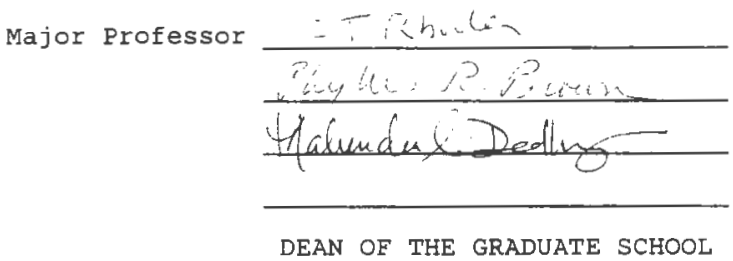

UNIVERSITY OF RHODE ISLAND

1.988 


\section{ABSTRACT}

The complexation of drugs with alpha, beta, gamma and hydroxyethyl beta cyclodextrins was investigated using the solubility method described by Higuchi and Connors. Beta cyclodextrin was shown to exhibit the most extensive complexation. The solubility isotherms of complexation were studied at different temperatures and at various pH conditions. The effect of ionization of drugs on complexation was thus evaluated for four drugs viz phenytoin, diazepam, ibuprofen and hydrochlothiazide. In the case of phenytoin and diazepam, both the non-ionized and the ionized species were shown to form a complex with cyclodextrins. The slope of complexation for ibuprofen and hydrochlorothiazide was found to be $\mathrm{pH}$-independent. The thermodynamic parameters of complexation were determined using the temperature dependence method. In order to characterize more specifically the parameters of complexation, a novel computerized method was then developed. A non-linear regression software was used to evaluate the values of the complexation parameters as well as their standard deviation and $95 \%$ confidence limit. The complexation of drugs with hydroxyethyl beta cyclodextrin showed that the substitution of the natural cyclodextrin affected the solubility of the complexing agent without altering its solubilizing power. A rule of prediction was 
then proposed, allowing the calculation of potential drug concentration upon complexation with the cyclodextrin derivative. The ratio of solubility of the two kinds of cyclodextrins was shown to correlate very well with the ratio of the concentration of drug complexed. The rule might be applied to all drugs at various $\mathrm{pH}$ values. The potential use of beta cyclodextrin as an additive in tableting was also evaluated. The mechanism of dissolution rate enhancement was found to be related not only to the inclusion complex formation but also to mechanical changes during the mixing process. 
I would like to express my thanks to my Major Professor, Dr. Christopher T. Rhodes, for his constant support, his scientific guidance and his great professional approach. I believe that it has been a fruitful and enjoyable teamwork for both of us.

I am very grateful to research committee members, Dr. P. Brown and Dr. M. Dedhiya. Dr. Brown has been very helpful and a great source of enthusiasm. Dr. Dedhiya has been a great advisor and a friend since our first association in 1984 .

During my four years in the Department of Pharmaceutics, I have seen people coming and going. I would especially like to thank Dr. B. Birmingham and Dr. M. Gardner, who had been assisting me in the computer aspects of the research project, and Dr. A. Paruta, who has been of great assistance. Also I thank Dr. G. Osborne, who was always there to give me the right advise, and Dr. J. Lausier, who has been of great help and support.

I would like to express my thanks to all the Faculty members of the University, with whom I took courses; they will be forever a part of my life and my future.

I also want to thank my fellow graduate students, those who have already left, those who are leaving soon, and those who are going to carry the torch for the next several years. 
I would like to express my gratitude to Miles Pharmaceuticals, the University of Rhode Island, Dr. Rhodes and the Department of pharmaceutics for the financial support throughout my graduate studies.

I also want to thank Dr. D.C. Monkhouse, who gave me the advise to pursue graduate studies and who served on the comittee until 1986.

I would like to thank my parents for their love and support. They have always been there when I needed them. Finally, I want to dedicate this work to my wife Elena, whom I met when I first came to Rhode Island, and who became my light in the darkness and my hope during the difficult steps. 
To my wife Elena 
PREFACE

This dissertation follows the format of the MANUSCRIPT PLAN, as described in section 11-3 of the Graduate Manual of the University of Rhode Island. The work is presented in three sections. Section I contains the introduction to the project and the objectives of the study. Section II consists of five manuscripts, which represent the core of the study. At the time of the defense, three manuscripts will have been either accepted or at least submitted to international scientific journals. The two other manuscripts are written according to the format suitable for publication. Section three consists of the specific details related to the various aspects of the study. The appendices thus describe either certain experimental considerations or computer manipulations. Appendix A is a manuscript published in Drug Development and Industrial Pharmacy, that is related to a study performed at Miles Pharmaceuticals, West Haven, CT, where the author of this thesis was awarded a Graduate student summer fellowship. Appendix B reports a study performed at the University of Rhode Island, in association with Dr. J. L. Kanig, who is an adjunct Professor in the Department of Pharmaceutics. Appendices $\mathrm{C}$ to I allows the reader to repeat certain procedures or to obtain more details regarding the computer work. 
TABLE OF CONTENTS

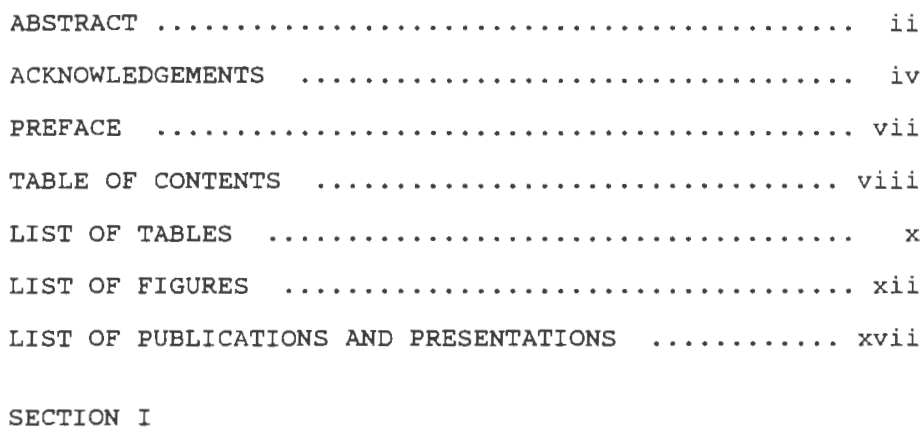

INTRODUCTION OF THE PROBLEM $\ldots \ldots \ldots \ldots \ldots \ldots \ldots \ldots$

\section{SECTION II}

MANUSCRIPTS

I A STUDY OF THE EFFECT OF PH, TEMPERATURE AND RING SIZE ON THE COMPLEXATION OE PHENYTOIN WITH

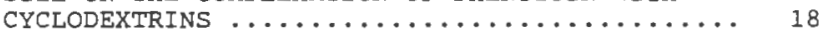

II DETERMINATION OF THERMODYNAMIC PARAMETERS OF COMPLEXATION USING A NON-LINEAR REGRESSION METHOD

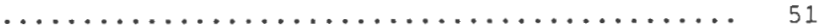

III POTENTIAL PHARMACEUTICAL APPLICATIONS OF A NEW BETA CXCLODEXTRIN DERIVATIVE ............. 77

IV PHYSICO-CHEMICAL ASPECTS OF THE COMPLEXATION OF SOME DRUGS WITH CYCLODEXTRINS ........... 110

$\checkmark$ POTENTIAL USE OF BETA CYCLODEXTRIN AS AN ADDITIVE IN TABLET FORMULATION $\ldots \ldots \ldots \ldots \ldots \ldots \ldots \ldots$

CONCLUSIONS AND SUGGESTIONS FOR FUTURE WORK $\ldots \ldots 176$ 
SECTION III

APPENDICES

A RELATIONSHIPS BETWEEN COMPRESSION PROEILE AND PHYSICAL PROPERTIES OF A LITHIUM CARBONATE

TABLET FORMULATION $\ldots \ldots \ldots \ldots \ldots \ldots \ldots \ldots \ldots \ldots 1$

B A COMPARATIVE STUDY OF SEVERAL LACTOSE PRODUCTS FOR DIRECT COMPRESSION TABLETING ............. 200

C DESCRIPTION OF THE EXPERIMENTAL PROTOCOL ..... 220

D SUMMARY OF SOLUBILITY ISOTHERMS $\ldots \ldots \ldots \ldots \ldots . \ldots 240$

E STATISTICAL TREATMENT OF DATA ........... 269

F NONLIN: PROGRAMS AND RESULTS $\ldots \ldots \ldots \ldots \ldots \ldots . \ldots 284$

G SASGRAPH: PROGRAMS AND RESULTS ........... 302

H BIBLIOGRARHY $\ldots \ldots \ldots \ldots \ldots \ldots \ldots \ldots \ldots \ldots \ldots \ldots \ldots \ldots$ 


\section{LIST OF TABLES}

\section{Manuscript I}

Table 1 Apparent heat of solution of phenytoin at

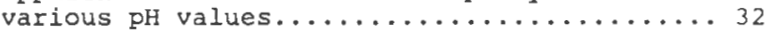

Table 2 Apparent values of the complexation constant and the free energy of complexation for phenytoin and beta cylodextrin at $20^{\circ} \mathrm{C} \ldots \ldots .33$

Table 3 Enthalpy and entropy values for the complexation of phenytoin (unionized and ionized) with beta cyclodextrin at various $\mathrm{pH}$ values......... 34

Manuscript II

Table 1 Thermodynanic parameters of complexation from a simulated set of data...........68

Table 2 overall enthalpies and entropies of complexation for the phenytoin/beta cyclodextrin interaction..............6 69

Table 3 Enthalpies and entropies for the complexation of phenytoin with beta cyclodextrin.......70

Manuscript III

Table I Basic properties of cyclodextrins......... 90

Table II Concentrations of drug complexed with beta and substituted beta cyclodextrins........... 91

Manuscript IV

Table I Values of the heat of solution of the drugs at various $\mathrm{pH}$ values................126

Table II Thermodynamic parameters for the ibuprofen/ $\beta$ cyclodextrin complexation............ 127

Table III Thermodynamic parameters for the diazepam/ $\beta$ cyclodextrin complexation............. 128

Table IV Thermodynamic parameters for the hydrochlorothiazide/ $\beta$ cyclodextrin complexation...... 129 
Manuscript $\mathrm{V}$

Table 1 Phenytoin: $\beta$ cyclodextrin formulations ..... 162

Table 2 Phenytoin: $\beta$ cyclodextrin formulations containing

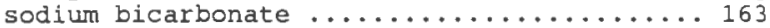

Table 3 process variables .................. 164

Table 4 Tablet specifications ............. 165 Appendix A

Table I Physical properties of ingredients ....... 191 Appendix B

Table 1 Elow properties ................... 208

Table 2 Lubrication study (compaction force $=5 \mathrm{kN}$ ) 209

Table 3 Evaluation of 10 o hydrochlorothiazide tablets 210

Table 4 Evaluation of $10 \%$ hydrochlorothiazide tablets

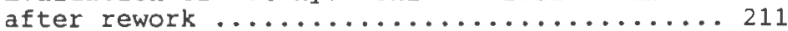

Appendix $\mathrm{C}$

Table 1 Direction of approach to equilibrium ...... 227 


\section{LIST OF FIGURES}

Introduction

Figure 1 schematic representation of the formation of cyclodextrin inclusion complexes ......... 14

Figure 2 Schematic representation of the thermodynamic process of drug:cyclodextrin complexation .. 16

Manuscript I

Figure 1 solubility profile of phenytoin at $25^{\circ} \mathrm{C} \ldots \ldots 36$

Figure 2 Plgt of $\log (\mathrm{S} / \mathrm{So}-1$ ) as a function of $\mathrm{pH}$ at

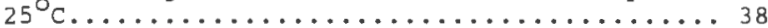

Figure 3 Complexation of phenytoin with alpha, beta and gamma cyclodextrins...............4 40

Figure 4 Complexation of phenytoin with beta cyclodextrin at $\mathrm{pH}$.................42

Figure 5 Determination of the overall enthalpy and entropy for the complexation of phenytoin with beta cyclodextrin................ 44

Figure 6 Effect of $\mathrm{pH}$ on the complexation of phenytoin with beta cyclodextrin at $20^{\circ} \mathrm{C} \ldots \ldots \ldots . . .46$

Figure 7 Effect of $\mathrm{pH}$ on the complexation of phenytoin with beat cyclodextrin at $20^{\circ} \mathrm{C}$. un=unionized. The lines noted un are parallel to the pH 5 solubility isotherm.................48

Figure 8 Solubility isotherms for the complexation of ionized phenytoin with beta cyclodextrin

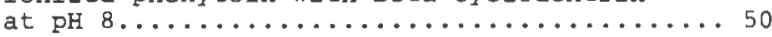

Manuscript II

Figure 1 Typical solubility isotherm of the complexation of unionized phenytoin with beta cyclodextrin at

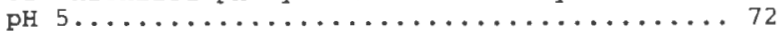

Figure 2 Typical solubility isotherm of the complexation of phenytoin with beta cyclodextrin at $\mathrm{pH}>7 \ldots \ldots \ldots \ldots \ldots \ldots \ldots \ldots$ 
Manuscript III

Figure I Complexation of phenytoin with beta cyclodextrins at $40^{\circ} \mathrm{C}$ and $\mathrm{pH} 5 \ldots \ldots \ldots . \ldots 9$

Figure II complexation of diazepan with beta cyclodextrins at $30^{\circ} \mathrm{C}$ and $\mathrm{pH} 6 \ldots \ldots . \ldots 9$

Figure III Complexation of ibuprofen with beta cyclodextrins at $50^{\circ} \mathrm{C}$ and $\mathrm{pH} \ldots \ldots \ldots 97$

Figure IV Complexation of hydrochlorothiazide with beta cyclodextrins at $50^{\circ} \mathrm{C}$ and $\mathrm{pH} 5 \ldots \ldots \ldots . \ldots 9$

Eigure $V$ Complexation of drugs with beta and substituted beta cyclodextrins........... 101

Figure VI Solubility of phenytoin as a function of temperature and substituted beta cyclodextrin

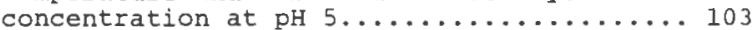

Figure VII Solubility of diazepam as a function of temperature and substituted beta cyclodextrin concentration at $\mathrm{pH} 6 \ldots \ldots . .105$

Figure VIII Solubility of ibuprofen as a function of temperature and substituted beta cyclodextrin concentration at pH $5 \ldots \ldots \ldots \ldots \ldots \ldots \ldots$

Figure IX Solubility of hydrochlorothiazide as a function of temperature and substituted beta cyclodextrin concentration at $\mathrm{pH} 5 \ldots \ldots \ldots 109$

Manuscript IV

Figure 1 Van't Hoff plots for the mole fraction solubility of ibuprofen............... 131

Figure 2 Van't Hoff plots for the mole fraction solubility of diazepam...............133

Figure 3 Van't Hoff plots for the mole fraction solubility of hydrochlorothiazide........ 135

Figure 4 Effect of $\mathrm{pH}$ on the solubility isotherms of ibuprofen at $50^{\circ} \mathrm{C} \ldots \ldots \ldots \ldots \ldots \ldots \ldots \ldots \ldots . \ldots . \ldots 137$

Figure 5 Effect of $\mathrm{pH}$ on the solubility isotherms of diazepam at $50^{\circ} \mathrm{C} \ldots \ldots \ldots \ldots \ldots \ldots \ldots . \ldots . \ldots 139$

Figure 6 Effect of $\mathrm{pH}$ on the solubility isotherms of hydrochlorothiazide at $50^{\circ} \mathrm{C} \ldots \ldots \ldots \ldots \ldots . . .141$ 
Figure 7 Effect of temperature on the solubility isotherms of diazepam at $\mathrm{pH} 4 \ldots \ldots \ldots \ldots 143$

Figure 8 Three-dimensional plot of the solubility of ibuprofen at $\mathrm{pH} 5 \ldots \ldots \ldots \ldots \ldots \ldots \ldots \ldots \ldots . \ldots \ldots$

Figure 9 Three-dimensional plot of the solubility of hydrochlorothiazide at $\mathrm{pH}$ 8......... 147

Figure 10 Three-dimensional plot of the solubility of diazepan at $\mathrm{pH} 6 \ldots \ldots \ldots \ldots \ldots \ldots \ldots \ldots \ldots$

Manuscript $v$

Figure 1 Dissolution profiles at $37^{\circ} \mathrm{C}$ in water: Effect of Drug:CD ratio ....................... 167

Figure 2 Dissolution profiles at $37^{\circ} \mathrm{C}$ in water: Effect of

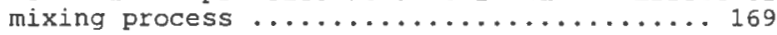

Figure 3 Dissolution profiles at $37^{\circ} \mathrm{C}$ in water: Effect of order of mixing .................... 171

Figure 4 Dissolution profiles at $37^{\circ} \mathrm{C}$ : Effect of

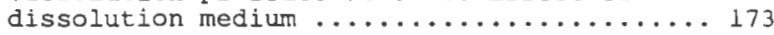

Figure 5 Dissolution profiles at $37^{\circ} \mathrm{C}$ and $\mathrm{pH} 7.4$ : Effect of sodium bicarbonate ............... 175

Appendix A

Figure 1 Particle size distribution ............ 193

Figure 2 Compression profile ...................... 195

Figure 3 Hardness/Compaction profile ............ 197

Figure 4 Dissolution profiles of lithium carbonate ... 199 Appendix B

Eigure 1 compaction profiles ............... 213

Figure 2 Drug capacity (10\% hydrochlorothiazide) .... 215

Figure 3 Drug capacity $(20 \%$ hydrochlorothiazide) .... 217

Figure 4 Lubrication study .................... 219 Appendix C

Figure 1 Time to reach equilibrium ............. 229

Eigure 2 U.V. calibration curve for phenytoin ...... 231 
Figure $3 \mathrm{U} . \mathrm{V}$. calibration curve for ibuprofen ...... 233

Figure $4 \mathrm{U} . \mathrm{V}$. calibration curve for diazepam ....... 235

Figure $5 \mathrm{U.V}$. calibration curve for hydrochlorothiazide 237

Figure $6 \mathrm{U} . \mathrm{V}$. Plot of solubility isotherm for phenytoin239 Appendix D

Figure 1 Complexation of phenytoin with $\beta^{\prime} \mathrm{CD}$ at $\mathrm{pH} 5242$

Figure 2 Complexation of phenytoin with $\beta^{\prime} \mathrm{CD}$ at pH 8243

Figure 3 complexation of ibuprofen with $\beta \mathrm{CD}$ at $30^{\circ} \mathrm{C}$ and

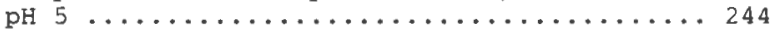

Figure 4 Complexation of ibuprofen with $\beta \mathrm{CD}$ at pH 2245

Figure 5 Complexation of ibuprofen with $\beta$ CD at pH $4 \quad 246$

Figure 6 Complexation of ibuprofen with $\beta$ CD at pH $5 \quad 247$

Figure 7 Complexation of ibuprofen with $\beta \mathrm{CD}$ at pH 6248

Figure 8 Complexation of ibuprofen with $\beta \mathrm{CD}$ at $20^{\circ} \mathrm{C} \quad 249$

Figure 9 Complexation of ibuprofen with $\beta \mathrm{CD}$ at $30^{\circ} \mathrm{C} 250$

Figure 10 complexation of ibuprofen with $\beta \mathrm{CD}$ at $40^{\circ} \mathrm{C} 251$

Figure 11 Complexation of ibuprofen with $\beta \mathrm{CD}$ at $50^{\circ} \mathrm{C} 252$

Figure 12 Complexation of diazepam with $\beta \mathrm{CD}$ at pH 2253

Figure 13 complexation of diazepam with $\beta$ CD at pH 3254

Eigure 14 Complexation of diazepam with $\beta \mathrm{CD}$ at pH 4255

Figure 15 complexation of diazepam with $\beta$ CD at pH $6 \quad 256$

Figure 16 complexation of diazepam with $\beta \mathrm{CD}$ at $20^{\circ} \mathrm{C} \quad 257$

Figure 17 Complexation of diazepam with $\beta \mathrm{CD}$ at $30^{\circ} \mathrm{C} \quad 258$

Figure 18 complexation of diazepam with $\beta \mathrm{CD}$ at $40^{\circ} \mathrm{C} \quad 259$

Figure 19 Complexation of diazepam with $\beta \mathrm{CD}$ at $50^{\circ} \mathrm{C} 260$

Figure 20 Complexation of hydrochlorothiazide with

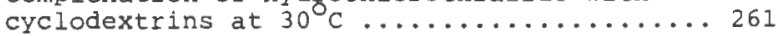

Figure 21 complexation of hydrochlorothiazide with $\beta \mathrm{CD}$

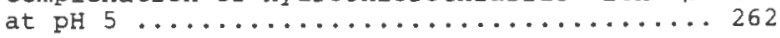


Figure 22 Complexation of hydrochlorothiazide with $\beta$ CD

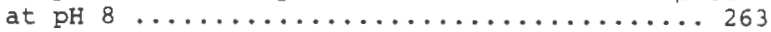

Figure 23 Complexation of hydrochlorothiazide with $\beta C D$

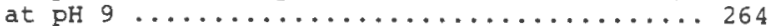

Figure 24 Complexation of hydrochlorothiazide with $\beta C D$

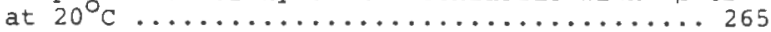

Figure 25 Complexation of hydrochlorothiazide with $\beta C D$

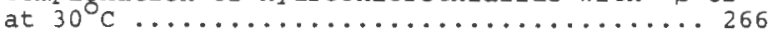

Figure 26 Complexation of hydrochlorothiazide with $\beta C D$

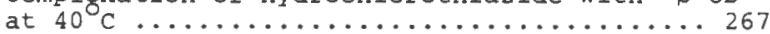

Eigure 27 Complexation of hydrochlorothiazide with $\beta \mathrm{CD}$

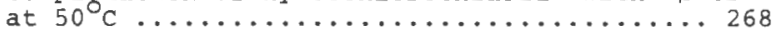

Appendix G

Figure 1 Complexation of phenytoin with $\beta$ CD at pH 5311

Eigure 2 Complexation of phenytoin with $\beta$ CD at $p H \quad 7 \quad 312$

Figure 3 Complexation of phenytoin with $\beta \mathrm{CD}$ at $\mathrm{pH} \quad 8 \quad 313$

Figure 4 Complexation of phenytoin with $\beta \mathrm{CD}$ at $\mathrm{pH} 9 \quad 314$

Figure 5 Complexation of ibuprofen with $\beta$ CD at pH 2315

Figure 6 Complexation of ibuprofen with $\beta$ CD at pH $4 \quad 316$

Figure 7 Complexation of ibuprofen with $\beta$ CD at pH $5 \quad 317$

Figure 8 Complexation of ibuprofen with $\beta$ CD at pH $6 \quad 318$

Figure 9 Complexation of diazepam with $\beta$ CD at pH $2 \quad 319$

Figure 10 Complexation of diazepam with $\beta$ CD at $\mathrm{pH} 3320$

Figure 11 Complexation of diazepam with $\beta$ CD at pH $4 \quad 321$

Figure 12 Complexation of diazepam with $\beta$ CD at pH $6 \quad 322$

Figure 13 Complexation of hydrochlorothiazide with $\beta C D$ at

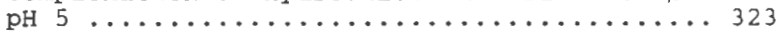

Figure 14 Complexation of hydrochlorothiazide with $\beta C D$ at

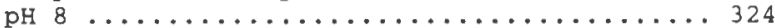

Figure 15 Complexation of hydrochlorothiazide with $\beta C D$ at

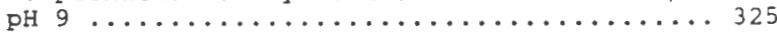




\section{PUBLICATIONS AND PRESENTATIONS}

1. Relationship between compression profile and physical properties of a lithium carbonate formulation.

M.G. Dedhiya, C.W. Woodruff, C.T. Rhodes and F.A. Menard. Presented at the 132 nd A.Ph.A. meeting, San Antonio, TX

(February 1985). Drug Dev. Ind. Pharm., 14 (1), (1988).

2. A comparative study of several lactose products for direct compression tableting. F.A. Menard and J. L. Kanig. Report submitted to Sheffield Products Inc.

3. A physico-chemical study of the complexation of phenytoin with cyclodextrins. F.A. Menard, Miles Pharmaceuticals, west Haven, CT., (October 1986).

4. Determination of thermodynamic parameters of the phenytoin/cyclodextrins complexation. F.A. Menard, M.G. Dedhiya and C.T. Rhodes. Presented at the 2nd A.A.P.S. Meeting, Boston, MA, (June 1987).

5. A study of the effect of $\mathrm{pH}$, temperature and ring size on the complexation of phenytoin with cyclodextrins. F.A. Menard, M.G. Dedhiya and C.T. Rhodes. Submitted to Pharm. Acta Helv., (1987).

6. Determination of thermodynamic parameters using non-linear regression. F.A. Menard, M.G. Dedhiya and C.T. Rhodes. Submitted to Pharm. Acta Helv., (1988).

7. Potential pharmaceutical applications of a new beta cyclodextrin derivative. F.A. Menard, M.G. Dedhiya and C.T. Rhodes. Submitted to Drug Dev. Ind. Pharm., (1988).

8. Physico-chemical aspects of the complexation of drugs with cyclodextrins. F.A. Menard, M.G. Dedhiya and C.T. Rhodes. To be submitted to J. Pharm. Sci., (1988).

9. Potential use of beta cyclodextrin as an additive in tablet formulation. $F^{\prime}$.A. Menard, M.G. Dedhiya and C.T. Rhodes. To be submitted to Journal de Pharmacie de Belgique, (1988). 


\section{INTRODUCTION}

Many of the new chemical entities recently synthesized or discovered in the pharmaceutical industry possess poor physico-chemical properties, which impact adversely on formulation. Thus low solubility, limited stability and erratic bioavailability sometimes make the development of acceptable dosage forms impossible. In addition, some drugs formely discarded for their formulation problems have recent $1 Y$ attracted new interest. One major new tool of solubilization and stabilization of drugs in the pharmaceutical industry has been the use of cyclodextrins. Cyclodextrins are cyclic oligosaccharides. The three major forms of cyclodextrins viz $\alpha, \beta$ and $\gamma$ consist of six, seven or eight units of glucose, respectively (1). The size of the cavity of these molecules gives the unique opportunity to adjust the affinity between the drug and the complexing agent, and therefore to optimize the complexation (2). There has been keen interest in the phenomenon of cyclodextrin complexation for the past decade or so, in the field of chemicals, agriculture and pharmaceuticals $(3,4,5)$ as well as in the food industry. The affinity of certain molecules for cyclodextrins has been the basis of many applications of cyclodextrin conplexation. Cyclodextrins have been used as enzymatic model in biochemistry and as a separation material in analytical 
chemistry (6). The terms clathrate, complex, inclusion compound and monomolecular encapsulate have all been used to refer to cyclodextrin complexation.

within the pharmaceutical industry, there are three advantages to cyclodextrin complexation:

a) the improvement of solubility, dissolution rate and bioavailability $(7,8,9)$;

b) the stabilization of drugs $(10,11)$;

c) the amelioration of organo-leptic properties such as sme1l or taste.

Numerous excellent reviews of the subject of complexation of drugs with cyclodextrins have been published in the past few years. Special references will be given to two books, edited by sjeztli (1) and Duchene (3). The review articles by Uekama (4) and Hegde (12) give a complete overview of history, structure, toxicity, uses and limitations of cyclodextrins in the pharmaceutical industry. Numerous publications have appeared in the literature, especially from Japan, during the past ten years. The structure of the work done is usually presented as a sequence of four steps $(13,14,15)$ :

a) results showing the complexation of the drug considered with cyclodextrin using the solubility method, spectroscopy, conductivity or diffusion;

b) preparation of the complex by freeze-drying or solvent evaporation; 
c) results of the physical properties of the complex prepared using Proton Magnetic Resonance (PMR), X-Ray crystallography, Infra-Red spectroscopy or Differential Scanning Calorimetry (DSC), and elucidation of the stoichiometry of the complex;

d) evidence of the advantages of complex formation by in-vitro dissolution studies or in-vivo animal bioavailability results.

The two areas lacking in-depth work have been the design of dosage forms of the drug/cyclodextrin complex, and the study of the physico-chemical aspects of the complexation phenomenon.

In this introduction the different aspects of cyclodextrin complexation, which have been suggested and discussed in the literature, will be briefly reviewed. special attention will be then given to the physical chemistry and the thermodynamics of complexation. The two main thermodynamic parameters considered will be the enthalpy, which corresponds to the heat exchange upon complexation, and the entropy, which may be largely regarded as reflecting the degree of order of the system. In addition, the current regulatory status of cyclodextrins in the Food and Drug industry world-wide will be discussed.

The mechanism of complexation of drugs with cyclodextrins is based on some basic characteristics of the cyclodextrin molecules. Each glucose unit included in the ring contains three hydroxyl groups: $c(2)$ and $C(3)$ are 
secondary hydroxyl whereas $c(6)$ is a primary hydroxyl. These hydroxyl groups are also of critical importance in the preparation of cyclodextrin derivatives, which have been synthetized and have great potential applications in the pharmaceutical industry (16). The hydroxyl groups laying on the outer surface of the ring give to the cyclodextrin molecule its hydrophilicity. The inside of the cavity is hydrophobic due to the glucosic oxygen bridges. Upon complexation, the apolar guest molecule will approach the host molecule of cyclodextrin and will fit into the cavity. The mechanism of cyclodextrin complexation in water or aqueous buffered solutions is closely related to the nature of the solvent. Water can be considered as a mixture of free water molecules and structured material. The water molecules are subject to hydrogen bonding; when a large number of hydrogen bonds are established, a structure calied clusters or ice-like hydrogen bonded material is formed (17). From a thermodynamic point of view, water is thus a very versatile solvent, with continual formation and rupture of hydrogen bonds. Water will influence the thermodynamics of complexation at two different levels: the water molecules trapped inside the cyclodextrin cavity are iceberg-like and enthalpy-rich, and a non-polar molecule will be also surrounded by structured water, likely to be perturbed upon complexation.

The complex formation can be represented by the schemes shown in Figures 1 and 2. Figure 1 represents the non polar 
aromatic ring of a potential guest molecule, that will replace the energetically rich water molecules from the inside of the cyclodextrin cavity. The result of this displacement will be a favorable non polar/non polar interaction. A more detailed representation is shown in Figure 2 .

The different steps occuring during the complexation formation process have been proposed as follows $(18,19)$ : a) the guest molecule or drug approaches the cyclodextrin molecule;

b) the ice-like water trapped in the cyclodextrin cavity is displaced, with loss of structure and corresponding release of energy;

c) the water molecules surrounding the apolar portion of the drug to be included are broken down and water molecules go into solution;

d) substituents of the drug interact with either the rim or the inside of the cyclodextrin ring;

e) hydrogen bonds may be formed between the drug and cyclodextrin;

f) the water structure is reestablished around the drug and cyclodextrin.

The question of the exact driving force in complex formation has been subject to controversy. The different theories proposed are as following:

1. Hydrophobic interaction 
The water molecules around the apolar drug are broken down. The increased degree of freedom of the liberated water molecules corresponds to a negative entropy and a positive enthalpy upon complexation.

2. Van der Waals interaction

This type of interaction can originate either from dipole/dipole (Keesom forces), dipole/induced dipole (Debye forces) or induced dipole/induced dipole (London forces) interaction. The van der wals forces are weak and are unlikely to establish stable complexes by themselves. These forces would correspond to a negative enthalpy and a negative entropy.

\section{Hydrogen bonding}

The inclusion complex formation involves three components: the drug or guest molecule, the cyclodextrin or host molecule and the solvent. Different possibilities of interaction exist between these three components. Not only drug and cyclodextrin can interact, but also the solvent interacts with both the drug and the cyclodextrin. Some substances have been shown to function as Hydrogen bond donors. However this mechanism of complexation is generally regarded of minor importance, since the average bond energy is only 2 to $8 \mathrm{Kcal}^{\mathrm{mol}}{ }^{-1}$.

4. Release of high energy water 
Water can be considered as existing with two different structures: water molecules can be tightly bound to water-solvating charged sites to form hydrogen bonding; water molecules enclosed within the cyclodextrin cavity cannot have a full complement of hydrogen bonds and are enthalpy-rich. The expulsion of these enthalpy-rich water molecules into bulk water upon complexation seems to be a major factor in the mechanism. The thermodynamic parameters observed in this case are usually a negative enthalpy and a negative entropy.

5. Release of conformational strain

This mode of action should be especially of critical importance in the case of alpha cyclodextrin complexation, that has the lowest number of glucose units. The torsion of the cyclodextrin molecules would be affected upon penetration of the guest molecule into the cavity, thus releasing energy.

Even though no general rule has been entirely accepted, it appears that a combination of the different factors described earlier is likely to play a role in the complex formation. The relative combination of each factor will depend upon the drug and the type of cyclodextrin. However, the definite point of agreement is that the thermodynamics of complexation deserve attention and clarification. It is generally accepted that both the extent and the sign of the 
thermodynamic parameters viz enthalpy and entropy will give a clear indication of the process involved. Furthermore, a variation of $\mathrm{pH}$. leading to a change in the ionization of the drug will undoubtedly affect the polarity of the drug, thus influencing the complexation phenomenon.

One major concern in the pharmaceutical industry has been the regulatory status of cyclodextrins. The nature of the interaction forces involved in the drug/cyclodextrin complex formation should give to the final product the status of materials such as solid dispersions, which means that a simplified approval process with no recognized new chemical entity may apply. In order to be approved for commercial use in food and drug products, a compound has to be Generally Regarded As Safe (GRAS) and usually a Drug Master File (DMF) will then be established with the Food and Drug Administration (FDA). The acceptance of a DMF is based of the results of clinical, toxicological and metabolic studies. Usually not only acute toxicity results, but also results from chronic use of the substance are required by the FDA. In the case of cyclodextrins, it appears that acute and chronic toxicity have been carried out in rats and dogs, but there is limited long term toxicity data. A report by the Food and Agriculture organization (FAO) classified cyclodextrins as enzymatically modified starches. This position seems to be confirmed by various European Health Agencies, which also recently considered $\beta$ 
cyclodextrin as an enzymatically modified starch. Since 1983, the use of $\beta$ cyclodextrin is thus approved for stabilization of flavors. In 1986. France granted approval for the use of $\beta$ cyclodextrin as a flavor carrier. A major breakthrough in the approval process has been the efforts of a Dutch starch company, Aebe, to gather data and to gain approval in Netherlands, Belgium and Luxemburg. German and Spanish authorities seem to follow the same position and are expected to approve cyclodextrins for food products (20). However, as far as the drug industry is concerned, the only products on the market world-wide are Prostaglandin/cyclodextrin complexes in Japan. Thus, ono Pharmaceuticals has launched a tablet formulation in 1976 and an injectable dosage form in 1979 (21).

The objectives of this study were:

1. To contribute to the characterization of the physico-chemical parameters that control the complexation of drugs with cyclodextrins;

2. To evaluate the effect of $\mathrm{pH}$ and temperature on the complexation of some drugs with cyclodextrins and to estimate the thermodynamic characteristiscs of the system at various conditions;

3. To develop a mathematical model using non-linear regression to calculate enthalpy and entropy of complexation;

4. To evaluate the potential use of a new $\beta$ cyclodextrin 
derivative as a complexing agent;

5. To investigate the properties of $\beta$ cyclodextrin as an additive in tablet formulation.

\section{REFERENCES}

1. J. Szejtli, Cyclodextrins and their inclusion complexes, Akademiai Kiado, Budapest (1982).

2. R. Breslow, Biomimet. Bioorg. Chem., 1-15 (1980).

3. Cyclodextrins and their industrial uses, Ed. de Sante, Paris (1987).

4. K. Uekama, Cyclodextrins in drug carrier systems, CRC Press (1986).

5. D. Duchene, B. Debrueres and C. Vaution, STP Pharm., 1 (1), 37-43 (1985).

6. E. Smolkova-Keulemansova and S. Krysl, J. Chromat., 184, 347-361 (1980).

7. S.Y. Lin and J.C. Yang, Pharm. Weekblad Sc. Ed., 8, $223-228(1986)$.

8. K. Uekama, T. Fujinaga, M. Otagiri, N. Matsuo and Y. Matsuoka, Acta Pharm. Suec., 20, 287-294 (1983).

9. T. Tokumura, T. Tsushima, M. Kanayo, Y. Machida and T. Nagai, J. Pharm. Sci., 74 (4), 496-497 (1985).

10. K. Uekama and F. Hirayama, Chem. Pharm. Bull., 26 (4), 1195-1200 (1978).

11. M, Kirushi, F. Hirayama and K. Uekama, Chem. Pharm. Bul1., 35 (1), 315-319 (1987).

12. R.P. Hegde, Ph.D. Thesis, University of Rhode Island (1985).

13. K. Uekama, N. Matsuo, F. Hirayama, T. Yamagushi, Y. Imamura and H. Ichibagase, Chem. Pharm. Bull., 27 (2), $398-402(1979)$.

14. H. Seo, M. Tsuruokoa, T. Hashimoto, F. Fujinaga, M. otagiri and K. Uekama, Chem. Pharm. Bull., 31 (1), 
286-291(1983).

15. K. Uekama, E. FUjinaga, F. Hirayama, M. Otagiri and $M$. Yamasaki, Int. J. Pharm., 10, 1-15 (1982).

16. B. Sebille, Cyclodextrins and their industrial uses, Ed. de Sante, Paris (1987).

17. G. Nemethy and H.A. Scheraga, J. Chem. Phys., 36 (2), 3401-3417 (1962).

18. Y. Matsui, T. Nishioka and T. Fujita, Biomet. Bioorg. Chem., 128, 61-89 (1985).

19. I. Tabushi, Y, Kiyosuke, T. Sugimoto and K. Yamamura, J. Am. Chem. Soc., 100 (3), 916 (1978).

20. Cyclodextrin News, $1(10), 1$ (1987).

21. K. Inaba, Personal communication (1986). 
Figure 1

Schematic representation of the formation of cyclodextrin inclusion complexes 
14

Figure 1

Schematic representation of the formation of cyclodextrin inclusion complexes

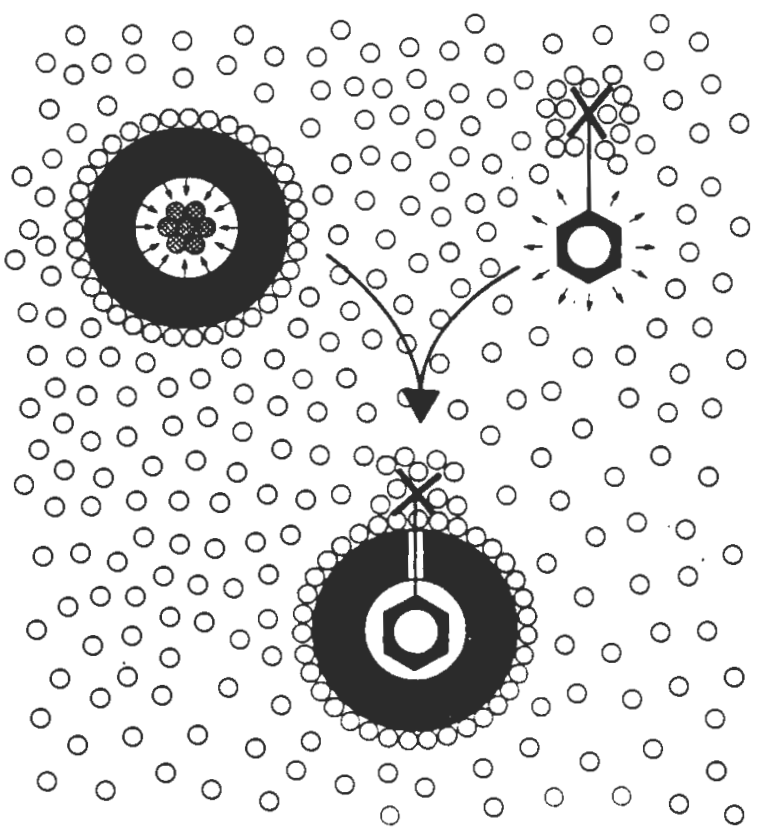


Figure 2

Schematic representation of the thermodynamic process of drug:cyclodextrin complexation 
Figure 2

Schematic representation of the thermodynamic process of drug:cyclodextrin complexation

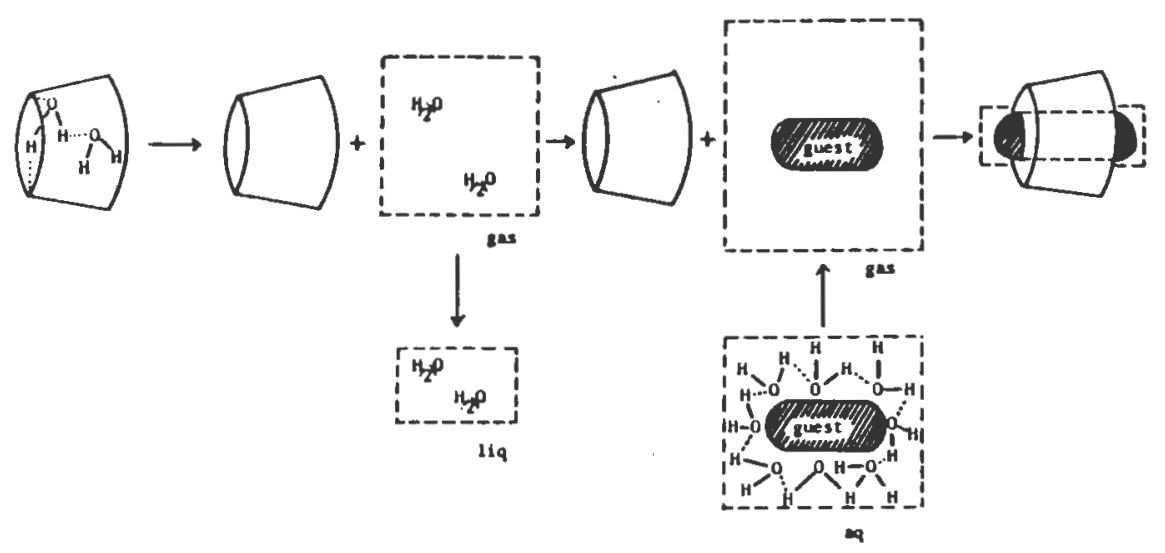


SECTION II 
MANUSCRIPT I 


\title{
STUDIES OF THE EFFECT OF PH, TEMPERATURE \\ AND RING SIZE ON THE COMPLEXATION OF PHENYTOIN WITH CYCLODEXIRINS
}

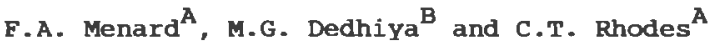 \\ A Department of Pharmaceutics, University of Rhode Island \\ B Kingston RI 02881-0809 \\ Miles Pharmaceuticals $\mathbf{4 0 0}$ Morgan Lane \\ West Haven CT 06516
}

\section{INTRODUCTION}

The molecular encapsulation of pharmaceutical

substances by cyclodextrins has been shown to enhance the solubility and the dissolution of a drug $(1,2)$, to decrease drug degradation (3) and to improve the absorption from the gastro-intestinal tract (4) and through the skin (5). phenytoin, a widely used anticonvulsant, has a low aqueous solubility and follows non linear pharmacokinetics (6). A coprecipitate of phenytoin with polyvinylpyrrolidone has been shown to produce a significant increase in the drug dissolution rate (7). Phenytoin has been reported to interact with beta cyclodextrin and to form a 1:1 complex (8). The complexation of phenytoin with cyclodextrins could improve solubility and dissolution rate of the drug as well as decrease the intra- and inter-variability of the absorption in patients.

Numerous publications in the field of drug/cyclodextrin complexation describe briefly studies of the complexation by the solubility method, but do not always indicate the exact 
conditions of the experiments ( $\mathrm{pH}$, ionic strength of the solutions). Few published studies are actually focused on the physico-chemical aspects of the complexation of drugs with cyclodextrins. The objective of the study was to investigate the effect of temperature and $\mathrm{pH}$ on the thermodynamics of the complexation, and to propose a model of the complexation mechanism, describing how both the unionized and the ionized forms of phenytoin interact with cyclodextrins.

\section{EXPERTMENTAL}

\section{Materials}

Phenytoin ${ }^{a}$ and alpha, beta and gamma cyclodextrins ${ }^{b}$ were used as received. All other reagents or solvents were of analytical grade. Deionized water was used to prepare all buffer solutions, which were adjusted to an ionic strength of 0.3 using potassium chloride.

\section{Methods}

Ultra-violet analysis of phenytoin. Phenytoin was assayed using a Hewlett-Packard HP 8451A diode array Ultra-Violet spectrophotometer at a wavelength of $225 \mathrm{~nm}$. The Beer-Lambert law was obeyed and the molar absorptivity at $225 \mathrm{~nm}$ was found to be $6.72 \times 10^{3}$.

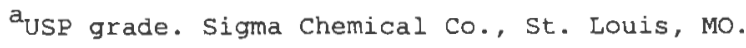

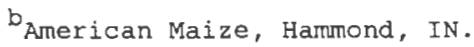


pKa determination. The pKa of phenytoin was determined from the solubility data using the Benet approach (9).

Solubility studies. The solubility method described by Higuchi and Lach (10) was used under different $\mathrm{pH}$ and temperature conditions. An excess of phenytoin was placed into screw-capped vials containing solutions of cyclodextrins at various concentrations. The vials were shaken using a rotating unit in a controlled temperature (+ $\left.0.1^{\circ} \mathrm{C}\right)$ waterbath. The time needed to reach equilibrium was determined to be about four hours. The samples were then pipetted, filtered through glass wool and diluted before being analyzed to determine the total concentration of phenytoin. All sampling, filtration and dilution steps were carried out in a constant temperature walk-in oven.

\section{RESULTS AND DISCUSSION}

\section{pKa determination}

The solubility of phenytoin as a function of $\mathrm{pH}$ is shown in Figure 1. From the plot shown in Figure 2, the value of $\mathrm{pKa}$ was determined to be 8.2 , which is in good agreement with the literature values $(11,12)$.

\section{Heat of solution}

The solubility of phenytoin was determined at different temperatures. The Van't Hoff equation gives a relationship between the solubility expressed in mole fraction and the absolute temperature for and ideal solution: 


$$
-\log \mathrm{Xi}=(\Delta \mathrm{Hf} / \mathrm{RT})+\text { constant }
$$

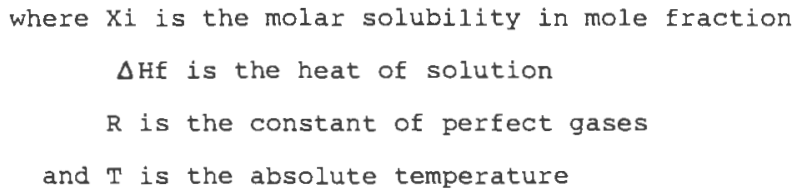

Table 1 shows the values of the heat of solution at different $\mathrm{pH}$ values. As $\mathrm{pH}$ increases, the heat of solution decreases, showing that the ionized form of phenytoin needs less energy to go into solution.

\section{Effect of ring size}

The solubility measurements were carried out using three cyclodextrins viz alpha, beta and gamma. Figure 3 shows the solubility isotherms of phenytoin with the three cyclodextrins at $25^{\circ} \mathrm{C}$. Phenytoin interacts with alpha and gamma cyclodextrins, but to a much lesser extent than with beta cyclodextrin. According to the Higuchi and Lach approach (10), and assuning the formation of a $1: 1$ complex, the apparent thermodynamic constant of complexation could be calculated from the slope and the intercept of the straight Iines obtained in Figure 3 .

$$
\mathrm{K}=\mathrm{SI} / \mathrm{I}(1-\mathrm{sl})
$$

where $K$ is the apparent thermodynamic constant 


\begin{abstract}
SI is the slope of the solubility isotherm and $I$ is the intercept of the solubility isotherm
\end{abstract}

The values of the complexation constants were determined to be $110 \mathrm{M}^{-1}, 850 \mathrm{M}^{-1}$ and $149 \mathrm{M}^{-1}$ at $25^{\circ} \mathrm{C}$ and $\mathrm{pH}$ 7 for alpha, beta and gamma cyclodextrins respectively.

\title{
Effect of temperature
}

Figure 4 shows the plot of the solubility of phenytoin as a function of cyclodextrin concentration at temperatures ranging from $20^{\circ} \mathrm{C}$ to $50^{\circ} \mathrm{C}$ and $\mathrm{pH}$ 5. At each temperature, the apparent complexation constant was calculated using equation (2). The apparent change in free energy $\Delta G$ was then computed from the following equation:

$$
\Delta G=-R T \text { ln } K
$$

The thermodynamic parameters of complexation were determined using the Gibbs equation:

$$
\Delta G=\Delta H-T \Delta S
$$

Figure 5 shows the plot of $\Delta G$ as a function of $T$ at $p H$ 5. The slope and the intercept correspond to the entropy $(\Delta S)$ and the enthalpy $(\Delta H)$ of complexation respectively. 
Figure 6 shows the solubility isotherms of phenytoin/cyclodextrin complexation at various $\mathrm{pH}$ values. From the straight lines obtained, the apparent values of the complexation constant and the free energy were determined and are shown in Table 2 at a given temperature of $20^{\circ} \mathrm{C}$. As $\mathrm{pH}$ increased the slope value increased showing that the ionized form of the drug does interact with beta cyclodextrin. However the interaction of the ionized form is weaker than for the unionized species.

The same experiment was performed at different temperatures. Table 3 shows the values of the overall entropy and enthalpy of complexation, calculated from the Van't Hoff plots, similar to that shown in Figure 5. The values in Table 3 are actually the geometric mean of the individual thermodynamic parameters describing the complexation for both the unionized and the ionized forms of phenytoin.

As $\mathrm{pH}$ increased, the intercept of the straight lines shown in Figure 6 increased, due to the ionization of phenytoin, which has a pKa of 8.3. However, as $\mathrm{pH}$ increased, the slope of the solubility isotherms also increased, clearly demonstrating a further increase of the total phenytoin concentration as shown in Figure 7 .

The following model was developed to describe the complexation process: 


$$
\mathrm{Ki}=\left(\mathrm{A}^{-} / \mathrm{CD}\right) /\left(\mathrm{A}^{-}\right)(\mathrm{CD}) \mathrm{i}
$$

where $\mathrm{Ku}$ and $\mathrm{Ki}$ are the apparent thermodynamic complexation constants for the unionized and ionized forms of phenytoin respectively. (CD) u and (CD) i correspond to the free cyclodextrin concentration at $\mathrm{pH} 5$ and $\mathrm{pH}>7$ respectively.

At any pH value, the total concentration of phenytoin and cyclodextrin, respectively noted (Phenytoin)t and (CD)t, can be expressed as:

$$
\begin{aligned}
(\text { Phenytoin }) t & =(A H)+(A H / C D)+\left(A^{-}\right)+\left(A^{-} / C D\right) \\
(C D) t & =(C D) i+(A H / C D)+\left(A^{-} / C D\right)
\end{aligned}
$$

By substituting at any given temperature one set of data ( $\mathrm{pH}$ 5) from another ( $\mathrm{pH}>7$ ), it is possible to obtain a plot of $\left(A^{-}\right)+\left(A^{-} / C D\right)$ as a function of $(C D) t$, as shown in Figure 8. The intercept corresponds to the concentration of the ionized species of phenytoin, and the slope can be written as:

$$
\text { slope }=\left(A^{-} / C D\right) /(C D) t
$$

By combining equations (7), (8) and (9):

$$
\begin{aligned}
\text { slope }=\mathrm{Ki}\left(\mathrm{A}^{-}\right)(\mathrm{CD}) \mathrm{i} /(\mathrm{CD}) \mathrm{i} & +\mathrm{Ku}(\mathrm{AH})(\mathrm{CD}) \mathrm{u} \\
& +\mathrm{Ki}\left(\mathrm{A}^{-}\right)(\mathrm{CD}) \mathrm{i}
\end{aligned}
$$


The expression $\mathrm{Ku}(\mathrm{AH})$ (CD) corresponds to ( $\mathrm{AH} / \mathrm{CD}$ ) at $\mathrm{pH}$ 5. The concentration of the free cyclodextrin varies with $\mathrm{pH}$, but can be expressed as a function of (CD) u at $\mathrm{pH} 5$, according to the following equation:

$$
(C D) i=r(C D) u
$$

where $r$ is the proportionality factor between (CD) $i$ and $(C D) u$.

Therefore, at $\mathrm{pH}>7$ :

$$
\text { slope }=K i\left(A^{-}\right) r /\left(r+K u(A H)+K i\left(A^{-}\right) r\right)
$$

$\mathrm{AH}$ and $\mathrm{A}^{-}$represent the intercepts shown in Figure 6. $\mathrm{AH}$ is the intercept (I) at $\mathrm{pH} 5$, and $\mathrm{A}^{-}$is the intercept ( ${ }^{-}$) at $\mathrm{pH}>7$.

If $\mathrm{SI}^{-}$represents the slope of the solubility isotherm at $\mathrm{pH} \mathrm{7:}$

$$
\begin{aligned}
& \mathrm{SI}^{-}=\mathrm{Ki} \mathrm{I}^{-} \mathrm{I} /\left(\mathrm{I}+\mathrm{KuI}+\mathrm{Ki} \mathrm{I}^{-} \mathrm{r}\right) \\
& \mathrm{rSI} I^{-}+\mathrm{KuISI^{- }}+\mathrm{Ki} \mathrm{I}^{-} \mathrm{r} \mathrm{SI}^{-}=\mathrm{Ki} \mathrm{I}^{-} \mathrm{r} \\
& \mathrm{Ki}=\left(\mathrm{SI}^{-}(\mathrm{r}+\mathrm{KuI}), /\left(\mathrm{I}^{-} \mathrm{I}\left(1-\mathrm{SI}^{-}\right)\right)\right.
\end{aligned}
$$

Equation 15 allows for the determination of the apparent complexation constant of the ionized form of phenytoin with beta cyclodextrin. 
The apparent values of the complexation constant (Ki) and the free energy $(\Delta \mathrm{Gi})$ were computed at different temperatures, and the Gibbs equation was used to determine the enthalpy $(\Delta \mathrm{Hi})$ and entropy ( $\Delta \mathrm{Si}$ ) of the ionized species of phenytoin with beta cyclodextrin.

The values are reported in Table 3. The coefficient of correlation of the linear plot obtained at pH 5 was high $(r=0.966$ in Figure 5). However, in the case of the complexation of the ionized species with beta cyclodextrin, the coefficient of correlation was lower (from $r=0.8$ to $r=0.6)$. The relatively poor correlation is probably due to the noise in the experimental values and to the fact that the data used for the plots from $\mathrm{pH} 7$ to $\mathrm{pH} 10$ were obtained by substraction of one set of data from another. Thus, the thermodynamic parameters obtained for the ionized species, since they are derived from two sets of experimental data, have the potential of twice as much an experimental error than in the case of the unionized species. At $\mathrm{pH} 7$ and $\mathrm{pH} 8$, the plot was linear at a $90 \%$ confidence level. The use of a computerized approach, providing a more precise determination of the thermodynamic parameters together with the exact standard deviation of the values, would allow a more extensive discussion of the results.

\section{SUMMARY}

Phenytoin interacts much more strongly with beta cyclodextrin than with alpha or gamma cyclodextrins. This 
result is in accordance with previously reported work, indicating that geometric parameters play a major role in controlling the mechanism of complexation (the hand in glove theory).

The study at various $\mathrm{pH}$ values shows that both the non-ionized and the ionized forms of phenytoin interact with cyclodextrins. If the purely geometric consideration were to be confirmed, the ionized species should either not interact at all, or interact to the same extent. The ionized form of phenytoin is shown here to interact to a much lesser extent, suggesting that some chemical parameters are involved in the complexation.

There are a few examples in the literature show the interaction of both species (15-18). The possible delocalization of electrons or the influence of the energy of solvation have been proposed but no definite explanation has been established.

The biopharmaceutical implications of the interaction of cyclodextrins with both species are quite significant. For an orally administered dosage form of the complex, the change of $\mathrm{pH}$ through the gastro-intestinal tract will eventually lead to a different overall amount of bound drug, with a clear effect on the bioavailability of the drug. For an intravenous injection, the dissociation of the complex would occur at $\mathrm{pH} 7.2$ to 7.6 . The assumption of a solely unionized form of the bound drug to cyclodextrin with both the unionized and the ionized forms free would then create 
an error in the results. For any type of interaction, Riegelman described the free drug as the activity factor and the bound drug as the capacity factor. The possible complexation of the ionized species with cyclodextrins in an intravenous solution would actually decrease the amount of free drug, but would also increase the amount of bound drug, therefore increasing the effective overall biological half-life.

\section{ACKNOWLEDGEAMENTS}

The authors are grateful to Miles Pharmaceuticals for financial support in the study, and American Maize for providing the cyclodextrin materials.

\section{REFERENCES}

1. D.D. Chow and A.D. Kanara. Int. J. Pharmaceutics. 28, 95-101 (1986).

2. K. Uekama, F. Hirayama, A. Eujise, M. Otagiri, K. Inaba and $\mathrm{H}$ Saito. J. Pharm. Sci. 73 (3), 382-384 (1984).

3. P. Hsyu, R.P. Hegde, B.K. Birmingham and C.T. Rhodes. Drug DEv. Ind. Pharm. 10 (4), 601-611 (1984).

4. T. Tokumura, Y. Tsushima, K. Tatsuishi, M. Kayano, Y. Machida and T. Nagai. Chem.Pharm.Bull. 33 (7), 2962-2967 $(1985)$.

5. K. Uekama, M. Otagiri, S. Sakai, T. Irie, N. Matsuo and Y. Matsuoka. J.Pharm. Pharmacol. 37 (8), 532-535 (1985).

6. E. Martin, T.N. Tozer, L.B. Sheiner and S. Riegelman. J. Pharmacokinetics Biopharm. 5 (6), 579-598 (1977).

7. S. Yakou, S. Yamasaki, T. Sonobe, T. nagai and M. sughihara. Chem. Pharm. Bu11. 34 (8), 3408-3414 (1986). 
8. R.P. Hegde and C.T. Rhodes. Pharm.Act.Helv. 6 (53), (1985).

9. C.C. Peck and L.Z. Benet. J.Pharm.Sci. 67 (1), 12-16 (1978).

10. T. Higuchi and J.L. Lach. J.Am.Pharm.Assoc. 43, 349 $(1954)$.

11. P.A. Schwartz, C.T. Rhodes and J.W. Cooper. J.Pharm.Sci. $66,994-997(1977)$.

12. S.P. Agarwal and M.I. Blake. J.Pharm.Sci. 57 (8), 1434-1435 (1968).

13. R.L. Vanttten, J.F. Sebastian, G.A. Clowes and M.I. Bender. J.Am. Chem.Soc. 89 (13), 3242-3262 (1967).

14. B. Siegel and R. Breslow. J.Am.Chem.Soc. 97 (23), 6869-6970 (1975).

15. T.K. Korpela and J.-P. Himanen. J.Chromatogr. 290, $351-361$ (1984).

16. R.J. Bergeron, M.A. Channing and K.A. MCGovern.

J.Am. Chem.Soc. 100 (9), 2878-2883 (1978).

17. K.A. Connors and J.M. Lipari. J.Pharm.Sci. 65 (3), 379-383 (1976).

18. K. Uekama, F. Hirayama, S. Nasu, N. Matsuo and T. Irie. Chem.Pharm. Bull. 26 (11), 3477-3484 (1978). 
Table 1

Apparent heat of solution of phenytoin at various $\mathrm{pH}$ values

\begin{tabular}{cc}
\hline pH & $\Delta$ Hf $(\mathrm{Kcal} / \mathrm{mole})$ \\
\hline 5 & 4.208 \\
7 & 4.224 \\
8 & 3.329 \\
9 & 2.325 \\
\hline
\end{tabular}




\section{Table 2}

Apparent values of the complexation constant and the free energy of complexation for phenytoin and beta cyclodextrin at $20^{\circ} \mathrm{C}$

\begin{tabular}{llll}
$\mathrm{pH}$ & $\mathrm{K}\left(\mathrm{M}^{-1}\right)$ & $\Delta \mathrm{G}(\mathrm{Kcal} / \mathrm{mole})$ & $\Delta \mathrm{G}(\mathrm{KJ} / \mathrm{mole})$ \\
\hline 5 & 847.9 & -3.93 & -16.43 \\
7 & 923.9 & -3.98 & -16.64 \\
8 & 695.9 & -3.82 & -15.97 \\
9 & 277.0 & -3.28 & -13.71
\end{tabular}




\section{Table 3}

Enthalpy and entropy values for the complexation of phenytoin (ionized and unionized) with beta cyclodextrin at various pHs

\begin{tabular}{lrrrr}
\hline & pH 7 & pH 8 & pH 9 & pH 10 \\
\hline$\Delta H i(\mathrm{Kcal} / \mathrm{mole})$ & -5.0 & -6.3 & -7.3 & -5.5 \\
$\Delta \mathrm{Si}(\mathrm{cal} / \mathrm{mole} / \mathrm{K})$ & -5.0 & -9.7 & -14.0 & -9.8 \\
& $\mathrm{pH} 5$ & & \\
$\Delta \mathrm{Hu}(\mathrm{kcal} / \mathrm{mole})$ & -9.1 \\
$\Delta \mathrm{Su}(\mathrm{cal} / \mathrm{mole} / \mathrm{K})$ & -16.0
\end{tabular}


Eigure 1

Solubility profile of phenytoin at $25^{\circ} \mathrm{C}$ 


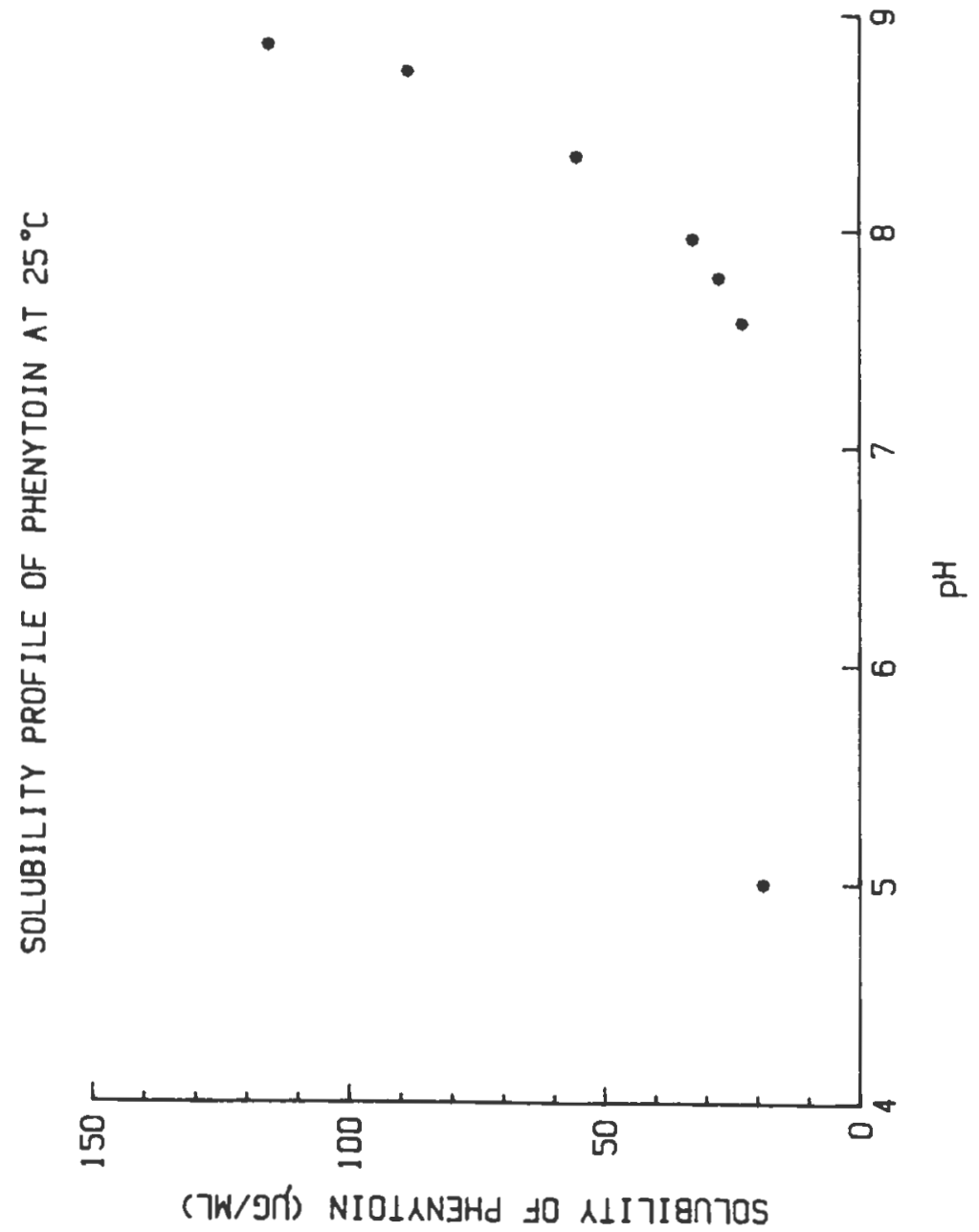


Figure 2

Plot of $\log (\mathrm{s} / \mathrm{So}-1)$ vs pH at $25^{\circ} \mathrm{C}$ 


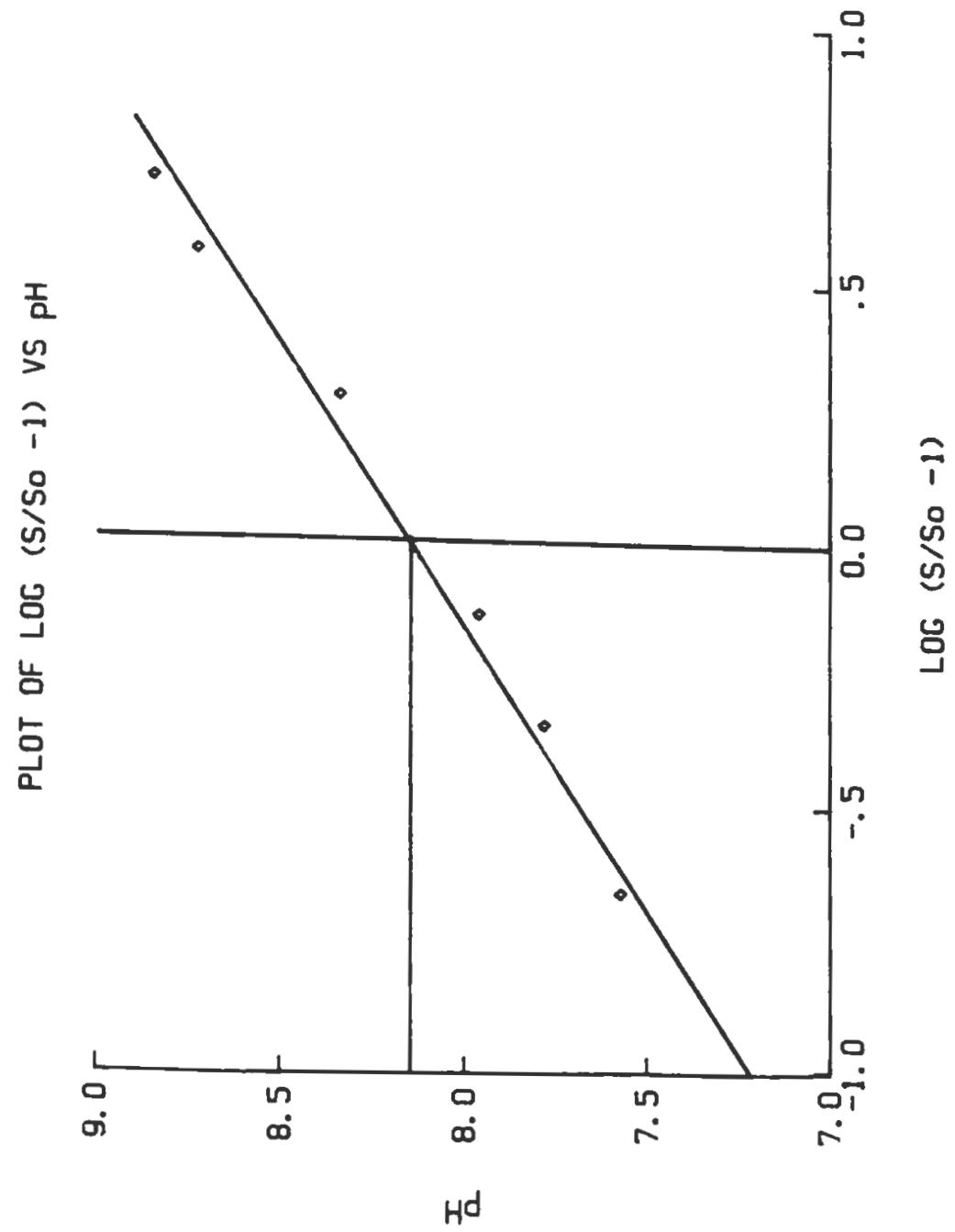




\section{Figure 3}

Complexation of phenytoin with $\alpha, \beta$ and $r y c l o d e x t r i n s$ 


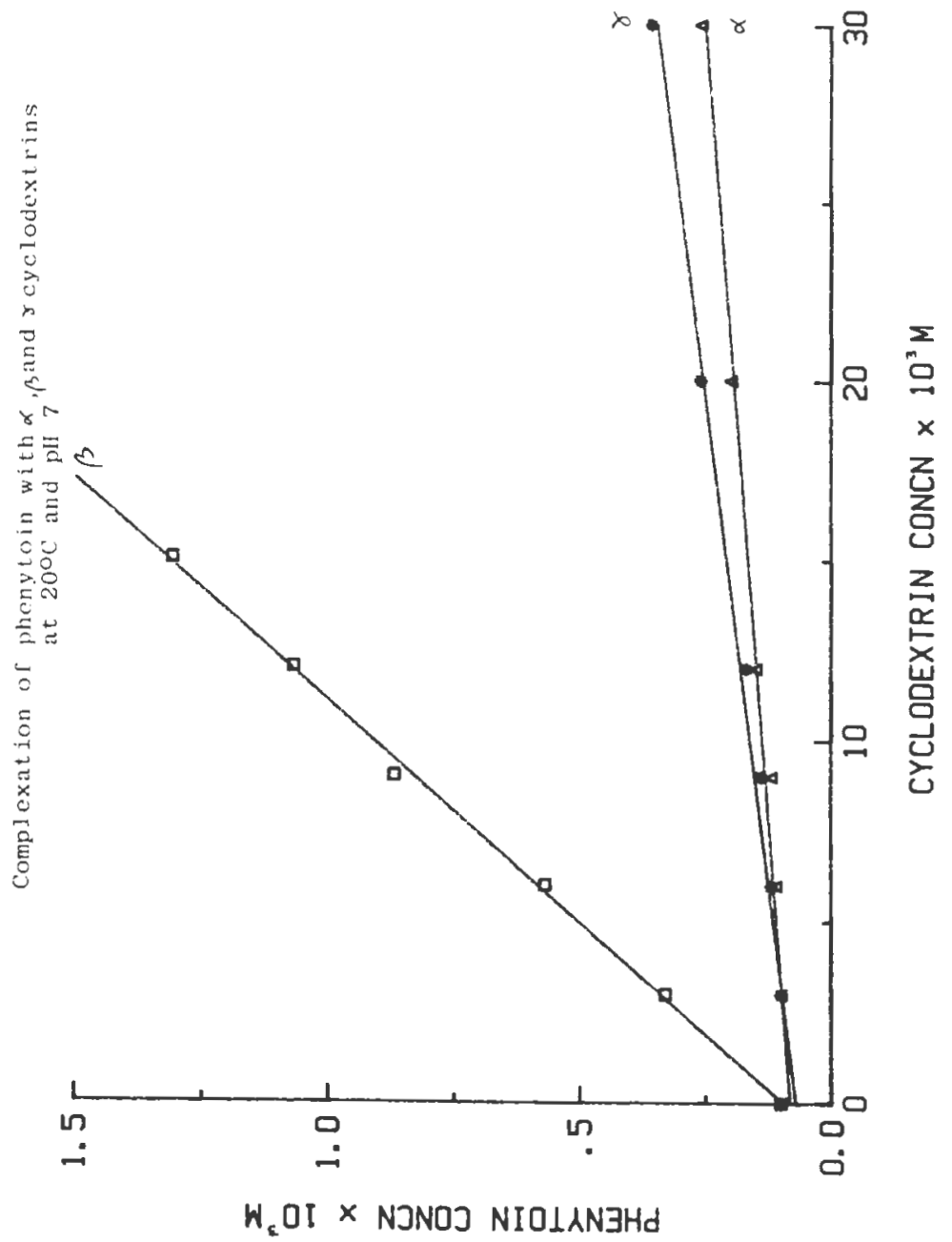


Figure 4

Complexation of phenytoin with $\beta$ cyclodextrin at pH 5 


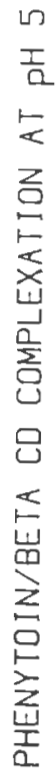

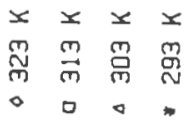
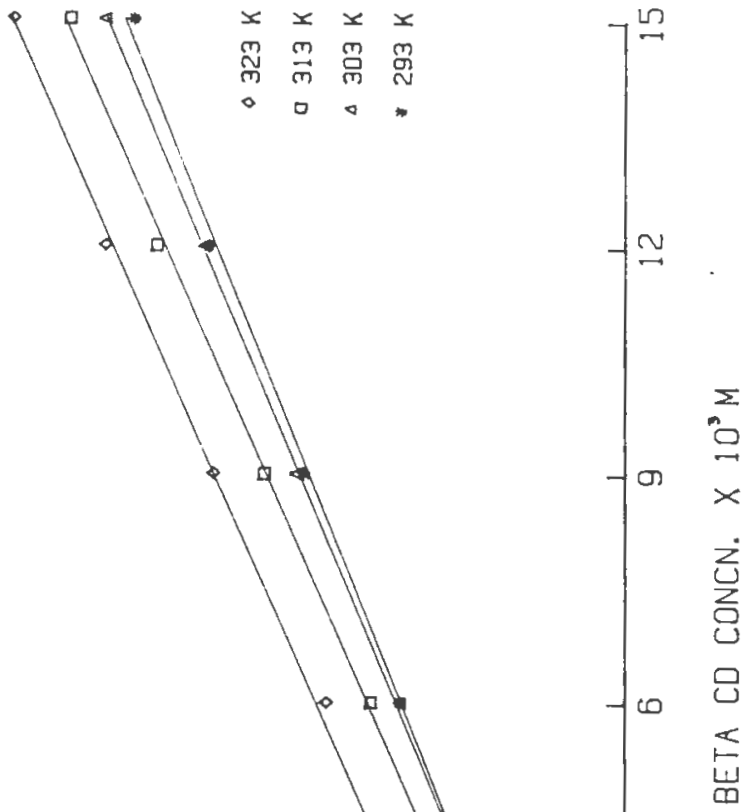

$\Sigma$

O

$x$

忘

9

点

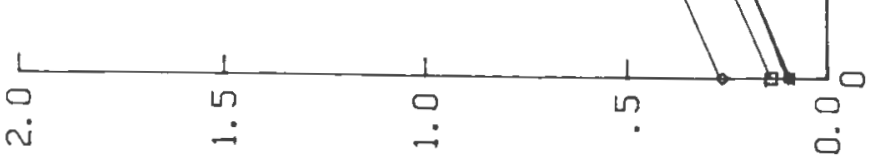

$W_{\varepsilon}$ OI X "NJNOJ NIOLANGHA 


\section{Figure 5}

Determination of the overall enthalpy and entropy for the complexation of phenytoin with $\beta$ cyclodextrin 


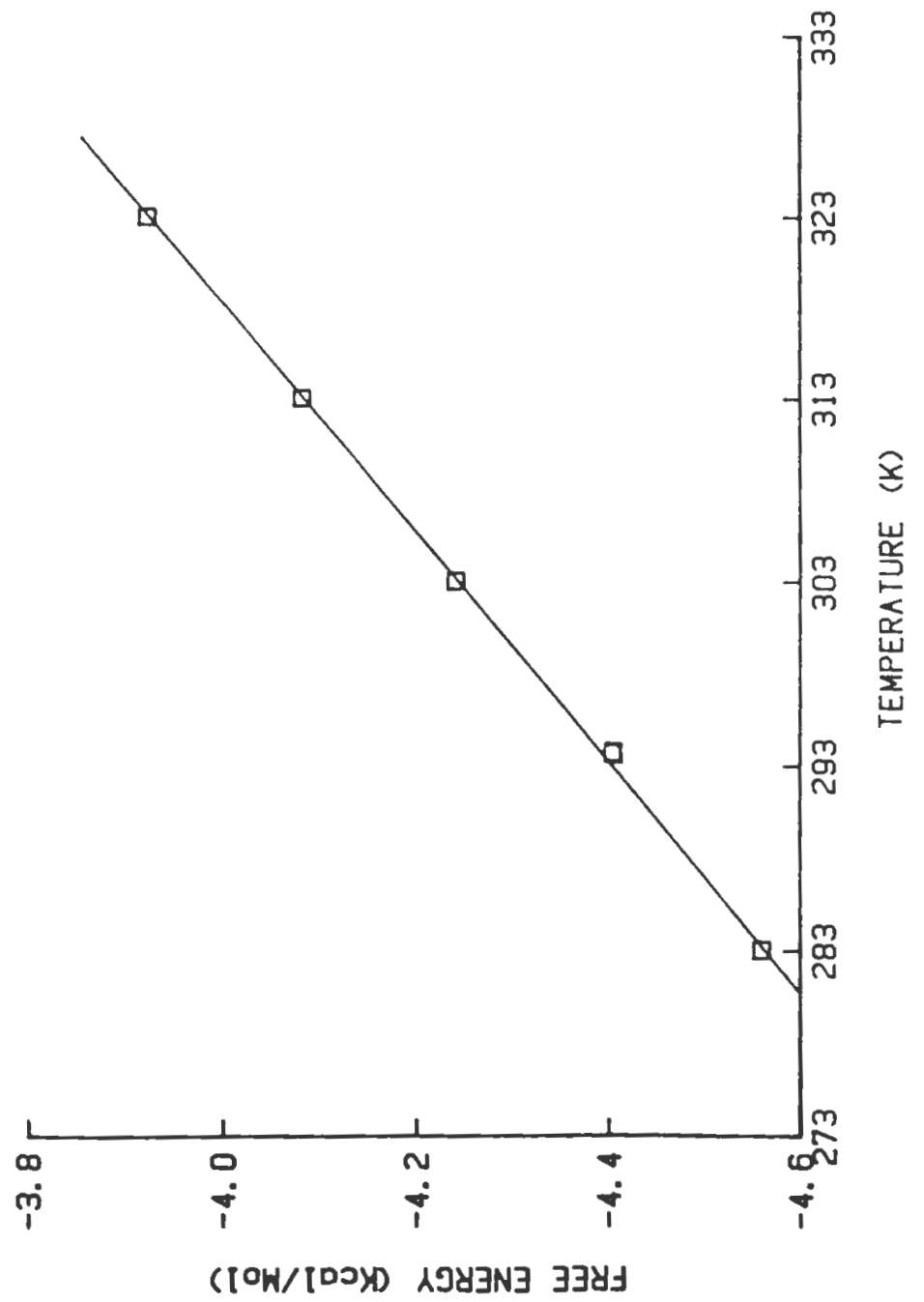


Figure 6

Effect of $\mathrm{pH}$ on the complexation of phenytoin with $\beta$ cyclodextrin at $20^{\circ} \mathrm{C}$ 


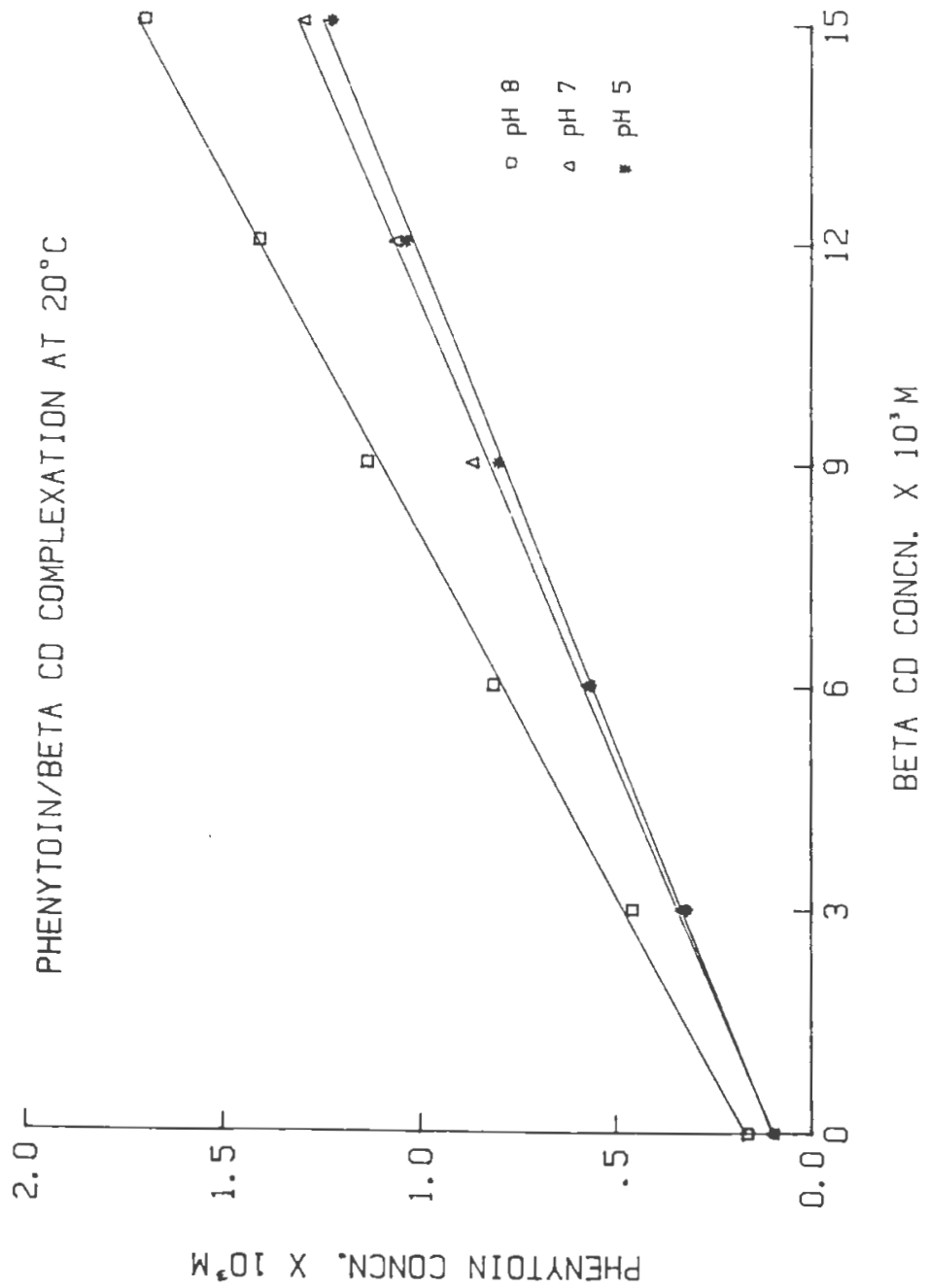


Figure 7

Effect of $\mathrm{pH}$ on the complexation of phenytoin with $\beta$ cyclodextrin at $20^{\circ} \mathrm{C}$ un = non-ionized

The lines noted un are parallel to the pH 5 solubility isotherm 


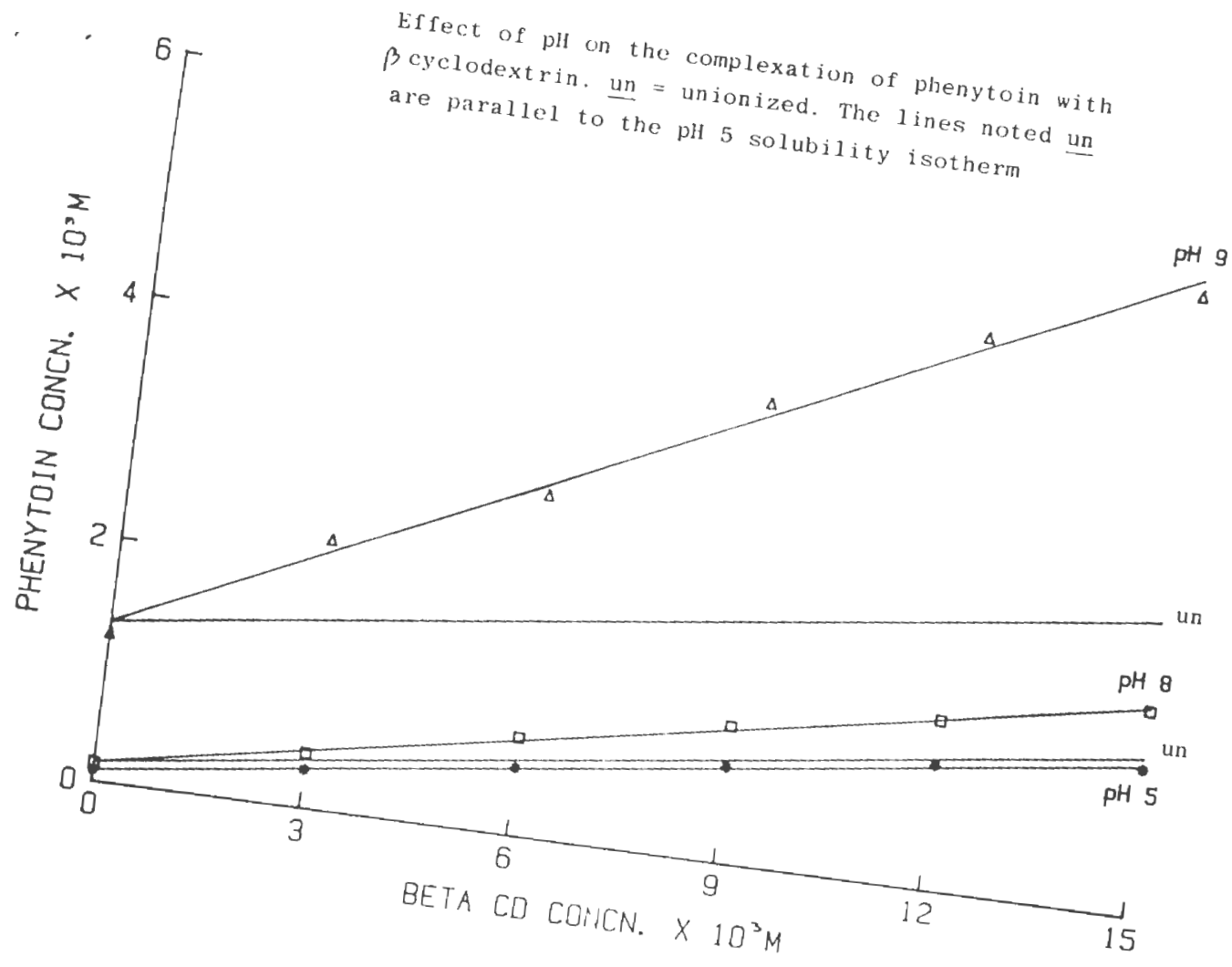


Figure 8

Solubility isotherms for the complexation of ionized phenytoin with $\beta$ cyclodextrin at $\mathrm{pH} 8$ 


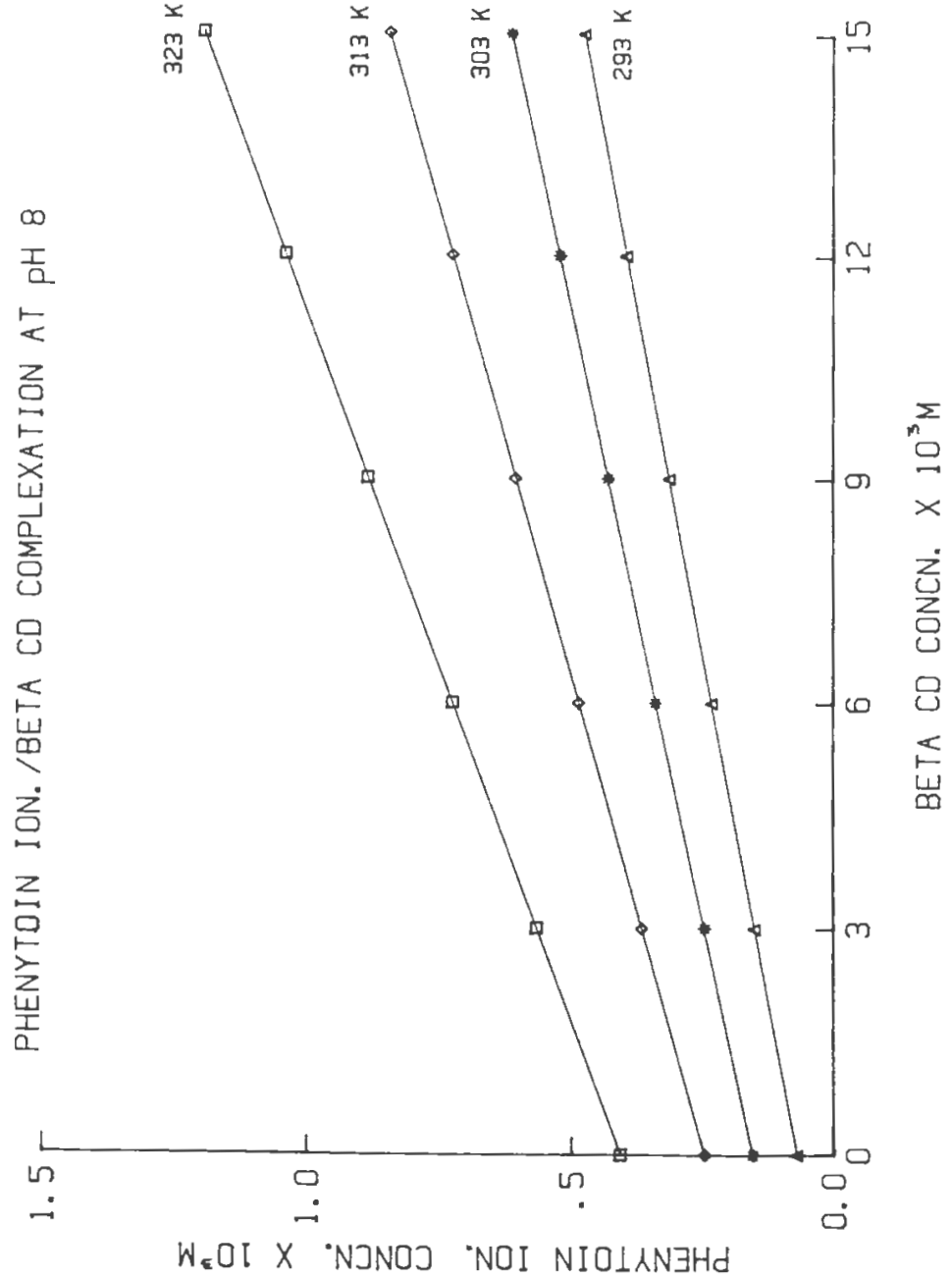


MANUSCRIPT II 


\section{ABSTRACT}

A new computer method was proposed to calculate the thermodynamic parameters of drug/cyclodextrin complexation. The method allowed the simultaneous determination of two or more parameters using non-linear regression. The mathematical model was developed and used to obtain the estimates of enthalpy, entropy and solubility parameters. The output of the NONLIN program also provided the value of the standard deviation of the parameters, thus allowing meaningful comparisons between different systems.

Key words: Non-linear regression, Thermodynamics, Phenytoin, Cyclodextrin, Complexation. 
Determination of Thermodynamic Parameters of Complexation using a Non-linear Regression Method

F.A. Menard ${ }^{a}$, M.G. Dedhiya ${ }^{b}$ and C.T. Rhodes ${ }^{a}$

a Department of Pharmaceutics

University of Rhode Island Kingston RI 02881

b Miles Pharmaceuticals

400 Morgan Lane West Haven CT 06516

\section{INTRODUCTION}

The complexation of pharmaceutical substances with cyclodextrins has been shown to improve stability $(1,2)$, solubility (2), dissolution rate (3) and bioavailability properties (4). The physico-chemical aspect of the complexation phenomenon and especially the determination of the thermodynamic parameters of complexation are essential to characterize the drug/cyclodextrin interaction. Different methods have been suggested for the determination of the values of both the enthalpy and the entropy of complexation (5). The microcalorimetric method has the advantage of using direct calorimetric measurements and has been proposed as the most reliable method (6). However, this method is not always readily available in the laboratory and requires specific expertise (7). Another widely used method is based on the temperature dependence of the complexation constant ( 8 ). The complexation constant and the free energy can be determined from solubility data 
using the Higuchi and Connors equation. After constructing the solubility isotherms at different temperatures, the enthalpy and entropy of complexation can be obtained from the plot of the free energy as a function of the absolute temperature. The major limitation of the temperature dependence method is the lack of precision of the thermodynamic parameters (9). The two successive steps requiring the use of linear regression really introduce an error, which can be critical in the comparison process of the parameters. The purpose of this paper is to present a novel computerized method allowing the direct treatment of the raw experimental data to determine the thermodynamic parameters of the drug/cyclodextrin complexation using non-linear regression. A similar approach has already been used by Dr. Fung for the determination of a single parameter $\underline{v i z}$ the energy of activation from raw experimental data of drug stability (10). In this paper we describe a method of general applicability for the simultaneous determination of two or more parameters.

\section{THEORY}

The first step is to develop a mathematical model, which describes the relationship between the concentration of the drug, the concentration of cyclodextrin (CD) and temperature (T). The drug noted $A H$ will be used as the model molecule interacting with cyclodextrins. The drug is 
subject to ionization, but will be assumed to be in its non-ionized form in the first part of the paper.

Based on a $1: 1$ stoichiometric ratio, the complexation reaction can be written as follows:

$$
\mathrm{AH}+\mathrm{CD} \rightleftharpoons \mathrm{AH} / \mathrm{CD}
$$

The overall complexation constant $\mathrm{K}$ is expressed as:

$$
\mathrm{K}=[\mathrm{AH} / \mathrm{CD}] /[\mathrm{AH}] \in[\mathrm{CD}] \mathrm{f}
$$

where the notation $f$ describes the free concentration.

It is possible to express the apparent free energy of complexation $\Delta G$ using the relationship:

$$
\Delta \mathrm{G}=-\mathrm{R} \mathrm{I} \text { In } \mathrm{K}
$$

where:

$T$ is the absolute temperature $(\mathrm{K})$

and $R$ is the gas constant

The Gibbs equation shows the relationship between free energy $(\Delta G)$, enthalpy $(\Delta H)$ and entropy $(\Delta S)$ of complexation:

$$
\Delta \mathrm{G}=\Delta \mathrm{H}-\mathrm{T} \Delta \mathrm{S}
$$

The overall complexation constant $\mathrm{K}$ can be expressed, after rearrangement of equations (3) and (4) as:

$$
K=e^{\Delta H / R T-\Delta S / R}=e^{A}
$$

with $A=\Delta H / R T-\Delta S / R$

A typical plot of solubility data for the drug/CD interaction is shown in Fig. 1. The total concentration of drug is plotted versus the total cyclodextrin concentration. 
The intercept of the straight line with the $Y$-axis

corresponds to the concentration of the free drug molecule, whereas the increase of the drug concentration represents the concentration of the complexed form.

The following equations can be written to ascribe the total concentration of both the drug and the complexing molecule:

$$
\begin{aligned}
& {[\mathrm{AH}] t=[\mathrm{AH}] \mathrm{f}+[\mathrm{AH} / \mathrm{CD}]} \\
& {[\mathrm{CD}] t=[\mathrm{CD}] f+[\mathrm{AH} / \mathrm{CD}]}
\end{aligned}
$$

where the notation $t$ stands for total concentration

From Eq. (6): $[\mathrm{AH} / \mathrm{CD}]=[\mathrm{AH}] t-[\mathrm{AH}] \mathrm{f}$

From Eq. (7) $(8):[C D] f=[C D] t-[A H] t+[A H] f$

BY substituting $[\mathrm{AH} / \mathrm{CD}],[\mathrm{AH}] \mathrm{f}$ and $[\mathrm{CD}] \mathrm{f}$ in Equation (2):

$$
K=[A H] t-[A H] f /[A H] f([C D] t-[A H] t+[A H] 0)
$$

The term $[A H] f$, which is the free guest concentration, represents the actual solubility of the guest molecule, which varies with temperature according to the Hildebrand equation:

$$
-\operatorname{In}[\mathrm{AH}] \mathrm{f}=\Delta \mathrm{HE}(\mathrm{TO}-\mathrm{T}) / \mathrm{R} \mathrm{T} \mathrm{TO}+\ln \gamma
$$

Eq. (11) can be rearranged, and ( $A H) f$ is then expressed as:

$$
\begin{aligned}
& \Delta H E(T-T O) / R T \text { TO - ln } \gamma \\
& {[\mathrm{AH}] \mathrm{f}=\mathrm{e} \quad=e^{\mathrm{B}}} \\
& \text { where: } \Delta \mathrm{Hf}=\text { heat of solution } \\
& T \text { = absolute temperature } \\
& \text { To = melting point } \\
& \gamma=\text { activity coefficient }
\end{aligned}
$$




$$
\mathrm{R}=\text { constant of perfect gases }
$$

The term $B$ can be written as:

$B=\Delta H f(T-T O) / R T$ To - In $\gamma$

Eq. (10) can then be arranged according to Higuchi and Connors, as:

$$
[A H] t=k[A H] f /(I+K[A H] f)[C D] t+[A H] f
$$

The terms $K$ and $[A H] f$ can be substituted by the exponential expression, and eq. (13) now becomes:

$$
[A H] t=e^{A} e^{B} /\left(1+e^{A} e^{B}\right)[C D] t+e^{B}
$$

or:

$$
[A H] t=e^{A+B} /\left(1+e^{A+B}\right)[C D] t+e^{B}
$$

Eq. (15) fully describes the relationship between the total concentration of the drug (the dependent variable), the total concentration of cyclodextrin (the first independent variable) and the absolute temperature (the second independent variable), which is included in the expression of both terms $A$ and $B$.

$A$ and $B$ also include the thermodynamic parameters of complexation $(\Delta H$ and $\Delta S$ ) and the free guest solubility parameters (AHf and In $\gamma$ ), respectively.

Eq. (15) will be used as the mathematical model, allowing for the direct treatment of the raw experimental data. Eq. (15) can therefore be applied to any type of interaction, in which the stoichiometric ratio complexation is known to be $1: 1$.

In the case of the complexation of phenytoin with $\beta$ cyclodextrin, some previously published work has shown that 
the stoichiometry of the complex is indeed 1:1 (11). This result was obtained after preparation of the freeze-dried form of the complex and analysis using X-Ray, PMN and DSC (12).

Figure 2 shows a typical solubility isotherm at $\mathrm{pH}>7$ together with that at pH 5. Assuming that the complexing ability of cyclodextrins is $\mathrm{pH}$-independent, the further increase of the slope corresponds to the complexation of the ionized form of the drug with $\beta$ cyclodextrin.

Phenytoin is a weak acid, with a pKa of $8.3(13,14)$, and has already been reported to interact with $\beta$ cyclodextrin both as the non-ionized and as the ionized forms (9). At low $\mathrm{pH}$ values ( $\mathrm{pH} 5$ ), phenytoin is nonionized, and Eq. (15) can be applied to study the complexation phenomenon from the solubility data. However, at higher $\mathrm{pH}$ values, the complexation of the ionized species with $\beta$ cyclodextrin has to be taken into consideration. An extension to the model is thus needed.

The symbols used in the development of the equations will take into consideration both complexation phenomena. If $A H$ represents the non-ionized form of the drug and $A^{-}$the ionized species, the different equations can be written as follows :

non-ionized species

pH 5

\section{ionized species}

$\mathrm{pH}>7$

$$
\mathrm{AH}+\mathrm{H}_{2} \mathrm{O} \rightleftharpoons \mathrm{A}^{-}+\mathrm{H}^{+}
$$




$$
\begin{aligned}
& \mathrm{AH}+\mathrm{CD} \stackrel{\mathrm{Ku}}{\rightleftharpoons} \mathrm{AH} / \mathrm{CD} \quad \mathrm{A}^{-}+\mathrm{CD} \stackrel{\mathrm{Ki}}{\rightleftharpoons} \mathrm{A}^{-} / \mathrm{CD} \\
& K^{u}=[A H / C D] /[A H]^{u_{f}}[C D] f \quad K i=\left[A^{-} / C D\right] /[A-]^{i} E[C D]^{\dot{I}_{f}} \\
& \Delta G^{\mathrm{U}}=-\mathrm{R} \mathrm{T} \ln \mathrm{K}^{\mathrm{U}} \quad \Delta \mathrm{G}^{\mathrm{i}}=-\mathrm{R} \mathrm{T} \ln \mathrm{K}^{\mathrm{i}} \\
& \Delta G^{U}=\Delta H^{U}-T S^{U} \quad \Delta G^{i}=\Delta H^{i}-T \Delta S^{i}
\end{aligned}
$$

$\ln [\mathrm{AH}]=\mathrm{Hf}^{\mathrm{u}}(\mathrm{T}-\mathrm{TO}) / \mathrm{RTTO}-\ln \gamma^{\mathrm{u}} \ln \left[\mathrm{A}^{-}\right]=H \mathrm{H}^{i}(\mathrm{~T}-\mathrm{TO}) / \mathrm{RTTO}-\ln \gamma^{i}$

Eq. (14) has already been developed:

$$
[A H]^{u_{t}}=\left(e^{A u_{+} B u}\right) /\left(1+e^{A u+B u}\right)[C D] t+e^{B u}
$$

The intercept of the solubility isotherm at pH $7 \mathrm{can}$ be expressed as:

$$
I^{i}=I^{u}+\left[A^{-}\right] f
$$

or

$$
\left[\mathrm{A}^{-}\right]^{\dot{i}} \mathrm{f}=I^{\dot{i}}-I^{U}
$$

The total drug concentration [AH]t can be written:

$$
[A H]^{i} t=[A H]^{u}+[A H / C D]^{u}+\left[A^{-}\right]^{i}+\left[A^{-} / C D\right]^{i}
$$

(24)

or

and: $\left[A^{-} / C D\right]^{i}=[A H]^{i} t-[A H]_{t-\left[I^{i}-I^{u}\right]}$

$[A H / C D]^{u}=[A H]^{u} t-I^{u}$

The total cyclodextrin concentration [CD]t can be written as:

$$
[C D]^{\dot{i}_{t}}=[C D]^{\dot{i}_{f}}+[A H / C D]^{u}+\left[A^{-} / C D\right]^{i}
$$

or

$$
[\mathrm{CD}]^{\dot{i}_{f}}=[\mathrm{CD}]^{\dot{i}_{t}}-[\mathrm{AH} / \mathrm{CD}]^{u}-\left[\mathrm{A}^{-} / \mathrm{CD}\right]^{\dot{i}}
$$


The apparent complexation constant $k^{i}$ under the current conditions can then be expressed as:

$$
\begin{aligned}
& K^{i}=\left[A^{-} / C D\right]^{i} /\left[A^{-}\right]^{i} f[C D]^{i} \mathbf{f} \\
& K^{i}=\left([A H]^{i} t-[A H]^{u} t-\left(I^{i}-I^{u}\right)\right) /\left(I^{i}-I^{u}\right)\left([C D]^{i} t-[A H / C D]^{u}-\left[A^{-} / C D\right]^{i}\right) \\
& k^{i}=\left([A H]^{i} t-[A H]^{u_{t}}-\left(I^{i}-I^{u}\right)\right) /\left(I^{i}-I^{u}\right)\left([C D]^{i} t-\left([A H]^{u} t-I^{u}\right)-\right. \\
& \left([\mathrm{AH}]^{i_{t}-[\mathrm{AH}}\right]^{\left.\left.u_{t-\left(I^{i}\right.}-I^{u}\right)\right)}
\end{aligned}
$$

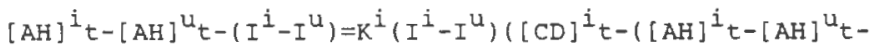

$$
\begin{aligned}
& \left.\left.\left(I^{i}-I^{u}\right)\right)-\left([A H]^{u_{t}}-I^{u}\right)\right)
\end{aligned}
$$

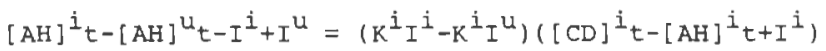

After rearrangement:

$$
\begin{array}{r}
{[A H]^{i} t=\left(K^{i} I^{i}-R^{i} I^{u}\right) /\left(I+K I^{i}-K I u\right)[C D]^{i} t+[A H]^{i} t+} \\
\left(I^{i}-I u\right)\left(I+K^{i} I^{i}\right)
\end{array}
$$

Equation (33) shows the relationship between the total drug concentration at $\mathrm{pH}>7$ (the dependent variable), the total cyclodextrin concentration (the first independent variable) and the temperature, at which the complexation occurs (the second independent variable).

The terms $I^{\mathrm{U}}$ and $[\mathrm{AH}]_{\mathrm{t}} \mathrm{U}_{\mathrm{t}}$ correspond to the free drug concentration and the total drug concentration at $\mathrm{pH} 5$, respectively. Since the complexation ability of cyclodextrin is assumed to remain constant through the $\mathrm{pH}$ range studied, $I^{\mathrm{u}}$ and $[A H]^{\mathrm{u}} \mathrm{t}$ remain constant. COMPUTER TREATMENT OF DATA 
The experimental data treated using the novel computer method have been published previously (9). The lack of precision of the thermodynamic parameters was the main limitation of the results, thus an extensive discussion of the thermodynamics of complexation was rather difficult.

The NONLIN computer program was used to determine the final estimates of all thermodynamic parameters. The NONLIN regression approach has been sucessfully used to determine parameters in many fields such as pharmacokinetics (15) and protein binding (16). The different programs needed to treat the data were:

1) the datafile, which included all the experimental data, the initial estimates and the limits of the parameters; 2) the subroutine program consisting of the declaration of the different variables and the full mathematical model describing the complexation;

3) a link program, which allows for the iterations of the NONLIN program to take place and the data to be called in. The method of determining the parameters using the NONLIN computer was validated by running a set of simulated data. The simulated data were obtained by giving a specific value to each of the parameters appearing in eg. 15. The enthalpy and the entropy of complexation were assigned a value of $-10.0 \mathrm{kcal} \cdot \mathrm{mol}^{-1}$ and $-10.0 \mathrm{eu}$ respectively. The solubility parameters used were $15.0 \mathrm{Kaal} \mathrm{mol}^{-1}$ for the heat of solution and 5.0 for the activity coefficient. All the concentrations were rounded to two significant digits. 
The schematic representation of the programs used is shown in Figure 3. Eq. (15) corresponds to the complexation at $\mathrm{pH} 5$ of the unionized species, whereas Eq. (33) fits the data obtained when both species form a complex. For a set of data at $\mathrm{pH}>7$, the subroutine program was designed so that the complexation occurring between the unionized species and the $\beta$ cyclodextrin was taken into account. Thus, for each temperature and at each cyclodextrin concentration, the program regenerated the drug concentrations calculated at $\mathrm{pH}$ 5 , based on the previous determination of $\Delta \mathrm{H}^{\mathrm{u}}$ and $\Delta \mathrm{S}^{\mathrm{u}}$. RESULTS AND DISCUSSION

Validation of the program

The datafile created from the set of simulated data was run with a subroutine program allowing the determination of the four unknown values, namely enthalpy, entropy, heat of solution and activity coefficient. The NONLIN program converged to the values shown in Table 1 . The values determined by the computer were in excellent agreement with the theoretical values. The results clearly show that this method is perfectly applicable for the determination of four unknown values from a set of 24 concentrations; in this case four temperatures and six cyclodextrin concentrations. Advantages and general application of the method All the equations, such as the expression of the equilibrium complexation constant and the Gibbs equation, are already included in the general equation; there is thus no need of the successive preliminary plots to determine the 
thermodynamic parameters of complexation. This method not only allows a direct treatment of the raw experimental data, but also gives a clear indication of the statistical significance and the level of confidence associated with the determined parameters.

Although the method has been developed for the case of the complexation of drugs with cyclodextrins, as far as the major assumptions of the model remain acceptable, this method is applicable to many other cases of drug interaction or molecular recognition.

Characterization of the phenytoin/BCD interaction Since our objective was to evaluate the effect of pH on the interaction of phenytoin with $\beta$ cyclodextrin, a typical set of data consisted of a set of phenytoin concentrations (independent variable) as a function of $\beta$ cyclodextrin concentration and temperature (dependent variables). Six levels of $\beta$ cyclodextrin concentrations and four levels of temperatures were used to build a database of 24 points at different $\mathrm{pH}$ values from $\mathrm{pH} 5$ to $\mathrm{pH} 10$.

Table 2 shows the values of the overall thermodynamic parameters determined using the NONLIN program, at different $\mathrm{pH}$ values. The enthalpies and entropies actually represent the geometric means for the complexation of both the non-ionized and the ionized species of phenytoin with $\beta$ cyclodextrin. As pH increases, the relative standard of deviation increases, probably due to the much higher concentrations of phenytoin at $\mathrm{pH} 9$ or 10 compared to those 
at $\mathrm{pH}$, when the drug is non ionized. The large negative values of enthalpy suggest a strong dipole interaction, either due to the interaction between the drug and the cyclodextrins or due to the change of behavior of the water molecules associated with both the drug and the cyclodextrin. The negative entropies suggest that the solvent has a more ordered structure after complex formation. At this point, it is difficult to be more specific, since the values in Table 2 are not exclusively related to either form of the drug, but rather represent an overall estimate of the thermodynamic changes occurring during the formation of the phenytoin/ $\beta$ cyclodextrin complex.

In order to further analyze the results, the more sophisticated mathematical model described in eq. (33) had to be used. In order to run the subroutine program for datafiles at $\mathrm{pH}>7$, the respective values $-9,714.9 \mathrm{cal}^{\mathrm{mol}}{ }^{-1}$ and $-10.49 \mathrm{e} . \mathrm{u}$. were used for the enthalpy and the entropy of complexation of the unionized form of phenytoin with $\beta$ cyclodextrin. It is assumed that the complexation of the non-ionized drug with cyclodextrin is not affected by change in $\mathrm{pH}$ used in the study, which also means graphically that a parallel line to the $\mathrm{pH}$ solubility isotherm could actually be drawn at any $\mathrm{pH}$ value. The results of the treatment of the raw experimental data using the computer method are shown in Table 3. The correlation between the data and the theoretical model of eq. (33) was excellent with a 
coefficient of correlation from 0.99 to 0.97 , with 24 points ie. 20 degrees of freedom.

The negative values of enthalpy show again a strong involvement of dipole interaction. It can be mentioned that the enthalpy of complexation is lower at $\mathrm{pH} 7$ and $\mathrm{pH} 8$, where the drug is only slightly ionized. The value increases at $\mathrm{pH} 9$ and $\mathrm{pH} 10$, suggesting a possible contribution of the charge of the ionized phenytoin molecule. A widely proposed theory is that the apolar and non-ionized drug molecule leaves behind a structured cavity, which allows the solvent molecules to redistribute upon complexation. This aspect of the mechanism is likely to vary as a function of $\mathrm{pH}$, since the polarity of phenytoin is pH-dependent. The relative standard deviation is very high at $\mathrm{pH} 7$, showing that the low percentage of ionization does not allow an accurate determination of $\Delta \mathrm{H}$. The values of entropy become large at $\mathrm{pH} 9$ and $\mathrm{pH}$ 10, suggesting a much more ordered solvent after complexation. At $\mathrm{pH} 7$ and $\mathrm{pH}$, the standard deviations are very high, and the positive value of entropy probably only indicates little or even no entropy change.

\section{SUMMARY}

The new model and method introduced here allow the determination of more than one unknown from one set of raw experimental data. Even though the method was used to treat data from the complexation of phenytoin with cyclodextrins, 
the same approach could be exploited for other drug interaction system. The method allows for a meaningful comparison of thermodynamic parameters for the interaction of either one drug with different cyclodextrins or one cyclodextrin with different drugs. The use of the approach could enhance the ability of the pharmaceutical scientist to analyze data from the solubility method to propose a rationale of interaction between drugs and complexing agents.

\section{ACKNOWLEDGEMENTS}

The authors are grateful to Dr. Ho-Leung Fung (SUNY at Buffalo) and Dr. Douglas S. Greene (Lederle Labs.) for their useful assistance in this study. Also we thank American Maize for the generous supply of cyclodextrins used in this study.

\section{REFERENCES}

1. T. Tokumura et al., Chem. Pharm. Bull., 33 (5), 2079-2083(1985).

2. P. Hsyu et al,. Drug Dev. Ind, Pharm., 10 (4), 601-611 (1984).

3. M. Kata and L. Papp, Pharmazie, 42, 65-66 (1987).

4. T. Tokumura et al., Chem. Pharm. Bull, , 33(7), 2962-2967 (1985).

5. E.E. Tucker and S.D. Christian, J. Am. Chem. Soc., 106, 1942-1945 (1985). 
6. J. Szejtii, Cyclodextrins and their inclusion complexes, Budapest (1982).

7. G.E. Hardee, M. Otagiri and J.H. Perrin, Acta Pharm. Suec., 15, 199-199 (1978).

8. F. Cramer, W. Saenger and H.-Ch. Spatz, J. Am. Chem. Soc., $89(1), 14-20(1967)$.

9. F.A. Menard, M.G. Dedhiya and C.T. Rhodes, submitted to Pharm. Act. Helv. (1987).

10. S.P. King, M. Kung and H. Fung, J. Pharm. Sci., 73 (5), $657-662(1984)$.

11. R.P. Hegde and C.T. Rhodes, Pharm. Act. Helv., 6 (53), $(1985)$.

12. R.P. Hegde, Ph. D. Thesis, University of Rhode Island (1985).

13. P.A. Schwartz, C.T. Rhodes and J.W. Cooper, Jr., J. Pharm. Sci., 66, 994-997 (1977).

14. S.P. Agarwal and M.I. Blake, J. Pharm. Sci., 73 (5), $657-662(1984)$.

15. C.M. Metzler, Pharmac. Ther., 13, 543-553 (1981).

16. R.H. Luecke and W.D. Wosilait, J. Pharmacokin. Biopharm., 14 (1), 65-78 (1986). 
Table 1

Thermodynamic parameters of complexation determined from a set of simulated data

\begin{tabular}{cccc} 
Parameter Theoretical & Final & Standard & $95 \%$ \\
Value & Estimate & Deviation & Conf. Limit \\
\hline
\end{tabular}

Enthalpy

$\begin{array}{lllll}\Delta \mathrm{H} & -10,000 & -10,164 & 60 & 9,959-10370\end{array}$
(cal.mol ${ }^{-1}$ )

Entropy

$\begin{array}{lllll}\Delta S & -10.0 & -10.55 & 0.19 & 9.91-11.19\end{array}$

(e.u.)

Heat

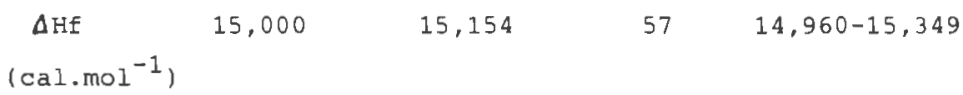

Activity
$\ln \gamma$
5.0
4. 43
1.0
$3.87-5.05$ 
Table 2

Overall enthalpies and entropies of complexation for the phenytoin/ $\beta$ cyclodextrin interaction

\begin{tabular}{|c|c|c|c|c|}
\hline $\mathrm{pH}$ & $\begin{array}{c}\Delta \mathrm{H} \\
\left(\mathrm{Kcal} \cdot \mathrm{mol}^{-1}\right)\end{array}$ & $\begin{array}{l}\text { RSD } \\
\left(\frac{\circ}{6}\right)\end{array}$ & $\begin{array}{c}\Delta S \\
(e . u .)\end{array}$ & $\begin{array}{l}\text { RSD } \\
\left(\frac{\circ}{6}\right)\end{array}$ \\
\hline 5.0 & $-9,721$ & 1.1 & -10.49 & 3.3 \\
\hline 7.0 & $-11,528$ & 1.2 & -16.32 & 2.8 \\
\hline 8.0 & $-9,292$ & 1.3 & -10.02 & 3.8 \\
\hline 9.0 & $-8,802$ & 4.2 & -10.18 & 11.8 \\
\hline 10.0 & $-8,982$ & 12.9 & -12.44 & 30.5 \\
\hline
\end{tabular}


Table 3

Enthalpies and entropies for the complexation of phenytoin ion with $\beta$ cyclodextrin

\begin{tabular}{|c|c|c|c|c|c|}
\hline $\mathrm{pH}$ & $r$ & $\begin{array}{c}\Delta H^{i} \\
\left(\mathrm{cal} \cdot \mathrm{mol}^{-1}\right)\end{array}$ & $\begin{array}{l}\text { RSD } \\
\left(\frac{\circ}{6}\right)\end{array}$ & $\begin{array}{c}\Delta s^{i} \\
(e \cdot u .)\end{array}$ & $\begin{array}{l}\text { RSD } \\
(\%)\end{array}$ \\
\hline 7.0 & 0.998 & $-5,326$ & 40.4 & 1.68 & 405.0 \\
\hline 8.0 & 0.999 & $-5,352$ & 5.8 & 1.35 & 74.0 \\
\hline 9.0 & 0.995 & $-8,899$ & 4.0 & -10.75 & 10.7 \\
\hline 10.0 & 0.973 & $-12,934$ & 5.2 & -25.41 & 8.6 \\
\hline
\end{tabular}


Figure 1

Typical solubility isotherm for the complexation of non-ionized phenytoin with $\beta \mathrm{CD}$ at $\mathrm{pH} 5$ 
$[\mathrm{AH}] t+\left[\mathrm{A}^{-}\right] t$

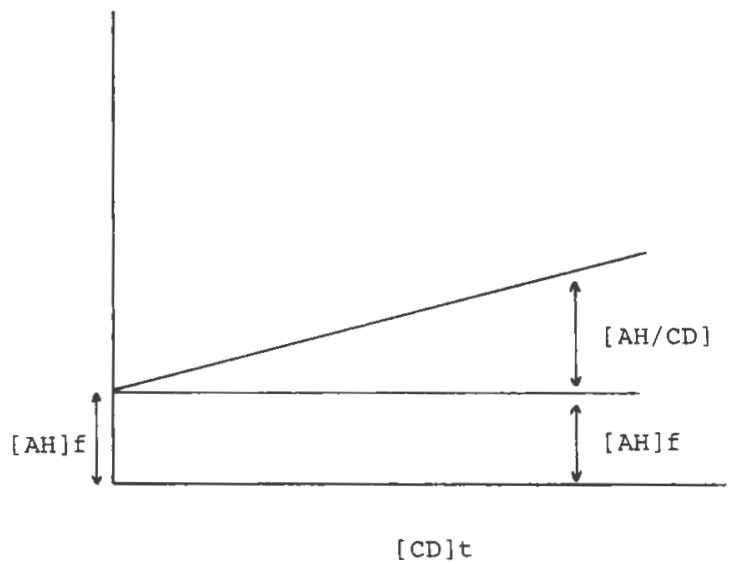

Figure 1: Typical solubility isotherm of the complexation of non-ionized phenytoin with $\beta$ cyclodextrin at $\mathrm{pH} 5$ 
Figure 2

Typical solubility isotherm of phenytoin with $\beta C D$ at $\mathrm{pH}>7$ 
$[\mathrm{AH}] t+\left[\mathrm{A}^{-}\right] t$

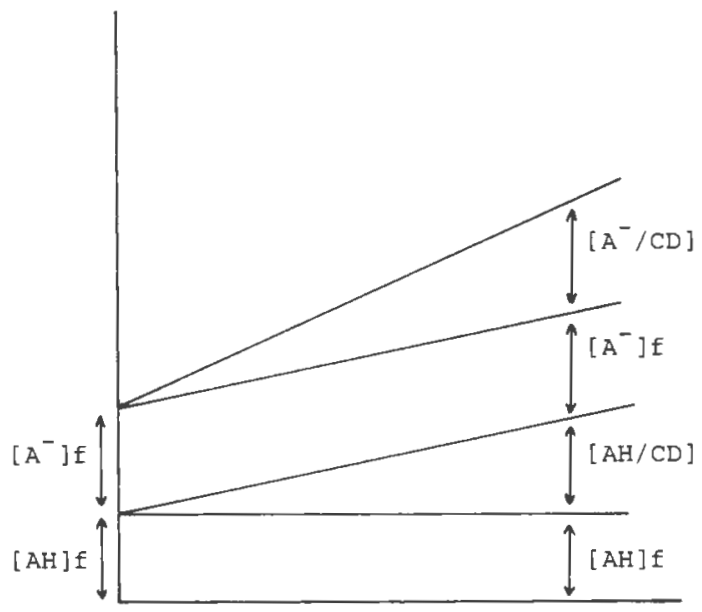

$[C D] t$

Figure 2: Typical solubility isotherm of the complexation of phenytoin with $\beta$ cyclodextrin at $\mathrm{pH} 7$ 
Figure 3

Schematic representation of the different programs 


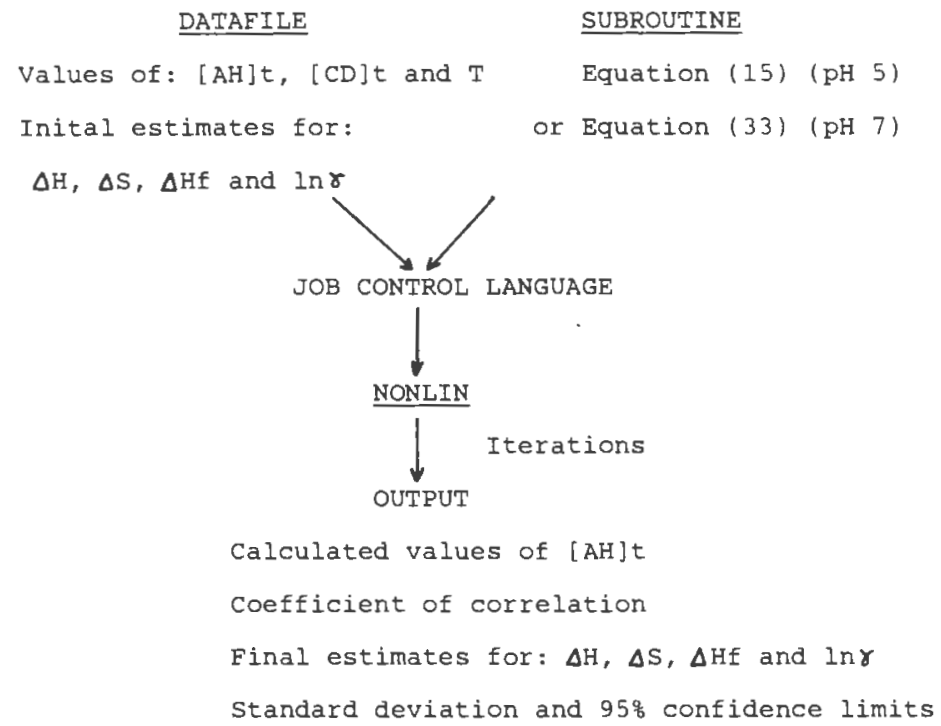

Figure 3: Schematic representation of the different programs 
MANUSCRIPT III 
Potential Pharmaceutical Applications of a New Beta Cyclodextrin Derivative

\author{
F.A. Menard ${ }^{a}$, M.G. Dedhiya ${ }^{b}$ and C.T. Rhodes ${ }^{a}$ \\ a Department of Pharmaceutics \\ University of Rhode Island Kingston RI 02881-0809 \\ biles Pharmaceuticals \\ 400 Morgan Lane West Haven $\mathrm{CT} 06516$
}

\title{
INTRODUCTION
}

The three major natural cyclodextrins viz alpha, beta and gamma, consist of six, seven or eight glucose units, respectively (1). In addition to the natural cyclodextrins, numerous new products have been shown to have potential for the pharmaceutical industry $(2,3)$. A clear distinction has to be made between cyclodextrin polymers, which are mainly used as separation materials in analytical chemistry (4) and cyclodextrin derivatives, which are monomers of substituted cyclodextrins (5). In the synthesis process of the latter, both the $c(2)$ and $c(3)$ secondary and the $c(6)$ primary hydroxyl groups have been the target of many chemical substitutions (6), leading to the development and the characterization of cyclodextrin derivatives of pharmaceutical interest (7). Such derivatives have been successfully used in the design of new drug carrier systems $(3,5)$. Hence, in addition to their increased solubility, these chemically modified cyclodextrins exhibit excellent complexing abilities ( 8 ). The different possibilities of modifying cyclodextrins have been reviewed by sebille (2), 
Szejtli (1) and Uekama (3). Szjetli also published an extensive list of the major cyclodextrin derivatives under investigation until 1982 (1).

The chemical considerations of the substitution of cyclodextrins have been investigated by Harata et al., who examined the macrolytic conformation of permethylated cyclodextrins (6). The main factor is the loss of the ability to form hydrogen bonds upon substitution. Further studies dealing with the properties of cyclodextrin derivatives have been recently published (9).

The stability of prostaglandins was improved by complexation with methylated cyclodextrins (10). On the other hand, an ammonium beta cyclodextrin derivative was shown to catalyze the hydrolysis of nitrophenyl ester (11). Nakai et al. studied the effect of a tri-methyl beta cyclodextrin on the partition of nitrophenol, and interpreted the data as the formation of a $1: 1$ complex (12). The use of cyclodextrin derivatives as agents of solubilization has been reported in the literature (13). Muller and Brauns have investigated the complexation of diazepam, hydrocortisone and digitoxin with methyl beta cyclodextrin (14), as well as the effect of the derivatization of garma cyclodextrin on the phase-solubility of progesterone (15). Otagiri et al, have also studied the complexation of several drugs with tri-methyl cyclodextrin. In most of the studies, the critical factor to be carefully considered in the interpretation of the data is the degree 
of substitution (DS) of the cyclodextrin derivatives (16). Muller and Brauns have established a relationship between the average degree of substitution and the complexing ability (14). From the data obtained, the lower the degree of substitution, the more extensive the complexation phenomenon. This result was attributed to the steric blockage of the cyclodextrin cavity by the substituents. Several researchers have published data regarding specific dosage forms of complexes of drug/cyclodextrin derivatives. Dimethyl beta cyclodextrin has been proposed as a parenteral drug carrier for such drugs as progesterone and hydrocortisone (17). The dissolution of flurbiprofen suppositories was shown to be greatly improved by complexation with dimethyl and trimethyl beta cyclodextrin (18). Also, a comparative study of the complexation of flurbiprofen with both beta cyclodextrin and its derivatives showed that the mode of inclusion was quite different, due to the different number of free hydroxyl groups on the cyclodextrin ring (18). In-vivo studies in rats suggested that the complexation of ketoprofen with methyl beta cyclodextrin could lead to high plasma levels (19). It was also proposed that the surface active properties of methyl beta cyclodextrins could facilitate drug absorption through membranes. However, as discussed further in this paper, the same surface active properties may well be responsible for negative toxic effects on the cells, causing hemolysis (3). Pitha et al. investigated the oral administration of 
steroidal hormones. The study showed that the complexation of progesterone and testosterone with beta cyclodextrin derivatives allowed for the correction of serum levels and could efficiently be used for therapeutic applications (17). Even though the hydrophilic cyclodextrins have been the focus of the attention of many researchers, Uekama recently published data showing that ethylated beta cyclodextrins could be used as hydrophobic drug carriers. An in-vivo study in rats showed that these hydrophobic derivatives produced a sustained release of diltiazem (21). It is very likely that more work will be done in the future to establish the exact potential of cyclodextrin derivatives in sustained release.

The purpose of this paper is to evaluate the complexing ability of hydroxyethyl beta cyclodextrin, a new beta cyclodextrin derivative. Furthermore, the complexation of several drugs with both the natural beta cyclodextrin and its new derivative was investigated in order to establish a possible comparison of the data and to propose a valid prediction of the overall increase in drug solubility upon complexation.

\section{EXPERTMENTAL}

Materials

Hydroxyethyl beta cyclodextrin (batch \#CDMI08) was obtained from American Maize (Hammond, IN). Table 1 shows 
some of its basic physico-chemical properties, compared to those of the natural cyclodextrins.

Three of the drugs viz phenytoin, diazepam and hydrochlorothiazide were obtained from Sigma Chemical co. (St. Louis, MO). Ibuprofen was generously given by Whitehall Laboratories. All drugs were used as received. All solvents and reagents used in the study were of analytical grade and were used as received.

\section{Methodology}

The complexation of the drugs with the new modified beta cyclodextrin was studied using the solubility method described by Higuchi and Connors (21). An excess of drug was placed into screw-capped vials containing various concentrations of cyclodextrins. The vials were then rotated at constant temperature $\left( \pm 0.05^{\circ} \mathrm{C}\right)$ in a waterbath, until the maximum solubility was reached. The samples of drug solutions were then filtered using glasswool, diluted and assayed for drug concentration using a diode-array ultra-violet spectrophotometer (Hewlett-Packard HP 8451A). The drug standards obeyed the Beer's law in all cases, and cyclodextrin was shown not to interfere with the assay.

\section{RESULTS AND DISCUSSION}

The solubility isotherms were obtained by plotting the total drug concentration as a function of total cyclodextrin concentration. In all cases the plots were 
linear, suggesting a type A phase solubility (21). The intercept represents the concentration of the free drug, while the slope represents the solubilization power of the complexing agent. Figures $1,2,3$ and 4 show the solubility isotherms of phenytoin, diazeparn, ibuprofen and hydrochlorothiazide, respectively. Each plot shows the complexation data with both beta cyclodextrin and the hydroxyethyl derivative. The maximum concentration of beta cyclodextrin used was $15 \times 10^{-3} \mathrm{M}$, except in the case of ibuprofen, where a maximum concentration of $5.0 \times 10^{-3} \mathrm{M}$ was used, due to the low solubility of the ibuprofen/beta cyclodextrin complex. The concentration of hydroxyethyl derivative varied from 0 to about $150 \times 10^{-3} \mathrm{M}(20 \% \mathrm{w} / \mathrm{w})$ (although, according to the supplier, solutions of up to $60 \%$ solids could actually be prepared). The molar concentration was calculated using a molecular weight of 1300 , value obtained from the average value of the degree of substitution. The concentrations of both complexing agents are plotted on the $\mathrm{X}$-axis using the same scale; the use of the derivative thus corresponds to an extension of the x-axis.

From Figures 1 to 4 , it appears that the slope of the solubility isotherms remained identical for both complexing agents. This result was confirmed statistically using a SAS program. The results thus suggest that even though the overall increase of drug solubility was much higher in the case of the derivative, the solubilizing power was 
unchanged. This observation confirms the "hand and glove" theory used to describe how the steric factors control the extent of complexation. Some researchers have reported that the complexation of drugs with cyclodextrin derivatives was associated with a lower solubilizing power (14). These results were obtained in the case of hydroxypropyl beta cyclodextrin, with high degrees of substitution. The decrease of complexing ability was therefore suggested to be due to steric hindrance. In the case of hydroxyethyl beta cyclodextrin, it seems that the low degree of substitution presents the unique advantage of preserving the complexing ability of the cyclodextrin.

The reactions of complexation can be written as following:

$$
\begin{aligned}
& \text { Drug }+\beta C D \rightleftharpoons \text { Drug } / \beta C D \\
& \text { Drug }+\beta^{\prime} C D \rightleftharpoons \text { Drug } / \beta^{\prime} C D
\end{aligned}
$$

The slope of the solubility isotherm corresponds to the concentration of the complexed drug over the total concentration of cyclodextrin, as shown in Figure 5 . Therefore:

$$
\begin{aligned}
& S=[\text { Drug } / \beta \mathrm{CD}] /[\beta \mathrm{CD}] \\
& S^{\prime}=\left[\mathrm{Drug} / \beta^{\prime} \mathrm{CD}\right] /\left[\beta^{\prime} \mathrm{CD}\right]
\end{aligned}
$$

where $S$ and $S^{\prime}$ represent the slope for the complexation of drugs with $\beta$ and $\beta^{\prime}$ cyclodextrins respectively. 
Assuming that the slope remains unchanged, the following equality can be written:

$$
S=S^{\prime}
$$

$[D r u g / \beta C D] /[\beta C D]=\left[D r u g / \beta^{\prime} C D\right] /\left[\begin{array}{ll}\beta & C D\end{array}\right]$

and $\left[\beta^{\prime} C D\right]=10 \times[\beta C D]$

Therefore: [Drug $\left./ \beta^{\top} \mathrm{CD}\right]=10 \mathrm{x}$ [Drug $\left./ \beta \mathrm{CD}\right]$

According to this model, the concentration of the complexed drug obtained upon complexation with the beta cyclodextrin derivative should be about ten times that observed in the case of the natural product. Both concentrations were calculated at different temperatures and at various $\mathrm{pH}$ values. The ratio was then computed and the results are reported in Table 2 . The ratios are in good agreement with the theory; values were in the range of 8.6 to 11.0. Two values were calculated for phenytoin and diazepam, since for these drugs both the ionized and the non-ionized species have been shown to interact with cyclodextrins. In the case of ibuprofen, the value was found to be 26.6. Once the adjustment of the concentration ratio is made, this value corresponds to 8.9 . It should be mentioned that the values of concentration of complexed drug reported in Table 2 represent almost the total concentration for ibuprofen, for which the interaction is very extensive. However, in the case of hydrochlorothiazide, the value 
represents merely half of the concentration of the free drug, suggesting a very weak interaction.

A SASGRAPH software was used to plot the drug solubility as a function of cyclodextrin concentration and temperature. The three dimensional plots obtained are shown in Figures 6, 7, 8 and 9, for phenytoin, diazepan, ibuprofen and hydrochlorothiazide respectively. The overall volume of these plots allows a good visualization of the extent of complexation.

The practical implications of the results of this study can be discussed at two levels. Firstly, it appears that it may be possible to predict the solubility of drug upon complexation with hydroxyethyl beta cyclodextrin, based on the data obtained with the natural form. Beta cyclodextrin. which is a much more readily available material, could be used as a model to evaluate whether a drug concentration in the range desired could be achieved through beta cyclodextrin derivative complexation. The empirical rule suggested here corresponds to the multiplication of the solubility observed with beta cyclodextrin by the ratio factor between the solubility of beta cyclodextrin and its derivative. This rule has been shown here to stand very well in the case of four drugs, at different $\mathrm{pH}$ values and different temperatures.

The second point of interest resides in examining the range of solubility obtained after complexation. The complexation of drugs with cyclodextrins can be particularly 
appropriate either to improve the physico-chemical properties or the organoleptic properties of drugs. Clearly, the concentrations of ibuprofen attained in this study are very high and would even make possible a liquid dosage form of the drug. However, ibuprofen has a bitter taste, that even a 60 to $70 \%$ complexation level may not totally mask. In the case of the other drugs, phenytoin is complexed at about $10 \%$ and diazepam around $20 \%$. This percentage would be a critical factor in the development of any dosage form of a drug/cyclodextrin complex. Obviously, on a development point of view, the closer to a $100 \%$ complexation, the better. The results of the study indicate that the use of hydroxyethyl beta cyclodextrin may offer clear advantage to the pharmaceutical formulator.

\section{CONCLUSIONS}

The complexation ability of $\beta^{\prime c y c l o d e x t r i n ~ h a s ~ b e e n ~}$ shown to be similar to that of the natural $\beta$ cyclodextrin. The slope of the solubility isotherms was indeed identical for the four drugs studied. It thus appears that the substituents do not affect the basic mechanism of complexation. The particular advantages of $\beta^{\prime}$ cyclodextrin are its high solubility and its low degree of substitution. The range of drug concentrations achieved in the study suggests real new possibilities of formulation. A liquid dosage form of ibuprofen with high bioavailability could very well be developed. One of the major concerns in the 
pharmaceutical industry has been the toxicity of the cyclodextrin derivatives, in particular unacceptable hemolytic properties. However, it has also been shown that the lower the degree of substitution, the lower the hemolytic properties. From the preformulation data presented here in the study, hydroxylethyl $\beta$ cyclodextrin seems to be an excellent candidate for future drug/cyclodextrin complex formulation.

\section{ACKNOWLEDGEMTENTS}

The authors thank American Maize for the generous supply of cyclodextrin samples. The offices of Mr. D. Downing and Mr. G. Reed worked with a particular diligence. The cooperation of $\mathrm{Dr}$. A. Smith from whitehall Laboratories is greatly appreciated in the supply of ibuprofen. The authors are also grateful to Dr. B. Birmingham for his expertise in plotting data on three-dimensional SAS graphs.

\section{REFERENCES}

1. J. Szejtli, cyclodextrins and their inclusion complexes, Akademiai Kiddo, Budapest (1982).

2. K. Uekama and T. Erie, Cyclodextrins and their industrial uses, Editions de la Sante, Paris (1987).

3. K. Uekama and M. Otagiri, Cyclodextrin in drug carrier systems, CRC Press (1986). 
4. M. Tanaka, Y. Kawagushi, M. Nakae, Y. Mizobuchi and T. Shono, J. Chromat., 246, 207-214 (1982).

5. J. Szejtli, J. Incl. Phen., 1, 135-150, (1983)

6. K. Harata, K. Uekama, M. Otagiri and F. Hirayama, J. Incl. Phen., 1, 279-293 (1984).

7. K. Uekama, Pharm. Int., 3, 61-65 (1985).

8. J.Szeman, H. Ueda, J. Szejtli, E. Fenyvesi, Y. Machida and T. Nagai, Chem. Pharm. Bull., 35, 282-288 (1987)

9. K. Uekama, K. Udo, T. Irie, A. Yoshida and M. Otagiri, Acta Pharm. Suee., 24, 27-36 (1987).

10. F. Hirayama, M. Kurihara and K. Uekama, Chem. Pharm. Bul1., 32, 4237-4240 (1984).

11. Y. Nakamura and T. Sugama, Chem. Pharm. Bu11., 32 , 4682-4685 (1984).

12. Y. Nakai, K. Yamamoto, K. Terada and H. Horibe, Chem. Pharm. Bull., 30, 1796-1802 (1982).

13. J. Pitha and J. Pitha, J, Pharm. Sci., 74, 987-990 (1987).

14. B.W. Muller and U. Brauns, Int. J. Pharm., 26, 77-88 (1985).

15. B.W. Muller and U. Brauns, Pharm. Res., 309-310 (1985).

16. M. Otagiri, K. Uekama, T. Imai, T. Maeda, A. Takadate and S. Goya, Acta Pharm. Suec., 21, 357-366 (1984).

17. J. Pitha, S.M. Harman and M.E. Michel, ,J. Pharm. Sci, $75,165-167$ (1986).

18. K. Uekana, T. Imai, T. Maeda, T. Irie, F. Hirayama and M. Otagiri, J. Pharm. Sci., 74, 841-845 (1985).

19. Y. Nakai, K. Yamamoto, K. Trada, H. Horibe and K. Ozawa, Chem. Pharm. Bul1., 31, 3745-3747 (1983).

20. K. Uekama, N. Hirashima, Y. Horiuchi, F. Hirayama, T. Ijitsu and M. Ueno, J. Pharm. Sci.,76, 660-661 (1987).

21. T. Higuchi and K.A. Connors, Anal. Chem. Instr., 4, 117-212 (1965). 
TAELE I

BASIC PROPERTIES OP CYCLODEXYRIMS

\begin{tabular}{|c|c|c|c|c|}
\hline$C D$ & $\begin{array}{l}\text { GLUCOSE } \\
\text { UNITS }\end{array}$ & MN & $\begin{array}{l}\text { WATER } \\
\text { MOLECULRS }\end{array}$ & $\begin{array}{c}\text { SOLUBILITY } \\
\mathrm{gm} / 100 \mathrm{ml}\end{array}$ \\
\hline $\mathbf{a}$ & 6 & 972 & 6 & 14.5 \\
\hline $\mathbf{B}$ & 7 & 1135 & 11 & 1.8 \\
\hline$\gamma$ & 8 & 1297 & 17 & 23.2 \\
\hline$B^{\prime}$ & 7 & 1300 & 11 & 60.0 \\
\hline
\end{tabular}


TABLE II

Concentrations of drug complexed with

$\beta$ and $\beta^{\prime}$ cyclodextrins at $50^{\circ} \mathrm{C}$

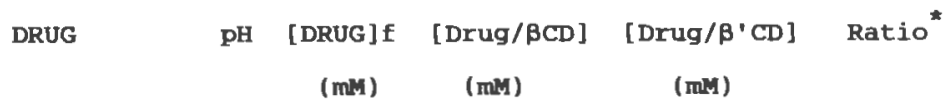

$\begin{array}{llllll} & 5.0 & 0.26 & 1.28 & 12.69 & 9.9 \\ \text { Phenytoin } & 8.0 & 0.68 & 1.62 & 13.98 & 8.6\end{array}$

$\begin{array}{cccccc} & 3.0 & 0.80 & 1.12 & 12.32 & 11.0 \\ \text { Diazepan } & 6.0 & 0.29 & 0.71 & 7.82 & 11.0\end{array}$

$\begin{array}{llllll}\text { Hydrochlo- } & 5.0 & 7.65 & 3.05 & 32.30 & 10.6\end{array}$

thiazide

$\begin{array}{llllll}\text { Ibuprofen } & 5.0 & 0.16 & 0.34 & 9.08 & 8.9^{*}\end{array}$

\footnotetext{
* Ratio $=\left[\mathrm{Drug} / \beta^{\prime} \mathrm{CD}\right] /[\mathrm{Drug} / \beta \mathrm{CD}]$

* the value of 8.9 was obtained by dividing 26.6 by 3

The maximum concentration of $\beta \mathrm{CD}$ was $5.0 \times 10^{-3} \mathrm{M}$ in

the case of ibuprofen and $15.0 \times 10^{-3} \mathrm{M}$ for the other drugs
} 
Figure I

Complexation of phenytoin with $\beta \mathrm{CD}$ at $40^{\circ} \mathrm{C}$ and $\mathrm{pH} 5$ 


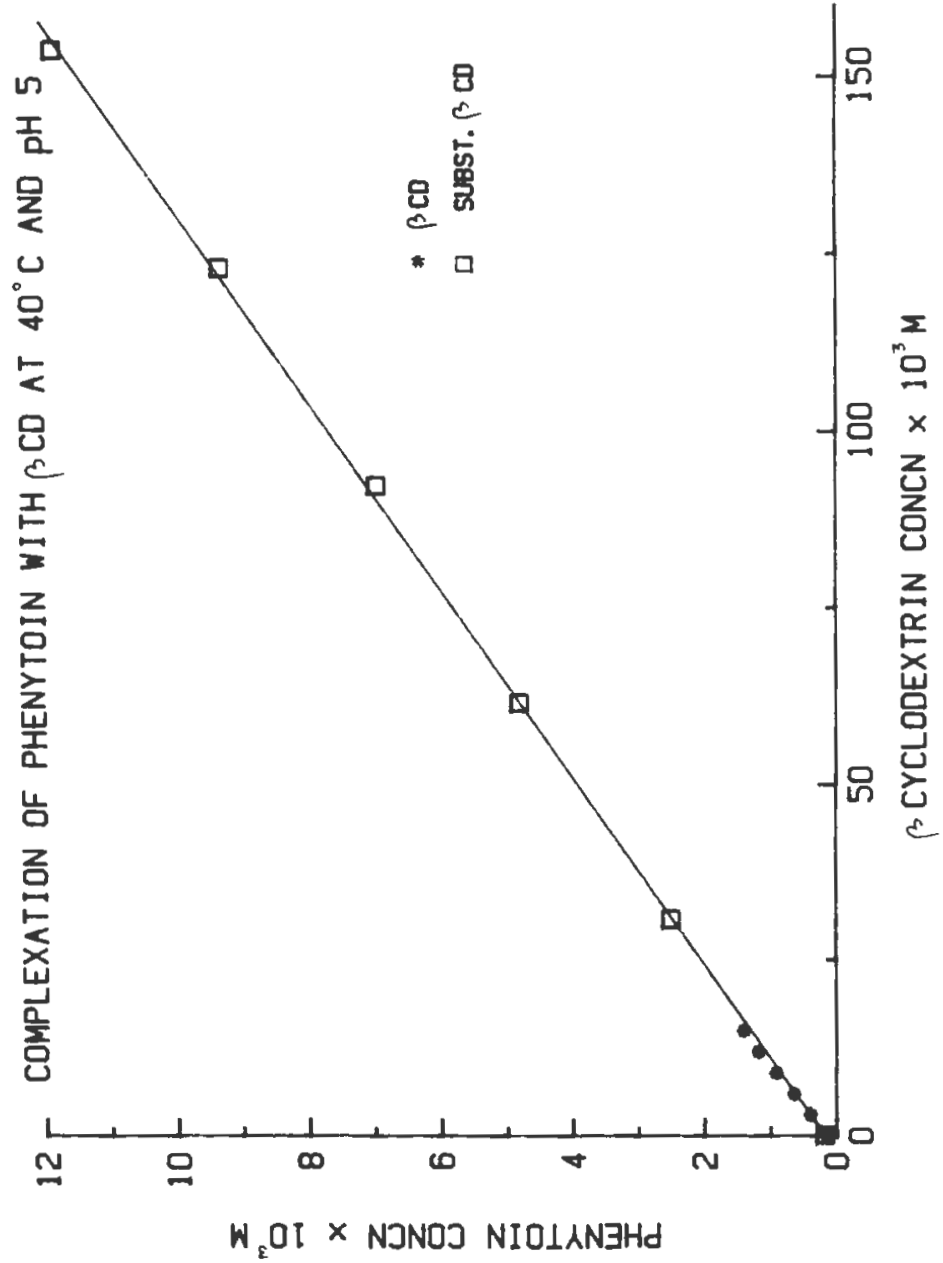


Figure II

Complexation of diazepam with $\beta \mathrm{CD}$ at $30^{\circ} \mathrm{C}$ and $\mathrm{pH} 6$ 


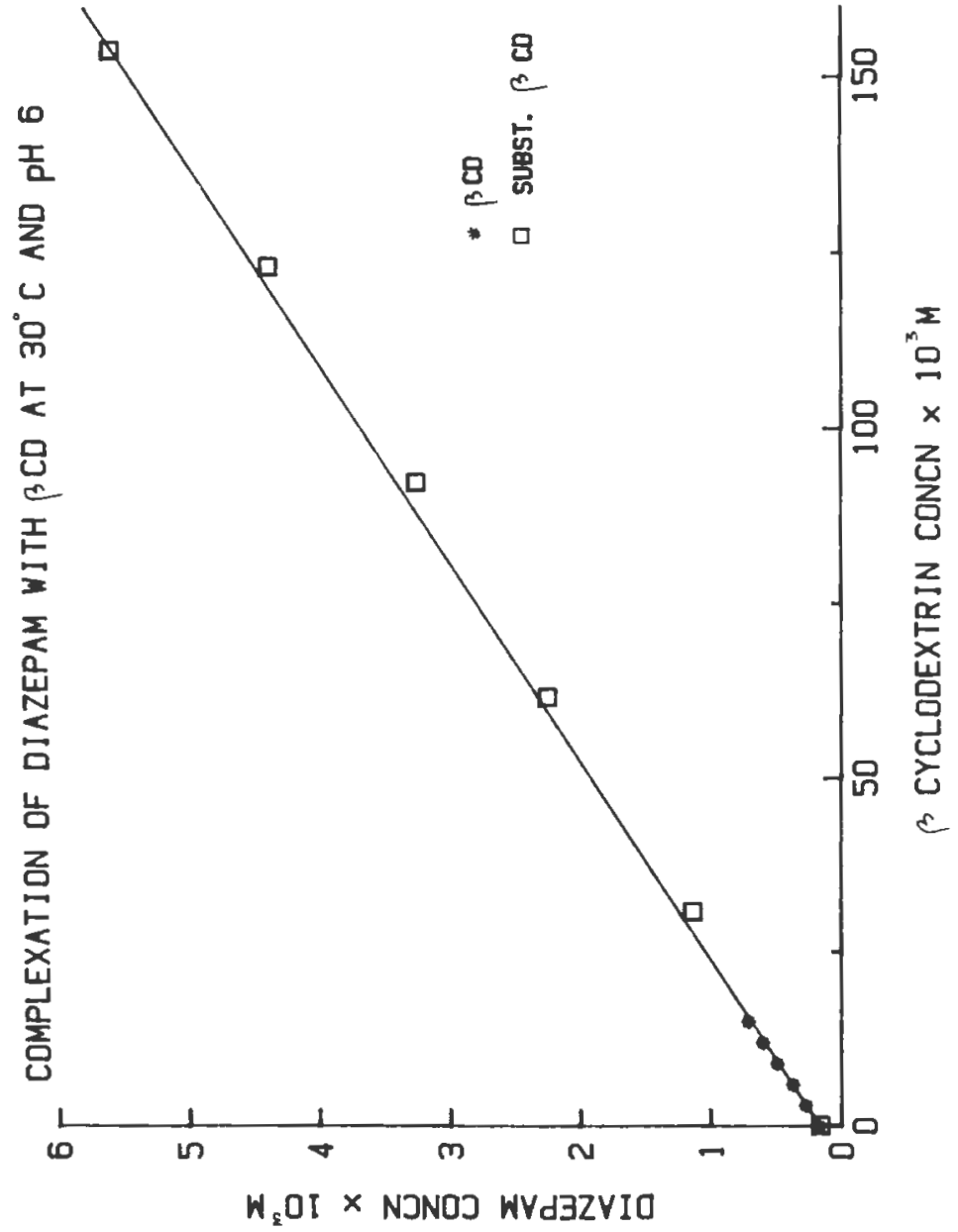


Figure III

Complexation of ibuprofen with $\beta \mathrm{CD}$ at $50^{\circ} \mathrm{C}$ and $\mathrm{pH} 5$ 


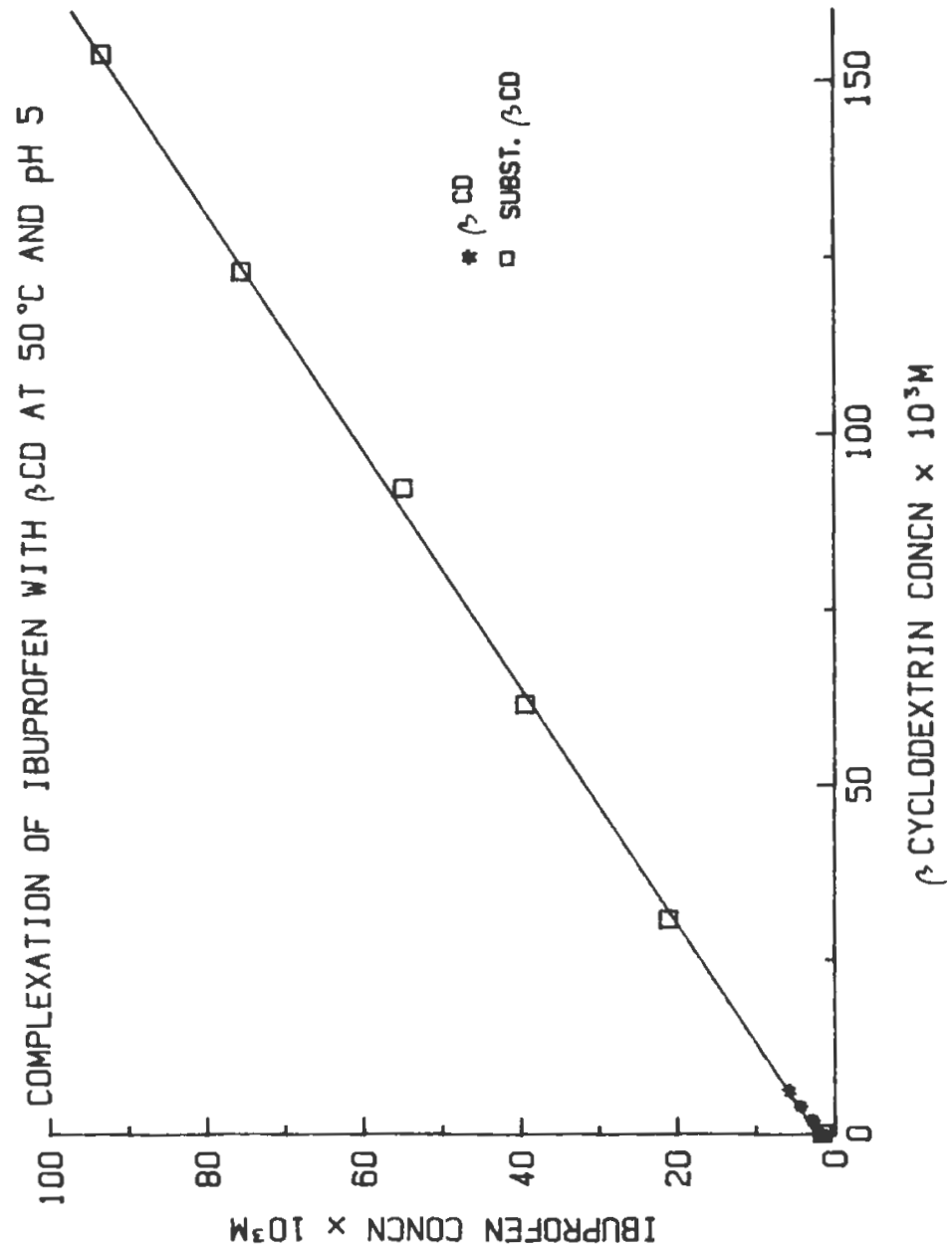




\section{Figure IV}

Complexation of $\mathrm{HCT}$ with $\beta \mathrm{CD}$ at $50^{\circ} \mathrm{C}$ and $\mathrm{pH} 5$ 


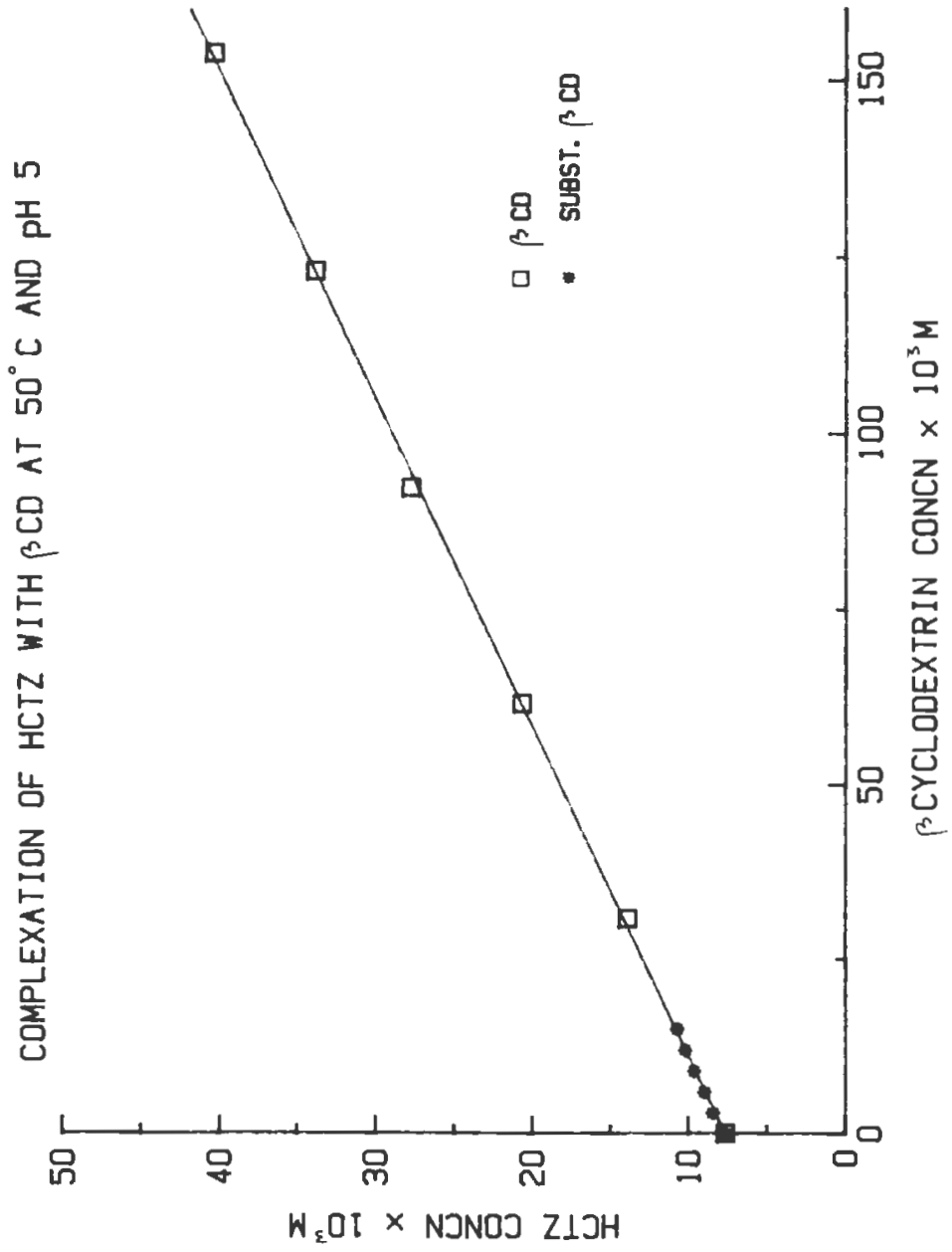


Figure $v$

Complexation of drugs with $\beta$ and $\beta^{\prime}$ cyclodextrins 
Figure $\mathrm{V}$

Complexation of drugs with both $\beta C D$ and $\beta^{\prime} C D$

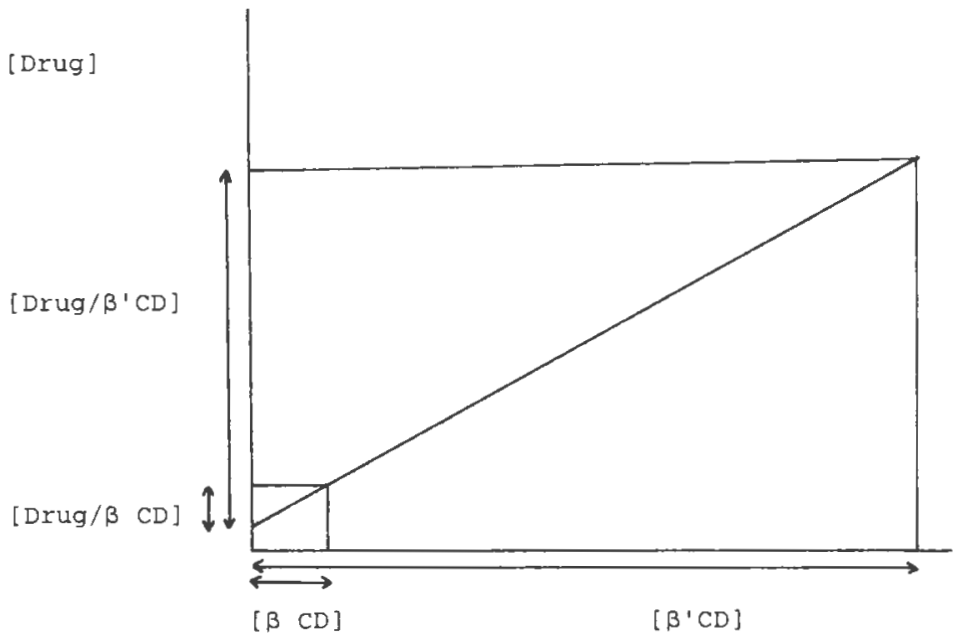


Figure VI

Solubility of phenytoin as a function of temperature and $\beta^{\prime} \mathrm{CD}$ concentration at $\mathrm{pH} 5$ 


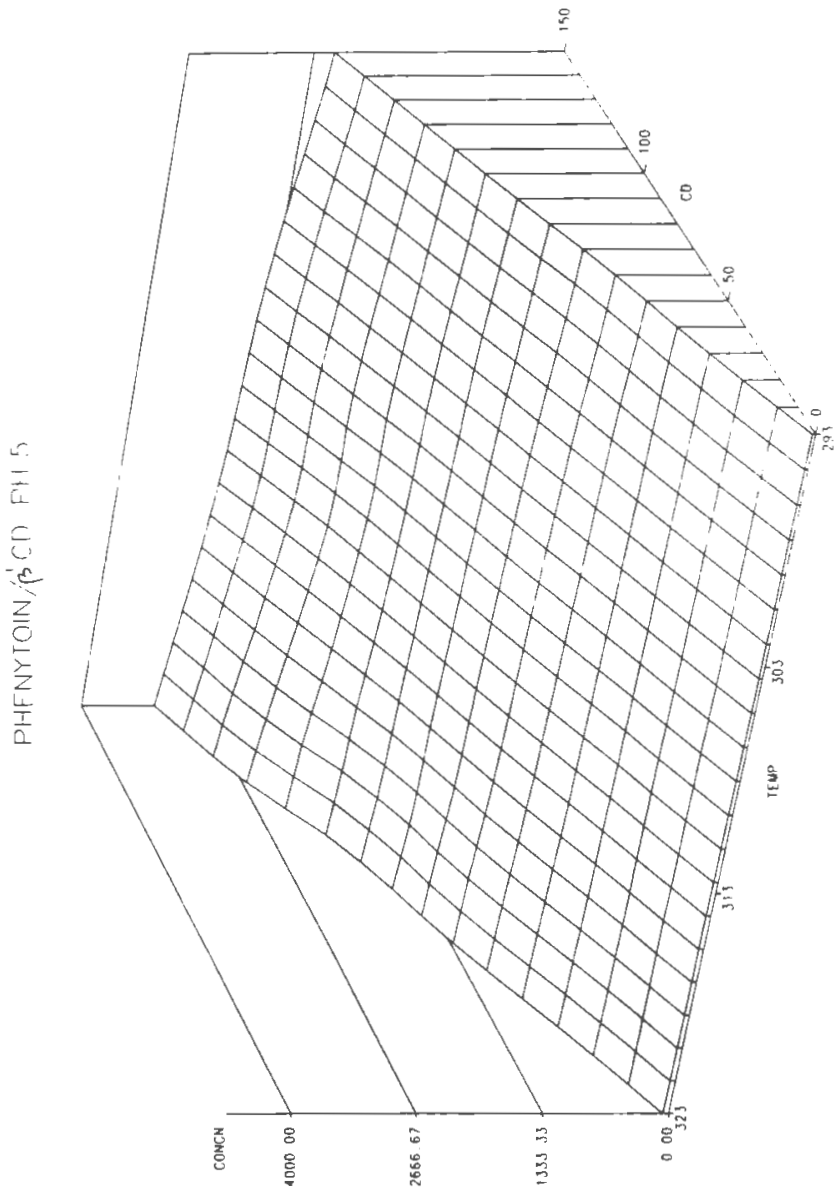


Figure VII

Solubility of diazepam as a function of temperature and $\beta^{\prime} \mathrm{CD}$ concentration at $\mathrm{pH} 6$ 


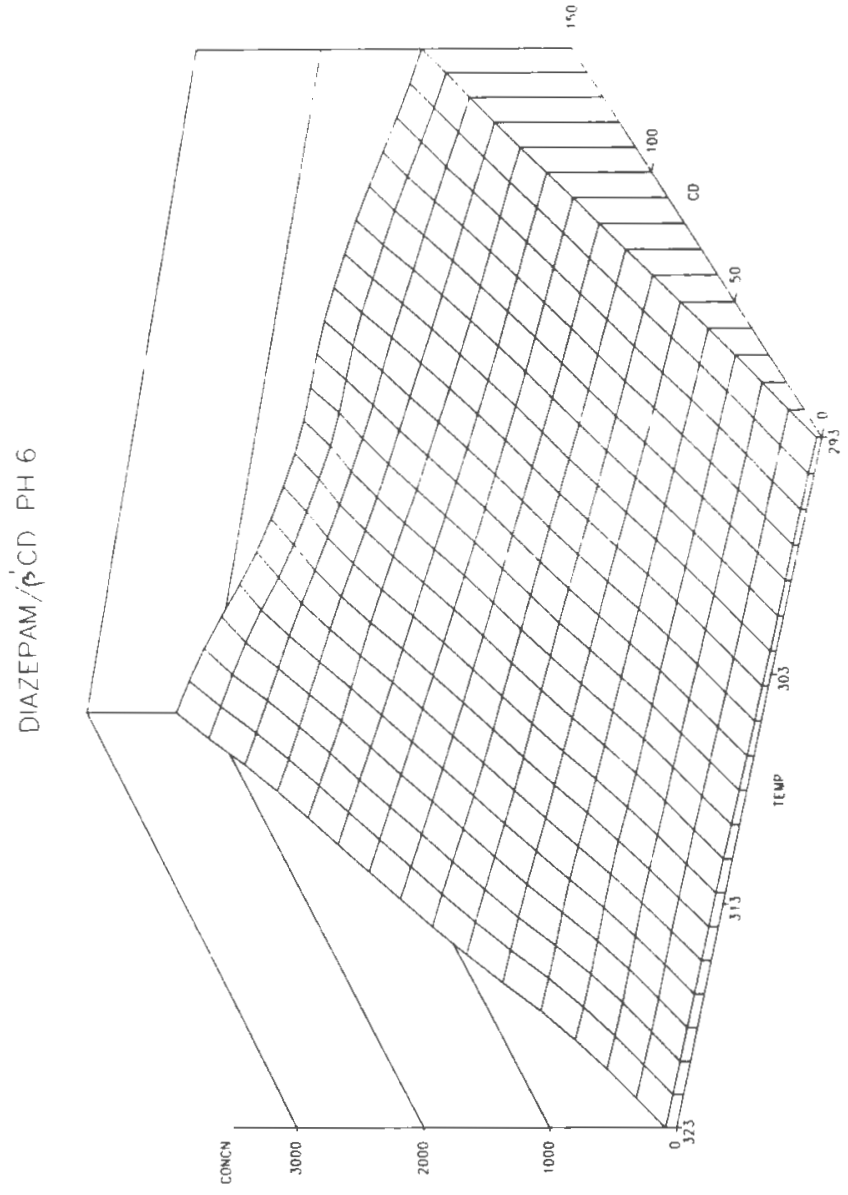




\section{Figure VIII}

Solubility of ibuprofen as a function of temperature and $\beta^{\prime}$ CD concentration at $\mathrm{pH} 5$ 


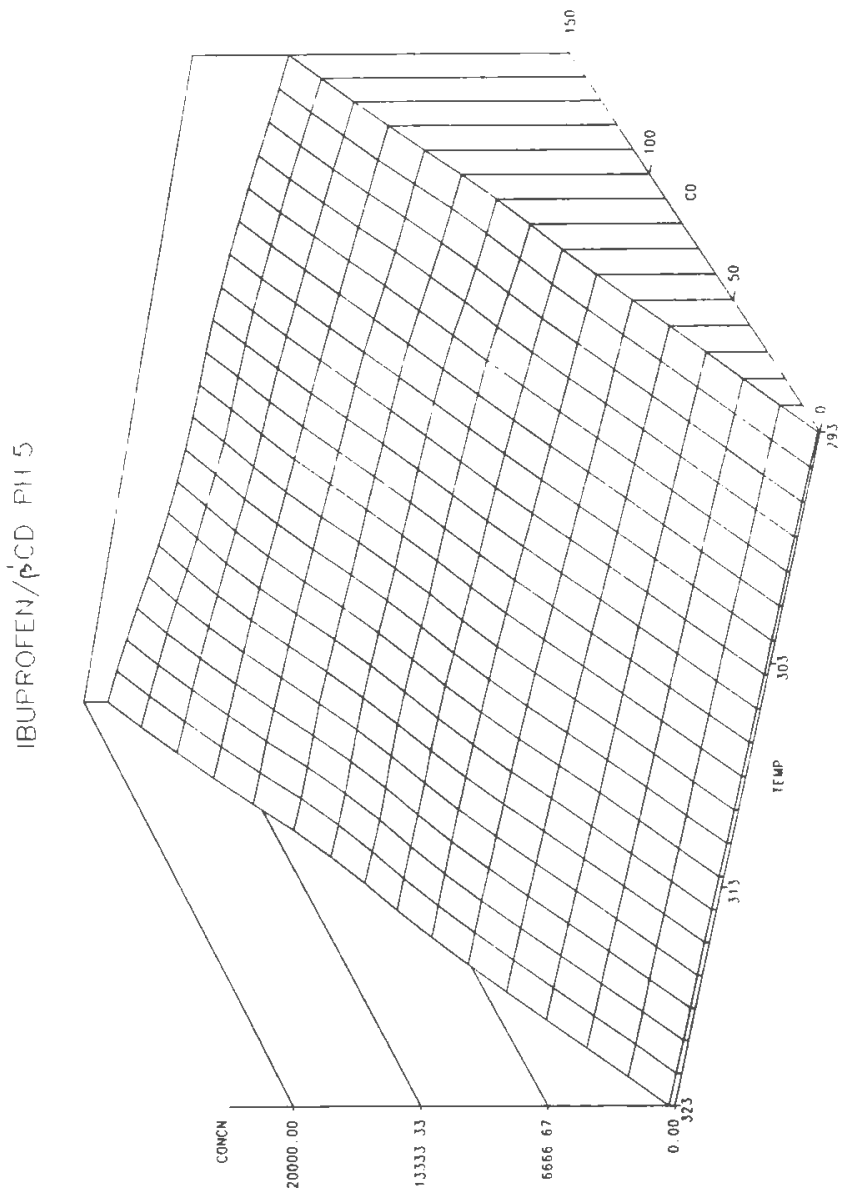


Figure IX

Solubility of hydrochlorothiazide as a function of temperature and $\beta^{\prime}$ CD concentration at $\mathrm{pH} 5$ 


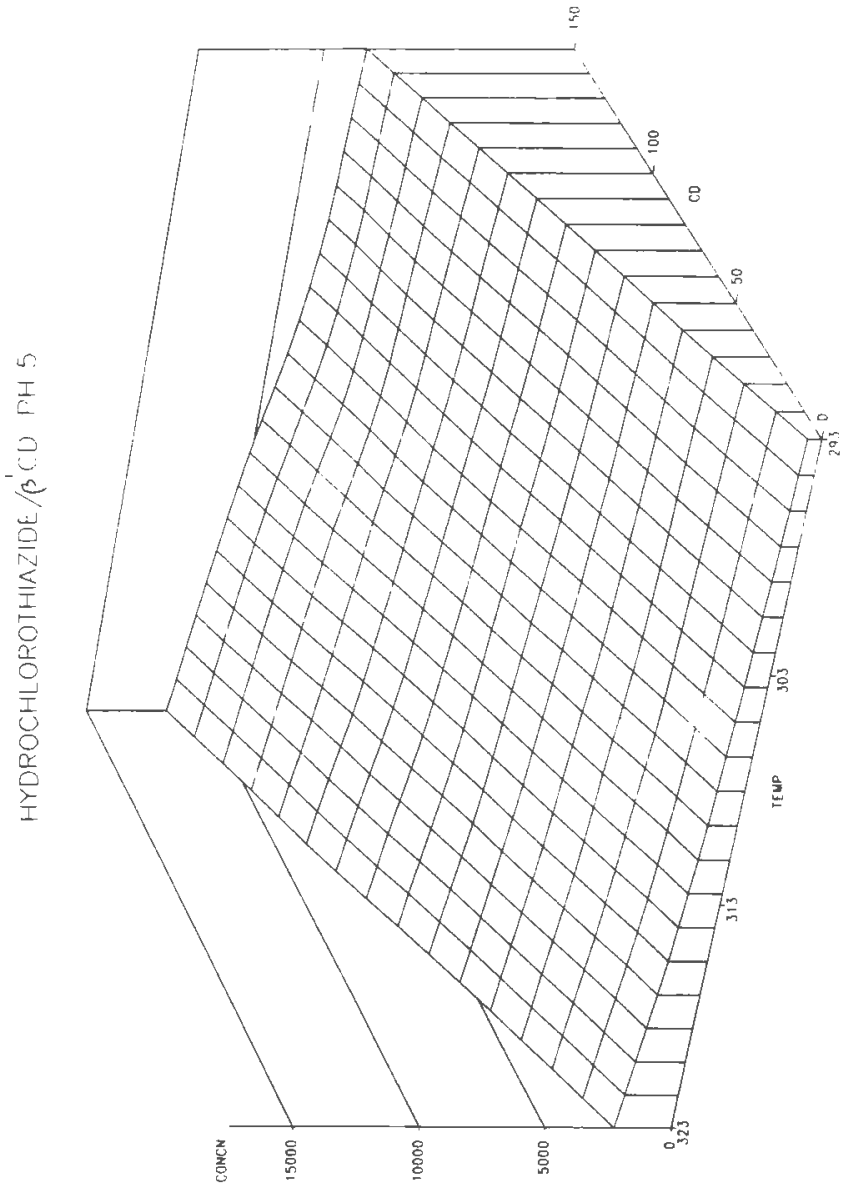


ABSTRACT

The complexation of several drugs with beta cyclodextrins was studied using the Higuchi and Connors solubility method. Solubility isotherms were plotted for each drug at various $\mathrm{pH}$ and temperature conditions. Both the non-ionized and the ionized species of diazepam were shown to form an inclusion complex. In the case of ibuprofen and hydrochlorothiazide, only the non-ionized species interacted with beta cyclodextrin. The thermodynamic parameters of complexation were estimated using a computer method based on non-linear regression. The enthalpy of complexation was large and negative in all cases, while the entropy of complexation was found to depend more upon the nature of the drug and the experimental conditions.

Key words: Cyclodextrins, complexation, thermodynamics, ibuprofen, diazepam, hydrochlorothiazide. 
PHYSICO-CHEMICAL ASPECTS OF THE COMPLEXATION

OF SOME DRUGS WITH CYCLODEXTRINS

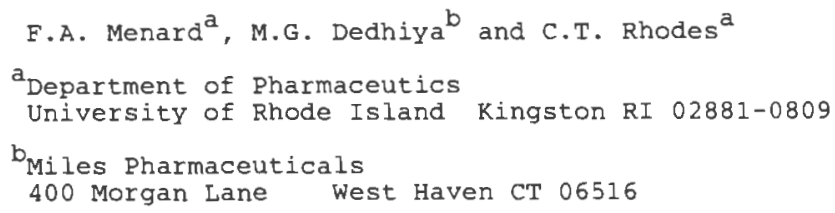

\section{INTRODUCTION}

The three major cyclodextrins consist of six, seven and eight units of glucose, respectively (1). Cyclodextrins readily form inclusion complexes with a wide number of organic compounds. The complexation of drugs with cyclodextrins has been shown to have great potential for the pharmaceutical industry (2). The main advantages of the drug-cyclodextrin complex formation include: a) enhancement of organo-leptic properties (i.e. taste and smell); b) stabilization of the drug; and $c$ ) improvement of the solubility, dissolution and bioavailability of drugs. A number of papers have been published by pharmaceutical scientists during the last decade that focused on the preparation, the physical analysis and the formulation of drug/cyclodextrin complexes (3-7). However, the physico -chemical aspects of complexation have received relatively little attention. 
The objectives of this paper were: to investigate the effect of $\mathrm{pH}$ and temperature on the phase-solubility of three drugs upon complexation with cyclodextrins and to determine the thermodynamic parameters of complexation using a novel computer approach based on a non-linear program.

\section{EXPERIMKATAL SECTION}

Reagents and Chemicals- All solvents and reagents were of analytical grade and were used as received. Hydrochlorothiazide and diazepam were obtained from Sigma Chemical Co. (St. Louis, MO). Ibuprofen was received from Whitehall Laboratories. The cyclodextrin materials used were generously offered by American Maize (Hamnond, IN). Methods- The solubility method used was based on that described by Higuchi and Connors (8). An excess of solid drug was added into screw-capped tubes containing solutions of cyclodextrins at various known concentrations. The tubes were rotated in a waterbath at constant temperature $( \pm$ $0.05^{\circ} \mathrm{C}$ ) until saturation was reached. The filtration and dilution steps were conducted in a walk-in oven. The complexation of ibuprofen, diazepam and hydrochlorothiazide were studied at various temperatures from $20^{\circ} \mathrm{C}$ to $50^{\circ} \mathrm{C}$, and at different pH values. The solubility isotherms were obtained by plotting the solubility of the drug as a function of cyclodextrin concentration.

Computer treatment of Data- The thermodynamic parameters of complexation were determined using a computer 
method based on non-linear regression. Three programs were used: 1) a datafile; 2) a subroutine; and 3) a JCL program which links the datafile and the subrouitne to the NONLIN software. The datafile included a full set of data consisting of drug concentration, cyclodextrin concentration and temperature at a given $\mathrm{pH}$ value and the initial estimates of the thermodynamic parameters. The three major parameters considered were the enthalpy ( $\mathrm{H})$ and entropy $(\mathrm{S})$ of complexation, and the heat of solution $\left(\mathrm{H}_{\mathrm{S}}\right)$. The subroutine program contained the following mathematical equation:

$$
[A H] t=e^{A+B} /\left(1+e^{A+B}\right)[C D] t+e^{B}
$$

where: $[A H] t=$ total concentration of drug in solution $[C D] t=$ total concentration of cyclodextrin

$$
\begin{aligned}
& A=\Delta H / R T-\Delta S / R \\
& B=\Delta H s\left(T-T_{0}\right) / R T T_{0}-\ln \gamma
\end{aligned}
$$

with: $\Delta \mathrm{H}=$ enthalpy of complexation

$\Delta S=$ entropy of complexation

$\Delta S s=$ heat of solution

$\mathrm{R} \quad$ = gas constant

$T=$ absolute temperature $\left({ }^{\circ} \mathrm{K}\right)$

$T_{0}=$ melting point

$\gamma=$ activity coefficient

This equation was based on the following assumptions: 1) the stoichiometry of the drug/cyclodextrin complex was $1: 1 ; 2$ ) 
the change of the free energy of complexation with temperature obeyed the Gibbs equation; 3) the complexing ability of the cyclodextrins was pH independent between $\mathrm{pH} 2$ and $\mathrm{pH}$ 9; and 4) the free drug solubility could be described by the general Van't Hoff equation. The output of the NONLIN program used gave the final estimates of the thermodynamic parameters, their standard deviation and their $95 \%$ confidence limits.

Statistical Analysis- An analysis of variance (ANOVA.) was performed on the slope of the solubility isotherms using a SAS statistical package. Temperature and $\mathrm{pH}$ were the two possible sources of variation. A SASGRAPH program was used to plot the solubility of the drug as a function of cyclodextrin concentration and pH. A G3D grid technique was used in all cases.

\section{RESULTS AND DISCUSSION}

Determination of pKa- The Benet and Peck approach was used to calculate the apparent pKa of each drug from the intercept data of the solubility isotherms built at a given temperature (9). The solubility $C$ varies as a function of $\mathrm{pH}$ according to the following equation:

$$
\log \left(\mathrm{C} / \mathrm{C}_{0}-1\right)=\mathrm{pH}-\mathrm{pKa}
$$

where $c_{0}=$ solubility of the unionized species The pKa value corresponds to the $\mathrm{pH}$ at which the solubility is twice that of the unionized species. The apparent pKa determined from the data available were $4.8,3.6$ and 8.0 for 
ibuprofen, diazepam and hydrochlorothiazide respectively. These values are in good agreement with the values available in the literature. In the case of diazepam, which is a weak base, 3.6 is the pKa of the conjugated acid.

Determination of Heat of solution- The heat of solution $\left(\Delta \mathrm{H}_{\mathrm{S}}\right)$ of the free drug representes the intercept of the solubility isotherm.

The Van't Hoff and Hildebrand equations can be used to show the solubility-temperature relationship (10). Although both equations have the same theoretical basis, the plot of the logarithm of the solubility expressed in mole fraction (X) as a function of the reciprocal of the absolute temperature is refered to as the Van't Hoff plot $(11,12)$.

$$
\log \mathrm{x}=-(\Delta \mathrm{H} / 2.303 \mathrm{R})(1 / \mathrm{T})+\mathrm{Ct}
$$

The Van't Hoff plots for ibuprofen, diazepam and hydrochlorothiazide are shown in Figures 1,2 and 3 respectively. Each straight line represents a set of data at a given $\mathrm{pH}$ value. The slope of the linear plots varied with pH indicating that the heat absorbed by the system during dissolution varied with the extent of ionization. Table I shows the values for the heat of solution of the three drugs determined by both the manual method using equation 2 and linear regression and the computer method using non-linear regression. The advantage of the computer approach is that each parameter is estimated with a $95 \%$ 
confidence interval. An excellent correlation was observed between the results obtained from the two different methods for all three drugs tested. In the case of ibuprofen and hydrochlorothiazide, which are both weak acids, an increase of $\mathrm{pH}$ resulted in lower heat of solution because of the increased ionization of the drug. The lack of variation in the $\mathrm{H}_{\mathrm{S}}$ with $\mathrm{pH}$ for hydrochlorothiazide can be correlated to the almost parallel lines observed in Figure 3 . For diazepam, the unionized species at $\mathrm{pH} 6$ required more energy to go into solution. In all cases, the solubility process was endothermic as indicated by the positive values of heat of solution.

Effect of pH on complexation- The solubility isotherms of the complexation of the three drugs with $\beta$ cyclodextrin at various $\mathrm{pH}$ values and constant temperature are presented in Figures 4,5 and 6 . As the $\mathrm{pH}$ increased, the intercept increased for ibuprofen and hydrochlorothiazide and decreased for diazepam due to the ionization of the drug. The solubility plots obtained for diazepan (Figure 5) indicate that there is an increase of the slope as the $\mathrm{pH}$ decreased. Since diazepam is completely ionized at pH 2, the observed increase of the slope would correspond to the interaction of $\beta$ cyclodextrin with the ionized species. Without such interaction, the $\mathrm{pH} 2$ line should have been parallel to those obtained at the other $\mathrm{pH}$ values. However, in the case of ibuprofen and hydrochlorothiazide, the SAS treatment showed that there was no significant difference in 
the slope as a function of $\mathrm{pH}$ i.e. for these two drugs the ionized species does not interact significantly with $\beta$ cyclodextrin.

In order to rationalize the differences in complexation behavior, one has to consider the basic mechanism of inclusion complex formation. The cavity of cyclodextrin is an hydrophobic environment that can host an hydrophobic molecule. It seems that $\beta$ cyclodextrin can fit a group similar to the benzene ring, which is one of the groups present in diazepam and phenytoin that has previously been shown to form a complex at the ionized state. For these two molecules the complexing group may remain mostly unaffected by the ionization and therefore the ionized species is still able to form a complex with cyclodextrin. Ibuprofen and hydrochlorothiazide do not form such a complex after ionization and the slope of the solubility isotherms is $\mathrm{pH}$ independent. It is possible that the ionization of both drugs greatly affects the polarity or the hydrophobicity of the complexing group, thus preventing the formation of a complex at higher $\mathrm{pH}$ values.

Effect of temperature on complexation- The solubility study was also conducted at different temperatures for each of the three drugs studied. Figure 7 shows an example of the plots obtained at each $\mathrm{pH}$ value. The analysis of variance using SAS did not show any significant difference of the slopes tested, which means that the solubilization power was essentially temperature-independent. 
Three-dimensional plots obtained at given $\mathrm{pH}$ values using SASGRAPH are shown in Figures 8,9 and 10 for ibuprofen, hydrochlorothiazide and diazepam, respectively.

Determination of thermodynamic parameters- The classical method to determine thermodynamic parameters of complexation is based on the temperature dependence of the complexation constant. However, this method based on two sequential steps of linearization of data, does not allow a precise determination of the enthalpy and entropy of complexation, which can make difficult further comparisons. The computer method developed in this study utilized datafiles that contained a set of solubility data at one pH value similar to that plotted in Figures 8 to 10.

Tables II, III and IV summarize the results of the treatment of the solubility data for the three drugs. The thermodynamic parameters of complexation can be used as a basis for discussion of the mechanism of complexation. The driving forces of complexation have long been a subject of controversy $(13,14)$. The different possibilities proposed include hydrophobic interaction, hydrogen bonding, van der Wals interaction, release of enthalpy rich water molecules and release of conformational strain (15). The contribution of each of these factors depends upon the nature of the drug. The overall thermodynamic parameters, namely enthalpy $(\Delta \mathrm{H})$ and entropy $(\Delta \mathrm{S})$ are releated to the apparent free energy $(\Delta G)$ by the Gibbs equation:

$$
\Delta \mathrm{G}=\Delta \mathrm{H}-\mathrm{T} \Delta \mathrm{S}
$$


The free energy can be considered as the sum of the energy changes due to each of the factors listed earlier. Therefore, the values given in Tables III to IV can be seen as overall thermodynamic parameters, that indicate which factors may be predominant in the mechanism of complexation.

In the case of ibuprofen, the apparent enthaply of complexation is negative at all pH values indicating that the system is releasing energy upon complexation. The extent of the energy released decreases as the drug becomes more ionized. There is no definite trend in the change in enthalpy from $\mathrm{pH} 2$ to $\mathrm{pH} 5$. However, the large negative enthalpies probably indicate a strong involvement of dipoles and wan der wals interaction during complexation. Also this loss of heat upon complexation could correspond to the energy released by the enthalpy rich water molecules trapped within the cyclodextrin cavity. The entropy factor is positive at all $\mathrm{pH}$ values, showing that the order of the systems decreases upon complexation. At pH 6, the entropy increase is particularly significant despite the high standard deviation. Ibuprofen is quite ionized at $\mathrm{pH} 6$ and it is likely that some water molecules of solvation are still in contact with the drug molecule. If one considers that the change in entropy corresponds to the difference in hydrogen bonds before and after complexation, one could suggest that the larger overall balance is due to the smaller number of hydrogen bonds broken. 
The thermodynamic parameters of complexation for the diazepam/ $\beta$ cyclodextrin interaction are presented in Table III. The enthalpy of complexation is again negative at all pH values. As pH decreases and drug ionization increases, the absolute value of $\mathrm{H}$ decreases. This lower value of $\mathrm{H}$ indicates a weaker binding and a lower loss of heat upon complexation. It has also been proposed that the complexation of an ionized species would occur on a more random fashion than for the ionized species (16). The entropy value is positive and increases as the $\mathrm{pH}$ is increased. As for ibuprofen, the entropy can be correlated to the forming and breaking of hydrogen bonds upon complexation. The ionized form of diazepam probably keeps a water solvation in the surroundings and gains hydrogen bonding without loosing such a great amount as in pH 6 . The overall result is a larger entropy upon complexation. Also, as the $\mathrm{pH}$ decreases the water molecules are more tightly bound to the drug molecule and therefore are only slowly removed, partially explaining the high entropy values.

The results shown in Figure IV for the complexation of hydrochlorothiazide with $\beta$ cyclodextrin are less dramatic but possibly easier to interpret. Hydrochlorothiazide is a weak acid with a pKa around 8.0. It seems that the ionization of the drug has very little effect on the thermodynamic parameters of complexation. This result also confirms the fact that hydrochlorothiazide does not form a complex with $\beta$ cyclodextrin in its ionized form. The 
negative values of enthalpy testifies again of the stong involvement of the enthalpy rich water during complexation. The large negative values of entropy suggest that the system becomes more ordered upon complexation.

\section{SUMMARY}

From the results for the complexation of three drugs with cyclodextrins, it appears that the main driving forces of complexation reside in the release of energy of the water molecules entrapped in the cyclodextrin cality. Althouh the negative enthalpy value was a common point between the drugs tested, the extent of the $\mathrm{pH}$ effect varied from one molecule to another. The entropy is probably more related to the solvent participation in the complexation phenomenon. The consideration of the interaction between water and non-polar drug, water and cyclodextrin before complexation as well as the breakage and establishment of hydrogen bonds, allowed for a description of the complexation mechanism for each drug. However, this arug/cyclodextrin interaction depended on the nature of the drug and the pH of the solution. The practical biopharmaceutical implications of the results can be quite significant. A drug/cyclodextrin complex dosage form either for parenteral or oral administration, would encounter various $\mathrm{pH}$ conditions in-vivo. The therapeutic effect might well be affected by the mechanism of complexation. Further work is still needed to fully explain 
negative values of enthalpy testifies again of the strong involvement of the enthalpy rich water during complexation. The large negative values of entropy suggest that the system becomes more ordered upon complexation.

\section{SUMMARY}

From the results for the complexation of three drugs with cyclodextrins, it appears that the main driving forces of complexation reside in the release of energy of the water molecules entrapped in the cyclodextrin cality. Althouh the negative enthalpy value was a common point between the drugs tested, the extent of the $\mathrm{pH}$ effect varied from one molecule to another. The entropy is probably more related to the solvent participation in the complexation phenomenon. The consideration of the interaction between water and non-polar drug, water and cyclodextrin before complexation as well as the breakage and establishment of hydrogen bonds, allowed for a description of the complexation mechanism for each drug. However, this drug/cyclodextrin interaction depended on the nature of the drug and the $\mathrm{pH}$ of the solution. The practical biopharmaceutical implications of the results can be quite significant. A drug /cyclodextrin complex dosage form either for parenteral or oral administration, would encounter various $\mathrm{pH}$ conditions in-vivo. The therapeutic effect might weIl be affected by the mechanism of complexation. Further work is still needed to fully explain 
the exact mechanism of drug/cyclodextrin complex formation and to eventually optimize complex formulation.

\section{REFERENCES}

1. M.L. Bender and M. Kornigama, Cyclodextrin Chemistry, Berlin Heidelberg, NY (1978).

2. S.P. Jones, D.J.W. Grant, J. Hadgraft and G.D. Parr, Acta Pharm. Techn., 30, 213-223 (1984).

3. A.L. Thakkar, P.B. Kuehn, J.H. Perrin and W.L. Wilham, J. Pharm. Sci., 61, 1841-1843 (1972).

4. K. Uekama and F. Kirayama, Chem. Pharm. Bull., 26, 1195-1200 (1978).

5. K. Uekama, T. Fujinaga, M. Otagiri, N. Matsuo and Y. Matsuoka, Acta Pharm. Suec., 20, 287-294 (1983).

6. S.Y. Lin and J.C. Yang, Drug Dev. Ind. Pharm., 13, 329-343 (1987).

7. T. Tokumura, Y. Tsushima, M. Kayano, Y. Machida and T. Nagai, J. Pharm. Sci., 74, 496 (1985).

8. T. Higuchi and K.A. Connors, Adv. Anal, Chem. Instr., 4, 117-212 (1965).

9. C.C. Peck and I.Z. Benet, J. Pharm. Sci., 67, 12-26 (1978).

10. D.J.W. Grant, M. Medhizadeh, A.H.-L. Chow and J.E. Fairbrother, Int. J. Pharm., 18, 25-38 (1984).

11. P.A. Schwartz and A.N. Paruta, J. Pharm. Sci., 65, 252-257 (1976).

12. K.S. Alexander, J.W. Mauger, H. Petersen and A.N. Paruta J. Pharm. Sci., 67, 625-627 (1978).

13. R.J. Bergeron, Inclusion Compounds: Atwood, Daries and MacNickol, Academic Press (1984).

14. F. Hirayama and $K$. Uekama, Cyclodextrins and their industrial uses, ed. De Sante, Paris (1987). 
15. Y. Matori, T. Niskioka and T. Fujita, Biometric. Bioorg. Chem., 128, 61-89 (1985).

16. R. J. Bergeron, M.A. Charming, and K.A. McGovern, J. Am. Chem. Soc., 100, 2878-2883 (1978). 
TABLE I: Heat of solution of the drugs at various $\mathrm{pH}$ values

\begin{tabular}{|c|c|c|c|}
\hline DRUG & pH & $\begin{array}{c}\left.\Delta \mathrm{H}_{\mathrm{S}} \text { ( linear }\right) \\
\left(\mathrm{cal} . \mathrm{mol}^{-1}\right)\end{array}$ & $\begin{array}{c}\Delta \mathrm{H}_{\mathrm{s}}(\text { non-linear }) \\
\left(\mathrm{cal} \cdot \mathrm{mol}^{-1}\right)\end{array}$ \\
\hline & 2 & $11,158.8$ & $8,718.9 \pm 1,266.2$ \\
\hline & 4 & $10,534.1$ & $9,447.9 \pm 1,223.0$ \\
\hline \multirow[t]{3}{*}{ IBUPROFEN } & 5 & $6,287.5$ & $6,207.5 \pm 375.7$ \\
\hline & 6 & $4,685.9$ & $4,157.7 \pm 385.8$ \\
\hline & 2 & 311.2 & $1,246.8 \pm 543.2$ \\
\hline \multirow[t]{4}{*}{ DIAZEPAM } & 3 & $1,565.2$ & $1,459.9 \pm 289.6$ \\
\hline & 4 & $3,724.9$ & $5,368.5 \pm 716.0$ \\
\hline & 6 & $5,381.4$ & $6,509.3 \pm 565.4$ \\
\hline & 5 & 10.392 .2 & $9,420.3 \pm 327.4$ \\
\hline HYDROCHLORO- & 8 & $9,756.2$ & $10.313 .4 \pm 332.2$ \\
\hline THIAZIDE & 9 & $8,808.9$ & $9,157.6 \pm 330.3$ \\
\hline
\end{tabular}


TABLE II: Ibuprofen/ $\beta$ cyclodextrin complexation thermodynamic parameters

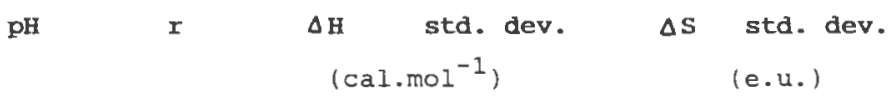

$\begin{array}{llllll}2 & 0.999 & -6,925.5 & 324.9 & +3.49 & 1.06 \\ 4 & 0.999 & -7,797.9 & 321.7 & +0.88 & 1.05 \\ 5 & 0.999 & -7,045.5 & 300.0 & +0.72 & 0.97 \\ 6 & 0.991 & -4,036.4 & 1,246.6 & +8.15 & 4.06\end{array}$


TABLE III: Diazepam/ $\beta$ cyclodextrin complexation thermodynamic parameters

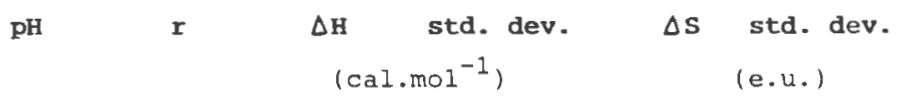

$\begin{array}{rrrrrr}2 & 0.960 & -51.4 & 1502.4 & +16.63 & 4.89 \\ 3 & 0.998 & -797.9 & 145.7 & +16.50 & 0.47 \\ 4 & 0.998 & -4.070 .7 & 184.2 & +5.22 & 0.60 \\ 6 & 0.999 & -4.416 .4 & 104.3 & +4.44 & 0.34\end{array}$


TABLE IV: Hydrochlorothiazide/B cyclodextrin complexation thermodynamic parameters

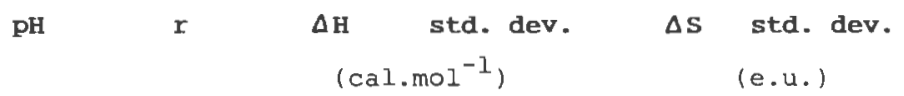

$\begin{array}{llllll}5 & 0.997 & -9,642.3 & 432.3 & +14.7 & 1.4 \\ 8 & 0.997 & -9,322.1 & 574.1 & +14.1 & 1.9 \\ 9 & 0.996 & -10,012.2 & 715.9 & +16.7 & 2.3\end{array}$


Figure 1

Van't Hoff plots for ibuprofen 


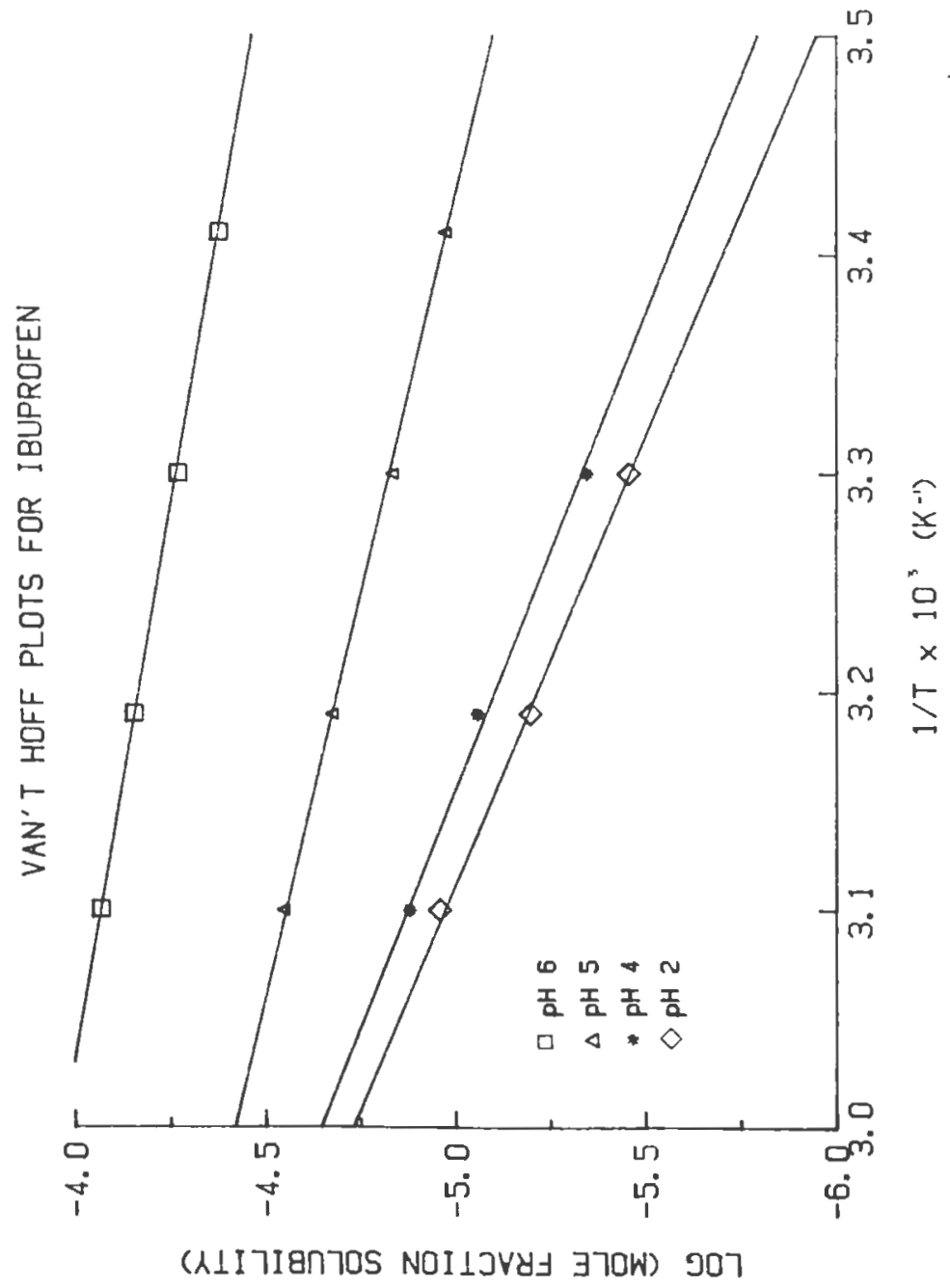


Figure 2

Van't Hoff plots for diazepam 


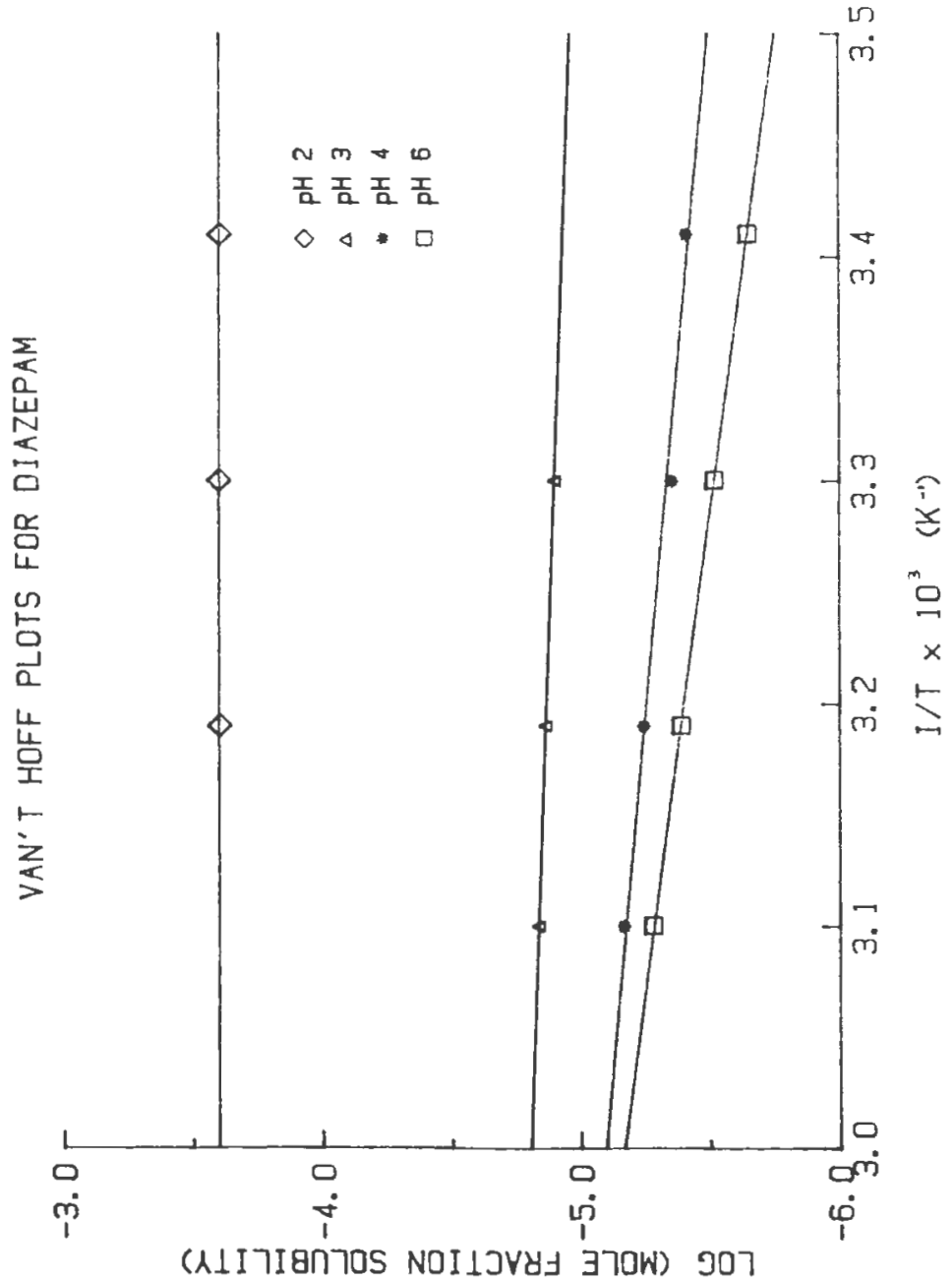


Figure 3

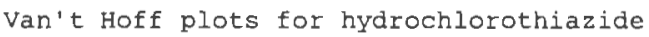




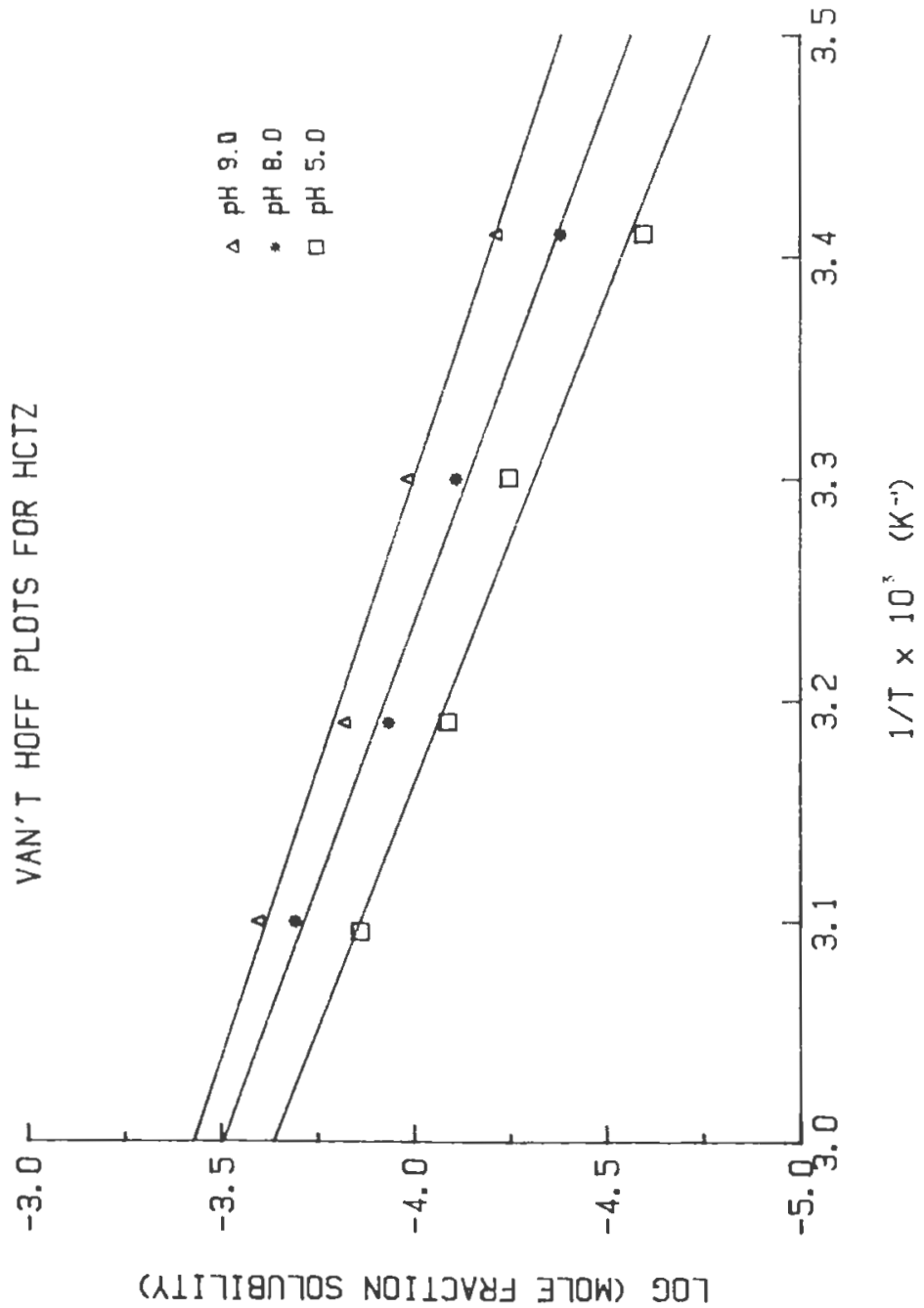


Figure 4

Effect of $\mathrm{pH}$ on the solubility isotherms of ibuprofen at $50^{\circ} \mathrm{C}$ 


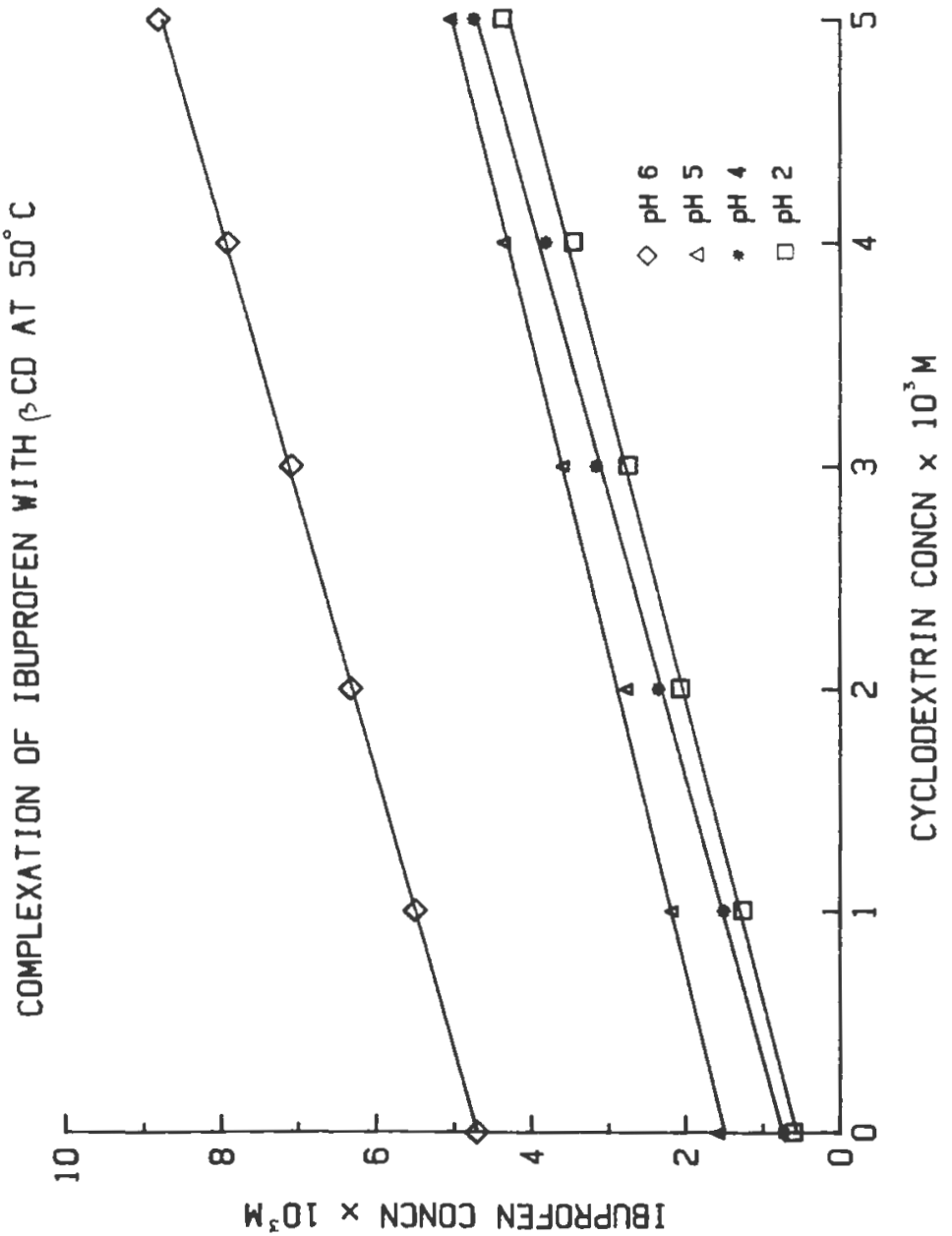


Figure 5

Effect of $\mathrm{pH}$ on the solubility isotherms of diazepam at $30^{\circ} \mathrm{C}$ 


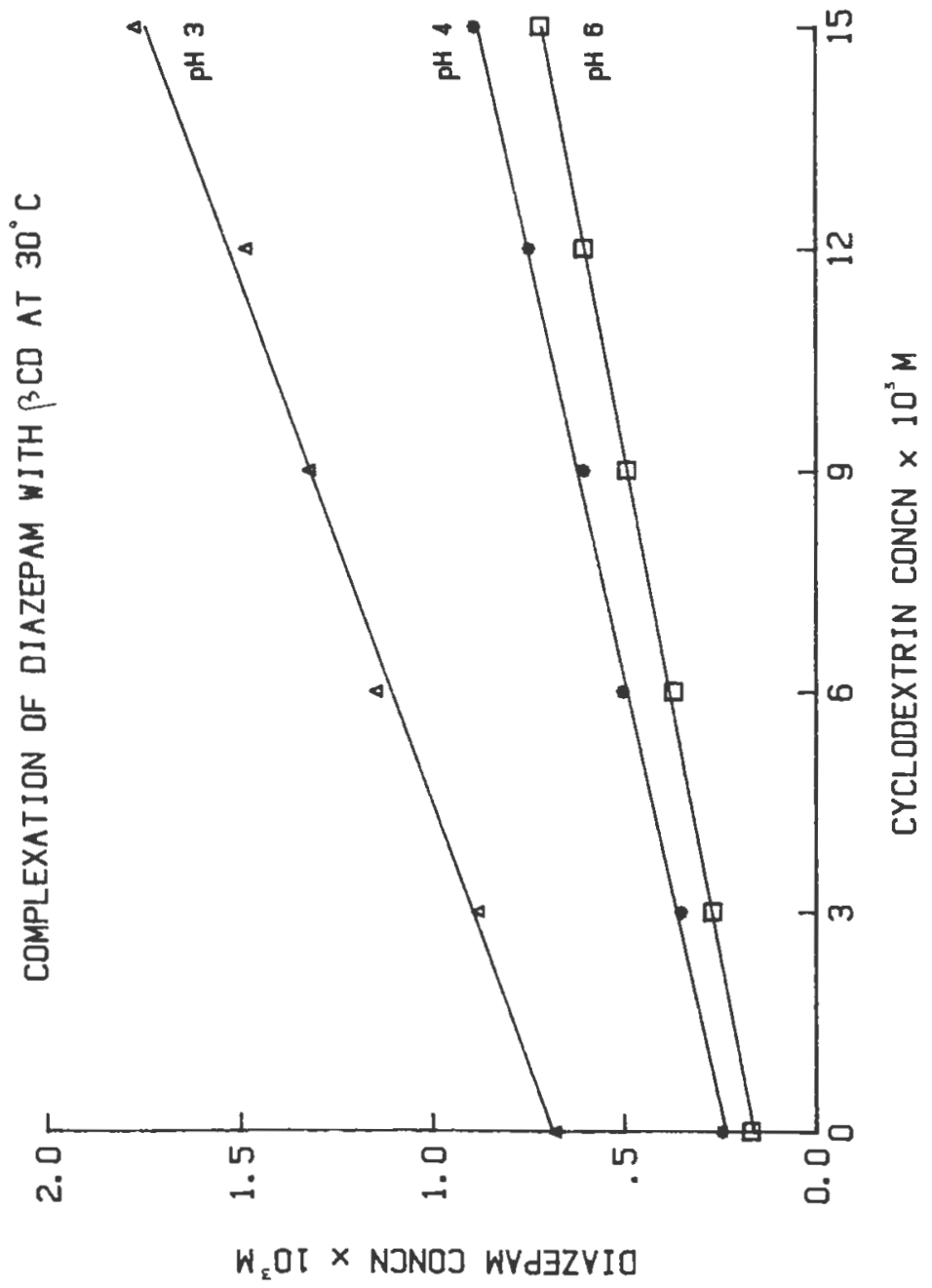


Figure 6

Effect of $p H$ on the solubility isgtherms of hydrochlorothiazide at $40^{\circ} \mathrm{C}$ 


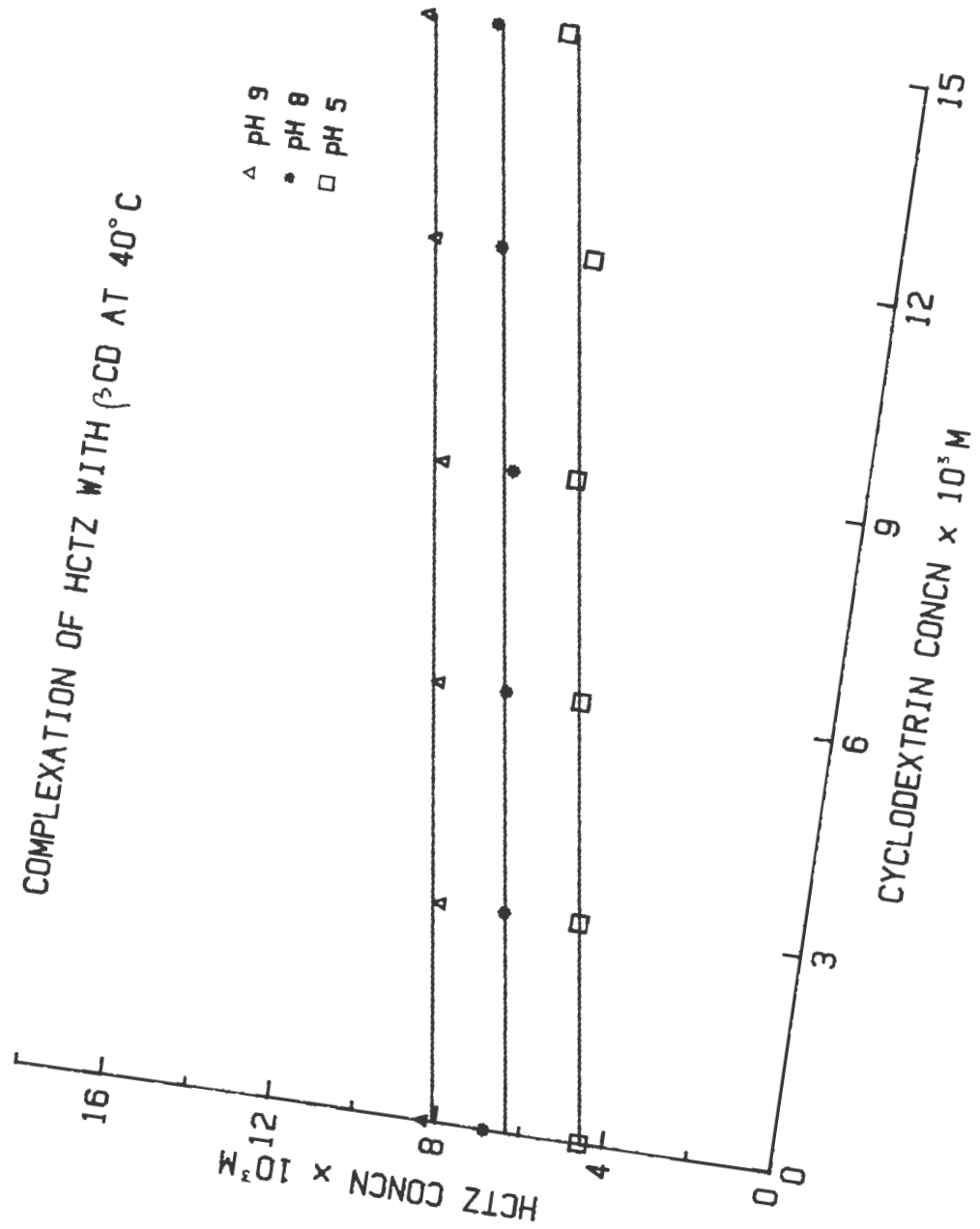


Figure 7

Effect of temperature on the solubility isotherms of diazepam at $\mathrm{pH} 4$ 


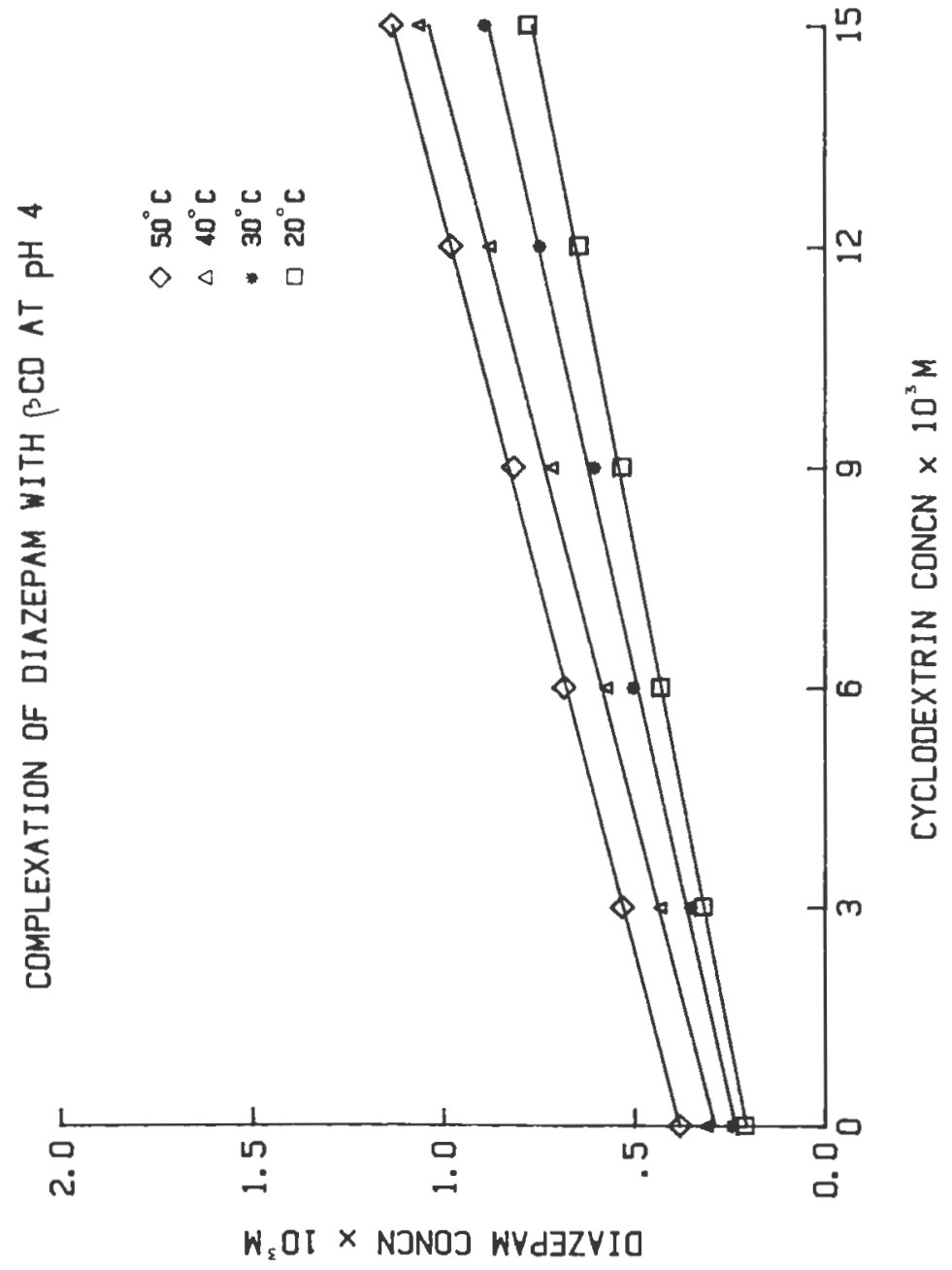


Figure 8

3D plot of the solubility of ibuprofen at pH 5 


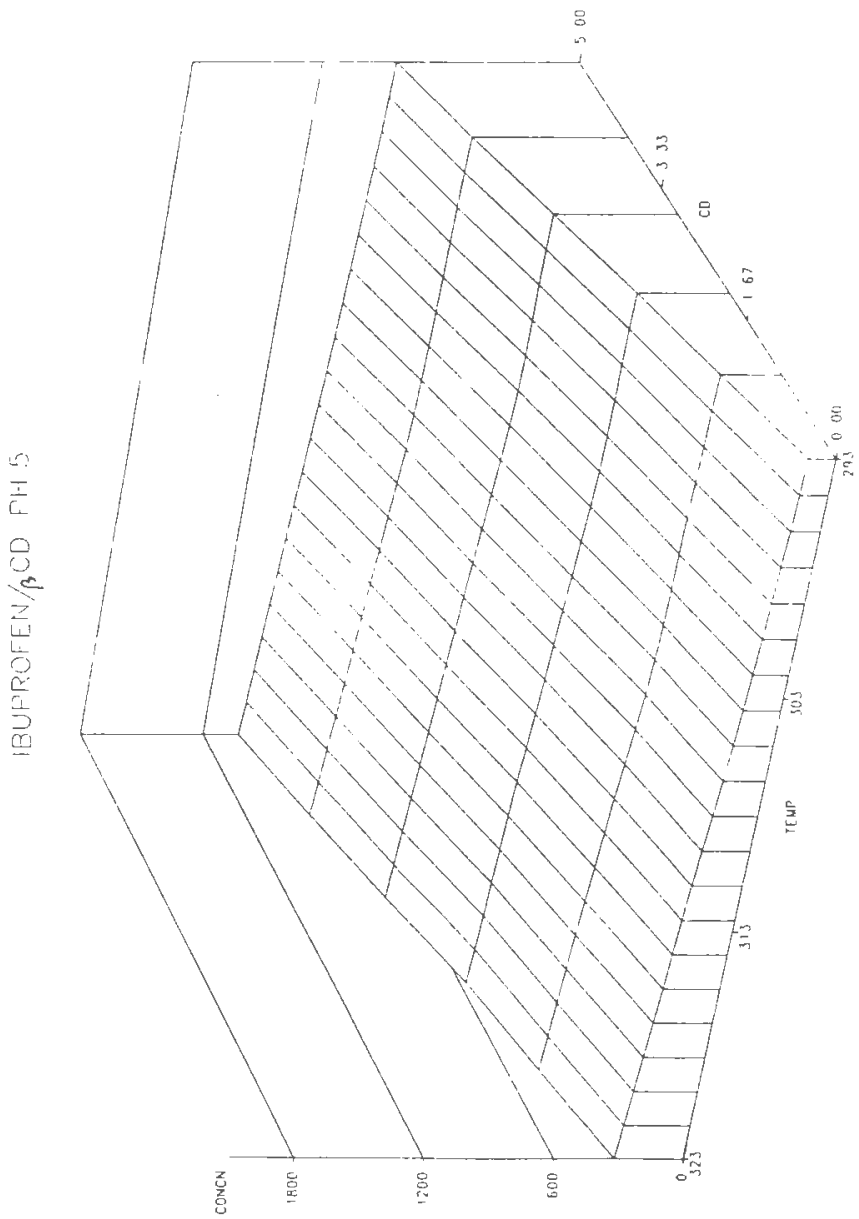


Figure 9

3D plot of the solubility of HCTZ at pH 8 


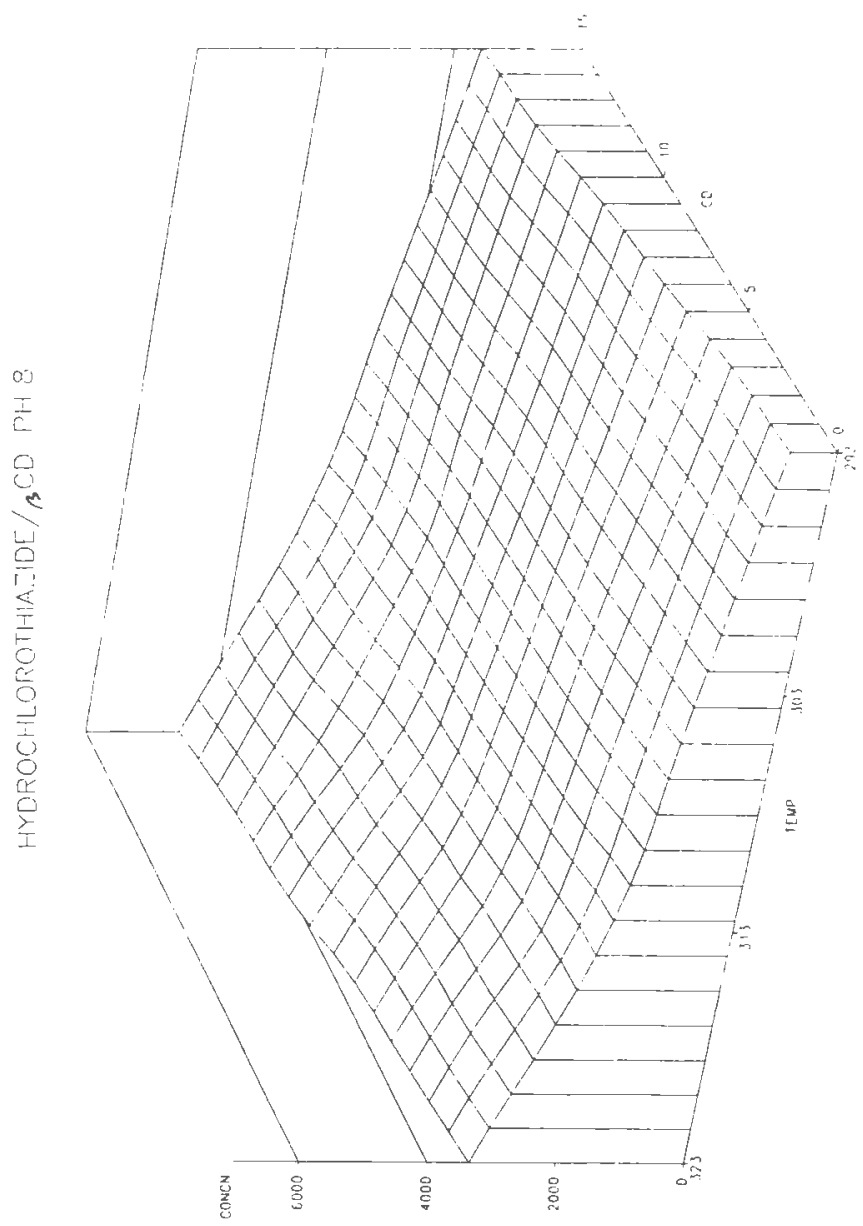


Figure 10

3D plot of the solubility of diazepam at $\mathrm{pH} 6$ 


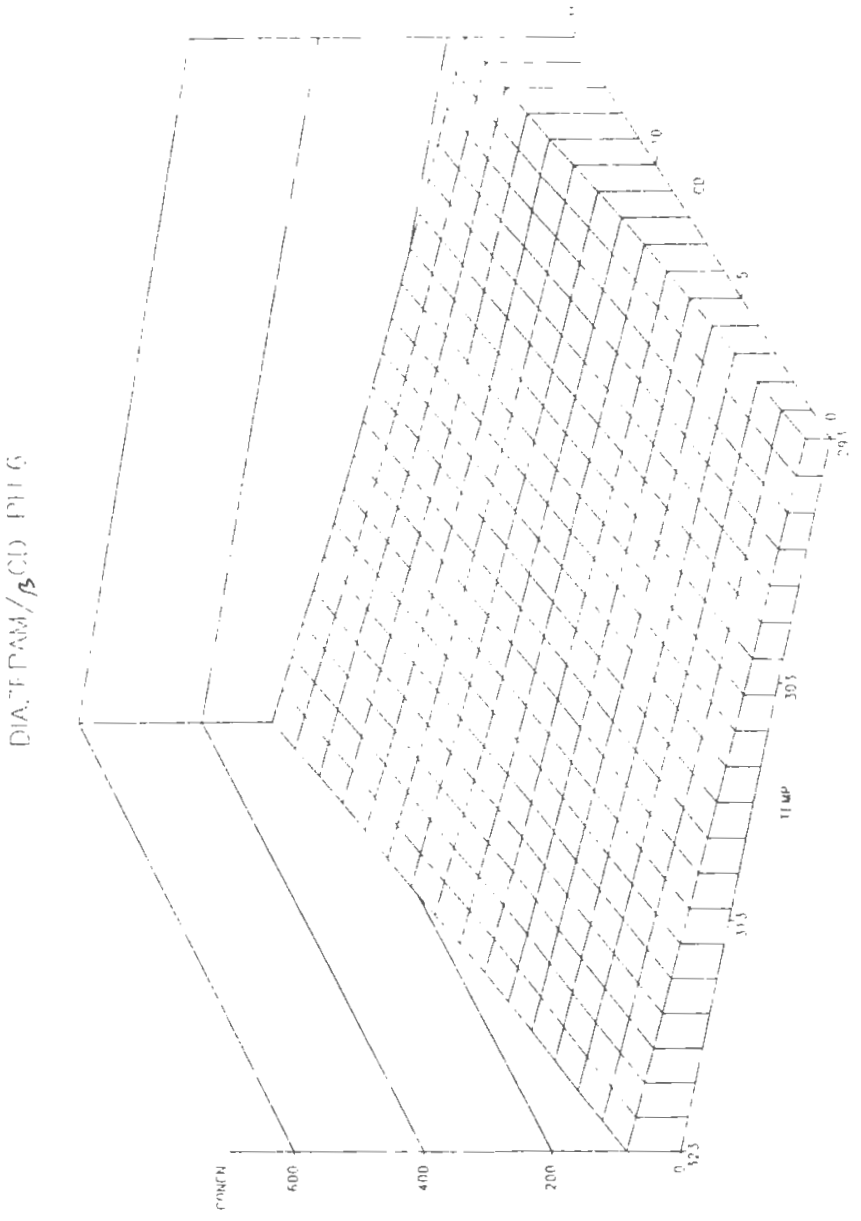


MANUSCRIPT V 
POTENTIAL USE OF BETA CYCLODEXTRIN

AS AN ADDITIVE IN TABLET FORMULATION

F.A. Menard ${ }^{a}$, M.G. Dedhiya ${ }^{b}$ and C.T. Rhodes ${ }^{a}$

a Department of Pharmaceutics

University of Rhode Island Kingston RI 02881-0809

b Miles Pharmaceuticals

400 Morgan Lane West Haven CT 06516 USA

\section{INTRODUCTION}

The dissolution of poorly soluble drugs can be the major limitation in the design of suitable solid dosage forms (1). The absorption rate is usually much higher than the dissolution rate in the gastro-intestinal tract.

Therefore an increase in the dissolution properties for many drugs is likely to lead to higher bioavailability (2). Much research has already been done in the field of pharmaceutics to improve the dissolution of poorly absorbed drugs $(3,4)$. Different techniques have been proposed such as micronization $(5,6)$, grinding (7) and preparation of solid dispersions $(8,9,10)$. The term solid dispersion refers to the dispersion of an active drug in an inert carrier or matrix (11), such as polyethylene glycol (PEG), urea, mannitol or polyvinylpyrrolidone (PVP). The complexation of drugs with beta cyclodextrin is a particular case of solid dispersion, in which the drug is actually encapsulated on a 
molecular basis in an hydrophilic oligosaccharide composed of seven units of glucose (12).

Cyclodextrins have been shown to have the ability to form inclusion complexes with drugs, which exist both in solution and in the solid state. This is the basis of the preparation of a solid dosage form containing a drug/cyclodextrin complex as the active ingredient. The dry method consists of a mechanical mixing of the drug with cyclodextrins. Different ratios of the two components and various methods of mixing can be used (13). Such formulations have been successfully prepared using grinding and roll-mixing. The advantages of the dry method include simplicity, one-step process and exact knowledge of the blend content. The second or wet method consists of a two-step process. The first step is the formation of the drug/cyclodextrin complex in solution. Drug and cyclodextrin are solubilized in a solvent according to a definite ratio and the solution is shaken until equilibrium is reached (14). The second step is the removal of the solvent. Different techniques have been proposed to prepare the dry complex, such as solvent evaporation (15), kneading, spray-drying (12) and freeze-drying (16). Upon drying, the complex obtained is usually amorphous (17), with two specific properties: a smaller particle size and a reduced crystal growth, due to the fast removal of water molecules (18). It has been well reported that amorphous forms have the largest energy and exhibit faster dissolution. Rarely 
in the literature are the dissolution profiles of drug/cyclodextrin complexes compared with those of the pure drug subjected to the same process (19). It is therefore often difficult to interpret the data, that compare dissolution rate of an amorphous form with a crystalline form.

Two main criteria should be taken into consideration in the development of a solid dosage form of drug/cyclodextrin complex: the stoichiometry of the complex and the degree of complexation, that can be evaluated from the slope of the phase-solubility diagram. The stoichiometry of the complex can be determined using different techniques such as Job's plots, titrations or physical analysis by $\mathrm{X}$-Ray crystallography, Infra-Red and Differential Scanning Calorimetry. T. Higuchi also determined the stoichiometry of complexes from the plateau region observed in the phase-diagram solubility of certain insoluble complexes (20). The slope of the solubility isotherms is also an useful indicator of the extent of complexation. It represents a ratio of the respective amounts of drug and cyclodextrin actually entering the complex. A slope higher than one suggests the formation of a $1: x$ complex $(x>1)$. A slope lower than the unity can correspond either to a $1: 1$ complex with low affinity between drug and cyclodextrin or to the formation of a $y: 1 \quad(y<1)$. For such a complex, the solution ready for drying does not contain exclusively the drug:cyclodextrin inclusion compound. There is also in 
solution a substantial amount of free drug and free cyclodextrin, An intermediate step of filtration or purification should then be used to ensure the complete isolation of the complex. Finally, the advantage of the precipitation method is the higher purity of the product obtained.

The drug considered in this study is phenytoin, a widely used anticonvulsant. Phenytoin has a low aqueous solubility and follows non-linear pharmacokinetics $(21,22)$. The complexation of phenytoin with cyclodextrin is expected to result in higher bioavailability and decrease in the intra- and inter-variability of the absorption in patients.

The objectives of the study are to investigate the potential use of beta cyclodextrin as dissolution enhancer in mechanical mixtures of phenytoin and cyclodextrin. Also, the study focusses on the dissolution profiles of direct compression tablets, prepared using various drug/cyclodextrin ratios and different methods of mixing.

\section{EXPERIMENTAL}

Materials

Phenytoin was obtained from Sigma Chemicals and used as received. The cyclodextrin materials were a generous gift of American Maize. Avicel PH101, Primojel, magnesium stearate and sodium bicarbonate were all of USP grade suitable for use in pharmaceutical research. 


\section{Methods}

\section{Formulations}

Several formulations were prepared. Tables 1 and 2 show the amount of each ingredient $(\mathrm{g} w / \mathrm{w})$ in the differents blends. The percentage of cyclodextrin in Table 1 corresponds to $1: 0,1: 1$ and $1: 2$ as drug:cyclodextrin ratio $(\% \mathrm{w} / \mathrm{w})$. In Table 2 , a $1: 1$ ratio was used for all the formulations, which contain various percentages of sodium bicarbonate. This 1:1 stoichiometric ratio has been shown to be that of the complex formed in solution. Blends of 25 grams were prepared using a Turbula Rapid Blender, in three steps:

1. Mix phenytoin and cyclodextrin for ten minutes.

2. Add Avicel $\mathrm{pH} 101$ and $\mathrm{mix}$ for ten minutes.

3. Add magnesium stearate and mix for five minutes.

The formulation variables considered were the order of mixing and the method of mixing, as described in Table 3 . The blends were then compacted on a model $F$ single-punch Stokes tablet press. The target specifications of the tablets manufactured are listed in Table 4.

Evaluation of tablets

All the tablets were tested according to USP standards. The tablets from all batches did meet the desired specifications. Dissolution studies were conducted using the USP paddle method, in $\mathrm{pH} 7.4$ phosphate buffer and distilled water. Samples were taken manually at 15, 30 and 
60 minutes in triplicate. The medium was replaced after each sample withdrawal and final concentrations were computed by taking into account medium replacement. Phenytoin concentrations were determined using a Hewlett-Plackard diode-array ultra-violet spectrophotometer. The standard calibration curve obtained at $222 \mathrm{~nm}$ obeyed the Beer's law.

\section{RESULTS AND DISCUSSION}

Different modeis have been developed to describe the dissolution of drugs. The following equation shows the relationship between dissolution rate and some critical parameters using the simplest theory:

$$
\mathrm{dM} / \mathrm{dt}=\mathrm{K} s\left(\mathrm{C}_{\mathrm{S}}-\mathrm{C}\right)
$$

where $\mathrm{dM} / \mathrm{dt}$ is the dissolution rate

$\mathrm{K}$ is the ratio of diffusion coefficient and thickness of the stationary layer

$S$ is the effective surface area

$\mathrm{c}_{\mathrm{S}}$ is the saturation solubility of the drug and $\mathrm{C}$ is the drug concentration at time $t$

This equation shows that both particle size and saturation solubility directly affect the dissolution rate. For instance, the effect of micronization of the drug on dissolution rate can be readily explained from this empirical equation.

Figure 1 shows the dissolution profiles of phenytoin from tablets containing different amounts of cyclodextrin. 
As the ratio of drug:cyclodextrin increases, the dissolution rates increases, suggesting that cyclodextrin promotes the transport of the drug from the dosage form into the dissolution medium. Cyclodextrin may behave either as an extra-granular disintegrating agent or as an in-situ solubilization agent. The larger the amount of cyclodextrin, the higher the probability for the drug molecules to interact with cyclodextrin. It can be mentioned that the increase in dissolution rate, although it was statistically significant, was not dramatic.

Figure 2 shows the effect of grinding on the dissolution rates of phenytoin. Grinding resulted in a significant increase in dissolution, which can be explained by two different factors. Grinding is a process mainly used to decrease particle size of certain drugs. It has been shown that ground phenytoin formulations exhibited higher dissolution characteristics and better bioavailability $(7,23)$. It is thus likely that the increase observed in Figure 2 corresponds to an increase of the specific surface area. Due to the intimate character of grinding, it is also possible that the tortuosity of the system is changed, with a change in the diffusion properties of the drug molecules from the tablet into the bulk (18). This effect would also explain the results shown in Figure 3, where the dissolution rate of the tablets made using method 2 is significantly lower than that observed using the first method. The lack 
of interaction between the drug and cyclodextrin during mixing may be related to the negative effect on dissolution.

Sodium bicarbonate has the property to change the microenvironment around the dissolution particles and to promote dissolution of acidic drugs. The dissolution profiles of the tablets made using various amounts of sodium bicarbonate are shown in Figure 4 and 5 . The two dissolution media used were $\mathrm{pH} 7.4$ phosphate buffer and distilled water. A significant increase was observed in Figure 4, that shows that sodium bicarbonate affects the pH of the dissolution medium, thus resulting in higher concentrations. However, the increase does not appear to be very extensive. Figure 5 confirms that sodium bicarbonate does not have a dramatic effect on the dissolution rates of phenytoin. The data overlapped after 45 minutes, showing no trend or difference from one formulation to another.

\section{SUMMARY}

From the results of this study, it appears that beta cyclodextrin does enhance the dissolution of phenytoin. However, the relatively small extent of the increase in dissolution rate is unlikely to justify the use of this approach simply to increase dissolution rate, although, of course, cyclodextrin has a clearly identified role in increasing equilibrium solubility. Grinding actually seemed to have been the main factor, and can be compared to freeze-drying as an additional formulation process, that can 
interfere with the basic effect of cyclodextrin complexation in drug dissolution. A physical analysis would allow a better establishment of the crystal nature on a qualitative basis.

In conclusion, the use of beta cyclodextrin as a non-complexed additive in direct compression formulation seems for phenytoin to be of limited value. A more positive effect might well be observed using wet granulation, in which water or other solvents would allow the formation of the inclusion complex. Cyclodextrin could then play the role of intra-granular disintegrating agent and is likely to promote a larger increase in dissolution rate. Also preformulation data such as solubility studies, degree of interaction and stoichiometry determination should be the basis of the development of drug:cyclodextrin complexation.

\section{ACKOWLEDGEMENTS}

The authors thank American Maize for the generous supply of the cyclodextrin materials.

\section{REFERENCES}

1. D.E. Wurster and P.W. Taylor, J. Pharm. Sci., 54, 169 (1965).

2. S. Yakou, S. Yamasaki, T. Sonobe, T. Nagai and M. Sugihara, Chem. Pharm. Bull., 34 (8), 3408-3414 (1986).

3. M. Kata and L. Papp, Pharmazie, 42, 65 (1985).

4. H. Sekikawa, N. Fukuda, M. Takada, K. Ohtani, T. Arita 
and M. Nakano, Chem. Pharm. Bul1., 31 (4), 1350-1356 $(1983)$.

5. C. Nystrom and M. Westerberg, J. Pharm. Pharmacol., 38, $161-165$ (1986).

6. W.I. Chiou and S. Riegelman, J. Pharm. Sci., 60 (9), $1376-1380$ (1971).

7. Y. Nakai, Drug Dev. Ind. Pharm., 12 (7), 1017-1039 $(1986)$.

8. S. Stavchansky and W.G. Gowan, J. Pharm. Sci., 73, 733 \{1984\}.

9. Y. Nozawa T. Mizumoto and F. Higashide, Pharm. Acta Helv., 61 (12), 337-341 (1986).

10. W.I. Chiou and S. Riegelman, J. Pharm. Sci., 60 (9), 281-302 (1971).

11. D.W. Block and P.P. Speiser, Pharm. Acta Helv., 62 (1), 23-27 (1987).

12. J. Szejtli, Cyclodextrin and their inclusion complexes, Akademiai Kiado, Budapest (1982).

13. E. Eenyvesi, K. Takayama, J. SzejtIi and T. Nagai, Chem. Pharm. Bu11., $32(20,670-677$ (1984).

14. M. Otagiri, T. Imai, N. Matsuo and K. Uekama, Acta Pharm. Suec., 20 (1), 1-10 (1983).

15. F. Cramer and F.M. Henglein, Chem. Ber., 90, 2561 (1957).

16. M. Kurzumi, N. Nambu and T. Nagai, Chem. Pharm. Bull., 23, 3062 (1975).

17. R. Hegde, Ph.D. thesis, University of Rhode Island, 1985.

18. A.N. Martin, J. Swarbrick and A. Commarata, Physical Pharmacy, 3rd Edition, Lea and Febiger, Philadelphia (1983).

19. O.I. Corrigan and C.T. Stanley, J. Pharm. Pharmacol., $34,621-626(1984)$.

20. T. Higuchi and K.A. Connors, Adv. Anal. Chem. Instr., 4, 117 (1965).

21. P.A. Schwartz, C.T. Rhodes and J.W. Cooper, J. Pharm. Sci., 66, 994-997 (1977). 
22. E. Martin, T.N. Tozer, L.B. Sheiner and S. Riegelman, J. Pharmacokin. Biopharm., 5 (6), 579-598 (1977).

23. S. Yakou, S. Yamazaki, T. Sonobe, M. Sugihara, K. Fukumuro and T. Nagai, Chem. Pharm. Bu11., 34 (10), 4400-4402 (1986). 
Table 1: Phenytoin: $\beta$ cyclodextrin formulations ( $\left.\frac{\mathrm{o}}{\mathrm{w}} \mathrm{w} / \mathrm{w}\right)$

\begin{tabular}{lrcc}
\hline & \multicolumn{3}{c}{ drug: $\beta$ CD ratio } \\
& $1: 0$ & $1: 1$ & $1: 2$ \\
\cline { 2 - 4 } & 8 & 8 & 8 \\
Phenytoin & 0 & 36 & 72 \\
$\beta$ cyclodextrin & 89 & 53 & 17 \\
Avicel ph 101 & 2 & 2 & 2 \\
Primojel & 1 & 1 & 1 \\
Magnesium stearate & & & \\
\hline
\end{tabular}


Table 2: Phenytoin: $\beta$ cyclodextrin formulations containing sodium bicarbonate $\left(\frac{8}{2} \mathrm{w} / \mathrm{w}\right)$

\begin{tabular}{lccc}
\hline & \multicolumn{3}{c}{ Batch } \\
& Na12 & Na24 & Na36 \\
\cline { 2 - 4 } & 8 & 8 & 8 \\
Phenytoin & 36 & 36 & 36 \\
B cyclodextrin & 41 & 29 & 17 \\
Avicel pH 101 & 2 & 2 & 2 \\
Erimojel & 1 & 1 & 36 \\
Magnesium stearate & 12 & 24 & 1 \\
\hline
\end{tabular}


Table 3: Process variables

\begin{tabular}{lll} 
Mixing process & Order of mixing & Method \\
\hline regular mixing & $\begin{array}{l}\text { (phenytoin + cyclodextrin) + Avicel } \\
\text { (phenytoin + Avicel) + cyclodextrin }\end{array}$ & 2 \\
grinding & (phenytoin + cyclodextrin) + Avicel & 1 \\
\hline
\end{tabular}


Table 4: Tablet specifications

Parameter

Unit

Specification

Weight

(mg)

$325 \pm 15$

Hardness

( $\mathrm{kg})$

$4-7$

Friability

(옹)

LT 0.8

Disintegration time(s)

LT 180

Diameter

(inch)

$0.378 \pm 0.001$

Thickness

(inch)

$0.205 \quad 0.005$ 
Figure 1

Dissolution profiles of phenytoin at $37^{\circ} \mathrm{C}$ in water Effect of drug:CD ratio 


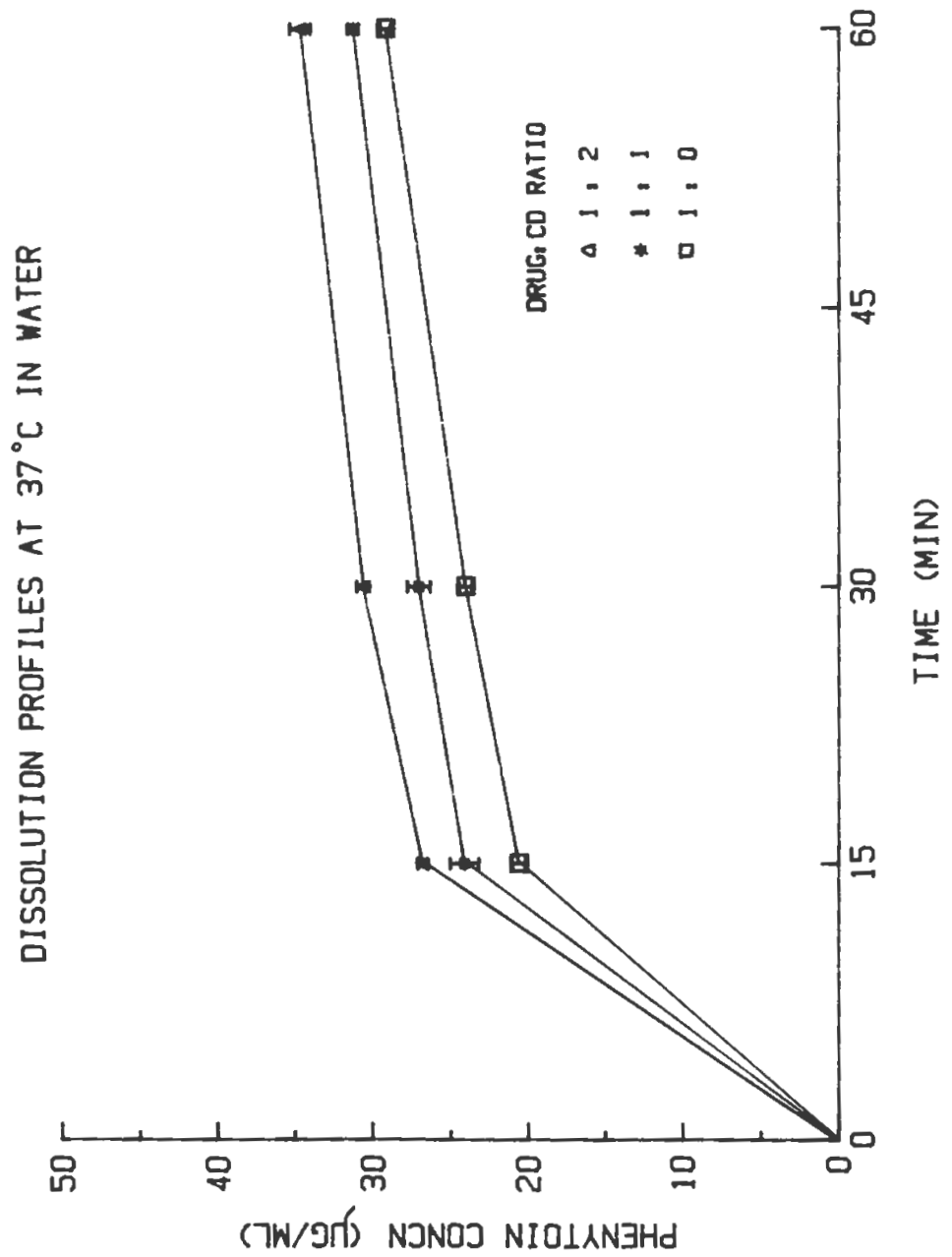


Figure 2

Dissolution profiles of phenytoin at $37^{\circ}$ in water Effect of mixing process 


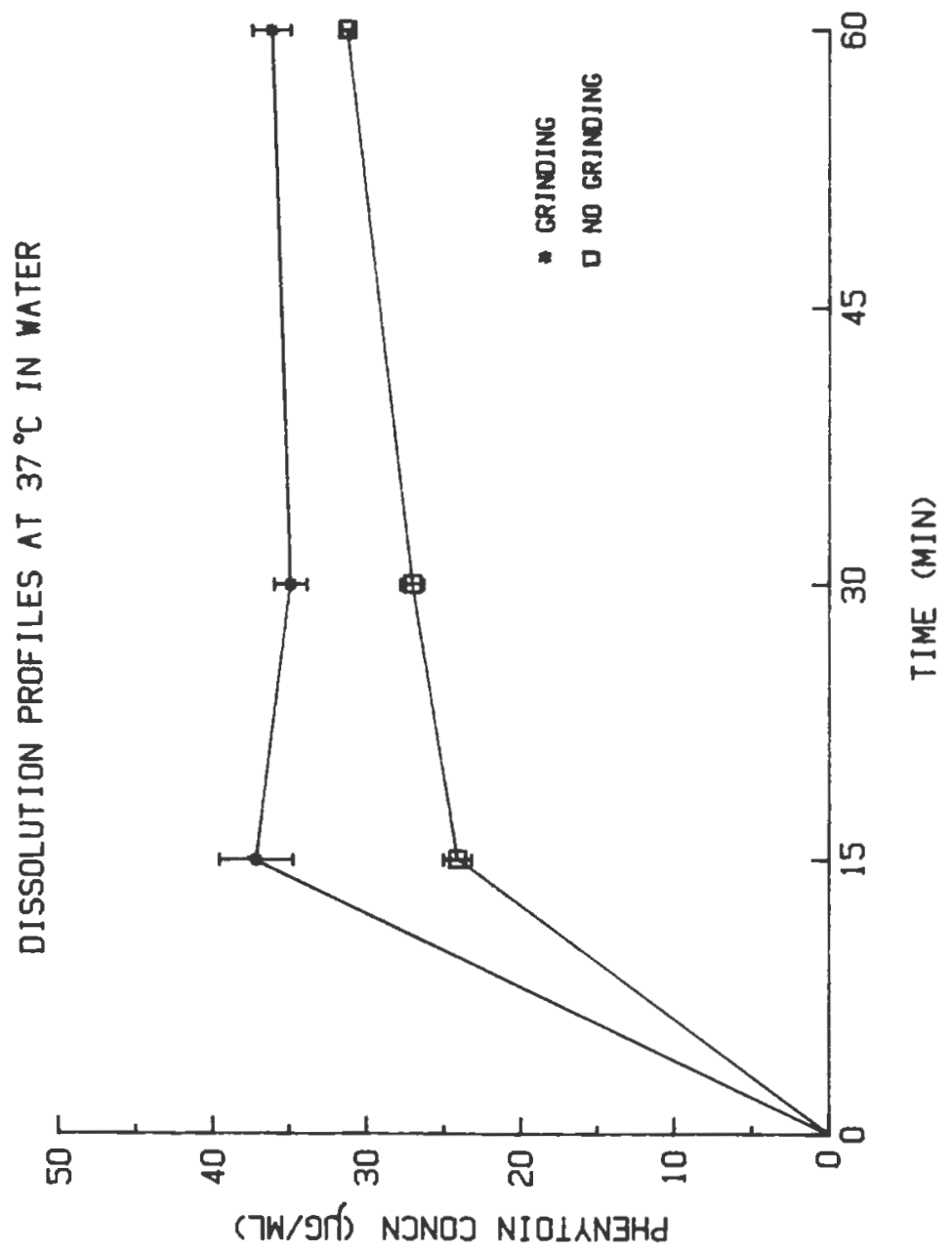


Figure 3

Dissolution profiles of phenytoin at $37^{\circ} \mathrm{C}$ in water Effect of order of mixing 


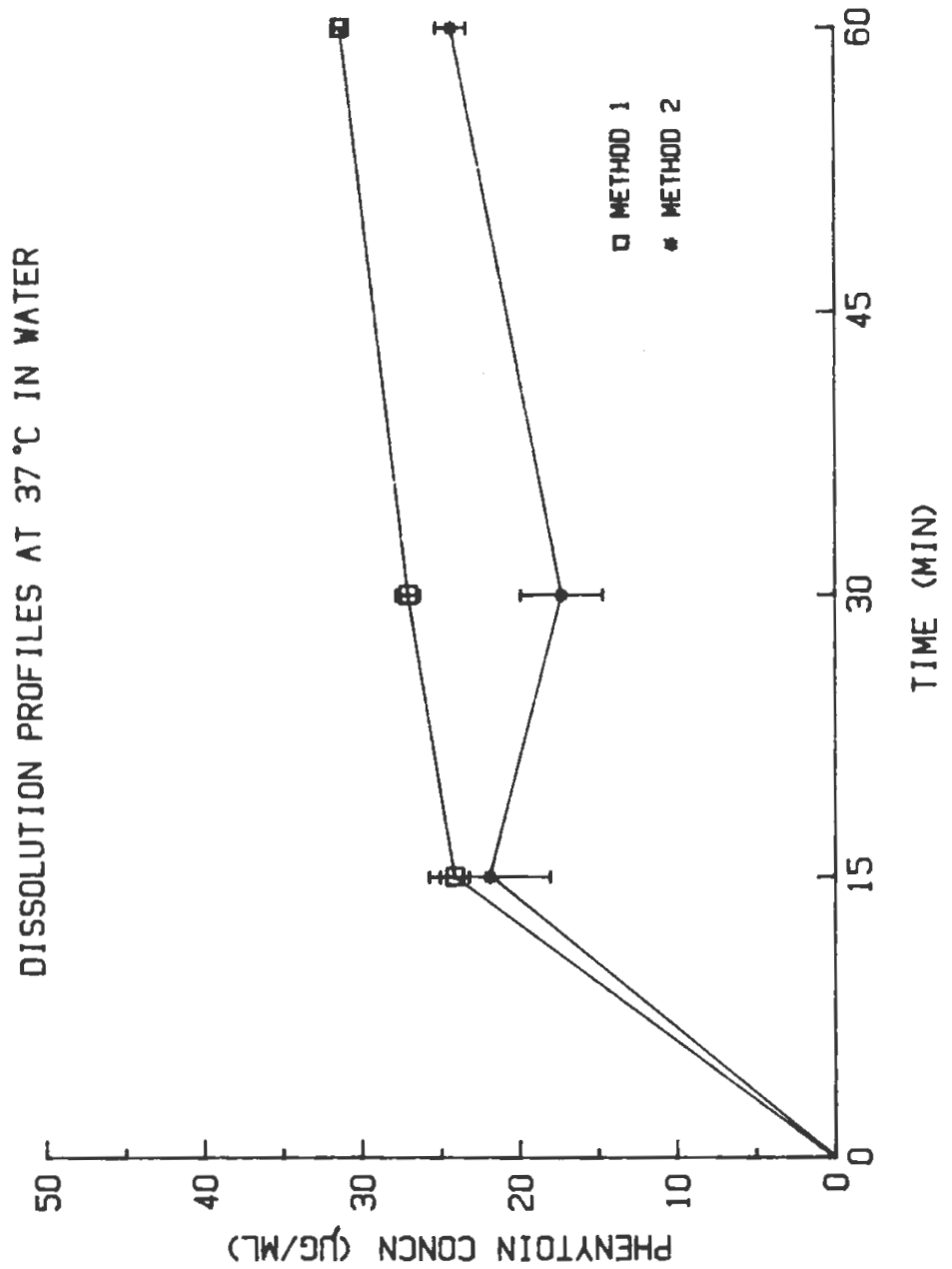




\section{Figure 4}

Dissolution profiles of phenytoin at $37^{\circ} \mathrm{C}$ Effect of dissolution medium 


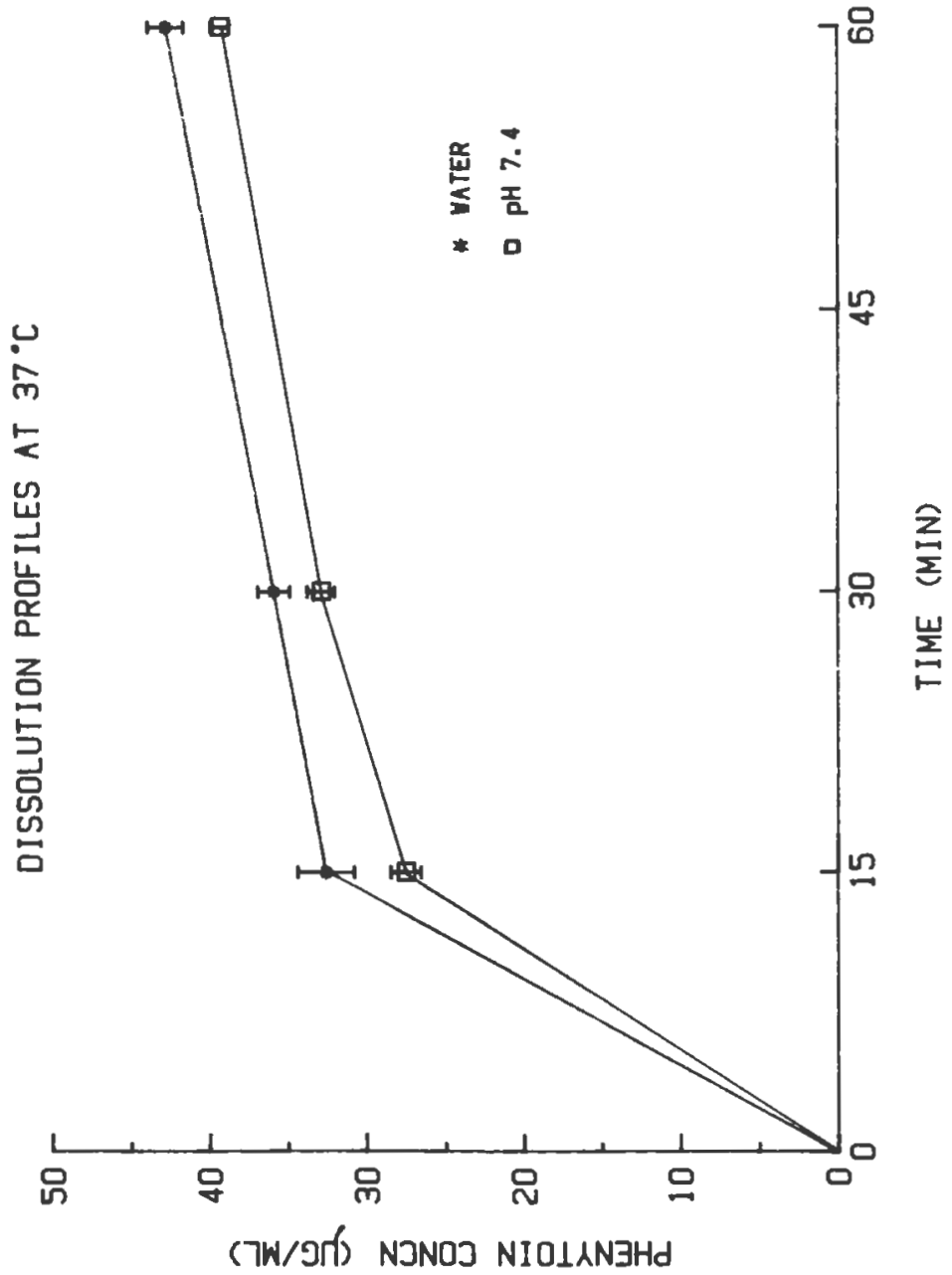


Figure 5

Dissolution profiles of phenytoin at $37^{\circ} \mathrm{C}$ and $\mathrm{pH} 7.4$ Effect of sodium bicarbonate 


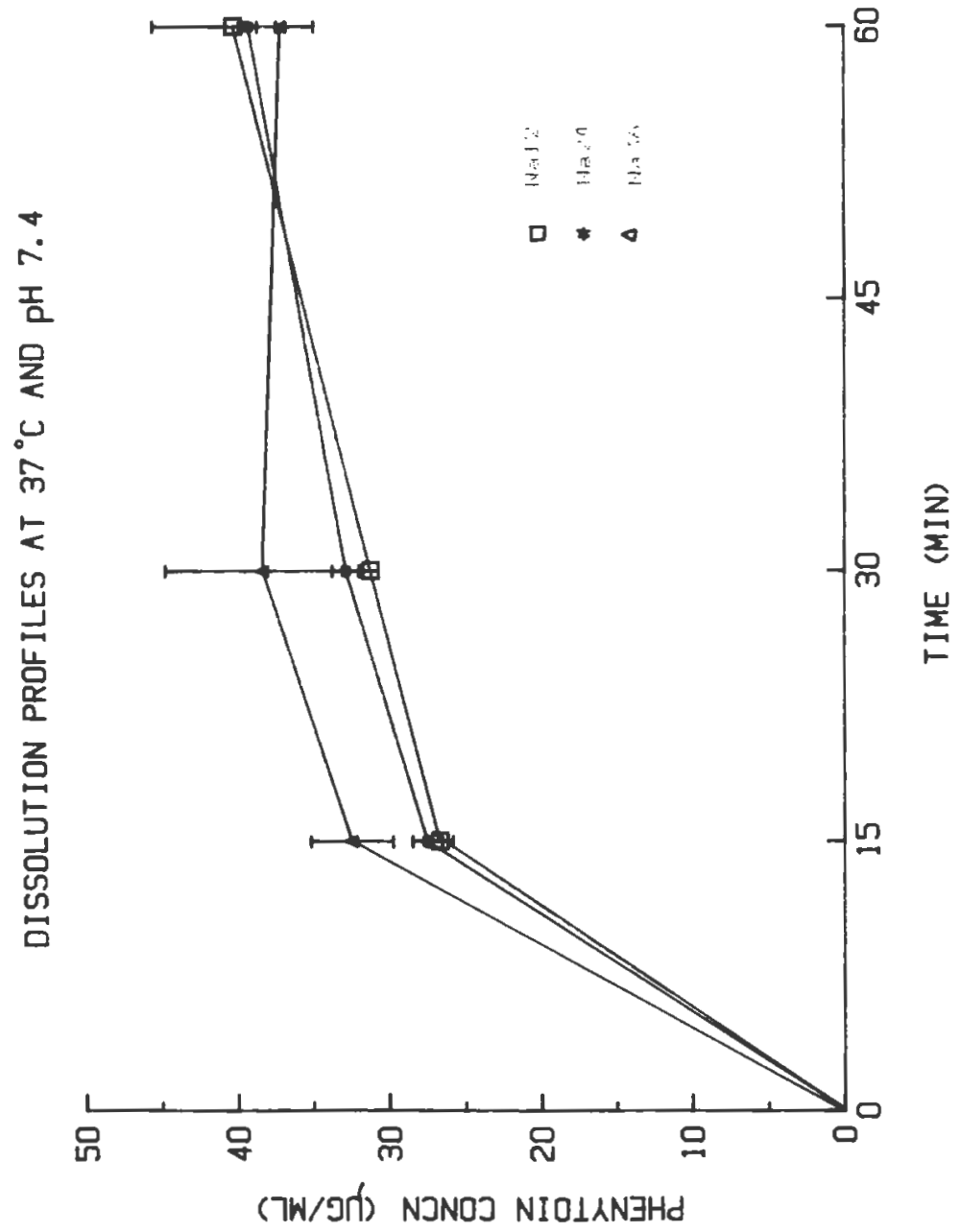


the drugs studied, thus preventing any interaction of the ionized species with cyclodextrin.

A novel computerized method of determination of thermodynamic parameters of the complexing group was developed and validated. The method allowed for a precise determination of enthalpy and entropy of complexation with known standard deviation. A large negative enthalpy was observed for all four drugs, suggesting a rather enthalpy controlled mechanism. This result shows the involvement of the enthalpy-rich water molecules trapped in the cyclodextrin cavity during complexation. Strong dipole interactions as well as Van der Waals forces are likely to accompany the complexation process. Classical hydrophobic interaction does not seem to play a major role. The results for the entropy of complexation indicate both the importance of the solvent and the differences in complexation behavior of the different drugs. Water seems to play a major role in the complexation phenomenon due to its ability to form hydrogen bonding. According to the nature and the polarity of the guest molecule, the extent of hydrogen bonding might vary and thus affect the stability of the complex.

The new chemically modified beta cyclodextrin was shown to have a great potential for the pharmaceutical industry. The solubilization power observed from the solubility data was basically identical to that obtained with the natural beta cyclodextrin. The total concentration reached in the case of phenytoin and ibuprofen could very well lead to new 
CONCLUSIONS AND SUGGESTIONS FOR FUTURE WORK

CONCLUSIONS

The solubility method has been shown to be an excellent practical mean of studying the complexation of drugs with cyclodextrins. From the solubility data obtained, a linear relationship was observed between the drug and the cyclodextrin concentrations. The general theory of "hand and glove" or "lock and key" applied for the four drugs studied. Beta cyclodextrin was shown to have the best complexing ability, suggesting that the steric factors are likely to control the complexation phenomenon. This result was also confirmed from the comparative study of the natural and the chemically modified beta cyclodextrin. A change in the external structure of the host molecule did not affect the solubilization power. However, the steric factors are not sufficient to explain the differences from one drug to another or from one degree of ionization to another. For two drugs, ibuprofen and hydrochlorothiazide, the ionized species have been shown not to interact with beta cyclodextrin, whereas the ionized form of phenytoin and diazepam had the ability to form a complex. These differences in behavior might well be due to the structure of the drugs. The ionization seemed to have an effect on the hydrophobic character of the complexing group of two of 
dosage forms, with improved bioavailability or better organo-leptic properties.

The formulation of phenytoin with cyclodextrin using a dry method without the intervention of solvents, did not show a great improvement in dissolution profiles. This part of the study pointed out the importance of water or other solvents to ensure an efficient interaction between arug and cyclodextrin.

SUGGESTIONS FOR FUTURE WORK

The physico-chemical aspects of complexation still deserve and necessitate a great amount of research before a clear elucidation of the complexation process can call for a full development of this new formulation tool. The main areas that can be mentioned are:

1. To investigate the thermodynamics of a series of drug analogs, and to compare the parameters of complexation. The computer method developed in this thesis could be valuable in the comparison process. A specific of the effect of particular substituents upon complexation could be identified.

2. To carry a full study in hydro-alcoholic mixtures. The change of polarity of the solvent would affect the stability of the complex and the thermodynamics of the mechanism. An 
optimization of the solvent polarity could lead to an improved solubilization of drugs.

3. To evaluate the potential of complexation applications of different cyclodextrin derivatives. Two classes of new compounds could be evaluated. Hydrophilic derivatives with various structures, substituents and degree of substitution could be used to increase optimally the solubility of poorly water-soluble drugs. Also a new class of hydrophobic derivatives could be investigated for their potential use as carriers in sustained release of soluble drugs.

4. To investigate the use of cyclodextrin on the dissolution of tablets prepared by wet granulation. A possible correlation between preformulation data formulation performance could be then established. 
SECTION III 
APPENDIX A 


\title{
RELATIONSHIP BETWEEN COMPRESSION PROFILE
}

AND PHYSICAL PROPERTIES OF A

LITHIUM CARBONATE FORMULATION

M.G. DEDHIYA AND C.W. WOODRUFF

MILES PHARMACEUTICALS

DIVISION OF MILES LABORATORIES. INC.

WEST HAVEN, CT 06516, USA

AND

\author{
C.T. RHODESX AND F.A. MENARD \\ COLLEGE OF PHARMACY, UNIVERSTTY OF RHODE ISLAND \\ KINGSTON, RI 02881, USA
}

\begin{abstract}
Relationship between the compression profile and physical properties of a directly compressed lithium carbonate tablet formulation was examined using an instrumented tablet press. The measured physical parameters included hardness, disintegration time, and dissolution. A linear correlation was observed

X To whom all inquiries should be directed.
\end{abstract}


between the compression force, 4000 to $702013 s$. and tablet hardness, 5 to $9 \mathrm{kp}$. The disintegration time, 80 to 100 seconds, did not significantly change with the increasing compression force. Dissolution of lithium carbonate tablets complied with the USP limits at all compression forces. A dissolution rate maximum related to compression force was observed. The overall results indicate that the processing parameter, compression force, affects the physical properties of the tablet formulation.

\section{INTRODUCT I ON}

The compression force is one of the critical physical factors which affects the dissolution and disintegration time and hardness of tablet dosage form ( $1-8)$. Several investigators (9) have examined methods to study relationship between the applied compression force and tablet properties. The purpose of this investigation was to characterize a relationship between the compression force and physical propertıes of a directly compressed lithium carbonate formulition. Once the correlation is established, the nopession force measurement can be used to monitor the paysizal properties such as hardness and isssolution of the active drug. 


\title{
MATERIALS
}

\begin{abstract}
A directly compressed lithium carbonate formulation included the following ingredients: lithium carbonate USP, corn starch USP, calcium phosphate dibasic USP, polyethylene glycol USP, magnesium stearate USP, and sodium lauryl sulfate USP.
\end{abstract}

\section{METHODS}

Two kilograms of direct compressible blend was prepared by mixing $60 \%$ of the formula lithium carbonate, corn starch, calcium phosphate, dibasic; and polyethylene glycol in a laboratory V-blender for 20 minutes. A sufficient quantity of lubricant mix containing the remaining materials was added and the mixing was continued for an additional 10 minutes. The particle size of the blend was determined using a sieve analysis, bulk and tapped densities were measured using a JEL apparatus ${ }^{1}$. The blend was compressed using a rotary tablet press with a standard round tooling of $3 / 8$ inch diameter and the compression force was measured using strain

1 J. Engelsmann. AB., Ludwigshafen, West Germany. 
guages ${ }^{2}$ and a high speed analog recorder ${ }^{3}$. The physical properties of tablets were determined as follows: tablet hardness was measured with a Schleuniger 4 hardness tester and disintegration 5 and dissolution 6 tests were performed according to the USP procedures. Lithium carbonate analysis was performed using an atomic absorption 7 spectrophotometric analysis and products complied with all USP requirements.

\section{RESULTS AND DISCUSSION}

Table 1 shows the physical properties of the major ingredients of the formulation. The percentage compressibility was computed as follows:

$$
\text { \% compressibility }=(D t-D b) / D t
$$

where Dt and Db are tapped and bulk densities, respectively.

2 Manesty B3B tablet press, Manesty Machine Ltd., Liverpool, England.

3 Gould 2200 Recorder, Gould Inc., Cleveland, $\mathrm{OH}$ USA.

4 Schleuniger Hardness Tester, Vector Corp., Marion, IA USA.

5 Tablet Disintegration Tester, Van kel Industries, Chatham, NJ USA.

6 Dissolution Apparatus, Hanson Research

Corporation, Northilge, CA [SA

7 Instrumentation Laboratory A Spectrophotometer, Instrumentation Laboratory, Inc. Lexington, MA USA. 


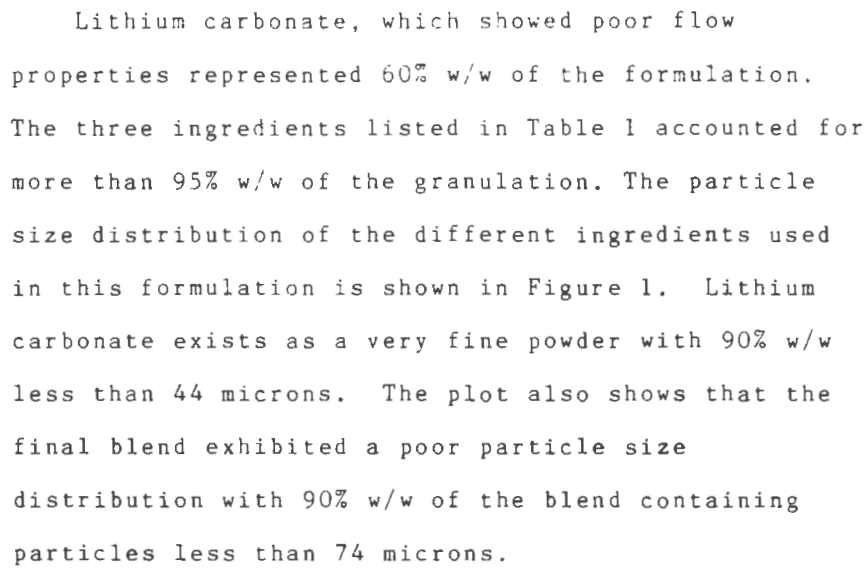

A typical compression profile of the lithium carbonate formulation is shown in Figure 2. The highest peak represents the maximum compression force developed during tableting. In this study, the maximum compression force varied from 4000 to 7020 lbs. Below 4000 lbs corpression force, the tablet friability exceeved a $1 / 7$ imit and above 70201 bs, tablet capping was observed.

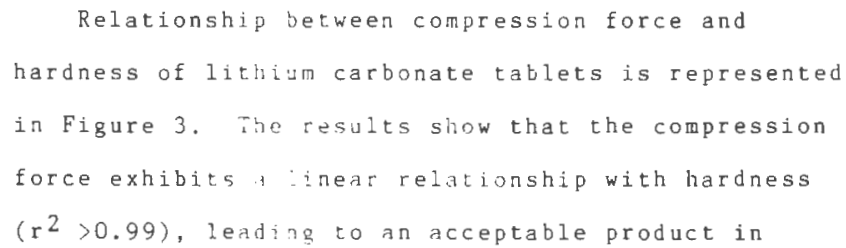


terms of compressibility. The compression force and hardness ranges are adequate for incorporating these values in scale up manufacturing of the product.

\begin{abstract}
Disintegration time was measured using the USP procedure. All tablets disintegrated within a time range from 80 to 100 seconds. No significant differences were observed in the disintegration time from one compression force to another.
\end{abstract}

\begin{abstract}
Dissolution of lithium carbonate tablets was examined using the USP XXI basket procedure. The dissolution profiles at different compression forces are shown in Figure 4. This formulation exhibits the dissolution compression force relationship in which the initial dissolution at 15 minutes is faster to a maximum as the compression force is increased and then further increases in the compression force slow the initial dissolution of lithium carbonate. These results correlate extremely well with those obtained by Smith et. al (6) on dissolution of tablets prepared by a wet granulation of 1 ithium carbonate. These investigators studied the dissolution at 20 minutes and tablet hardness relationship of a lithium carbonate formulation containing lithium carbonate, lactose, cornstarch and magnesium stearate. In their
\end{abstract}


study, the tablet hardness was increased using higher compression force. The dissolution at 20 rinutes showed $\tau$ wo maxima as the hardness of the tablets were increased.

Levy et. al (5) showed that the initial dissolution rates of salicylic acid tablets increased when the tableting compression force was increased. This increase in dissolution of salicylic acid was attributed to fracturing of the drug particles at higher force yielding smaller particles with increased surface area. In case of the directly compressed 1 ithium carbonate, initial increase in the compress force probably results to fracture of 1 ithium carbonate and subsequent increase in the compression force leads to bonding and or the fusion. The fracture and bonding mechanism is postulated to increase and decrease the apparent surface area of lithium carbonate. This increase or decrease, therefore, enhances or retards the initial dissolution flux of lithium carbonate. The thermodynamic solubility governing mechanism, independent of the surface area, controls the amount of drug dissolval atter 45 minutes as indicated by a constant plateal vile. It is possible that such fracture and bonding of lithium carbonate can yield a 
dissolution rate maximum.

\title{
CONCLUSION
}

\begin{abstract}
Results of this study show that the compression force is directly correlated to the hardness of lithium carbonate tablets. The results of initial dissolution rate show a $\therefore$ ximum when the compression force is increased. It is suggested that the dissolution behavior is caused by the fracture and bonding of lithium carbonate. The method described in correlating the compression force with physical properties provides a process monitoring procedure for lithium carbonate tablets.
\end{abstract}

\section{REFERENCES}

1. Greist, J.H., Jefferson, J.W., and Marcetich, J., Behavioral Medicine, 12, 25 (1978).

2. Wal1, B.P., Parkin, J.E., and Sunderland, V.B., Australian Journal of Pharmaceutical Sciences, 7,57 (1978).

3. Wa11, B.P., Parkin, J.E., Sunderland, V.B., and Zorbas, A., J. Pharm. Pharmacol, 34, 601 (1982).

4. Ritschel, H. A. and Parab, P., Drug Development and Industrial Pharmacy, 11, 147 (I985). 
5. Levy, G., Antkowiak, J.M., Prockna1, J.A., and White, D.C., J. Pharm. Sci, 52, 1047 (1963).

6. Smith, H., Baker, C., and Hood, J.W., J. Pharm. Pharmacol, 23, 536 (1971).

7. Higuchi, T., Elowe, L.N., and Busse, L.W., J. American Pharm. Association, 43, 685 (1954).

8. Nystrom, C., Mazur, J. and Sjogren, J, , Int. J. Pharmaceutics, 10, 209 (1982).

9. Parrott, E. "Compression" in Pharmaceutical Dosage form, Tablets volume II, Edited By Libercan, H. and Lachman, L., Marcel Dekker, Inc., New York, 1980. 
TABLE I

Physical Properties of Ingredients

$\begin{array}{lccc}\text { Ingredients } & \text { Bulk Density } & \text { Tapped Density } & \text { \% Compressibilty } \\ & (\mathrm{g} / \mathrm{cc}) & (\mathrm{g} / \mathrm{cc}) & \\ \text { L.jllibll Carbunte } & 0.53 & 0.80 & 34 \\ \text { Dicalcium Pliosphate } & 0.92 & 1.47 & 37 \\ \text { Corn Starch } & 0.59 & 0.78 & 24 \\ \text { Formulation Blend } & 0.63 & 0.90 & 30\end{array}$


Figure 1

Particle size distribution of the lithium carbonate blend 


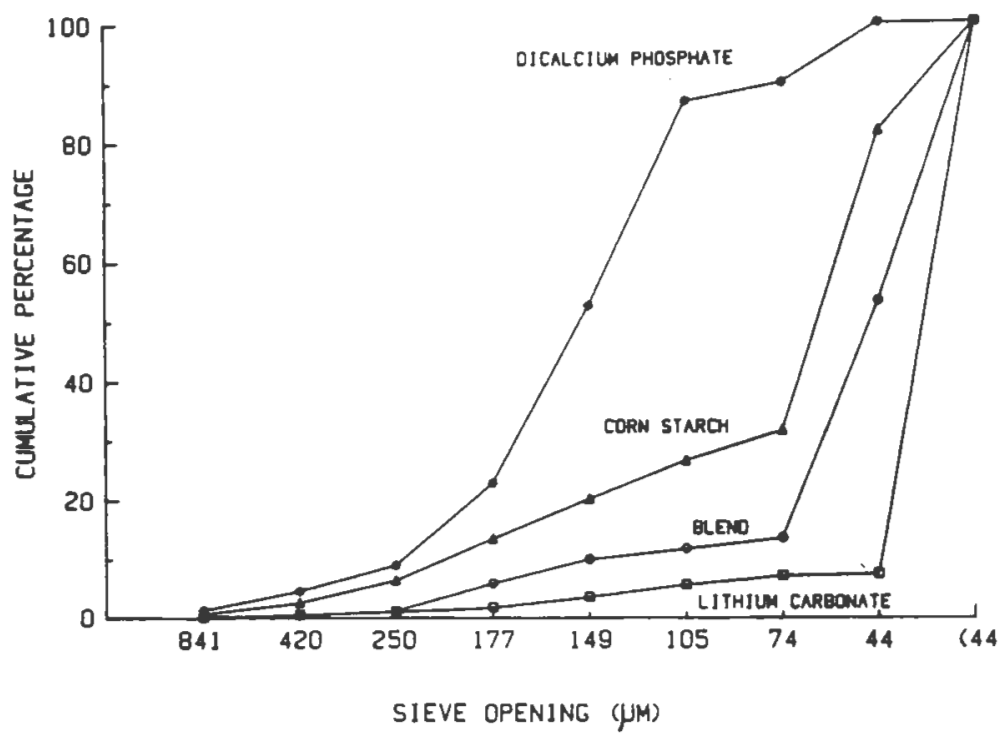

FIGUEE 1

Particle size distribution 
Figure 2

compression profile 


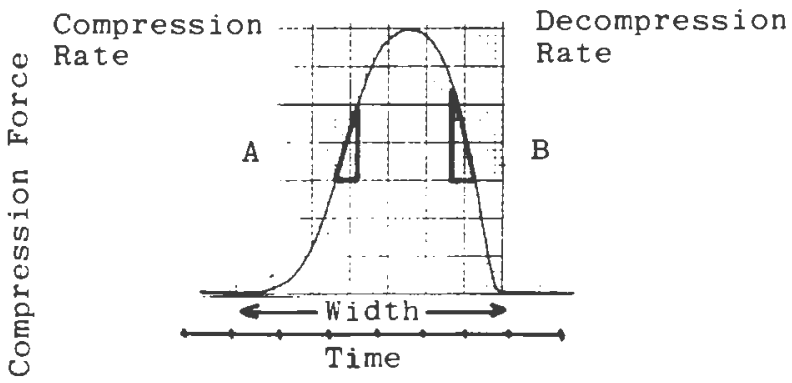

FIGLRE 2

Compression profile 
Figure 3

Hardness/compression profile 


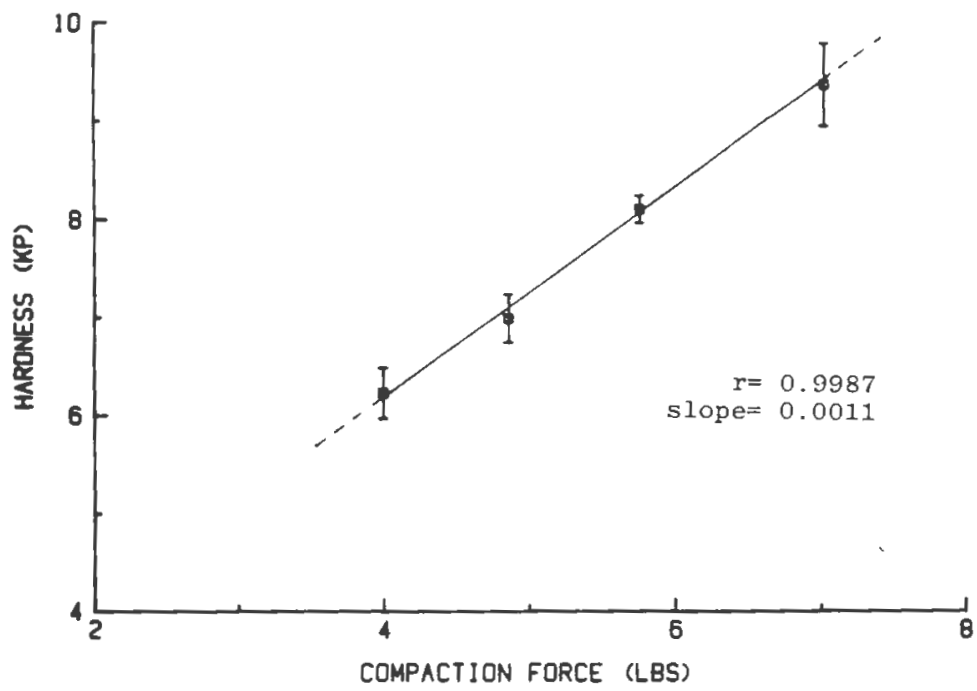

FIGURE 3

Hardness/Compaction profile 
Figure 4

Dissolution profiles of lithium carbonate 


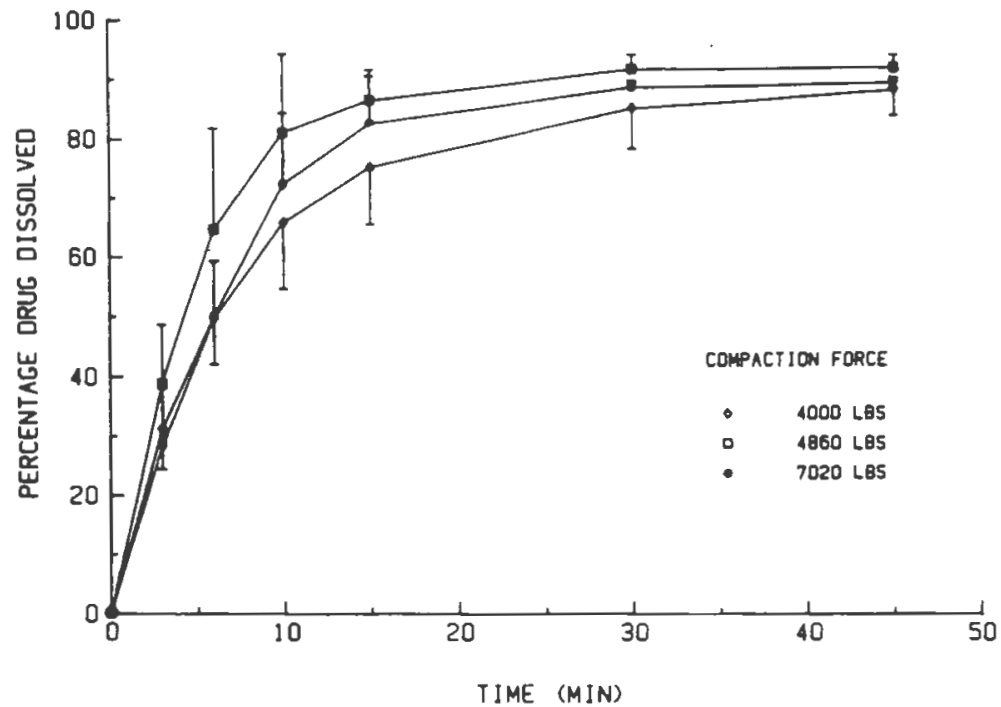

FIGLRE 4

Dissolution profiles of lithium carbonate 
APPENDIX B 
A Comparative Study of Several Lactose

Products for Direct Compression Tabletting

F.A. Menard and C.T. Rhodes University of Rhode Island. RI

J. Kanig

Kanig Consulting and Research Associates. CT

\section{ABSTRACT}

Physical characteristics such as density, flow and compaction properties of four brands of anhydrous lactose were evaluated. The drug capacity of the four products was studied by preparing 107 and 207 hydrochlorothiazide tablets. Plots of the tablet hardness as a function of the compaction force are presented. It was possible to make tablets with acceptable properties with all four products. A lubrication study was conducted by varying the amount of lubricant from $0.2 \%$ to $0.4 \%$. The ejection force was plotted as a function of the compaction force. The lubrication profiles showed that an increase from $0.2 \%$ to $0.3 \%$ of lubricant led to a significant decrease of the ejection force. All tablets were evaluated for hardness, thickness, friability and disintegration. Furthermore, the reworkability was shown to be technically feasible with all products. 


\section{INTRODUCTION}

It is widely recognized that different brands of a same ingredient used in a tablet formulation can lead to a significant change in the physico-chemical properties and the stability of tablets as well as the in vivo performance of the drug $(6,7)$. The objective of the study was to compare four commercially avallable anhydrous lactose products. Three of the products considered had the same structure, whereas the fourth product, despite a different structure, could very well be used for similar formulation purposes. The study was limited to one drug and two lots of each product.

\section{MATERIAL AND METHODS}

\section{MATERIALS}

The anhydrous lactose products were obtained from Sheffield Products $^{1}$, Foremost ${ }^{2}$, Dairy Crest ${ }^{3}$ and De Melkindustrie Veghel ${ }^{4}$. Two lots of each product were used. The drug used in the formulations was hydrochlorothlazide (HCTZ) USP ${ }^{5}$. Magnesium Stearate ${ }^{6}$ was used as a lubricant. METHODS

BULK/TAP DENSITY.

Bulk density was determined by weighing the amount needed to fill a $50 \mathrm{ml}$ graduated cylinder. Tap density was measured by tapping the material until complete settling. All determinations were done in triplicate.

${ }_{2}^{1}$ Sheffield Products, Norwich, NY

2 Foremost whey Products, Baraboo, WI

3 DeMelkindustrie Veghe1, Veghe1, The Netherlands

5 Dairy Crest - Whey Division, Suney, England

Sigma Chemical Company, St. Louis, MO

$\sigma_{\mathrm{Fisher}}$ Scientific Company, Fair Lawn, NJ 
PARTICLE SIZE DISTRIBUTION.

Particle size distribution was determined by shaking a 50

gram sample of material on a Fisher Wheeler Sieve shaker for 20 minutes.

POWDER FLOW.

Powder flow was measured using a Mettler PR 1200 scale connected to a Mettler GA12 chart recorder (1).

PREPARATION OF TABLETS.

Two hundred gram batches of the formulations were blended in a Wab Ambula mixing unit for ten minutes. The blend was further blended for three minutes after the addition of the lubricant.

TABLET COMPACTION.

Tablets were compressed using a Stoke's sixteen station rotary press. The press was instrumented with piezo transducers and interfaced to a Apple II personal computer. The details of methods used in tablet formulation and evaluation have already been published by Rhodes and his research associates $(2,3,4,5)$.

TABLET EVALUATION.

The weight of 20 tablets was determined using a standard analytical balance. The average tablet weight and its standard deviation were computed and expressed in mg.

The thickness of 20 tablets was measured using a standard micrometer. The average tablet thickness and its standard eviation were calculated.

The hardness of 20 tablets was determined using a Erweka hardness tester. The standard deviation was calculated and represented as a vertical bar on the graphs. 
The friability of 20 tablets was measured by comparing the initial weight with that after 4 minutes at $100 \mathrm{rpm}$.

The disintegration time of 6 tablets was evaluated using the apparatus described in the USPINF $\mathrm{XX}$-test $\$ 701$.

RESULTS AND DISCUSSION.

PHYSICAL CHARACTERISTICS.

From the results of the bulk and tap densities, the coefficient of compressibility was calculated as follows:

$$
\begin{aligned}
& \text { \% compressibility }=\left(D_{T}-D_{B}\right) / D_{T} \\
& \text { where } D_{T}=\text { tap density } \\
& \qquad D_{B}=\text { bulk density }
\end{aligned}
$$

Table 1 shows the percent compressibility and the flow rate of the four products. The highest flow rate was observed for the Foremost product, which also showed the lowest \% compressibility. A lower flow rate was obtained in the case of the Sheffield product. However, when actually making the tablets, no problem of flow was observed from the hopper to the press table, nor from the table into the die, for any of the products. Tablet weight uniformity was acceptable.

The particle size distribution study showed that the Sheffield and the DMV products had similar properties with a respective percentage underweight of $51 \%$ and $41 \%$ through the sieve 1150. The two other products appeared to be finer materials with 79\% for Foremost and $90 \%$ for Dairy Crest under the same conditions. 
The results of the compaction study are shown in Figure 1, where the hardness of the tablets is plotted as a function of compaction force. For all products, as the compaction force increased, the hardness increased until capping occurred. DRUG CAPACITY.

Figures 2 and 3 show the hardness of the $10 \%$ and $20 \%$ HCTZ tablets respectively, as a function of the compression force. The formulation of $10 \%$ HCTZ tablets showed acceptable levels for all products. At a $20 \%$ level of drug, the hardness of all tablets was lower. The differences observed from product to product in Figures 2 and 3 followed the trend shown in Figure 1.

LUBRICATION.

For each product, blends containing $0.2 \%, 0.37$ and 0.47 of magnestum stearate were prepared and compressed at different compaction forces. Plots of the ejection force as a function of the compaction force has been previously used to evaluate the lubrication proftle ( 8 ). The lubrication profile of the Sheffield product is thus shown in Figure 4. As the compaction force increased, the ejection force increased, and the lower the percentage of lubricant, the higher the ejection force. An increase from $0.2 \%$ to $0.3 \%$ showed a significant decrease of the ejection force, whereas an increase from $0.3 \%$ to $0.4 \%$ did not show any further significant decrease. A comparison of the four products was made at one single compression force of $5 \mathrm{KN}$. Table 2 shows that the results were similar for all products. It appeared that $0.3 \%$ would be a reasonable level of lubricant. 
EVALUATION OF TABLETS.

The properties of the tablets made using the four different lactose products are shown in Table 3 . All the tablets had a same weight of $350 \mathrm{mg}$ and were compressed at a similar compaction force. Even though some variations were observed, it would have been possible to make tablets with acceptable specifications with all products.

Rework was technically feasible for all four matrices, although the quality of the tablets obtained varied for the different excipients. 
REFERENCES.

1. R.P. Jordan and C.T. Rhodes, Drug Development and Industrial Pharmacy. 5, 151 (1979).

2. R.N.Chilamkurti, C.T. Rhodes and J.B. Schwartz. Drug Development and Industrial Pharmacy. 8,63 (1982).

3. Rudnic et al. ibid. 8,87 (1982).

4. D.S.Desai, C.T. Rhodes and J.L. Kanig, Proc. Pharm. Techn. Conf. P. 172 (1981).

5. K.A.Khan and C.T. Rhodes. J. Pharm. Sci., 66, 14 (1977).

6. G.K. Bolhuis, G. Reichman, C.F. Lerk, H.V. VanKamp and K. Zuurman. Drug Development and Industrial Pharmacy. 11 (8), $1657-1681$ (1985).

7. C. Ondari. Ph.D. thesis. University of Rhode Island, Department of Pharmaceutics (1984).

8. M.J. Waring, H. Sen, J.W. Forrester and J.R. Salmon, Proc. 5th Pharm. Tech. Conference, 145 (1986). 
Table 1: Flow Properties

\begin{tabular}{|c|c|c|c|}
\hline Lactose product & $\underline{\text { Lot } \#}$ & $\%$ compressibility & $\frac{\text { flow rate }}{\mathrm{gm} . / \mathrm{sec} .}$ \\
\hline Sheffield & $\begin{array}{l}\text { 4NL13 } \\
\text { 4NL14 }\end{array}$ & $\begin{array}{l}24 \\
28\end{array}$ & $\begin{array}{l}10.3(0.6) \\
11.4(1.2)\end{array}$ \\
\hline Foremost & $\begin{array}{l}\text { 1RA527 } \\
\text { 2RH431 }\end{array}$ & $\begin{array}{l}11 \\
10\end{array}$ & $\begin{array}{l}24.2(1.9) \\
29.0(1.9)\end{array}$ \\
\hline Dairy Crest & $\begin{array}{l}635024 \\
635025\end{array}$ & $\begin{array}{l}22 \\
23\end{array}$ & $\begin{array}{l}23.6(0.5) \\
22.6(1.0)\end{array}$ \\
\hline DMV & $\begin{array}{l}\text { A } 369 \\
\text { A0741 }\end{array}$ & $\begin{array}{l}25 \\
24\end{array}$ & $\begin{array}{l}23.8(2.2) \\
22.0(1.1)\end{array}$ \\
\hline
\end{tabular}

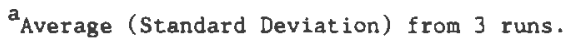


Table 2: Lubrication study (Compaction Force $\approx 5 \mathrm{KN}$ )

Ejection Force

(N)

Magnesium Stearate

$\begin{array}{llll} & \underline{0.27} & \underline{0.37} & \underline{0.47} \\ \text { Sheffieid } & 390 & 320 & 300 \\ \text { Foremost } & 380 & 330 & 310 \\ \text { DMV } & 430 & 350 & 330 \\ \text { Dairy Crest } & 350 & 250 & 240\end{array}$


Table 3: Evaluation of 10\% HCTZ tablets,

\begin{tabular}{|c|c|c|c|c|}
\hline Lactose product & $\frac{\text { Thickness }}{\text { inch }}$ & $\frac{\text { Hardness }}{\mathrm{kg}}$ & $\frac{\text { Disintegration time }}{\min .}$ & $\frac{\text { Content uniformity }}{\mathrm{z}}$ \\
\hline Sheffield & $.173(.001)^{a}$ & $10.5(0.5)^{b}$ & 10 & 1.1 \\
\hline Foremost & $.177(.001)$ & $3.9(0.7)$ & 17 & 2.4 \\
\hline DMV & $.176(.001)$ & $4.8(1.3)$ & 0 & 2.0 \\
\hline Dairy Crest & $.177(.001)$ & $3.5(0.8)$ & 20 & 4.4 \\
\hline
\end{tabular}


Table 4: Evaluation of $10 \%$ HCTZ tablets after rework.

\begin{tabular}{|c|c|c|c|c|}
\hline Lactose product & $\frac{\text { Thickness }}{\text { inch }}$ & $\frac{\text { Hardness }}{\mathbf{k g}}$ & $\frac{\text { Friability }}{z}$ & $\frac{\text { Disintegration time }}{\min .}$ \\
\hline Sheffield & $.168(.002)^{a}$ & $4.8(1.3)^{b}$ & 0.34 & 10 \\
\hline Foremost & $.165(.002)$ & $2.1(0.8)$ & 0.25 & 20 \\
\hline DMV & $.170(.002)$ & $2.8(0.7)$ & 0.56 & 12 \\
\hline Dairy Crest & $.165(.002)$ & $2.0(0.6)$ & 0.55 & 20 \\
\hline
\end{tabular}




\section{FIGURE 1}

COMPACTION PROFILES 


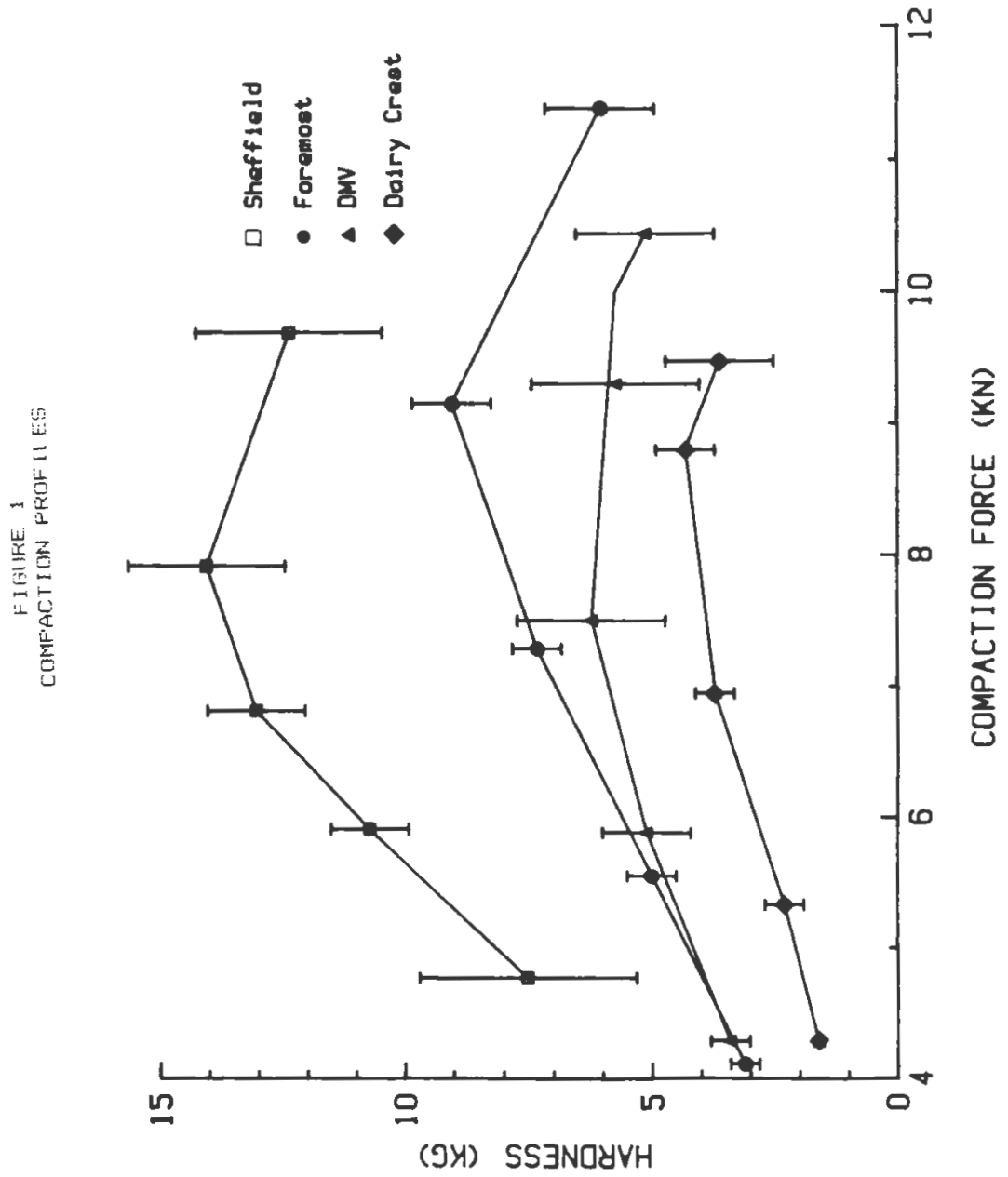


FIGURE 2

DRUG CAPACITY (108 HCTZ) 
FIGURE ?

DRUG CAFACITY $(10 \%$ HCT $)$

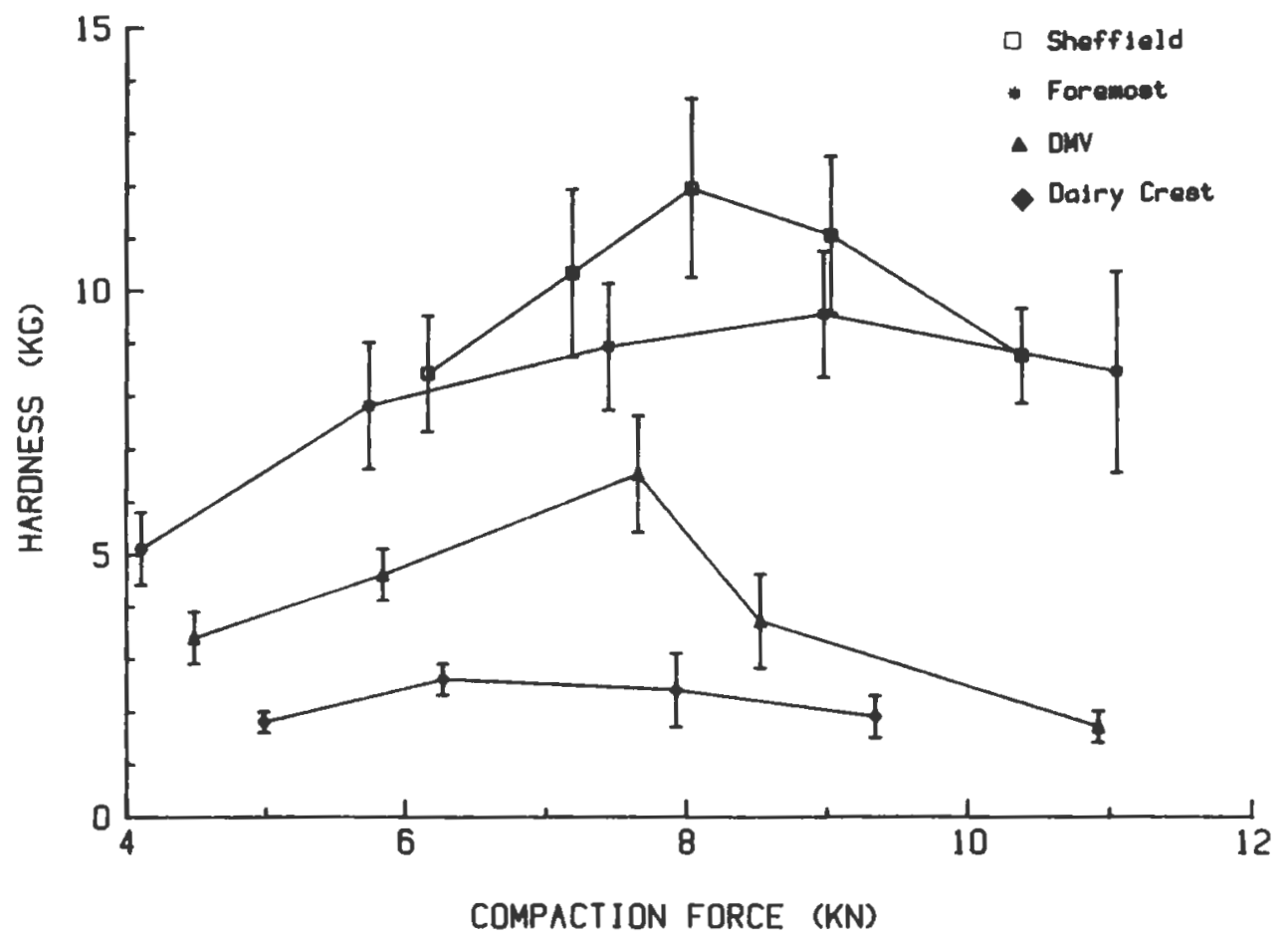


FIGURE 3

DRUG CAPACITY (20\% HCTZ) 


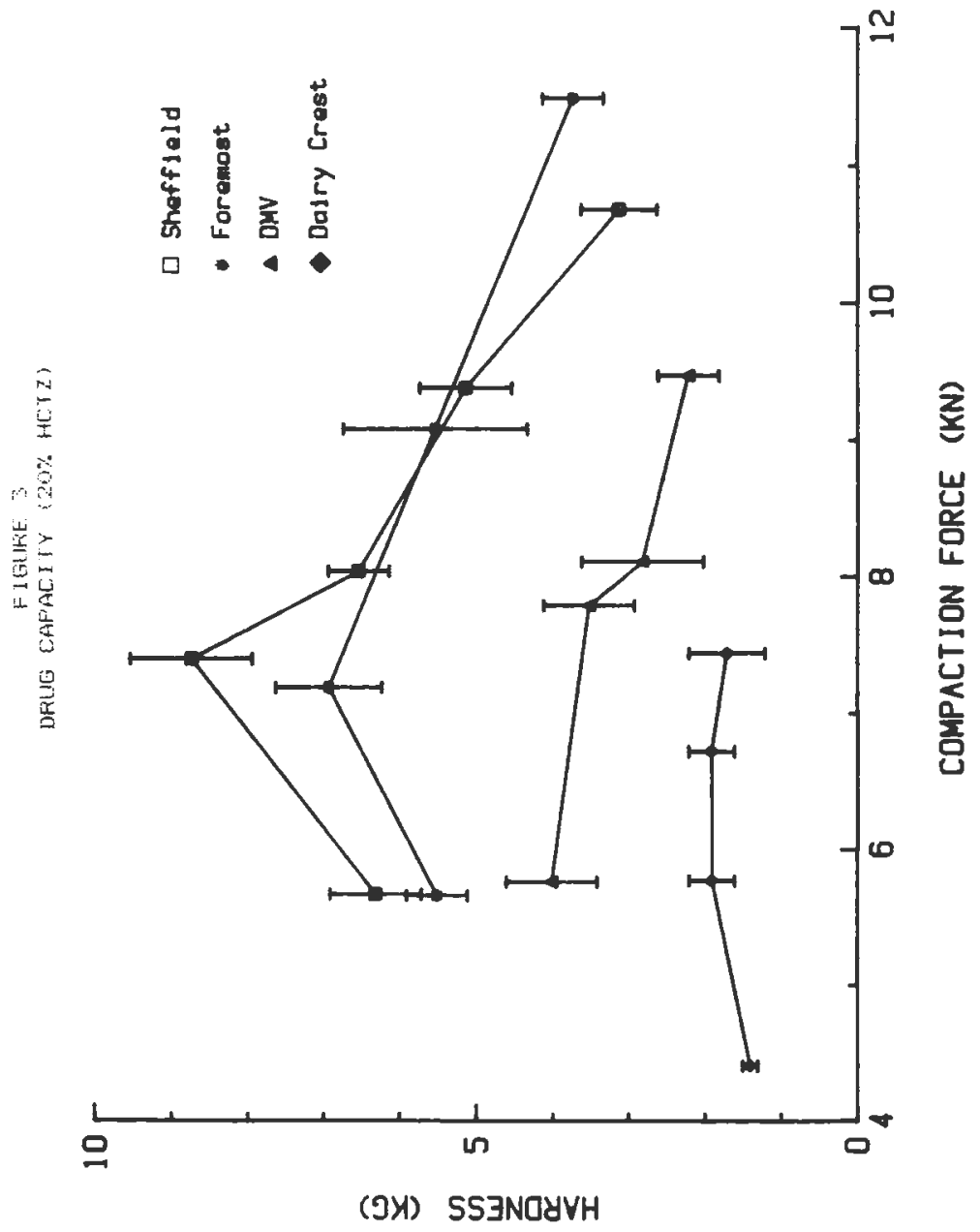


FIGURE 4 LUBRICATION STUDY 


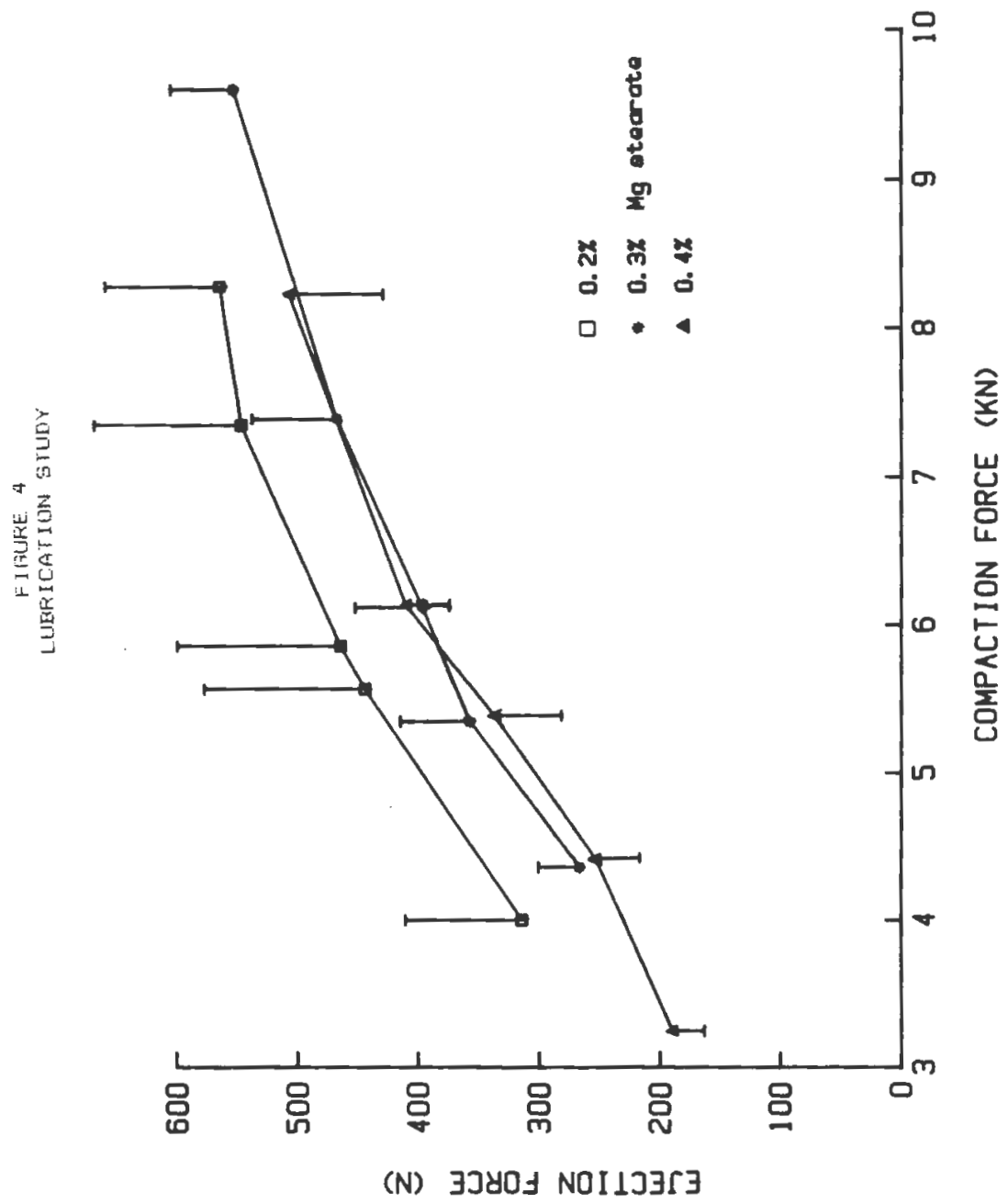


APPENDIX C 
DESCRIPTION OF THE EXPERIMENTAL PROTOCOL

1. Principle of the solubility method

2. Preparation of the buffered solutions of cyclodextrins

3. Preparation of the solubility vials

4. Description of the solubility apparatus

5. Time to reach equilibrium

6. Direction to approach the desired temperature

7. Sampling, filtration and dilution of samples

8. Ultra-Violet analysis of the drugs

9. Plot of solubility isotherm 
1. Principle of solubility method

Higuchi and Connors described the solubility method in the 5th chapter of Advanced Analytical Chemistry and Instrumentation. An excess of solid drug is placed in vials containing various known concentrations of the complexing agent. The solubility isotherm is then obtained by plotting the total drug concentration as a function of the total cyclodextrin concentration. Different types of phase-solubility diagrams may be observed. The type observed in this study was in all cases the A-type, in which there is linearity throughout the range of concentrations of the complexing agent.

2. Preparation of the buffered solutions of cyclodextrins

The solutions of cyclodextrins were prepared by dissolving known amounts of solid cyclodextrins in buffered solutions adjusted to the required $\mathrm{pH}$. The buffered solutions were prepared by using monobasic and dibasic phosphate. The four characteristics of the buffer are: nature, $\mathrm{pH}$, concentration and ionic strength.

The buffers made were phosphate buffers. The buffer concentration used was 0.1 mole per liter. The ionic strength was adjusted to 0.3 mole per liter using potassium chloride ( $\mathrm{KCl})$. The first step was to make two stock 
solutions, one of monobasic phosphate and one of dibasic phosphate. The concentration and the ionic strength of these two solutions were known. The second step was to mix the two stock solutions such that the $\mathrm{pH}$ desired would be exactly obtained. All the $\mathrm{pH}$ values were also checked at the end of the experiment at room temperature.

3. Preparation of the solubility vials

Test tubes of ten or twenty milliliters were used to carry out the solubility experiments. The excess of drug was approximatively measured so that the solution would be saturated after equilibrium. The amount varied from drug to drug and from one cyclodextrin to another. The solutions were then added to the solid drug in the vial. The tubes were then tightly closed using screw-caps, and Parafilm strips were used to secure a perfect sealing of the vials.

4. Description of the solubility apparatus

The tubes prepared were placed and attached on the rotating unit. The rotating unit was immersed in a waterbath at a constant temperature in the range of $20^{\circ} \mathrm{C}$ to $50^{\circ} \mathrm{C}\left( \pm 0.05^{\circ} \mathrm{C}\right)$. A cooling unit was also used to ensure a double source of energy thus allowing a better control of temperature. The capacity of the apparatus was about 70 tubes, which corresponded to fourteen clamps each holding up 
to five tubes. The tubes were rotated until saturation was reached.

5. Time to reach equilibrium

Two solutions of cyclodextrins, namely $3 \times 10^{-3} \mathrm{M}$ and $12 \times 10^{-3} \mathrm{M}$ were used to evaluate the time needed to reach equilibrium in the case of phenytoin at $20^{\circ} \mathrm{C}$ and pH 7 . Samples were withdrawn and analyzed for drug concentration after intervals of time. The drug concentration was then plotted as a function of time, as shown in Figure 1 . Even though the maximum concentration of drug was reached after about one hour, all the results shown in this study were obtained after a rotating time of two to three hours.

6. Direction to approach the desired temperature

In the study of the effect of temperature on the complexation of drugs with cyclodextrins, the same tube containing drug and cyclodextrin solution was brought to temperatures from $20^{\circ} \mathrm{C}$ to $50^{\circ} \mathrm{C}$. There were two ways to change the temperature of the waterbath, one is to go from low to high temperatures and the other from high to low temperatures. In order to evaluate whether the direction to approach the desired temperature would affect the solubility results, a study was performed, in which the same samples were treated according to the two possibilities. As shown 
in Table 1, there was no effect on the final drug concentration. In all the experiments, the temperature was then increased from $20^{\circ} \mathrm{C}$ to $50^{\circ} \mathrm{C}$.

7. Sampling, filtration and dilution of samples

Samples of drug/cyclodextrin complex solutions of one to three milliliters were withdrawn from the tubes using a pipette. The samples were then filtered using glasswool, and filtration was shown not to interfere with the final concentration. An aliquot of 500 ul or one milliliter was then used to dilute the sample before analysis of the drug concentration. All manipulations of the samples were performed at the respective temperature by either working in a cool place (at $20^{\circ} \mathrm{C}$ ) or in a walk-in oven $\left(30^{\circ} \mathrm{C}\right.$ to $\left.50^{\circ} \mathrm{C}\right)$.

8. Ultra-Violet analysis of the drug

Tha diluted drug samples were analyzed using a diode array ultra-violet spectrophotometer. Standards of the respective drug were prepared by dissolving an exactly amount of pure drug placed in a hundred milliliters volumetric flask in twenty or thirty milliliters of acetonitrile. The volume was adjusted using distilled water. The standards had a concentration from ten to fifty ug/ml for phenytoin, diazepam and hydrochlorothiazide, and twenty 
to hundred ug/ml for ibuprofen. The Beer's law was obeyed in all

cases. The calibration curves are shown in Figures 2, 3, 4 and 5 for phenytoin, ibuprofen, diazepam and hydrochlorothiazide, respectively. Cyclodextrins were shown not to interfere with the assay.

9. Plot of solubility isotherm

In the case of phenytoin at $\mathrm{pH} 7$ and $25^{\circ} \mathrm{C}$, six tubes were prepared for each cyclodextrin concentration. The protocol was followed as described earlier. The final concentrations were plotted by considering the average value and its standard deviation as a function of cyclodextrin concentration. The results are presented in Figure 6 . 
Table 1

Direction of approach to equilibrium

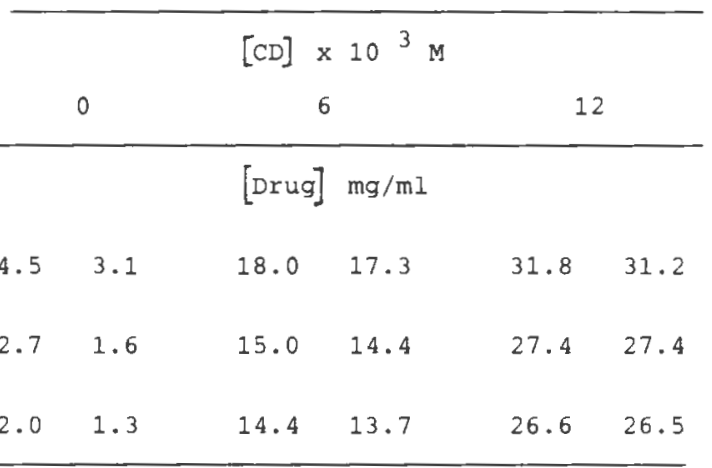




\section{Figure 1}

Time to reach equilibrium 


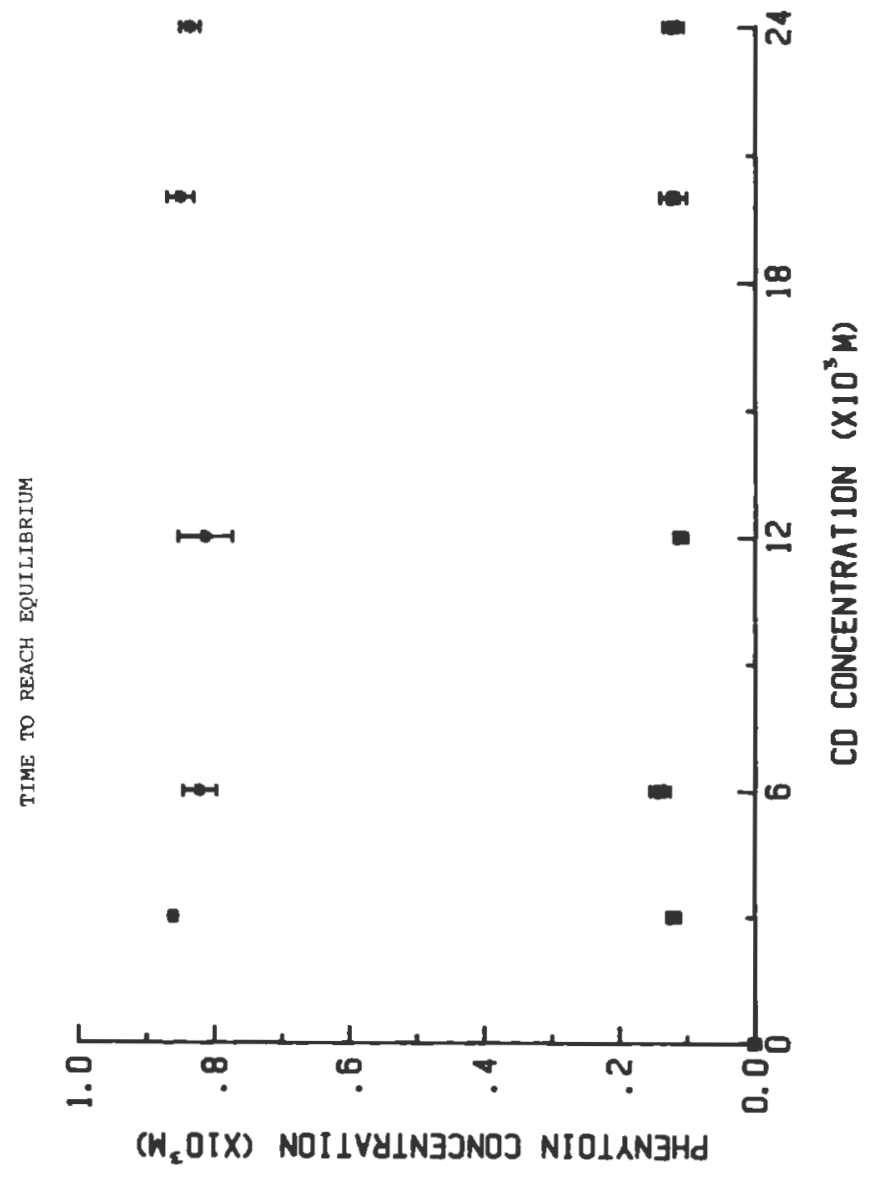


Figure 2

U.v. calibration curve for phenytoin 


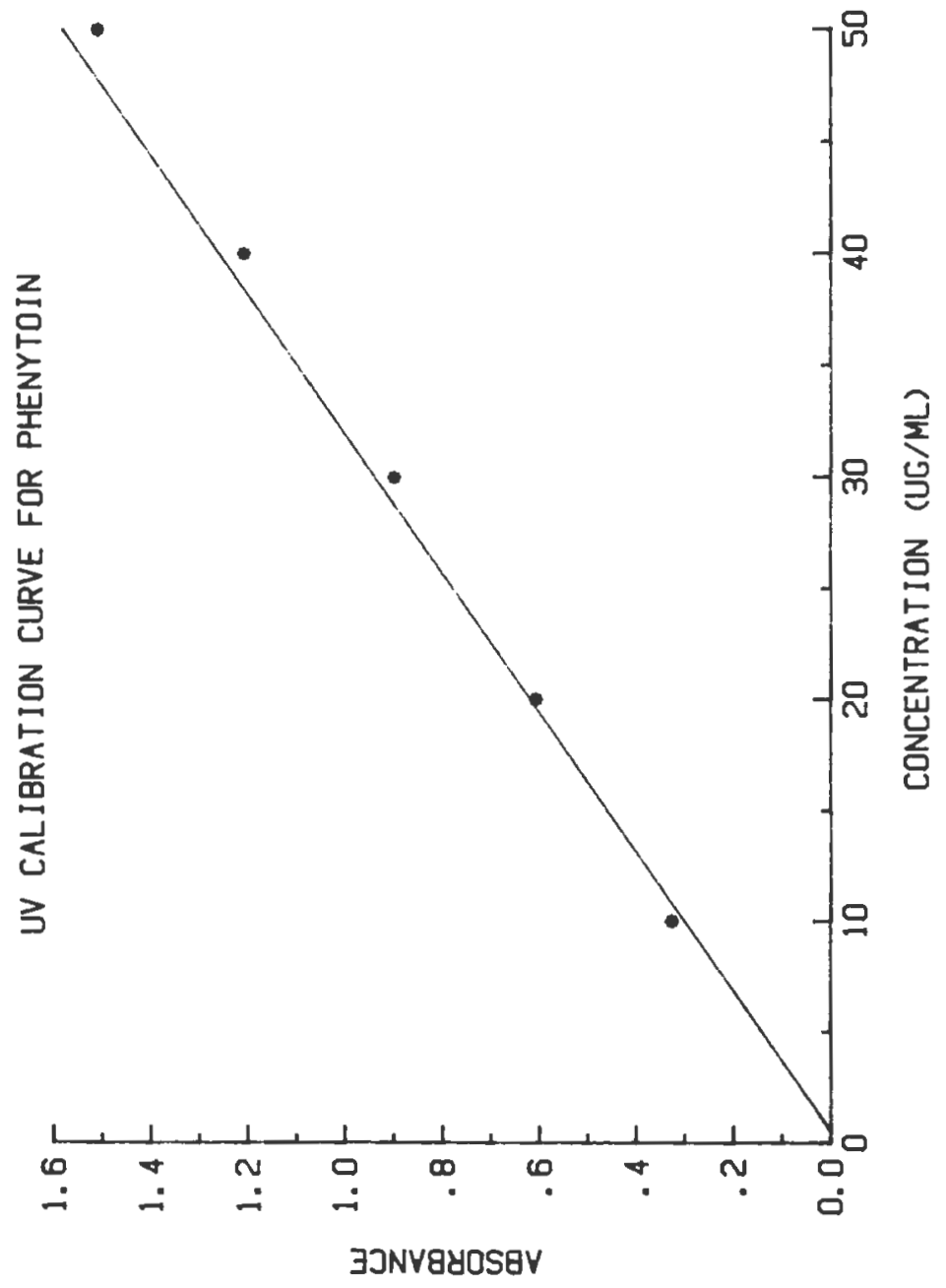




\section{Figure 3}

U.V. calibration curve for ibuprofen 


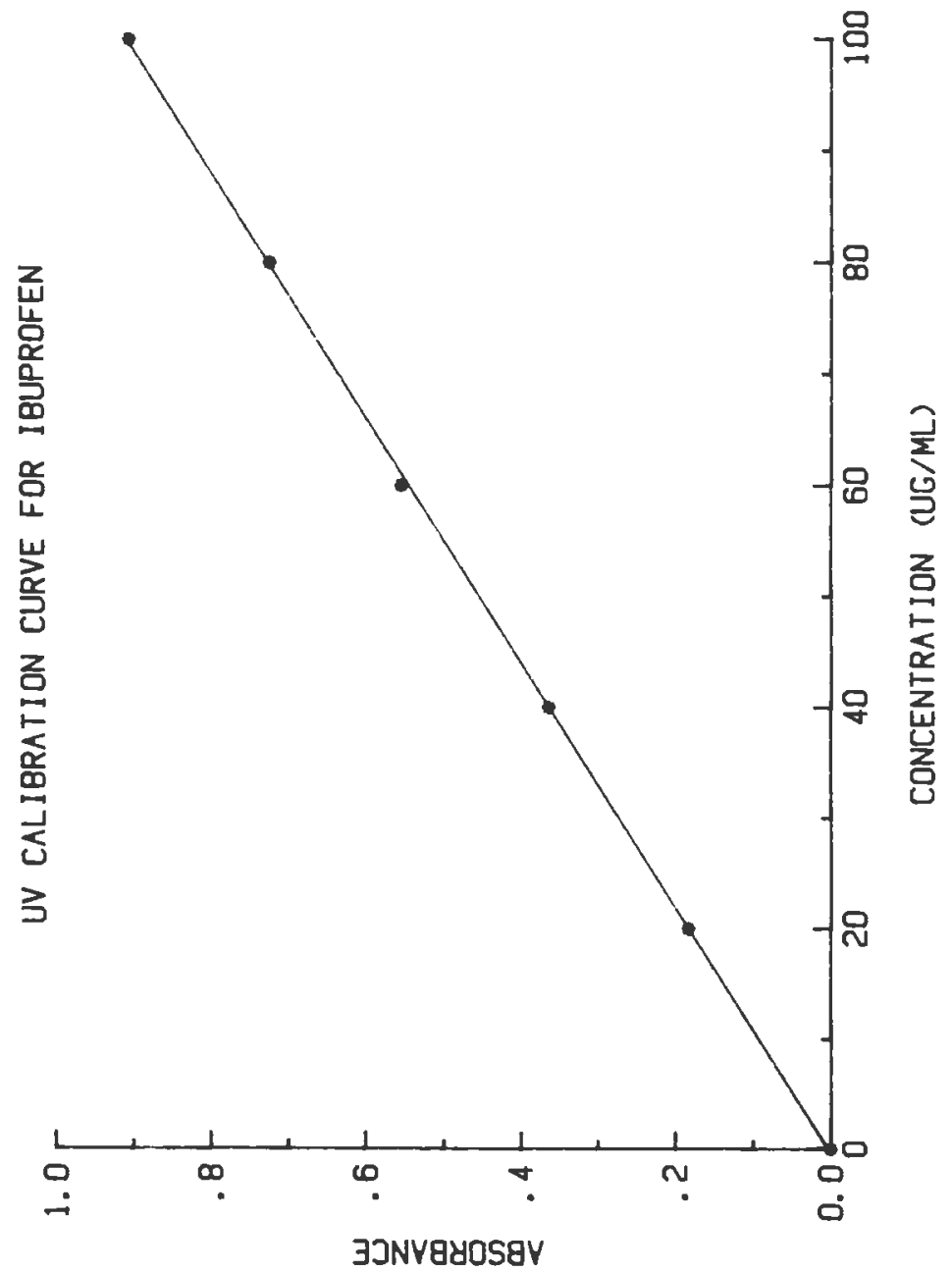


Figure 4

U.V. calibration curve for diazepam 


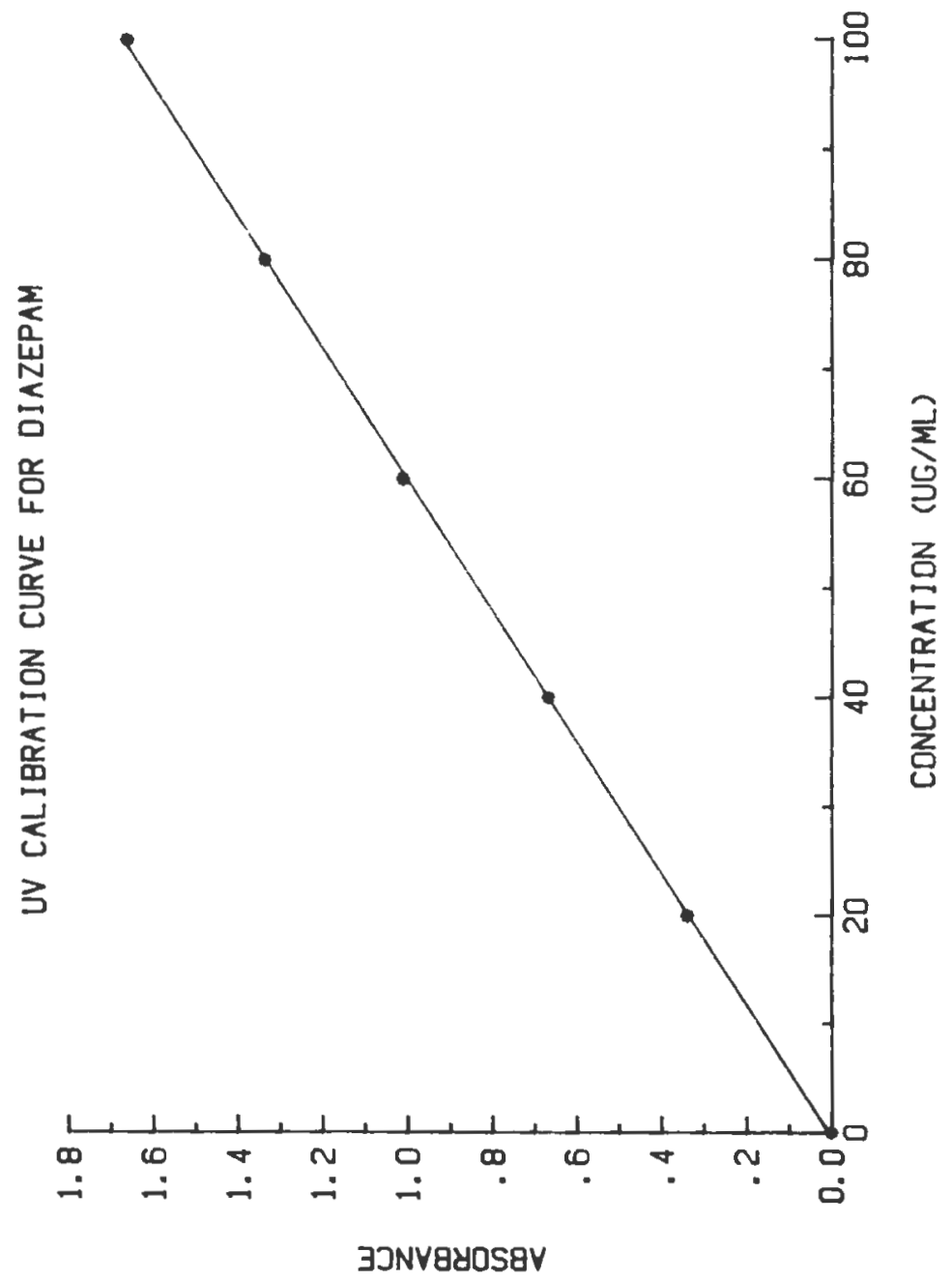


Figure 5

U.V. calibration curve for hydrochlorothiazide 


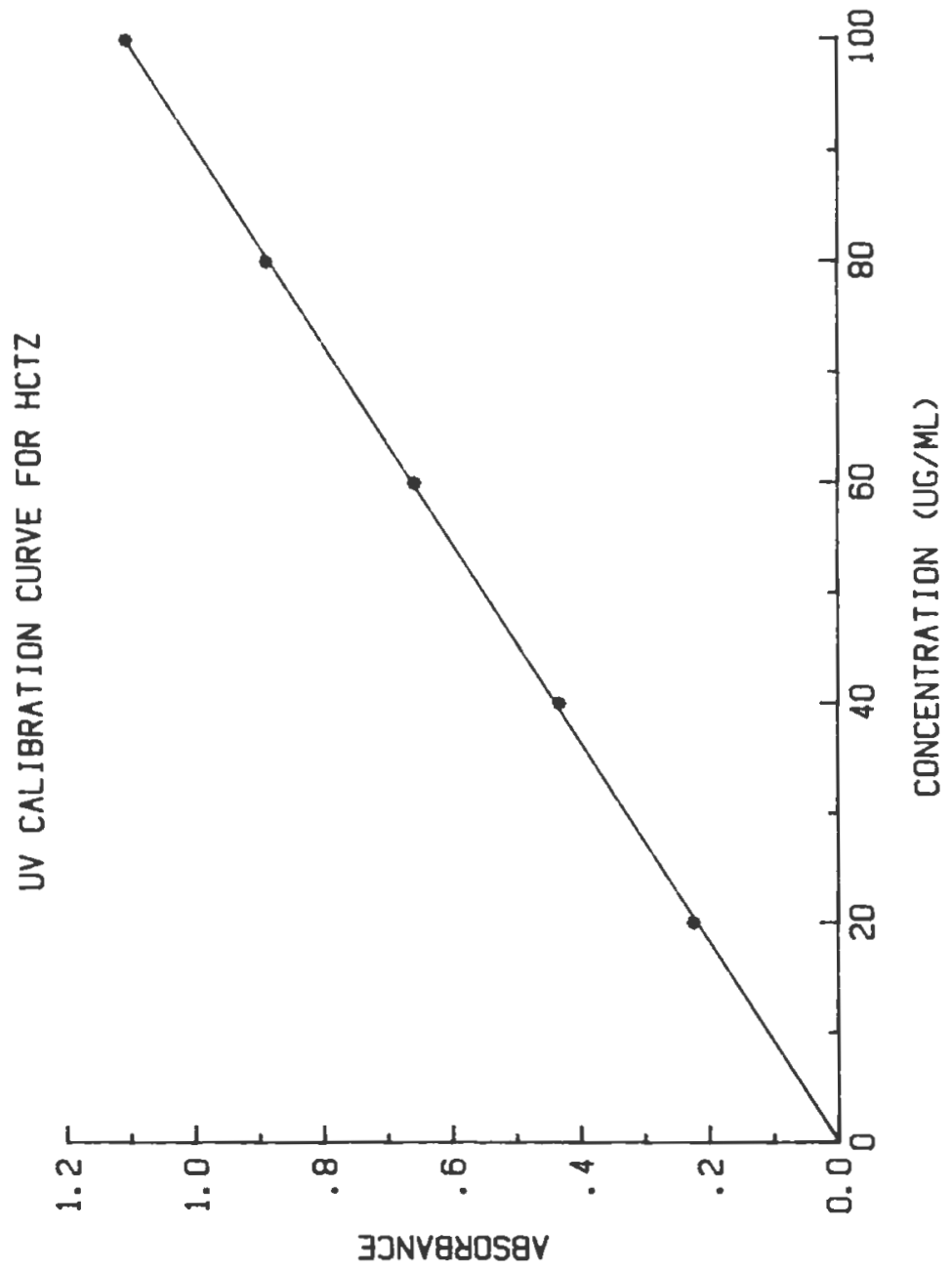


Figure 6

Plot of solubility isotherm for phenytoin 


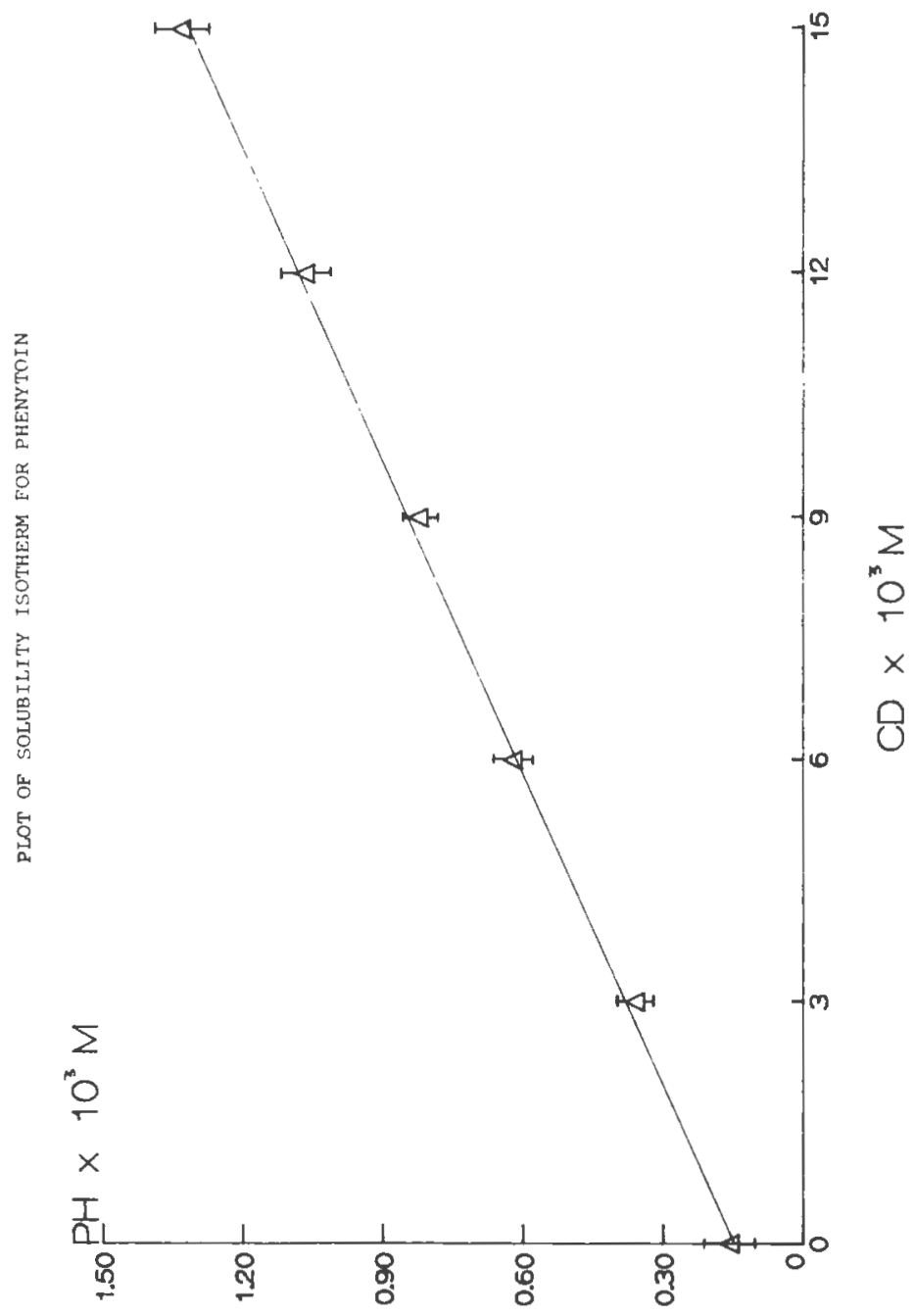


APPENDIX D 
SUMMARY OF SOLUBILITY ISOTHERMS

The following section contains the plots of the solubility isotherms obtained for the four drugs considered at different $\mathrm{pH}$ and temperature conditions. Some of these plots are already presented in Manuscript I and Manuscript IV. However, it was not possible to include all the data in the manuscripts, and this summary may be useful to review the experimental results.

The plots are presented drug by drug, as follows:

1. Phenytoin

Complexation with $\beta^{\prime} C D$ at $\mathrm{pH} 5$ and $\mathrm{pH} 8$

2. Ibuprofen

Complexation with $\beta \mathrm{CD}$ at $\mathrm{pH} 5$ and $30^{\circ} \mathrm{C}$

Complexation with $\beta \mathrm{CD}$ at $\mathrm{pH} 2,4,5$ and 6

Complexation with $\beta C D$ at $20,30,40$ and $50^{\circ} \mathrm{C}$

3. Diazepam

Complexation with $\beta \mathrm{CD}$ at $\mathrm{pH} 2,3,4$, and 6 Complexation with $\beta \mathrm{CD}$ at $20,30,40$, and $50^{\circ} \mathrm{C}$

4. Hydrochlorothiazide

Complexation with $\alpha, \beta$ and $\mathrm{CD}$ at $\mathrm{pH} 5$ and $30^{\circ} \mathrm{C}$ Complexation with $\beta \mathrm{CD}$ at $\mathrm{pH} 5,8$ and 9 Complexation with $\beta \mathrm{CD}$ at $20,30,40$ and $50^{\circ} \mathrm{C}$ 


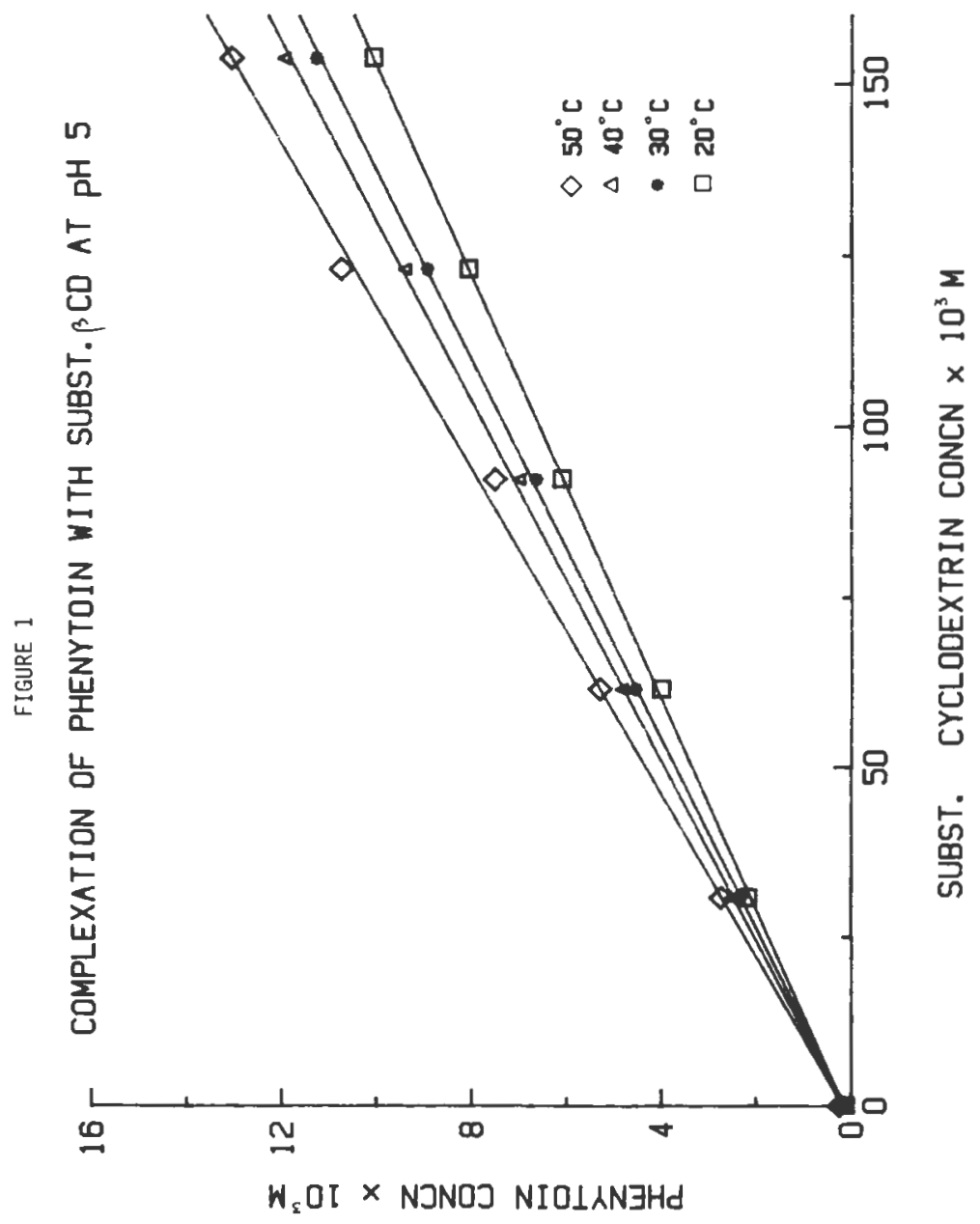




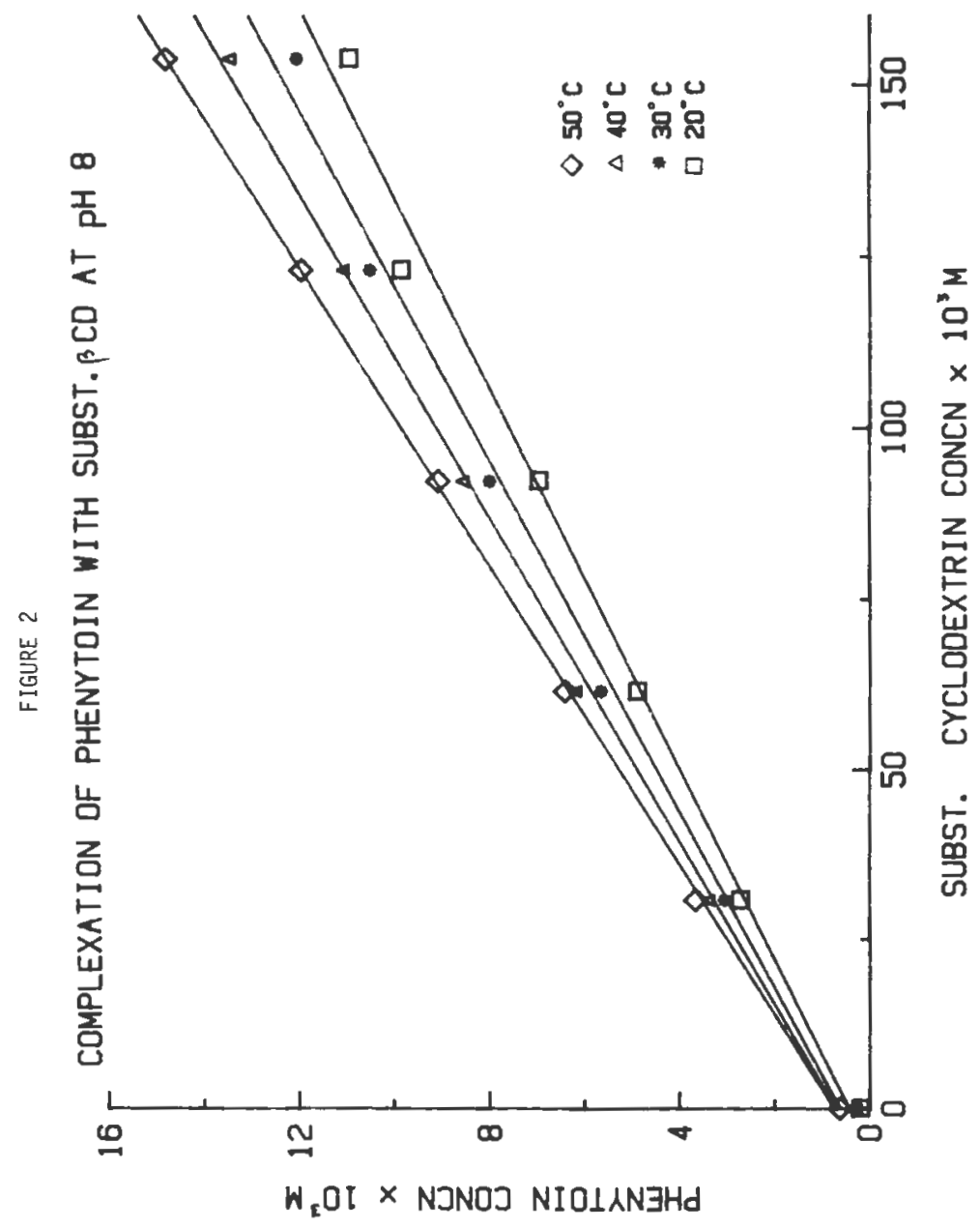




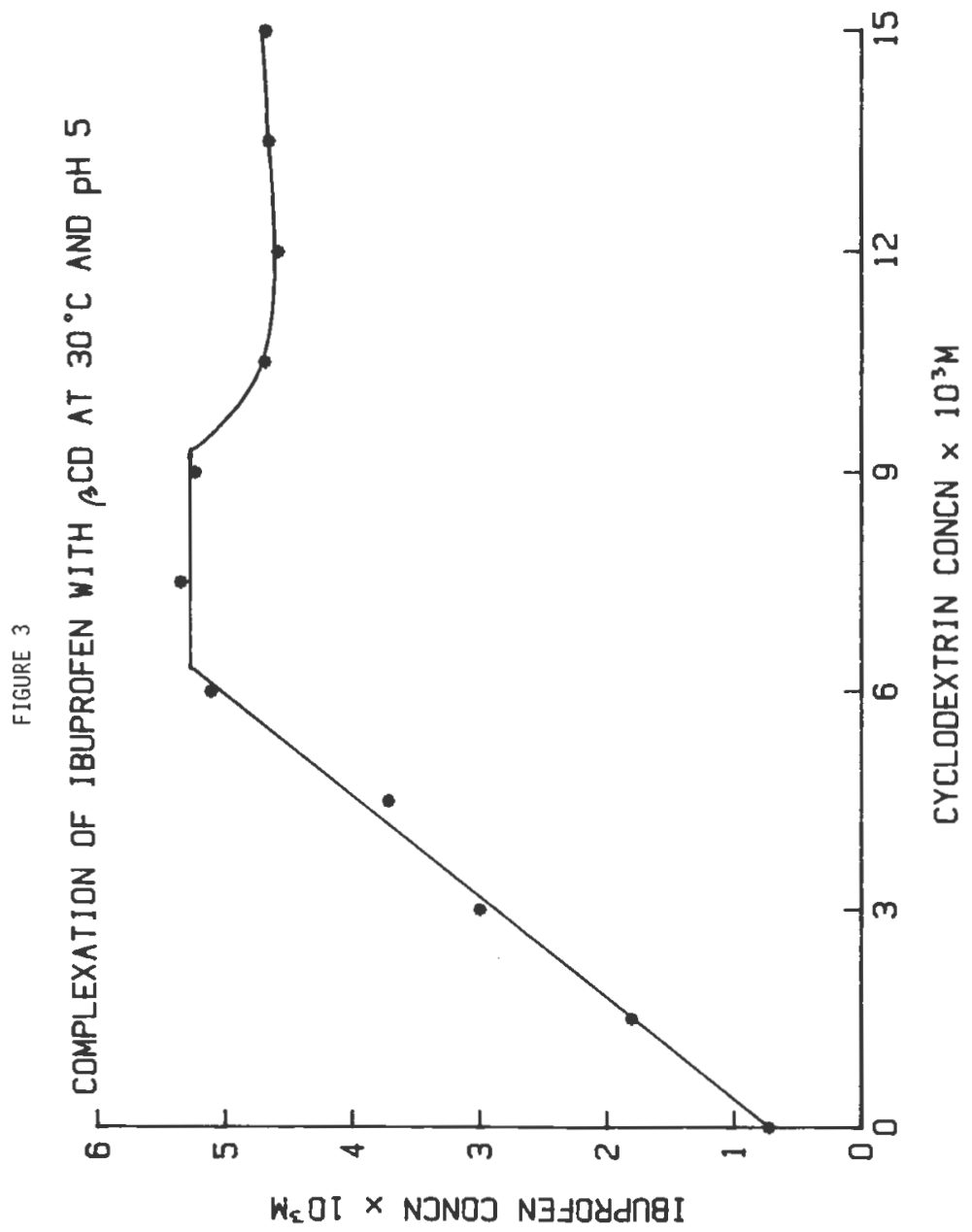




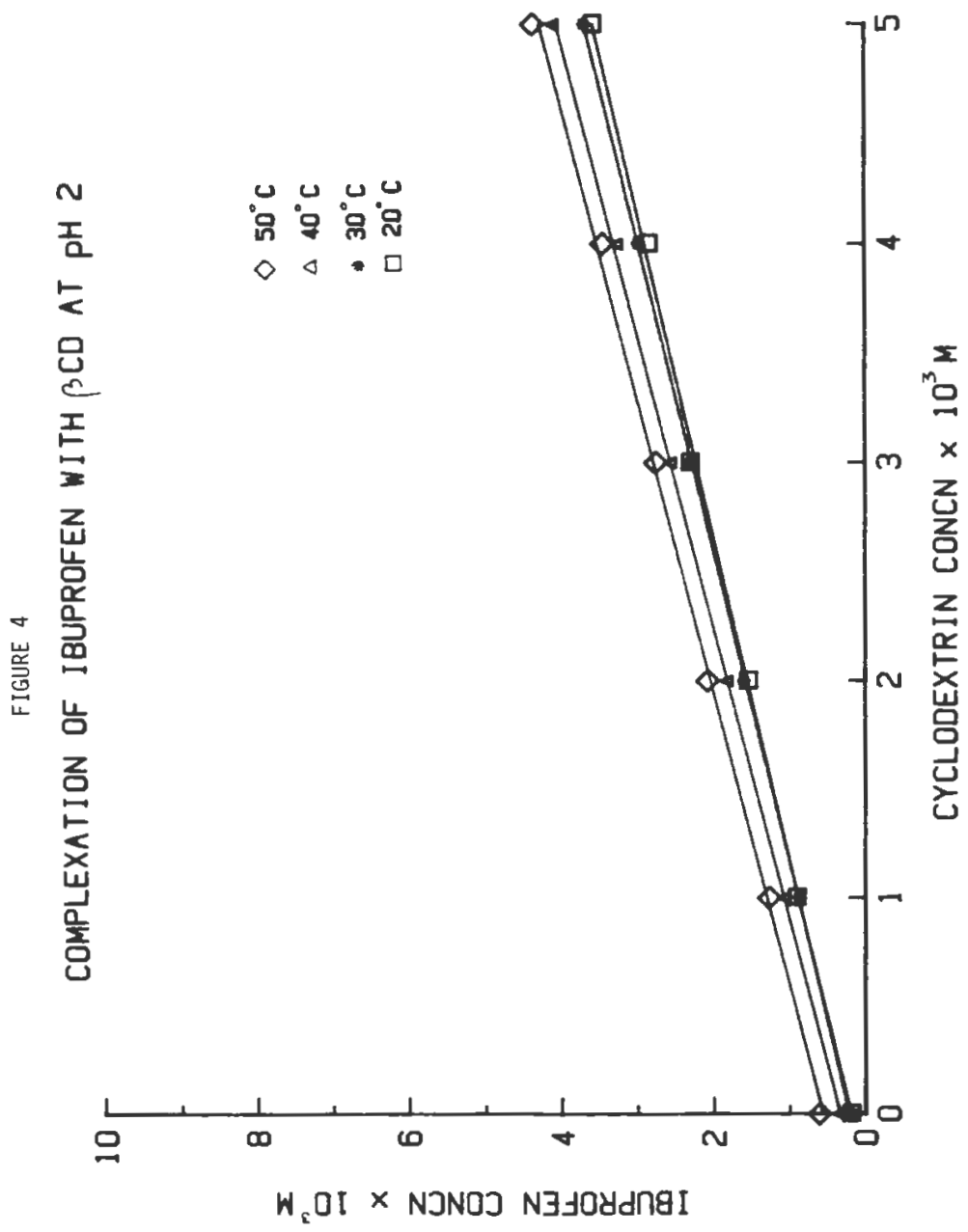


FIGURE 5

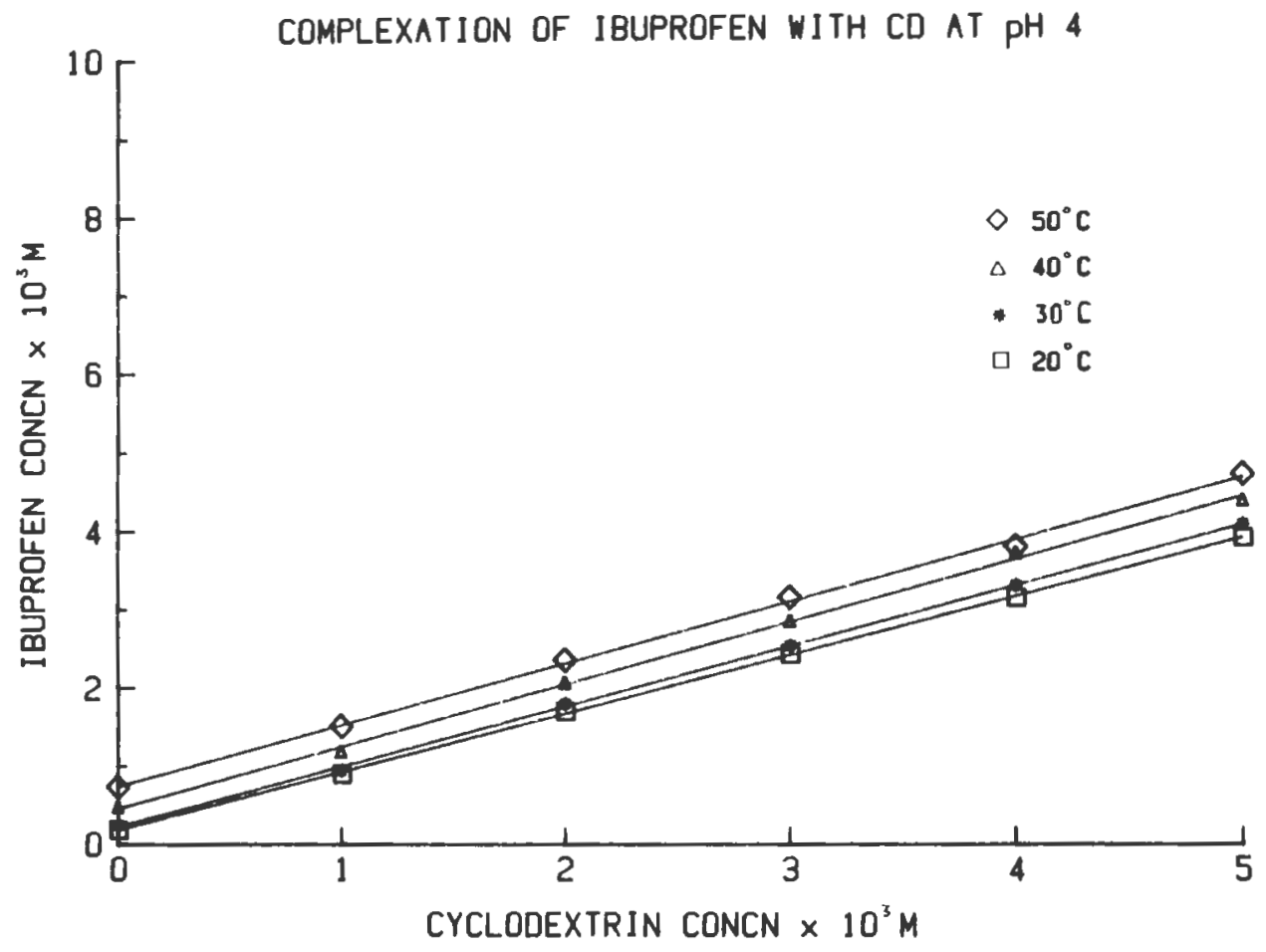




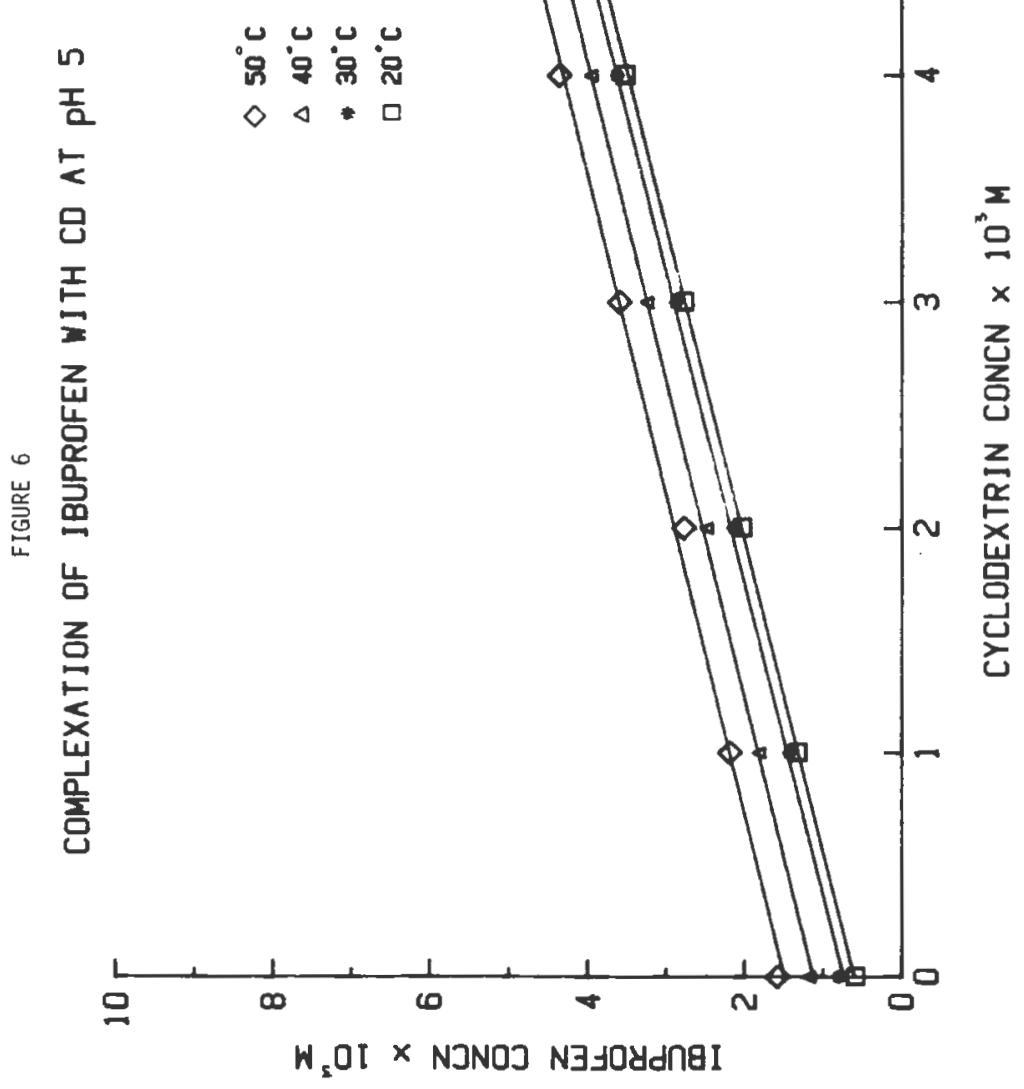




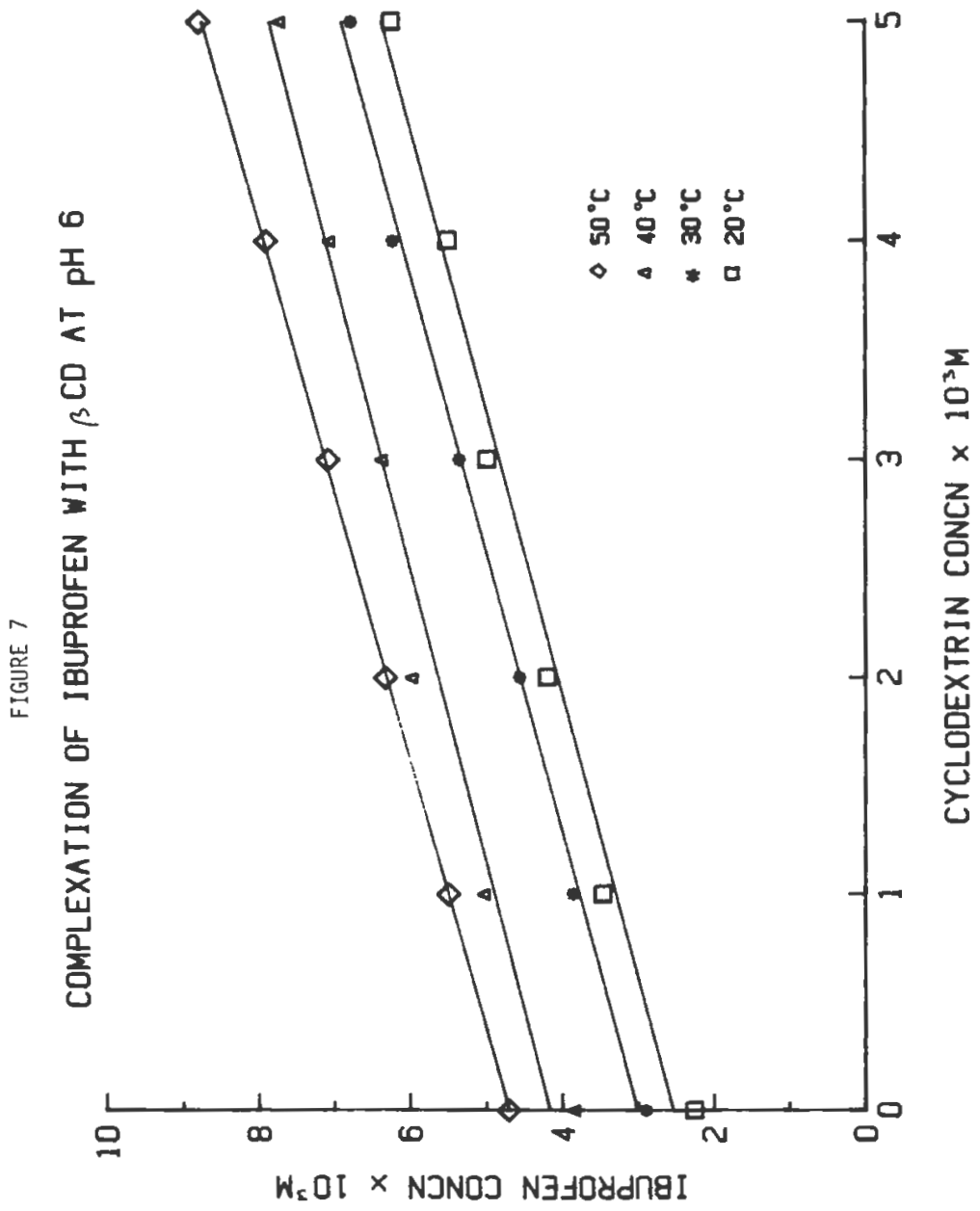




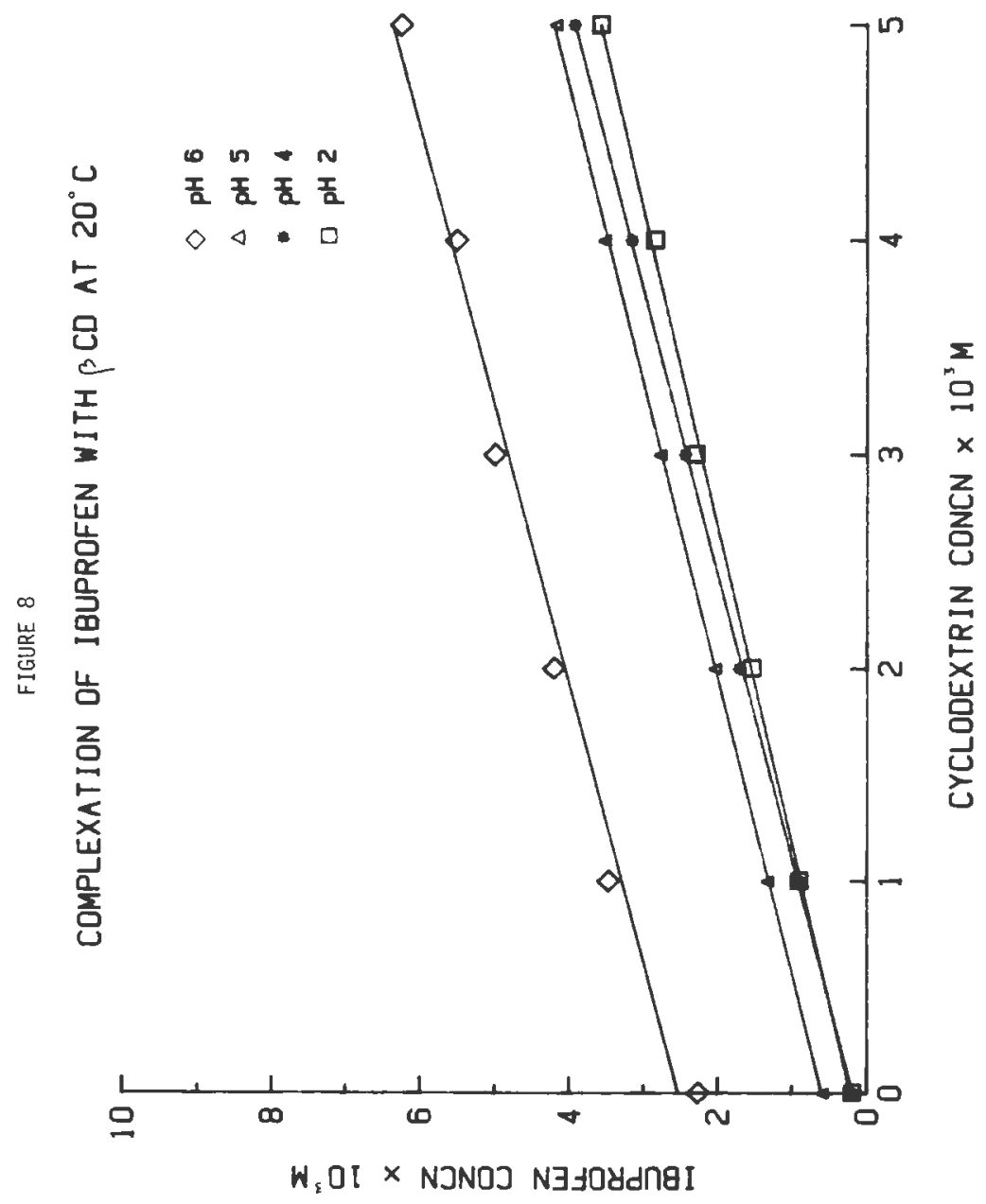


FIGURE 9

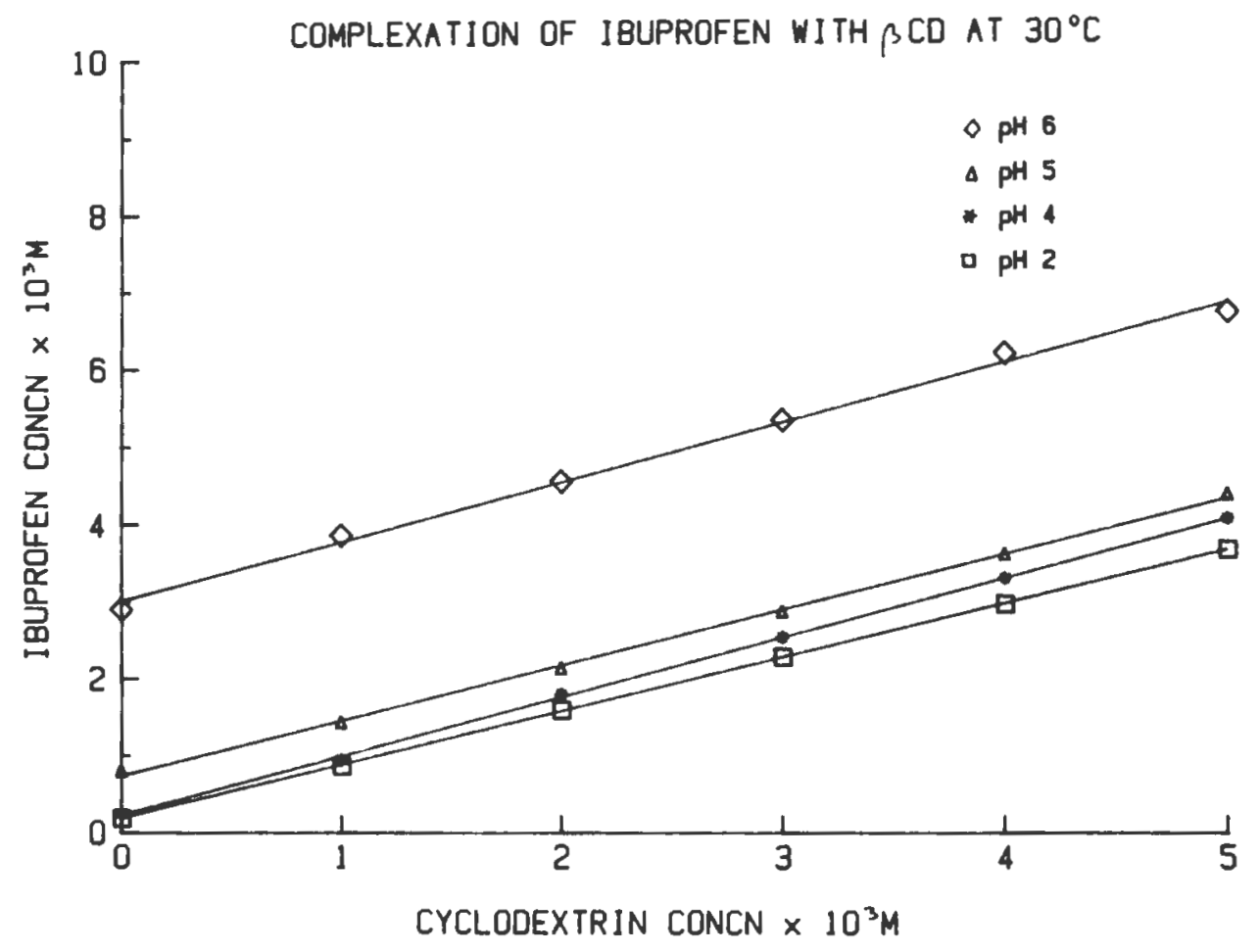


FIGURE 10

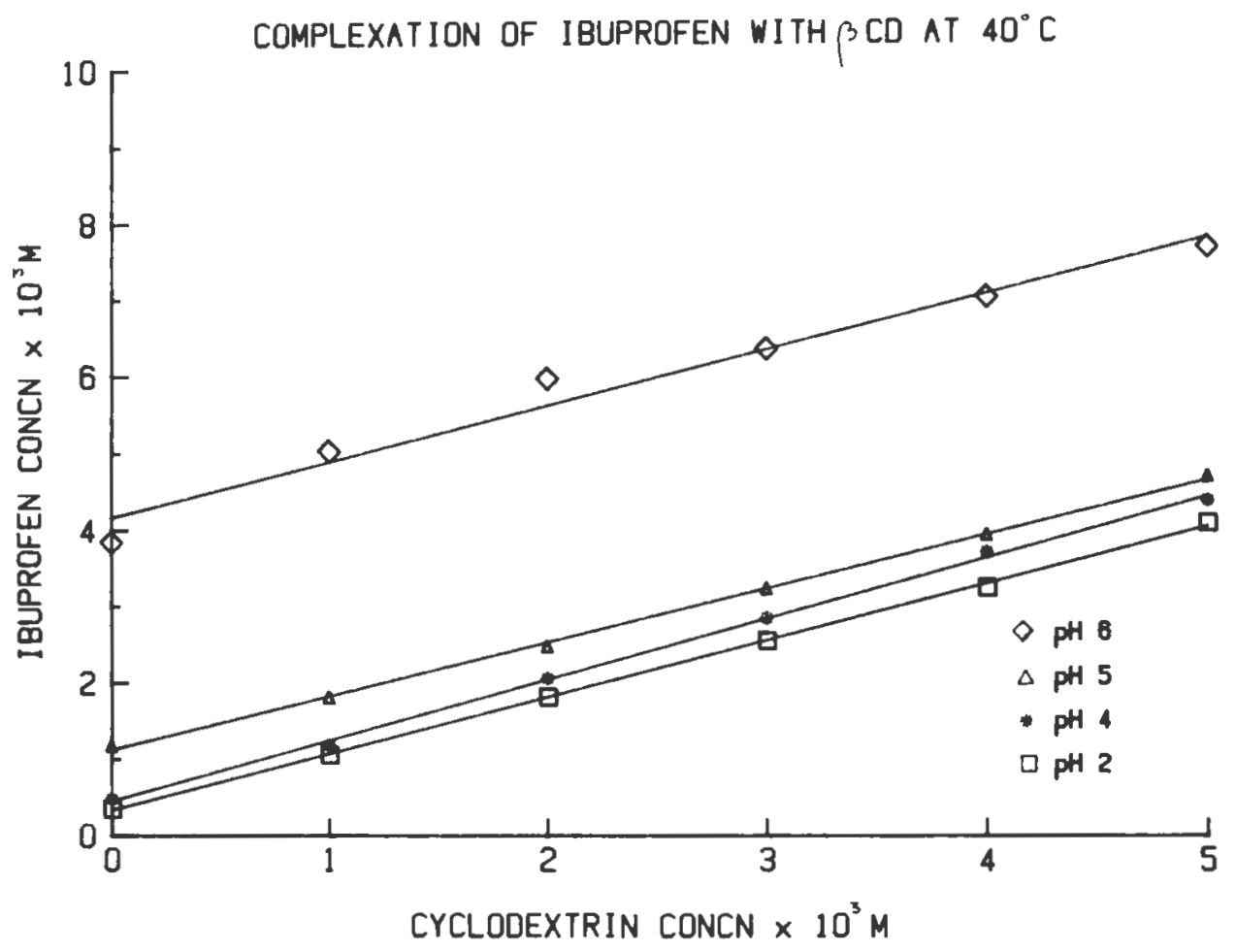


FIGURE 11

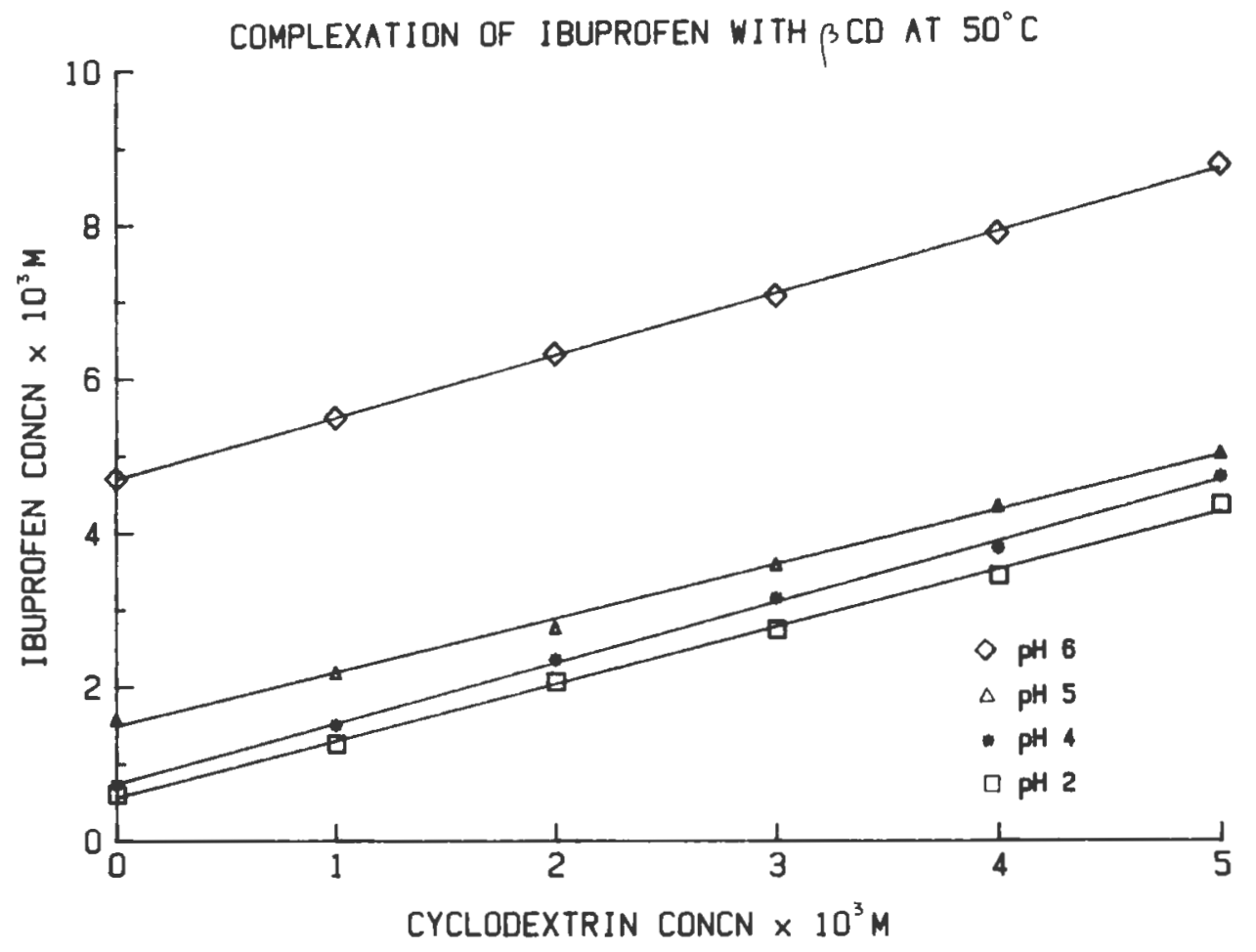




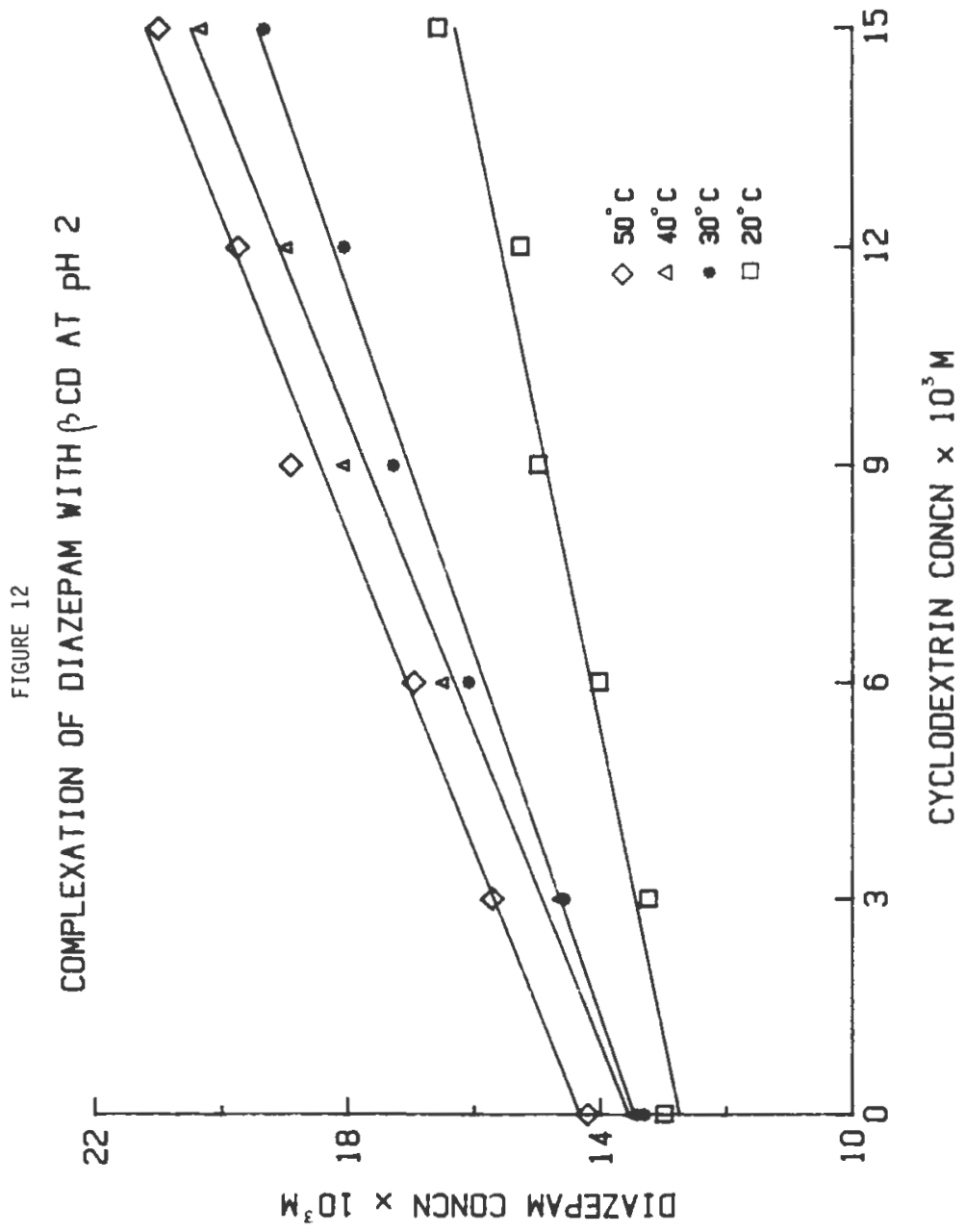




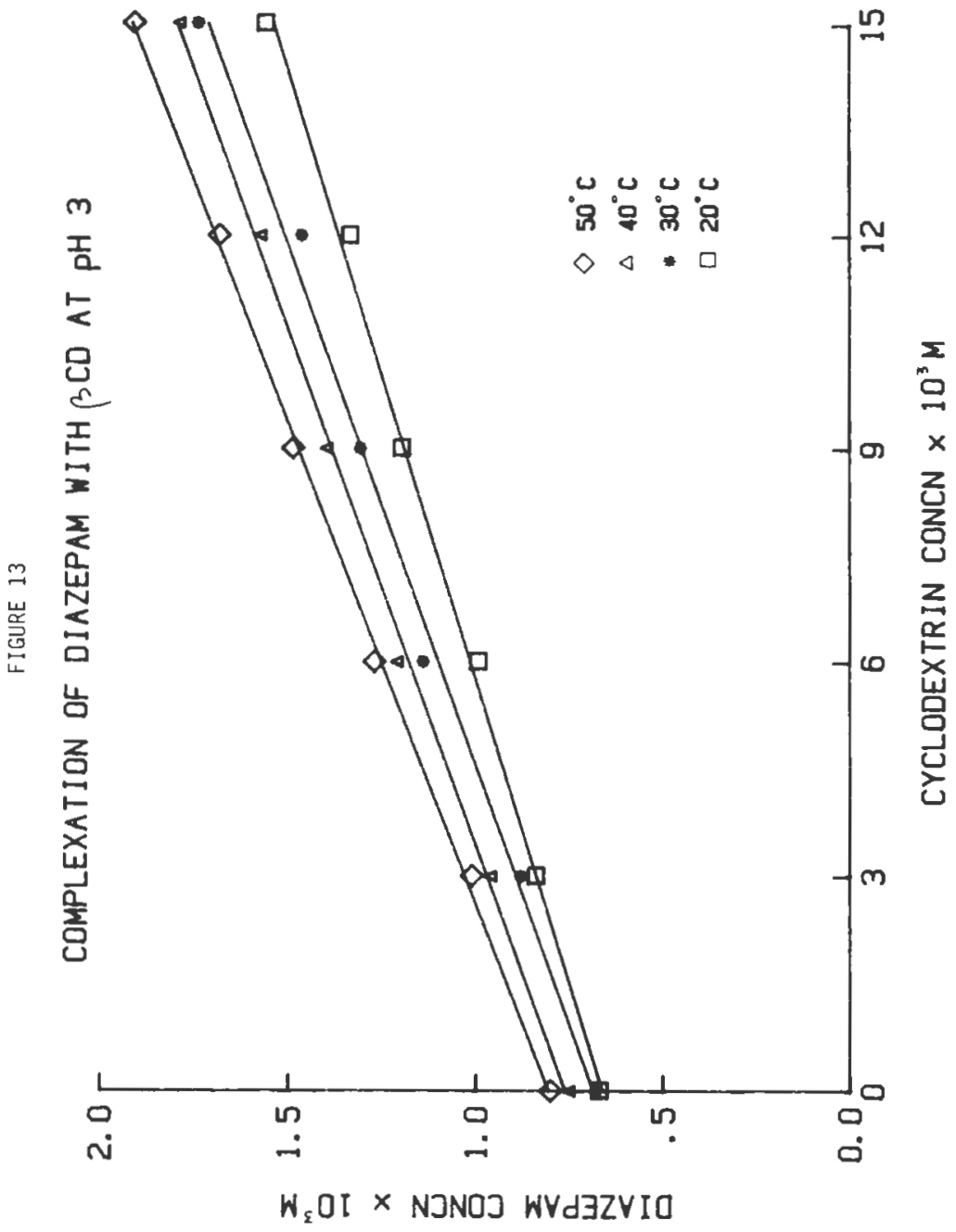




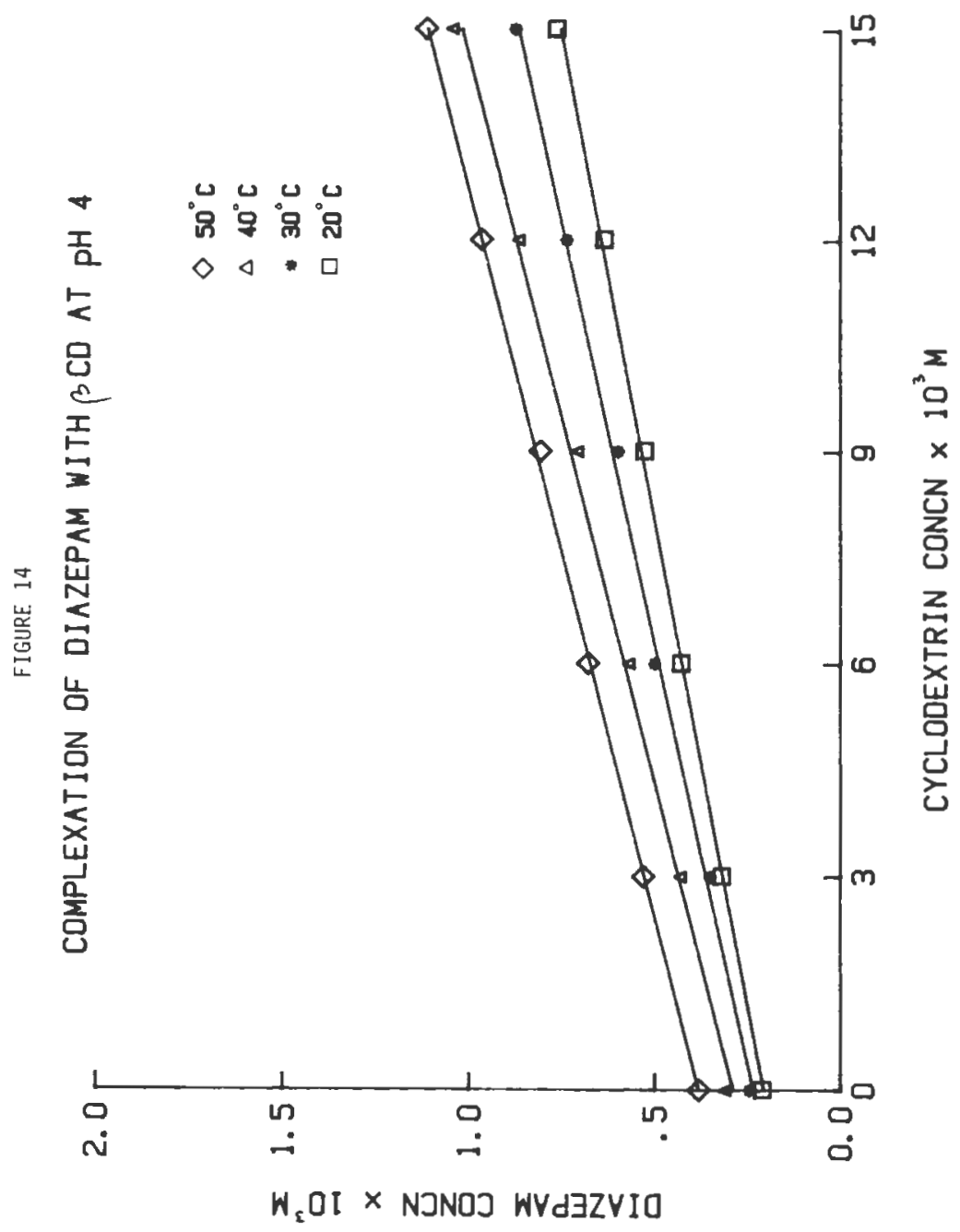




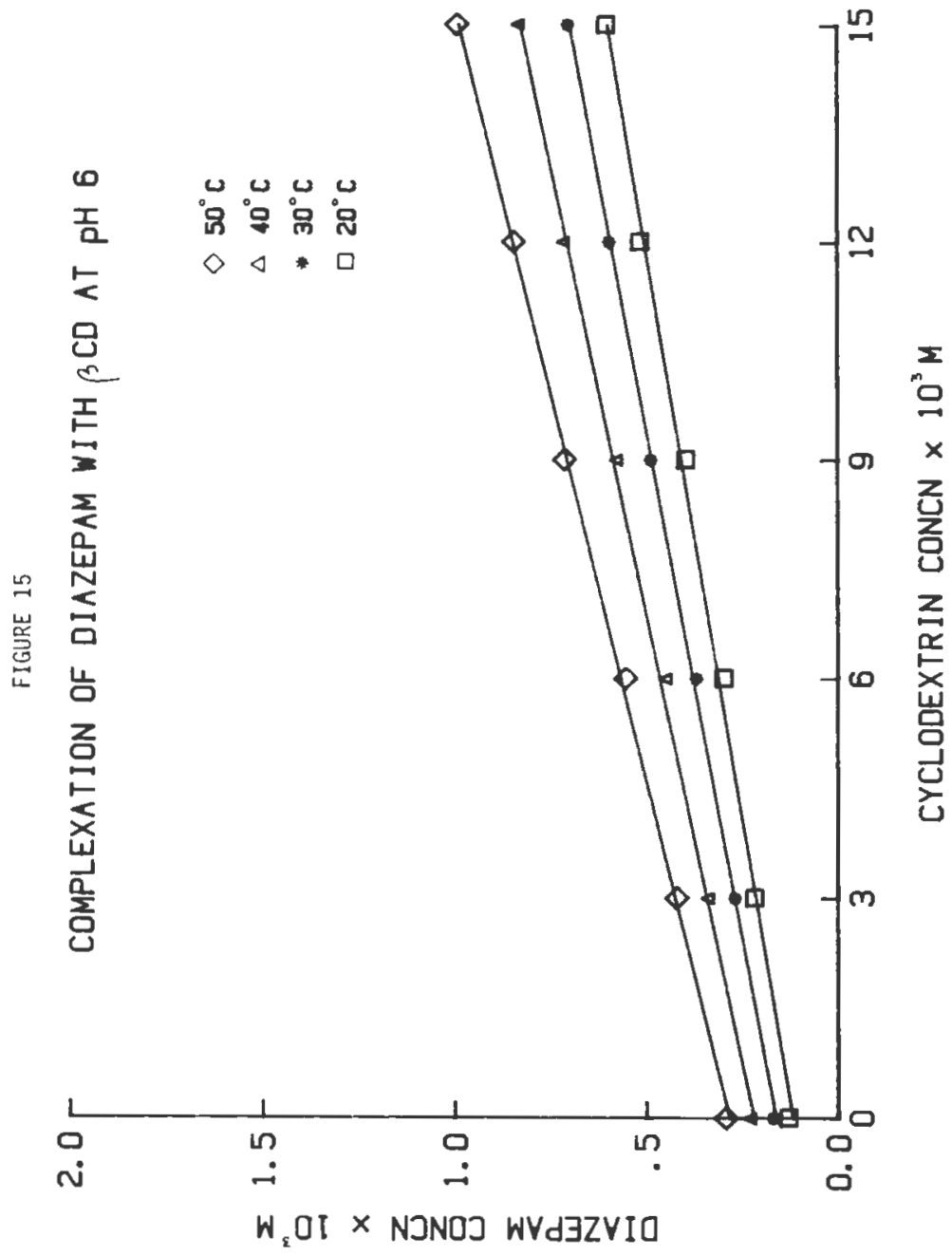




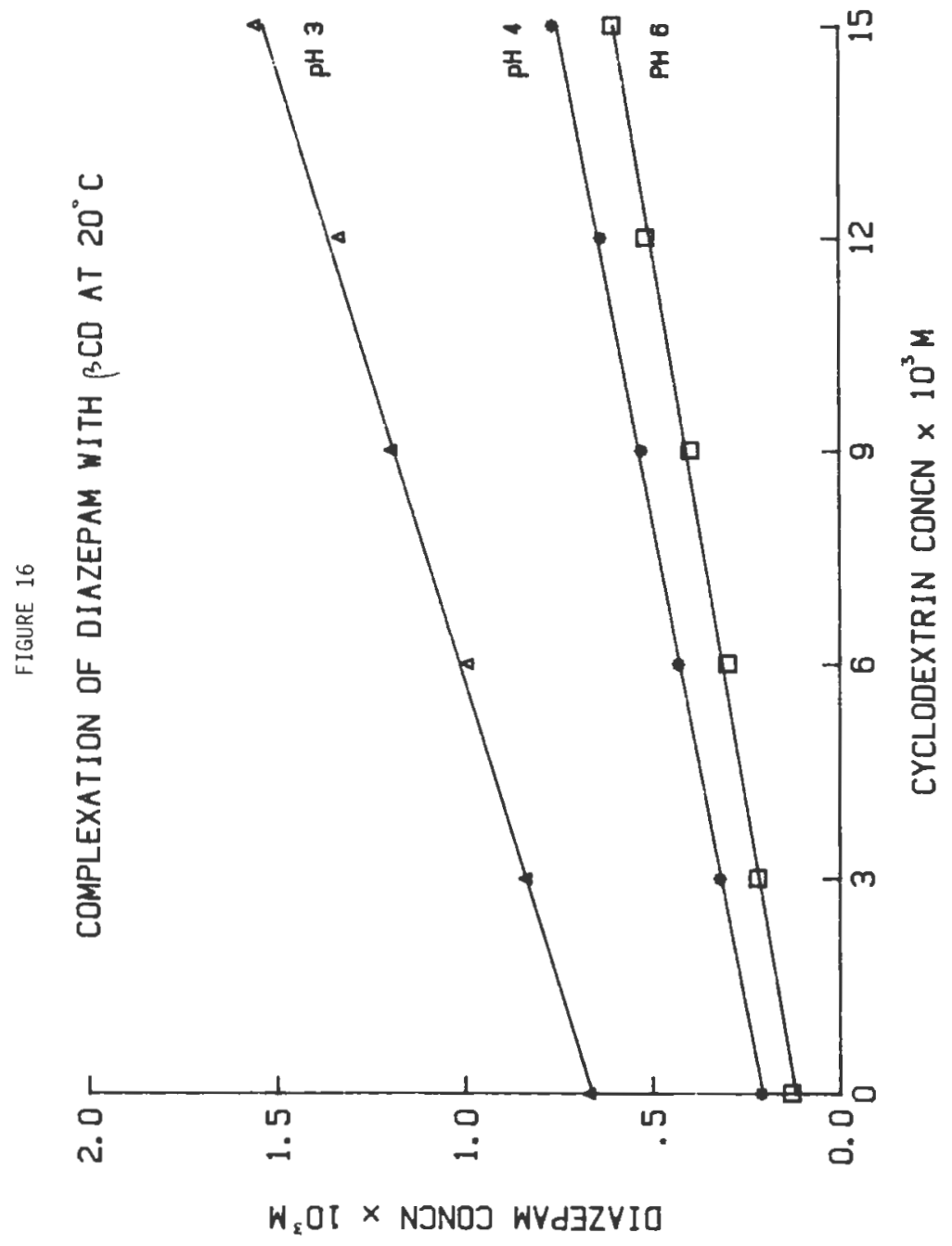




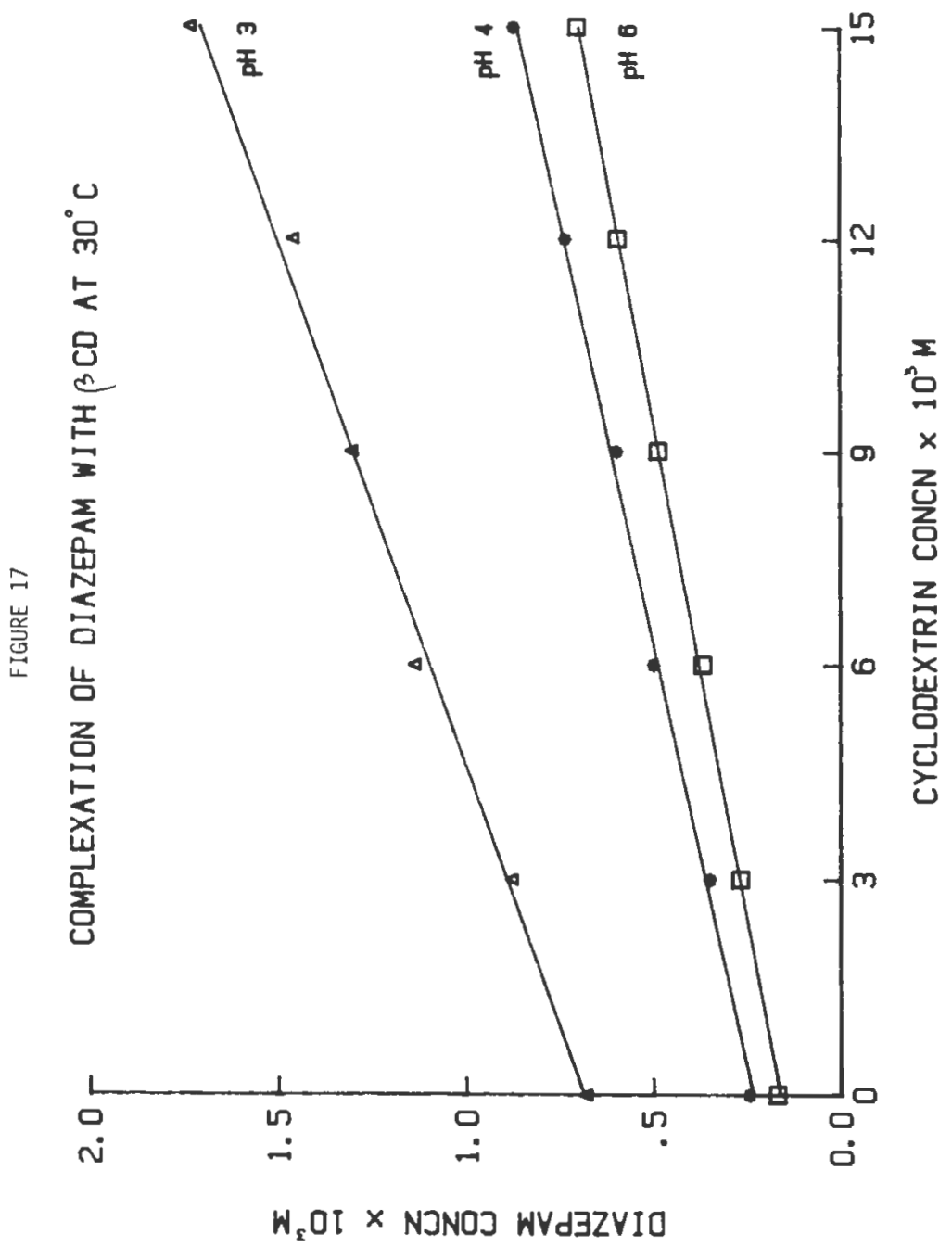




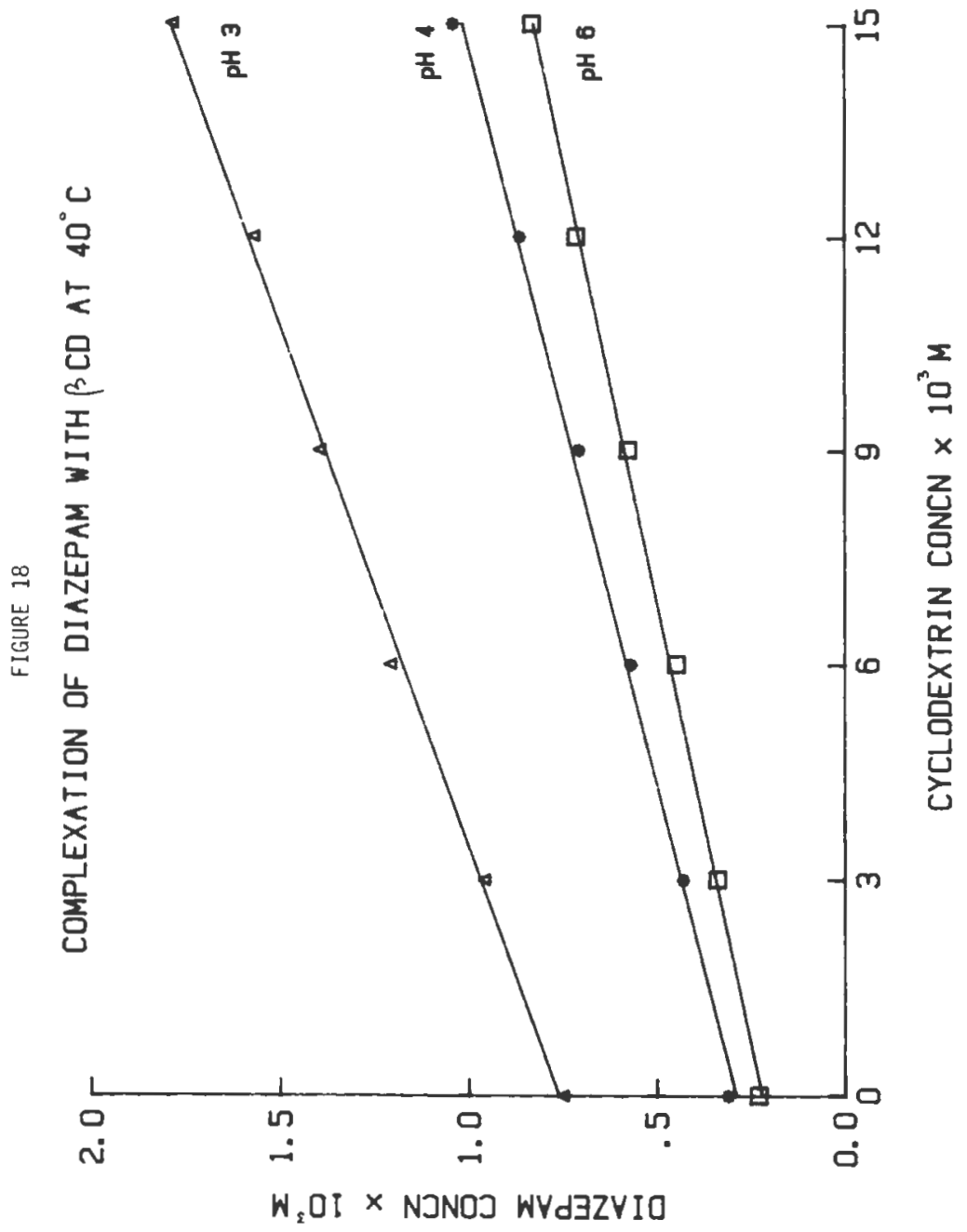




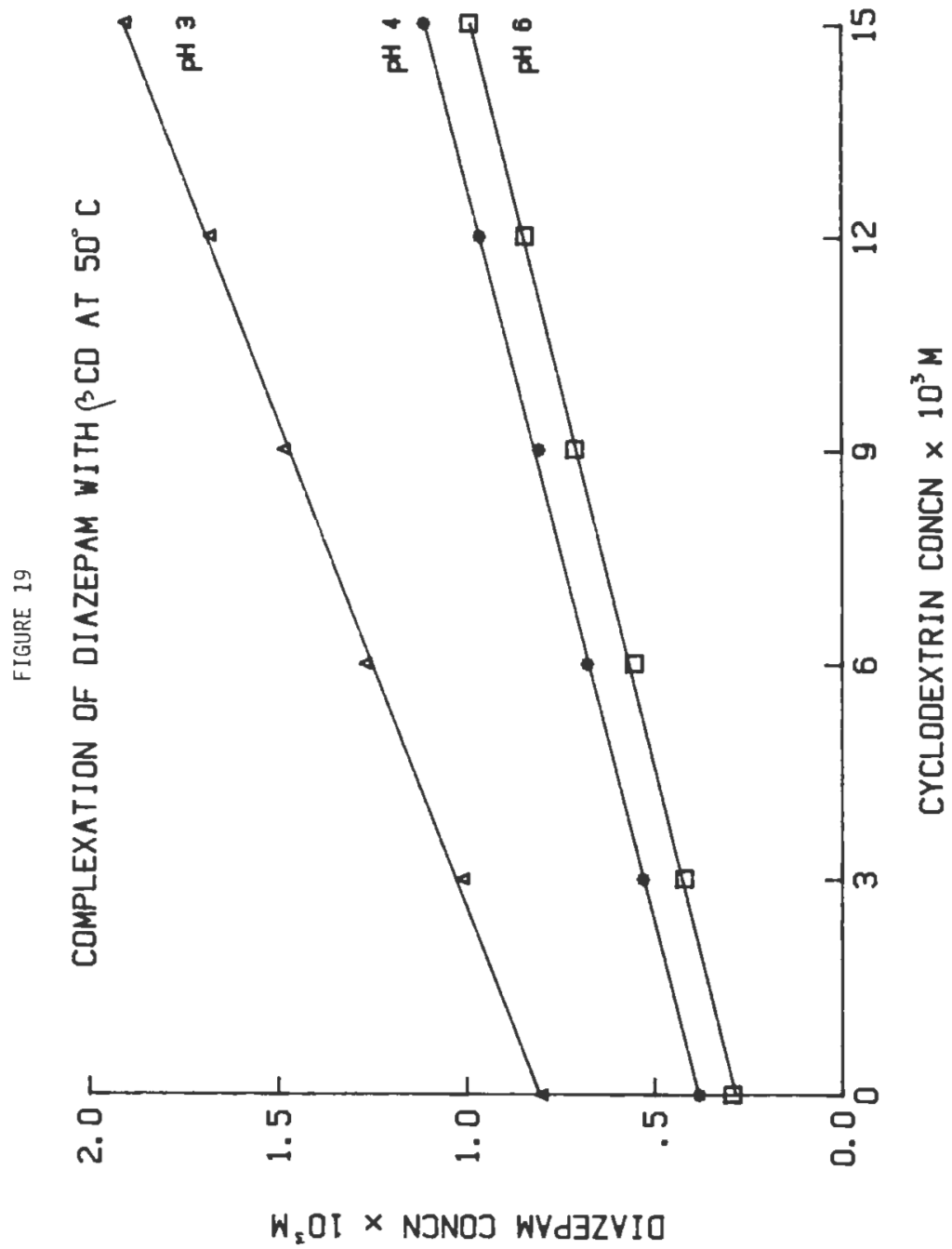




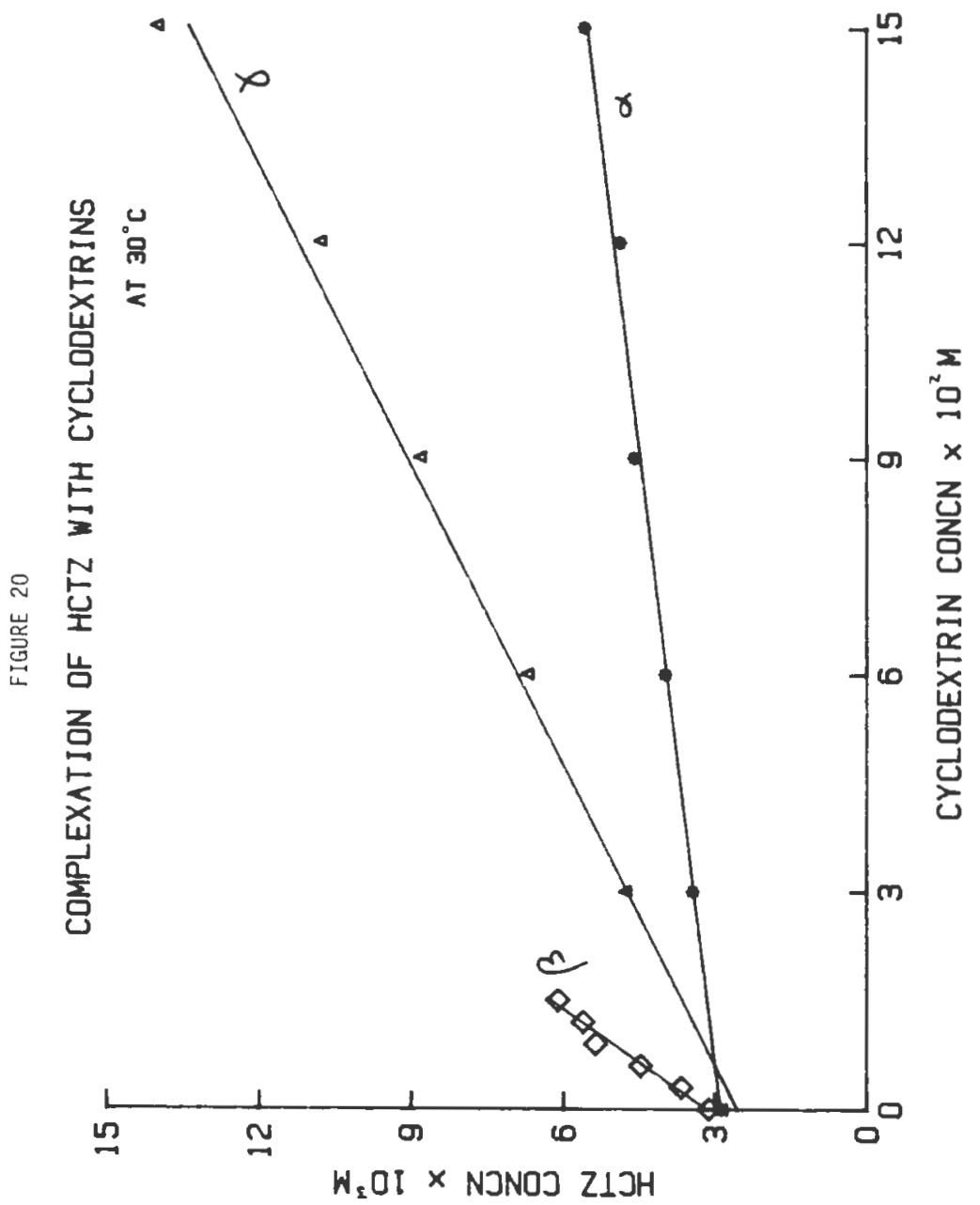




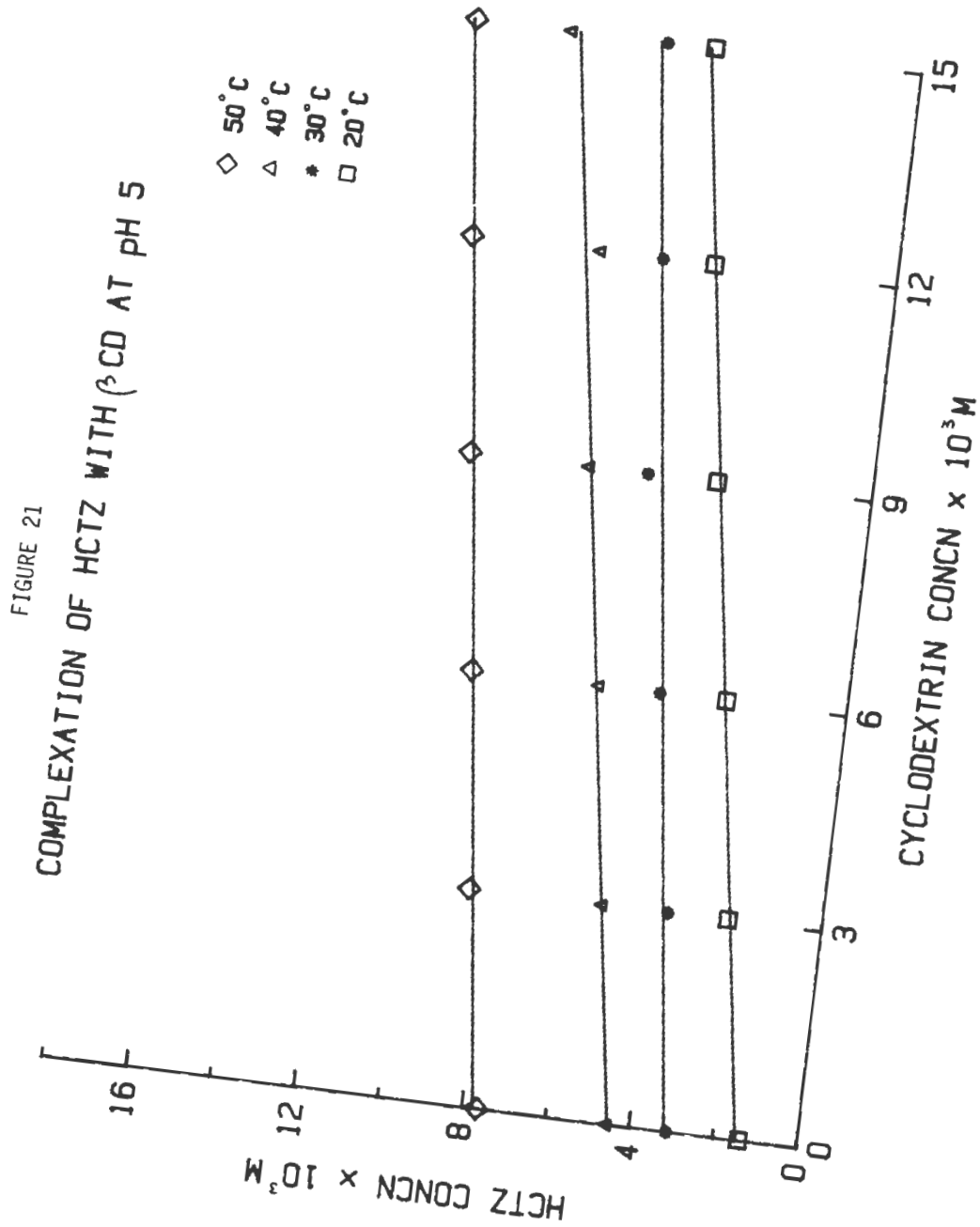




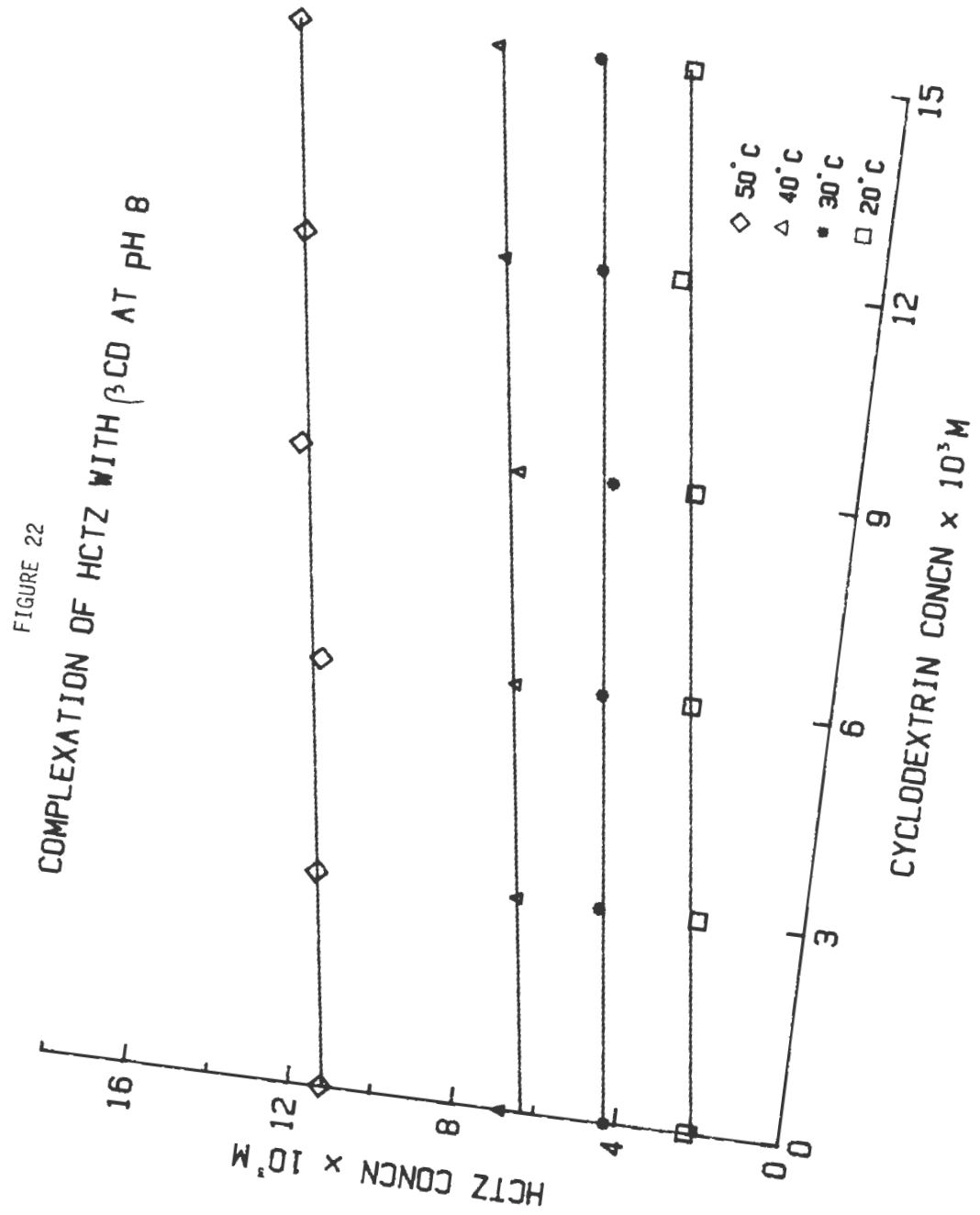




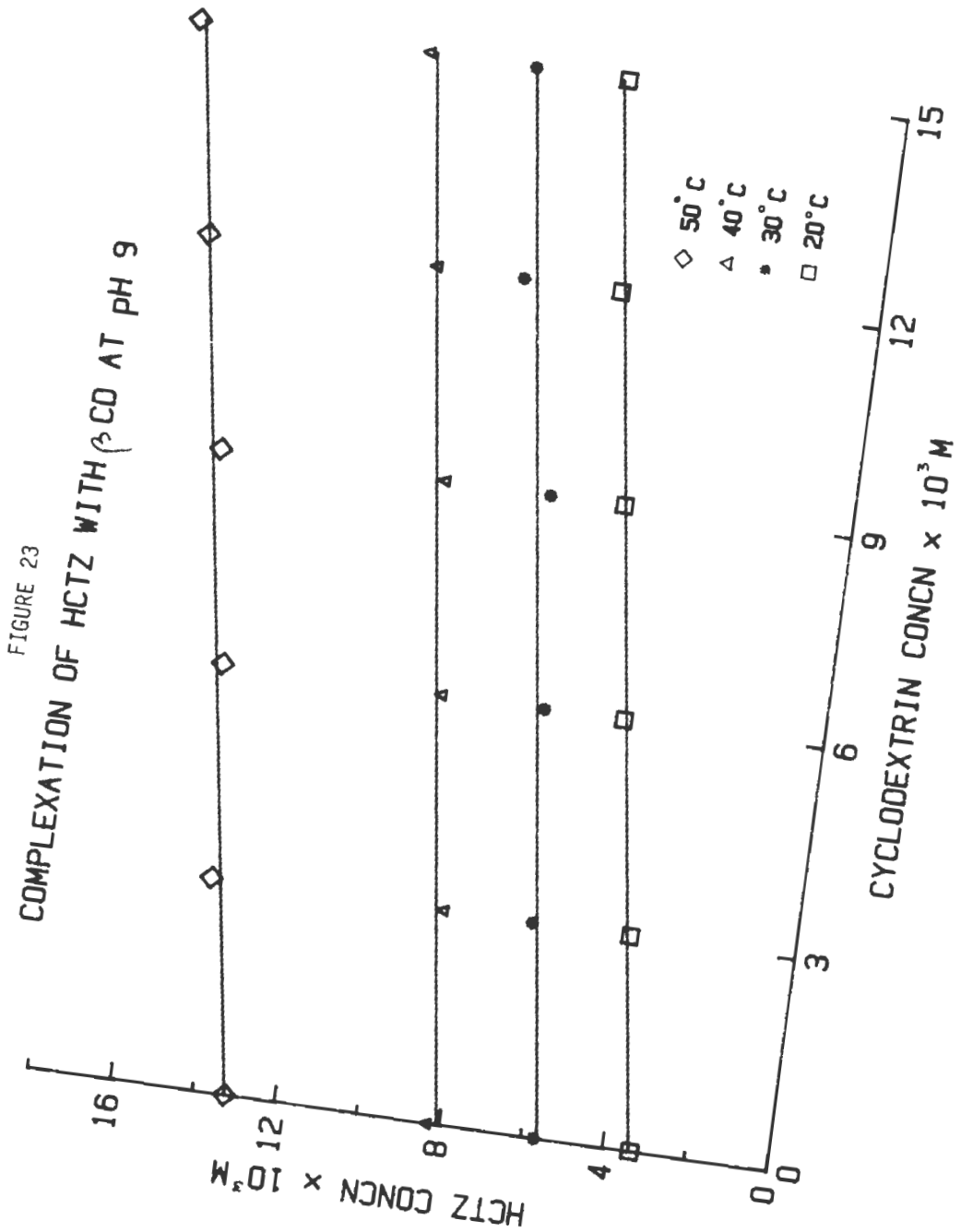




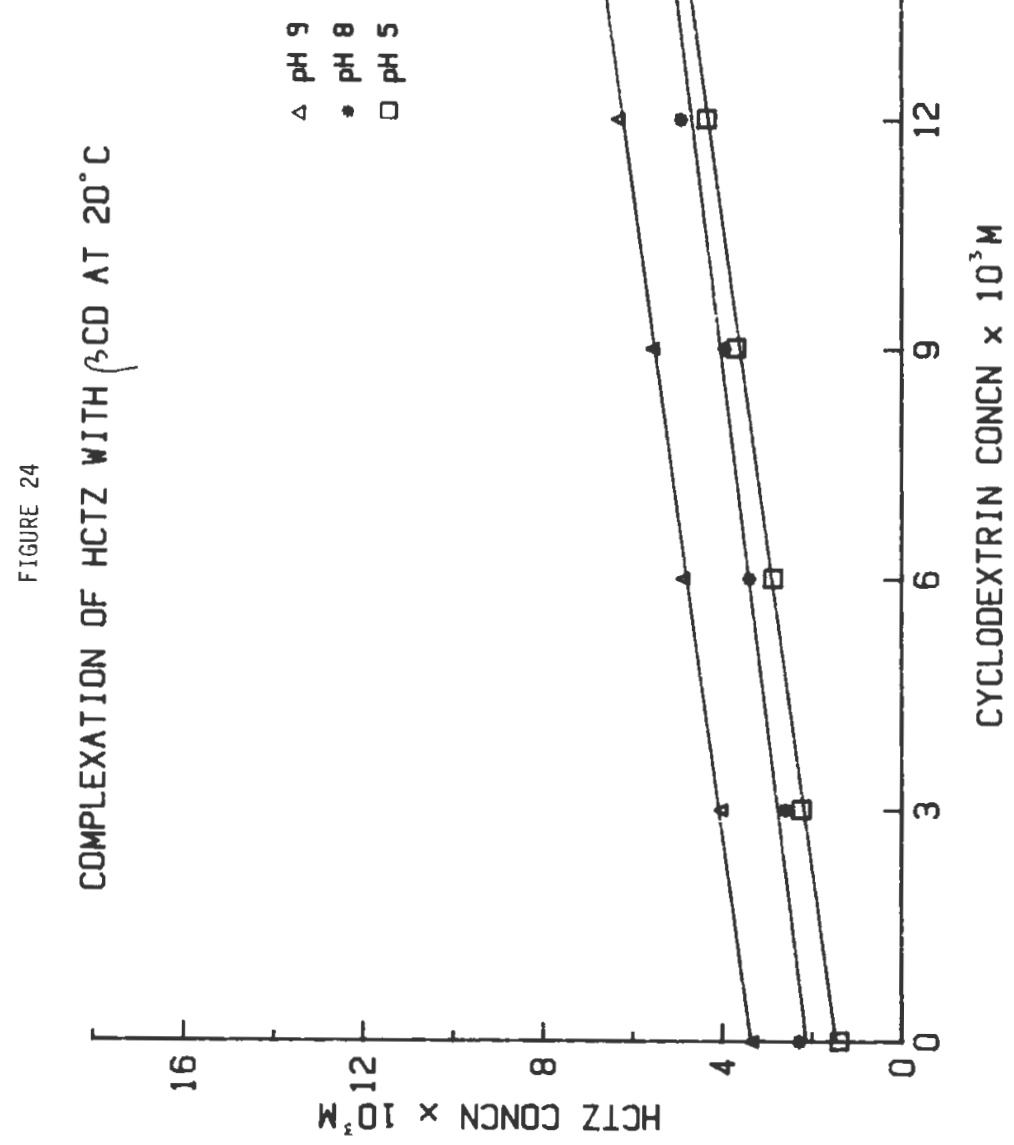




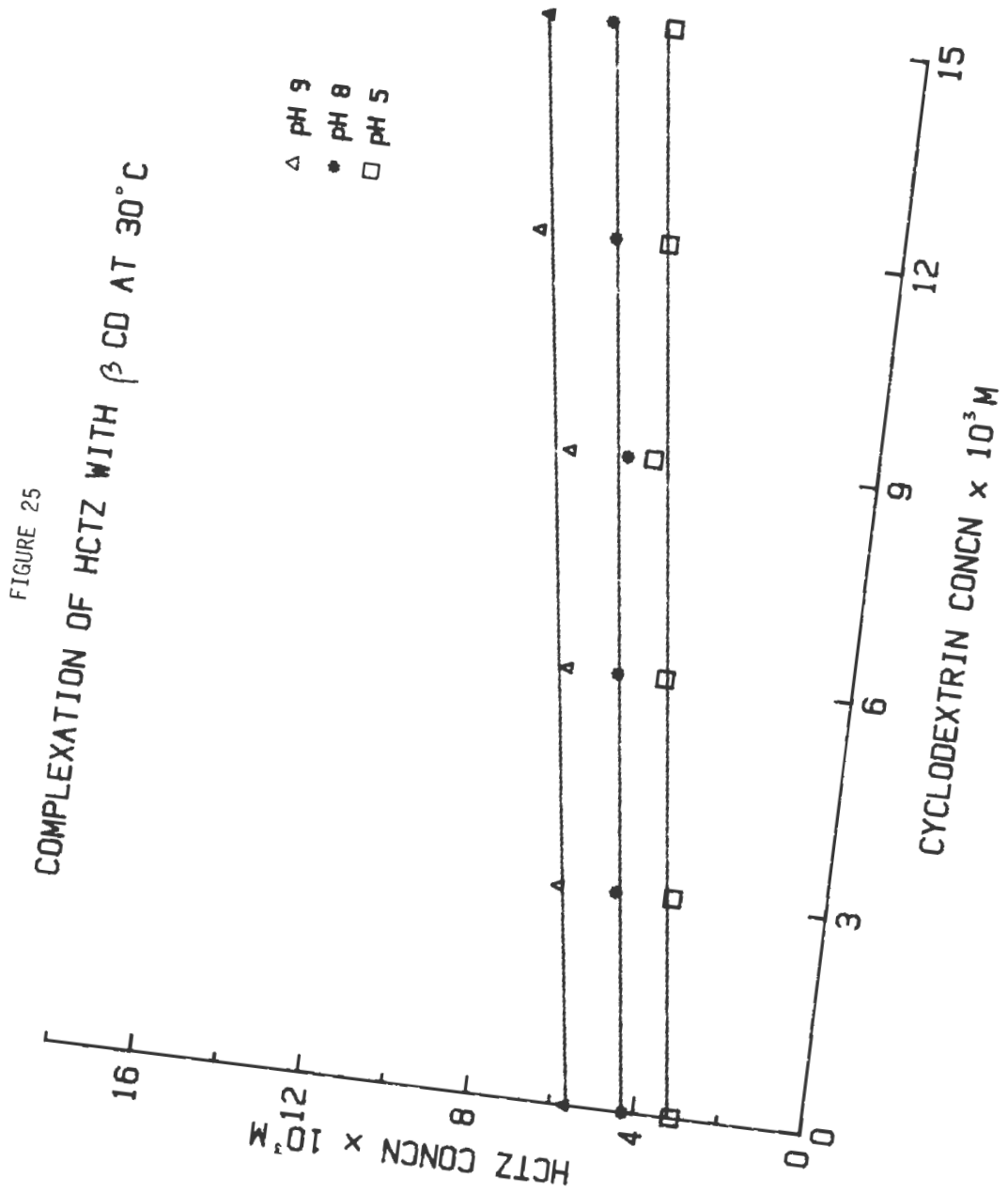




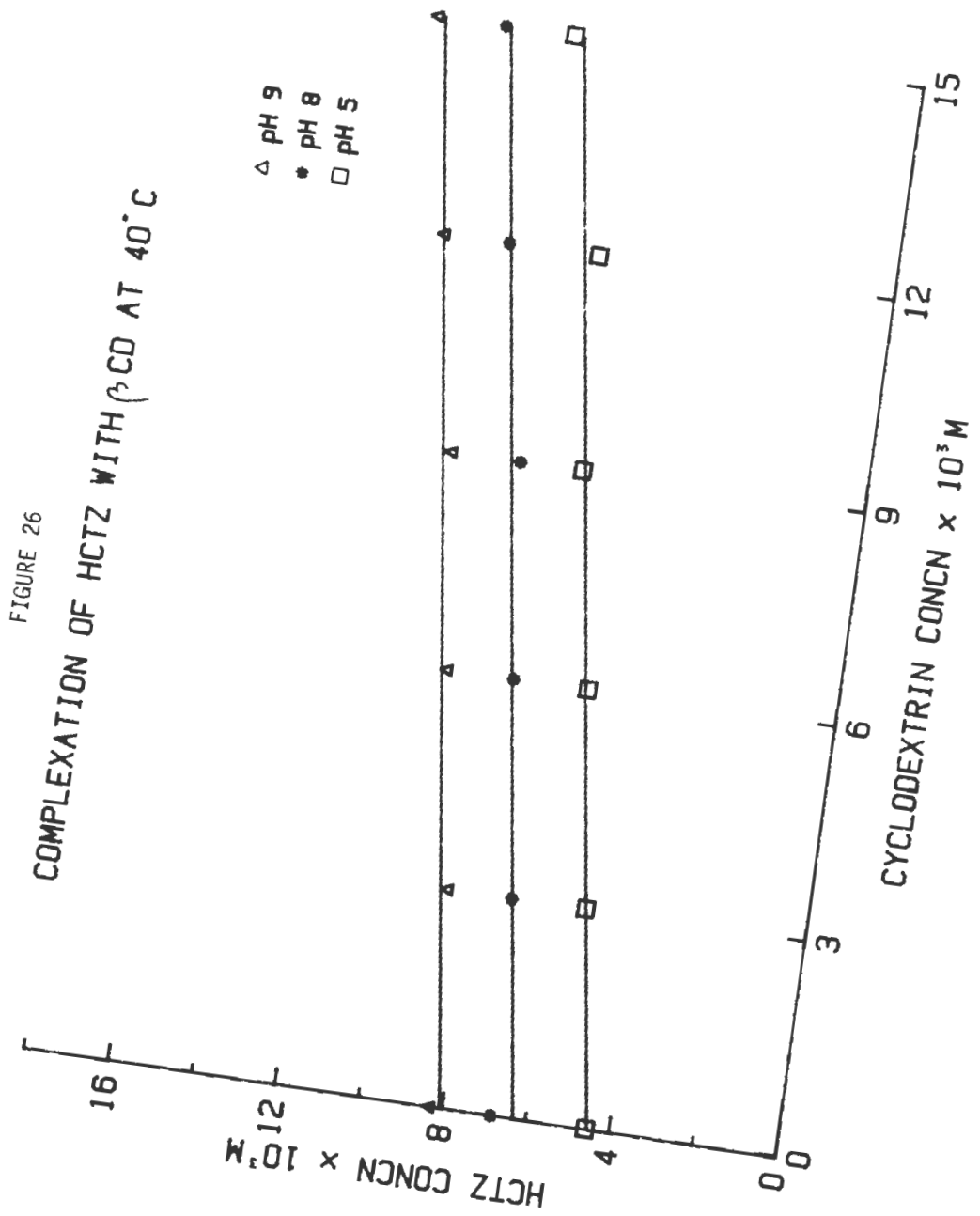


FIGURE 27

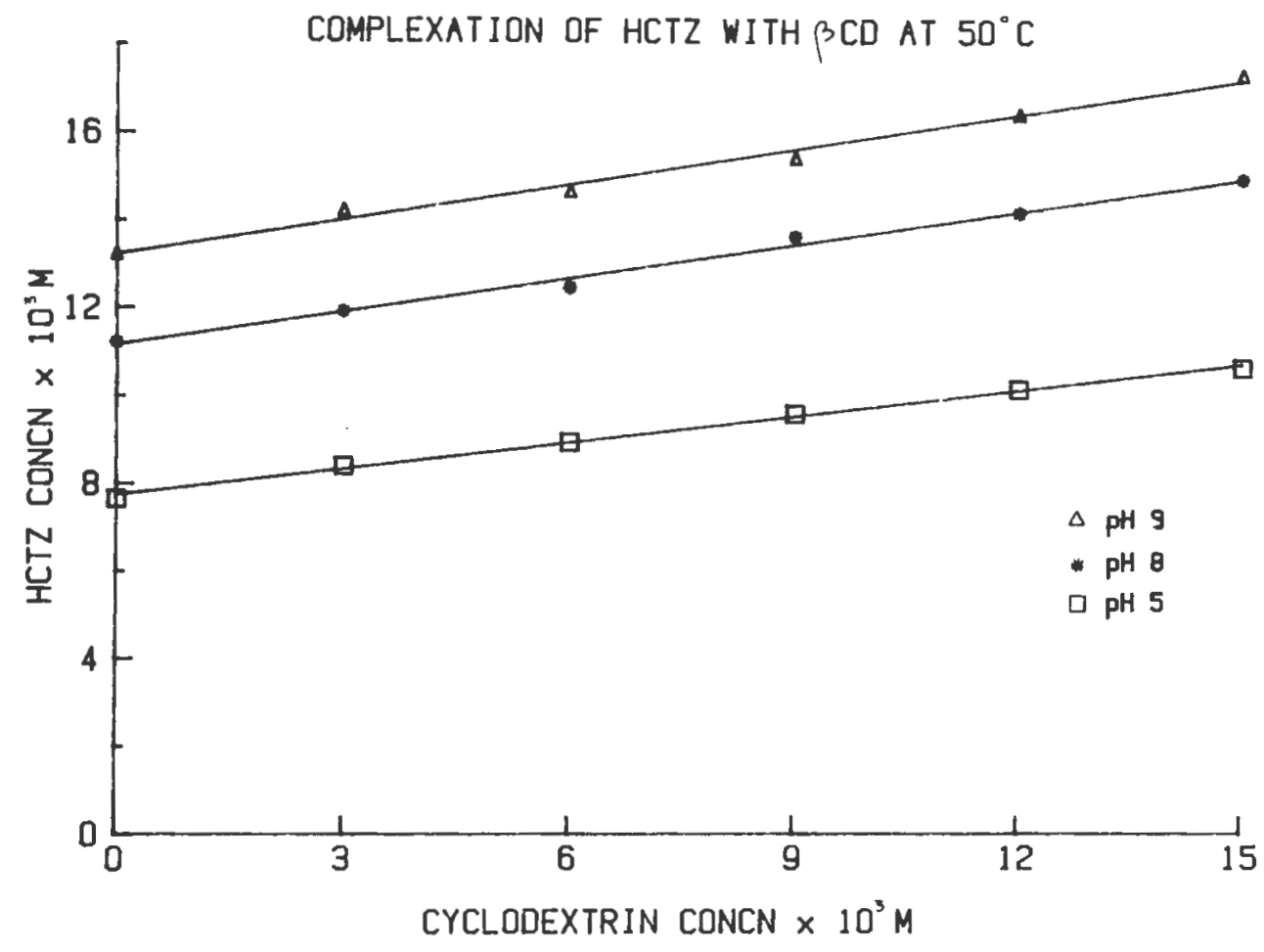


APPENDIX E 
STATISTICAL TREATMENT OF THE DATA

The solubility isotherms obtained in this study correspond to the complexation of several drugs with cyclodextrins, at different $\mathrm{pH}$ values and different temperatures. The effect of these two variables on the slope of the plots of drug concentration vs. cyclodextrin concentration was tested for their statistical significance using a sAS program.

The following section describes the datafiles, the Job Control Language (JCL), which was identical in all cases, and the results of sAS teatment of the data. The datafiles are listed for phenytoin, ibuprofen, diazepam and hydrochlorothiazide, respectively. The results listed are those obtained at a $95 \%$ confidence level (alpha $=5 \%$ ), for the four drugs in the same order as above. The data were also tested at the $1 \%$ and $10 \%$ levels. 


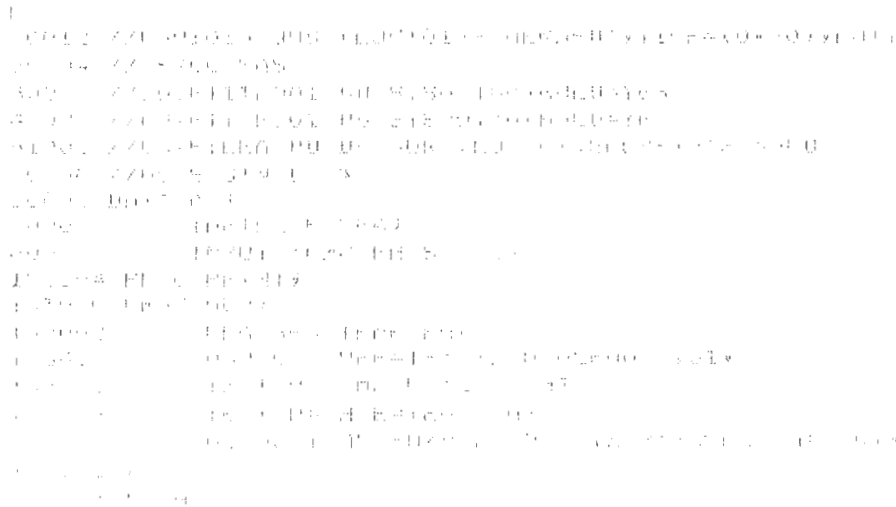




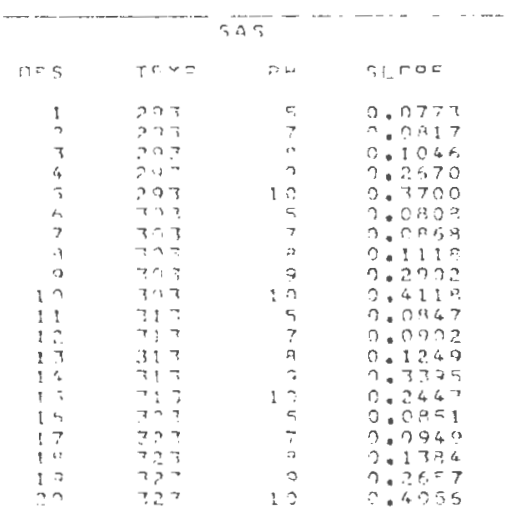




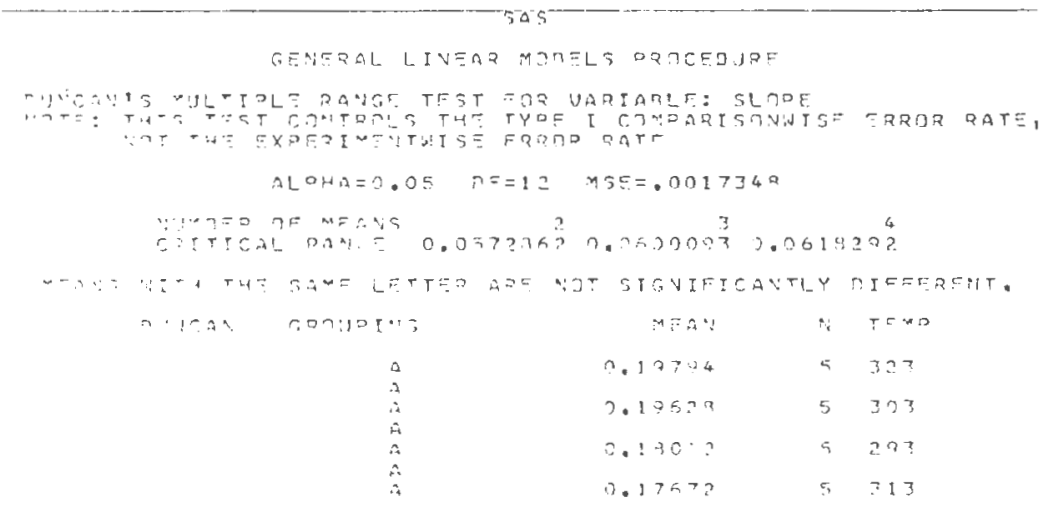




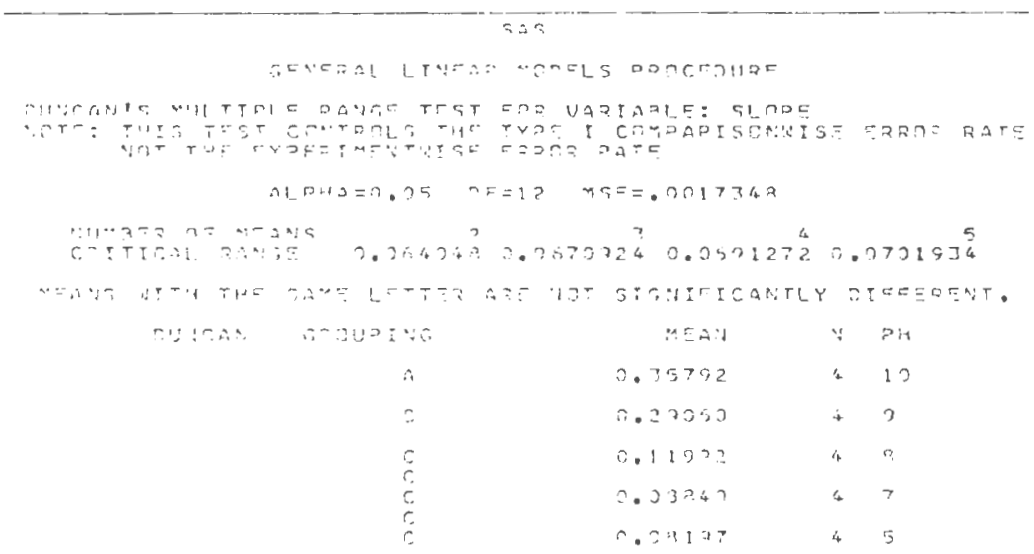




\begin{tabular}{|c|c|c|c|}
\hline $0.3=$ & $T+40$ & $P: 4$ & TLこDE \\
\hline$!$ & 277 & 2 & 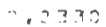 \\
\hline$\therefore$ & 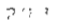 & ᄀ. & $c:=2 i$ \\
\hline 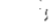 & 777 & 6 & 6.厂万น \\
\hline$\therefore$ & $\because 1$ & $\cdot$ & $\because .723$ \\
\hline $1 ;$ & $3: 3$ & $?$ & $2.7=30$ \\
\hline$\therefore$ & $7 \div 7$ & $=$ & $\therefore=\therefore 31$ \\
\hline ? & 733 & 4 & 0.2225 \\
\hline ?ִ & 37 & $h$ & $\therefore=753$ \\
\hline 4 & $3: 3$ & ? & $1, .56 \%$ \\
\hline 17 & 713 & 7 & $7.57 ?$ \\
\hline$i i$ & $\because 17$ & $\therefore$ & $\therefore \therefore 271$ \\
\hline i? & $7 i 7$ & $\rightarrow$ & $r .-41:$ \\
\hline$i:$ & $7=-1$ & $?$ & $i, 4<1$. \\
\hline $1 \therefore$ & 9.3 & 3 & $=0-167$ \\
\hline 15 & $3.7=$ & $\div$ & $5 .=481$ \\
\hline 1 in & $7=7$ & $=$ & $\because .795$ \\
\hline
\end{tabular}




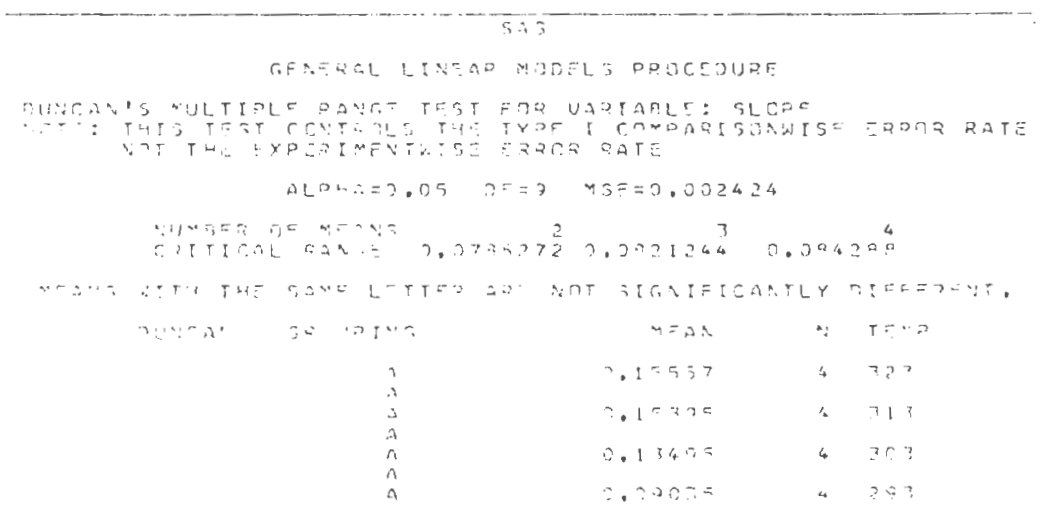




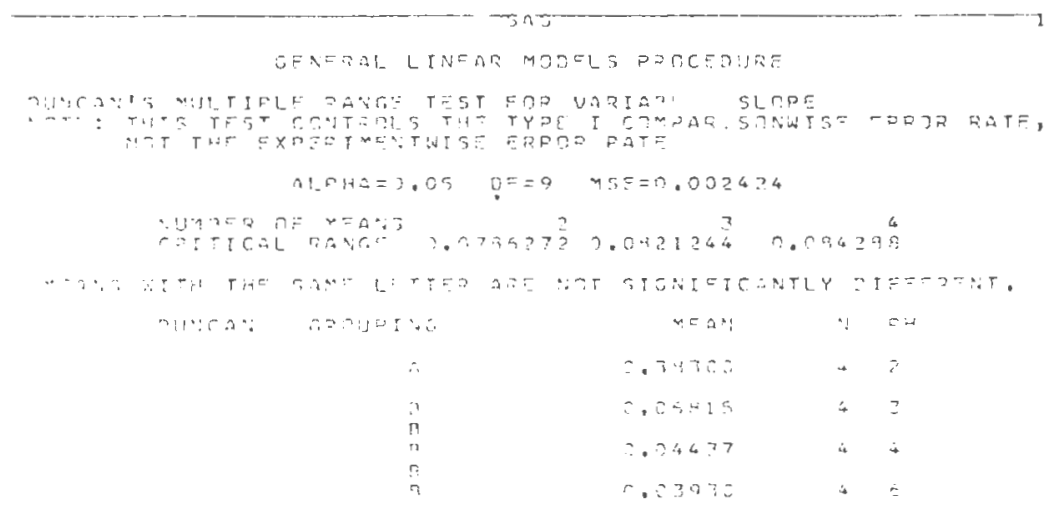




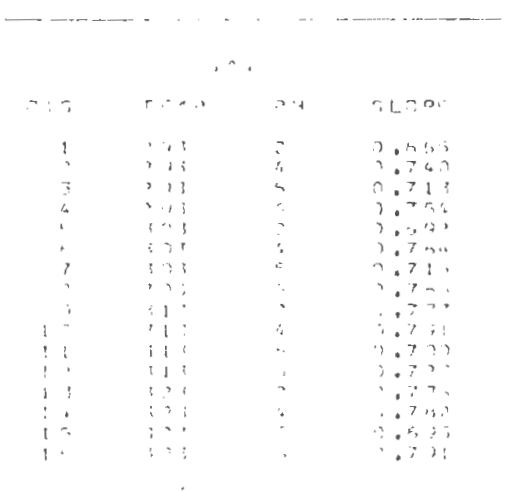




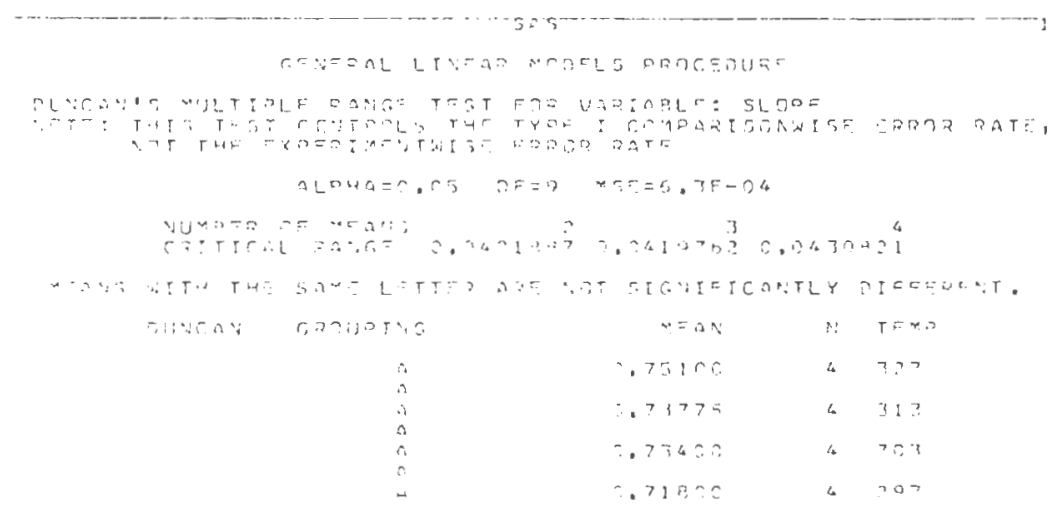




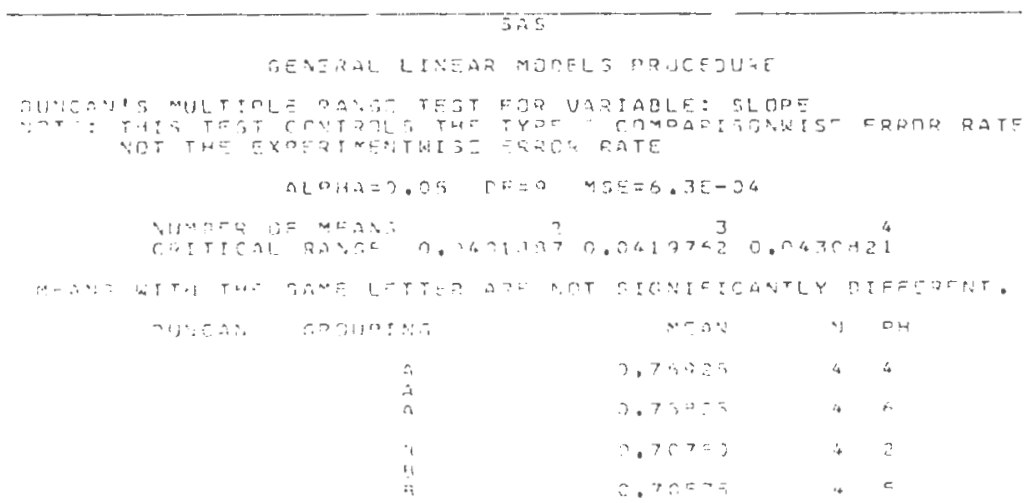




\begin{tabular}{|c|c|c|c|}
\hline $7: 5$ & $T \Xi P$ & $P 4$ & $3200=$ \\
\hline 1 & 203 & $丂_{7}$ & a. 240 \\
\hline$?$ & 277 & 9 & 0.216 \\
\hline 7 & $i n 3$ & 3 & $0.24 ?$ \\
\hline 4 & 723 & $=$ & 0.237 \\
\hline ラ & 303 & $?$ & r. 210 \\
\hline$\therefore$ & 773 & ? & $\therefore 275$ \\
\hline 7 & 313 & 5 & $\therefore 2347$ \\
\hline$\therefore$ & 313 & ה & $\therefore 247$ \\
\hline 9 & 313 & 0 & 0.235 \\
\hline $1 ?$ & $7=3$ & 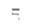 & $2.20 ?$ \\
\hline 11 & $3=3$ & $?$ & $\therefore . \hat{1}=7$ \\
\hline 12 & 723 & 7 & $\therefore .770$ \\
\hline
\end{tabular}




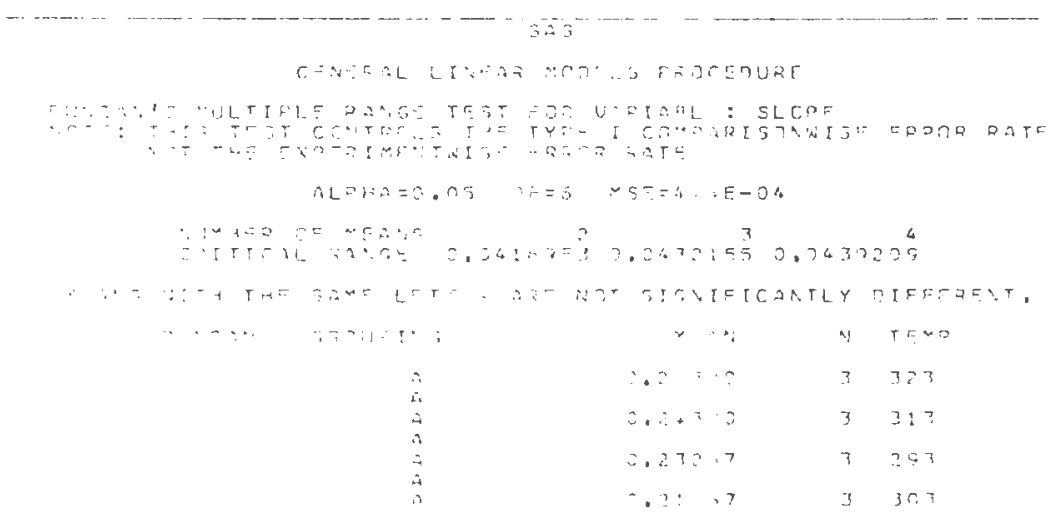




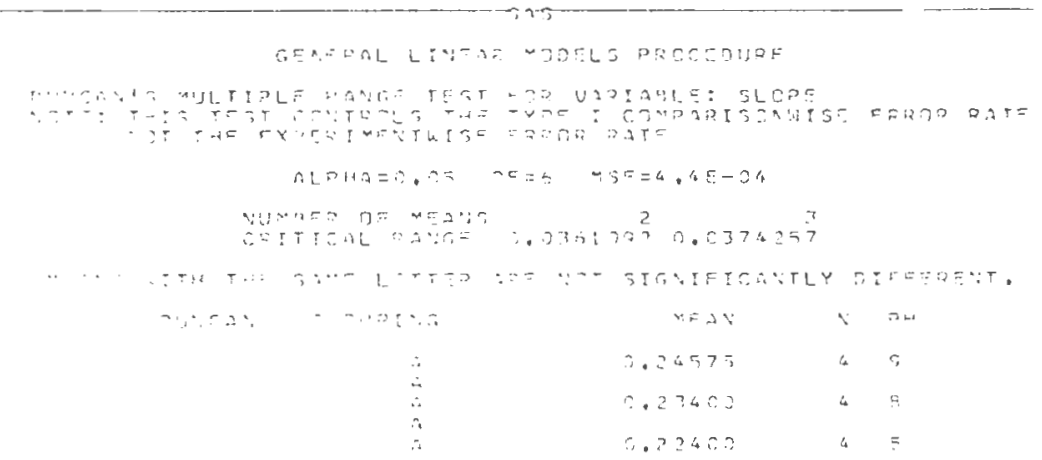


APPENDIX $F$ 
NONLIN: PROGRAMS AND RESULTS

As described in Manuscript II, the determination of the thermodynamic parameters using NONLIN, requires the use of three different programs: a datafile, a subroutine program and a Job control Language (JCL).

The following section contains the listing of the programs used for the four drugs considered in this study. An example of datafile is shown for phenytoin, ibuprofen, diazepam and hydrochlorothiazide, respectively. Two different listings of subroutine programs are then presented. The first set of programs was used for the complexation of the non-ionized species of the drug with cyclodextrins. These programs are given in the order: phenytoin, ibuprofen, diazepam and hydrochlorothiazide. Following is the listing of the subroutine program, used in the case of phenytoin and diazepam, for the complexation of the ionized species with cyclodextrins. Finally, an example of JCL program and a listing of a complete output of the NONLIN program are shown. 

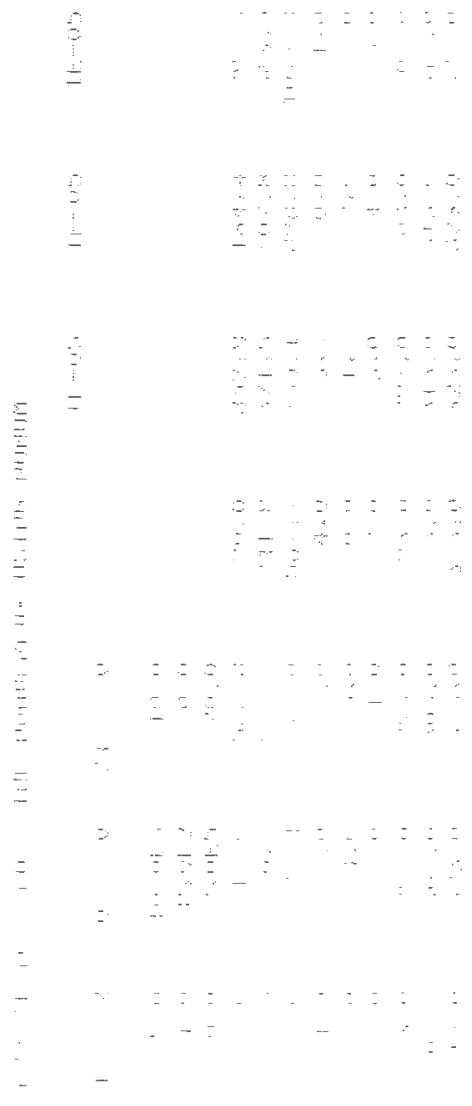

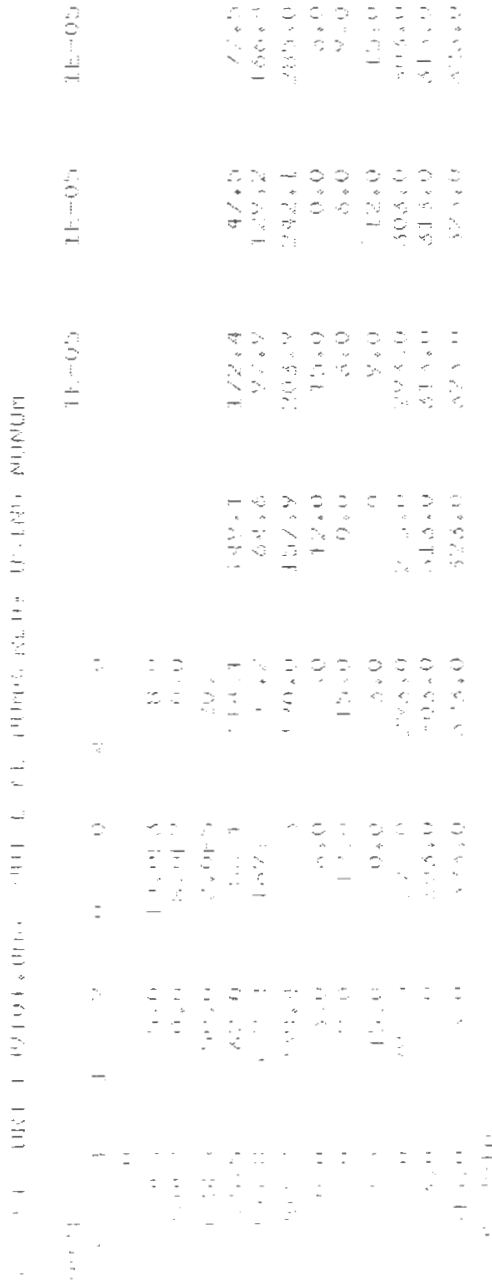

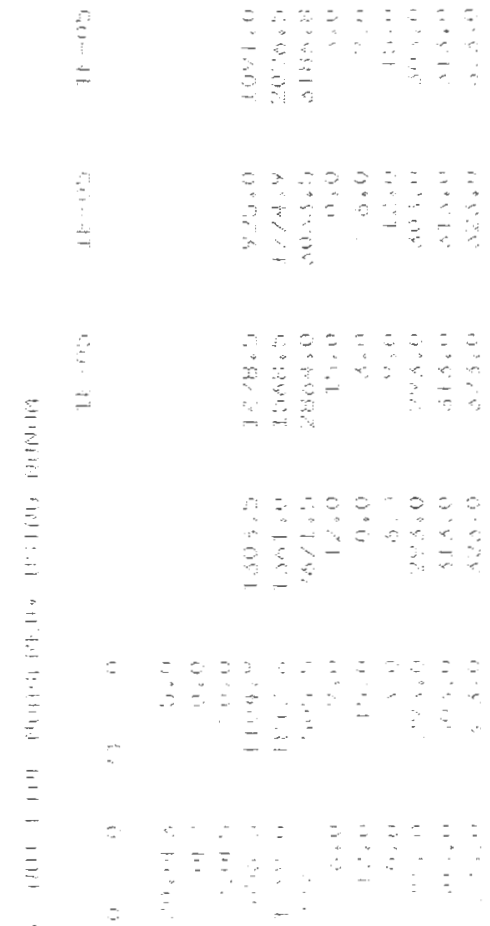


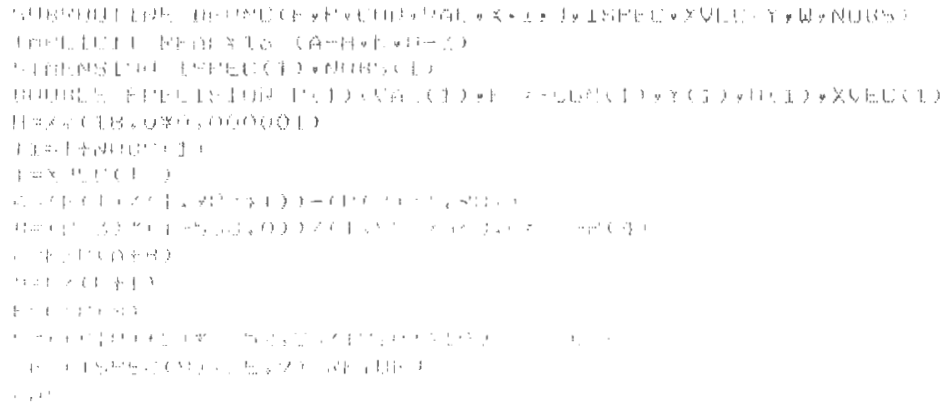




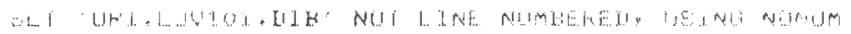

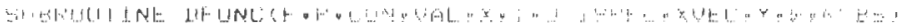

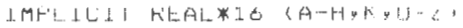

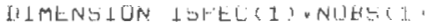

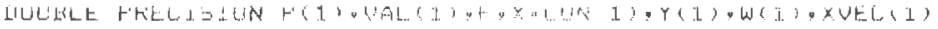
$H=x *(16,0 * 0.00000 \%)$

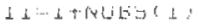

$1=x \cup t_{-} L ! 1:$

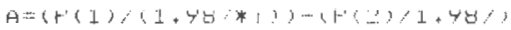

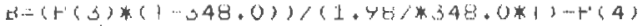

$\mathrm{L}=\mathrm{E} \times \mathrm{F}(\mathrm{A}+\mathrm{H})$

$1=\mathrm{t} ;(\mathrm{t}+1)$

$\mathrm{E}=\mathrm{E} \times \mathrm{X} \cdot \mathrm{CH})$

$1 \backsim+=((11 *+1)+t)+20 t+28 / 18+0) * 1000000+0$

IF $(1$ SHEC $(\theta), N E, 9)$ RE IURN

ENII 


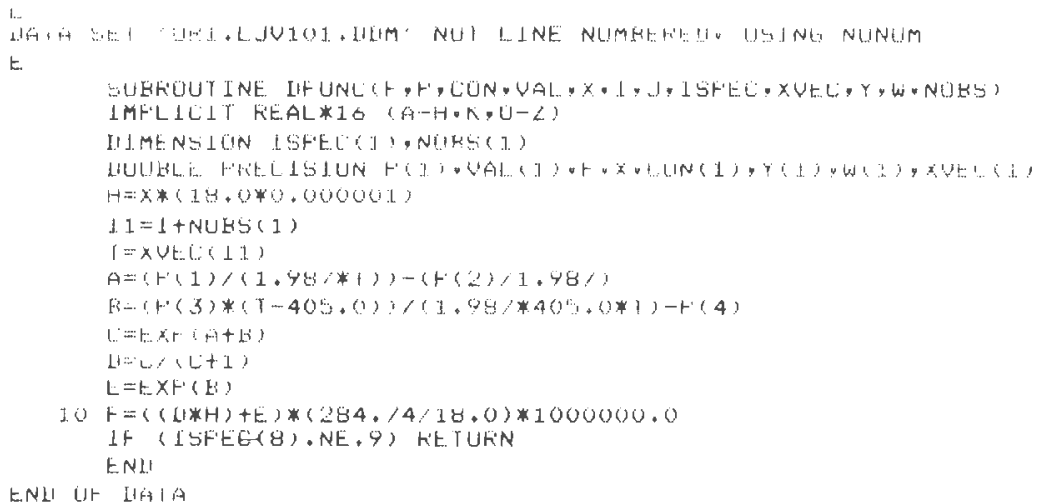




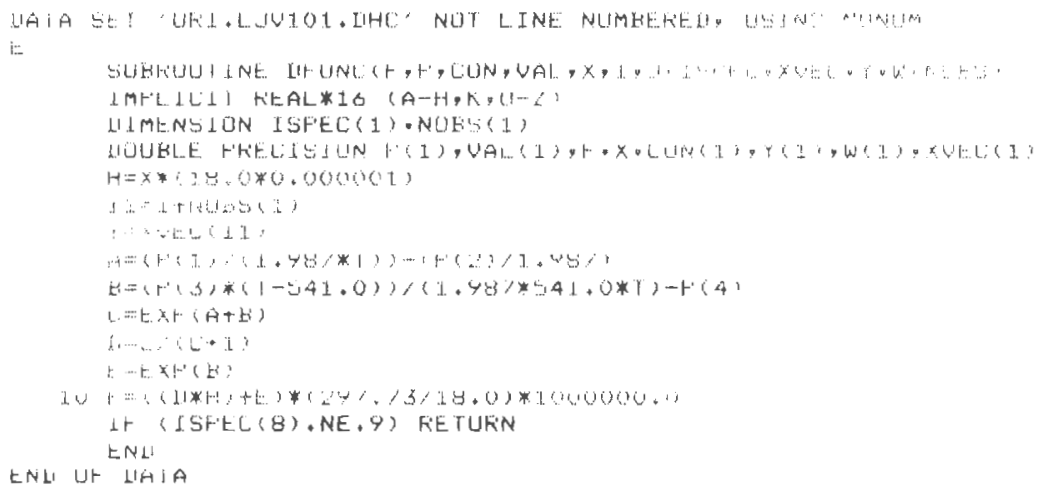


IHATA SEY 'URL, LJUIOI, IUNA' NUI LINE NUMBEKEW, USINLS NUNUM E.

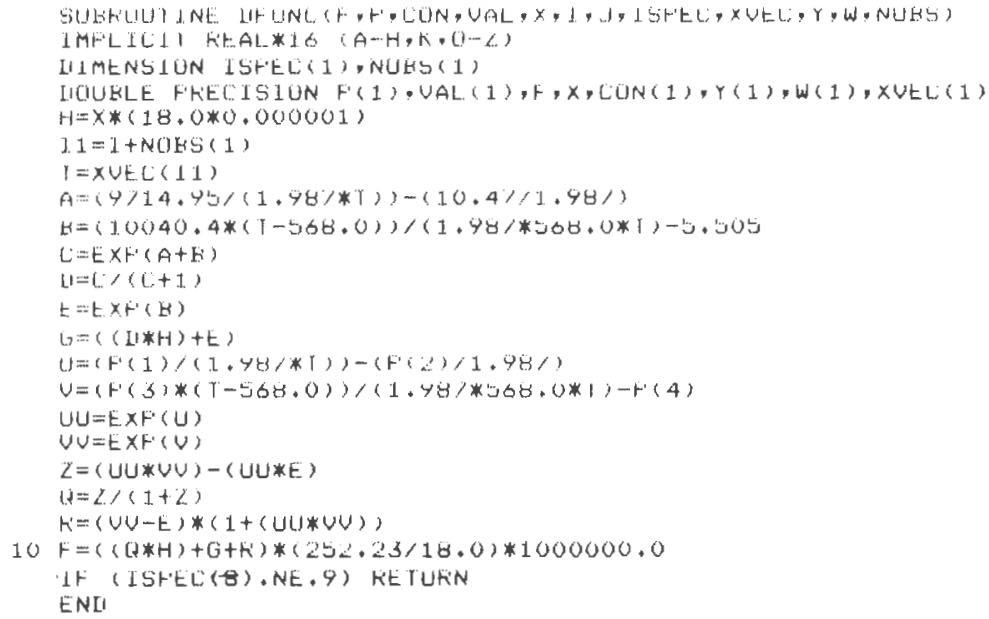


DIATA SEI 'UKI.L.JULO1. NUNL IN' NUI L JNE NUMBEREL', USING NUNUM $1=$

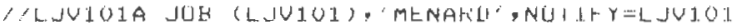

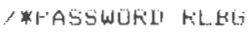

II EXEL: NUNLINFH, REULUN=:2048K

$\therefore /$ II LINC.SYSFRINT LII LUMMY

$\because$ LIF UNE D SYSTEKIM LII LUUMY

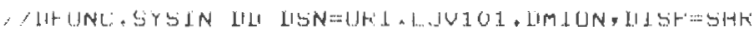

$\because$ LELEL.SYSHRINI IILI HLIMMY

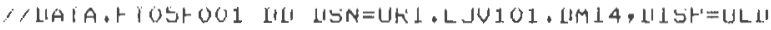

$\triangle I I A 1 A, F$ YOOFOOI III SYSOUT=A, HOLLI=YES ENL UF LIATA 


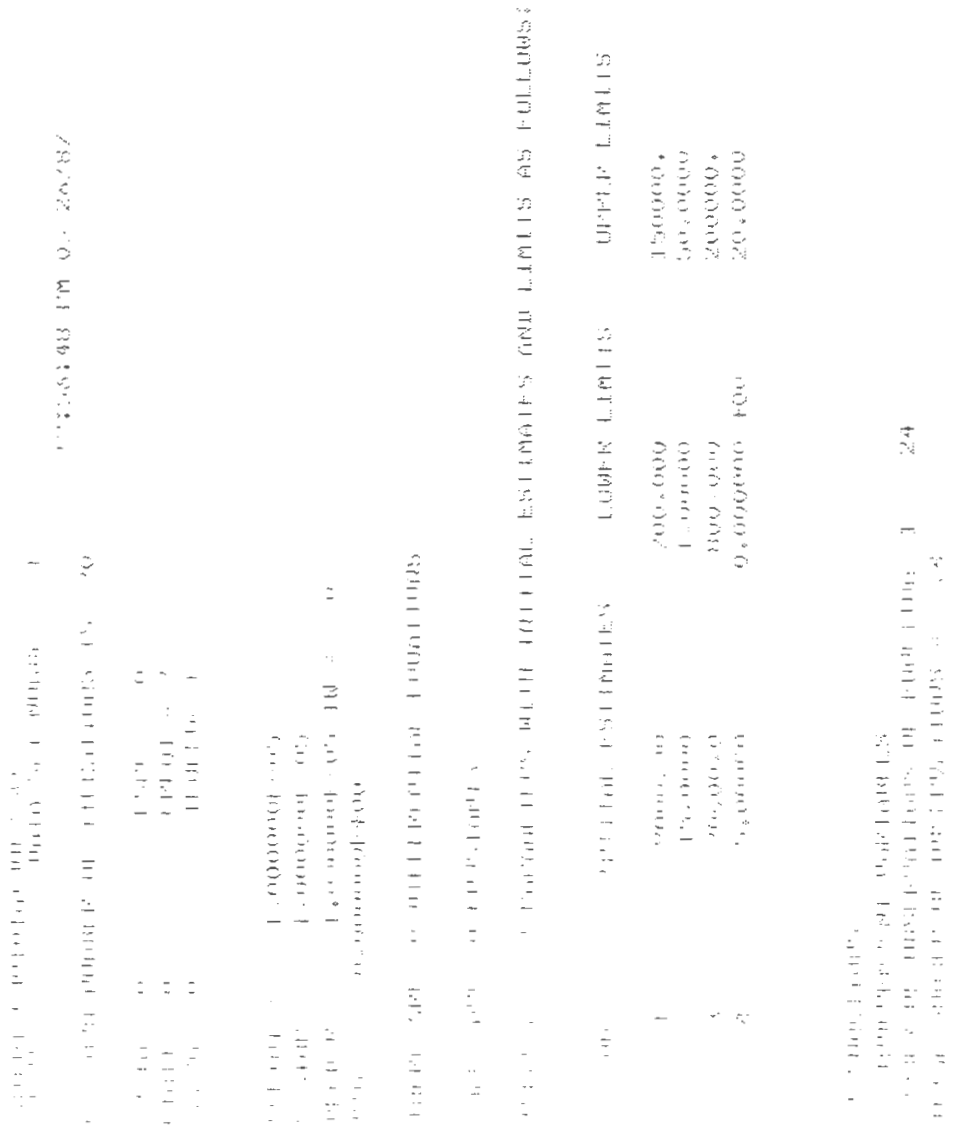




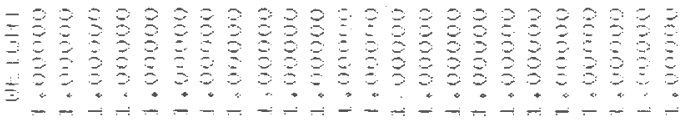

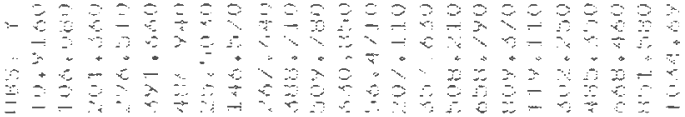
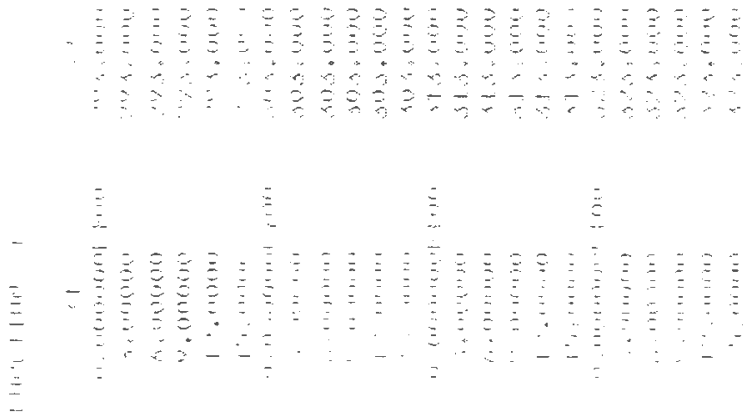


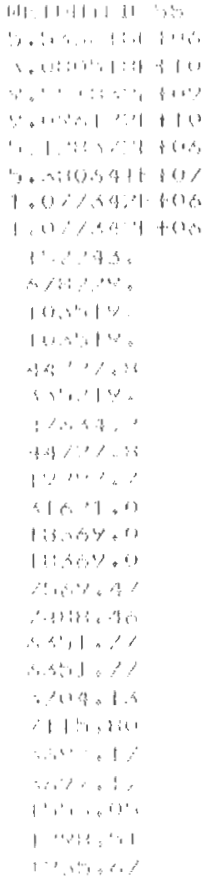

\begin{tabular}{|c|c|}
\hline$\cdots 19,10:$ & $1+\pi, d t$ \\
\hline $1 \cdot \because 1 / 1:+0)$ & 1.4 .64 \\
\hline $1.1 \therefore t^{2} 1+104$ & $14,2$. \\
\hline $1: \therefore 11,1,+14$ & 14.01 \\
\hline$\because 4 / 3$ & $14+4 y$ \\
\hline 1. (1) & 14.14 \\
\hline $8.70(0)+10+04$ & 14.83 \\
\hline $1.03: 301: 31 .+1,44$ & 14.62 \\
\hline$\because 40 \%$ & $10, \cdots 6$ \\
\hline $3+01$. & $6 \cdot y+3$ \\
\hline$\because 23$ & $10: 11 \%$ \\
\hline$y+34$. & $10+0.3$ \\
\hline$a: a i b y$. & $1.8 \div 1$ \\
\hline $9.44 x^{2}$ & $6,0,1,3)$ \\
\hline $\left.3 x^{3}\right) 44$ & $(1, \cdots y$, \\
\hline $124 \%$ & 1.4 .21 \\
\hline Malibis & 1.400 \\
\hline$(\because \cdots \%$ & 0.346 \\
\hline 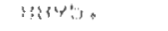 & 1.611 \\
\hline istorit. &,$\ldots 11$ \\
\hline $314 /$ & $1,2,3$ \\
\hline yatis. & $H+\therefore()\}$ \\
\hline 12100 & $1+y\{\leq\}$ \\
\hline $4 \therefore 16$ & $1+985$ \\
\hline$\because, x_{4}, 4$ & $B+A y$ \\
\hline$\because 5,6=$ & $y+6,5.2$ \\
\hline 91303 & Ho $\langle 4$ \\
\hline$y+4:$ & 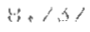 \\
\hline "'> & $y \cdot 2>4$ \\
\hline$\because 40$ & $4.82 \%$ \\
\hline 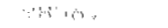 & $y+0 \therefore 0$ \\
\hline
\end{tabular}

\begin{tabular}{|c|c|}
\hline$\therefore \cdot 00+10\}+04$ & $\therefore(n) 0$, \\
\hline$\therefore 9+8$. & $4 \cdot 1.46$ \\
\hline $7.5 .: y^{\prime}$ & 4.344 \\
\hline $1 / 36$. & $4 \phi+124$ \\
\hline $1.23,1+2+4$ & $4 . / 44$ \\
\hline$(2,60$. & 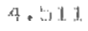 \\
\hline 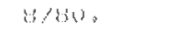 & 4.048 \\
\hline $3 / 30$. & $4 . \therefore 36$ \\
\hline $1+04 / 60+04$ & 3.635 \\
\hline $1.25,5010+4$ & $3 \cdot 1,6$ \\
\hline $1+0 \%(1)+04$ & $5+6.60$ \\
\hline $1+(1 / 2), 4+04$ & 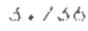 \\
\hline $1+21,31: 104$ & .3 .013 .5 \\
\hline 1. $.16491 \%+04$ & $\because 483$ \\
\hline $1.10 .1 \ldots+4$ & $3.5,2,4 \times 4$ \\
\hline $1 . \because 1.501+04$ & 5.083 \\
\hline $1+50+441+04$ & $\therefore 2.64+6$ \\
\hline $1.406 / 1+04$ & $\therefore+23$ \\
\hline $1.920,0+0+0\}$ & $2 x+10$ \\
\hline $1.52+2: 1004$ & $2+6 / 1$ \\
\hline $1, x+16+6+04$ & $\therefore 8: 6 y$ \\
\hline 1. $426801 \%, 84$ & 1. ryist \\
\hline $1.41641,1 \% t$ & $\therefore 1 \therefore$ \\
\hline 1. $431.6<1+04$ & $\therefore \cdot 1 \%$ \\
\hline 1. $4+1+204$ & 1.412 \\
\hline $1.446,16044$ & $1+/ 1.1$ \\
\hline 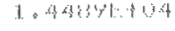 & 1.421 \\
\hline I. $4408 y 1.004$ & $1 . y^{\prime}+1$ \\
\hline 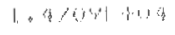 & $1 . / 30$ \\
\hline 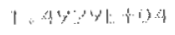 & $1.69 \%$ \\
\hline 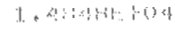 & i. .01 \\
\hline
\end{tabular}




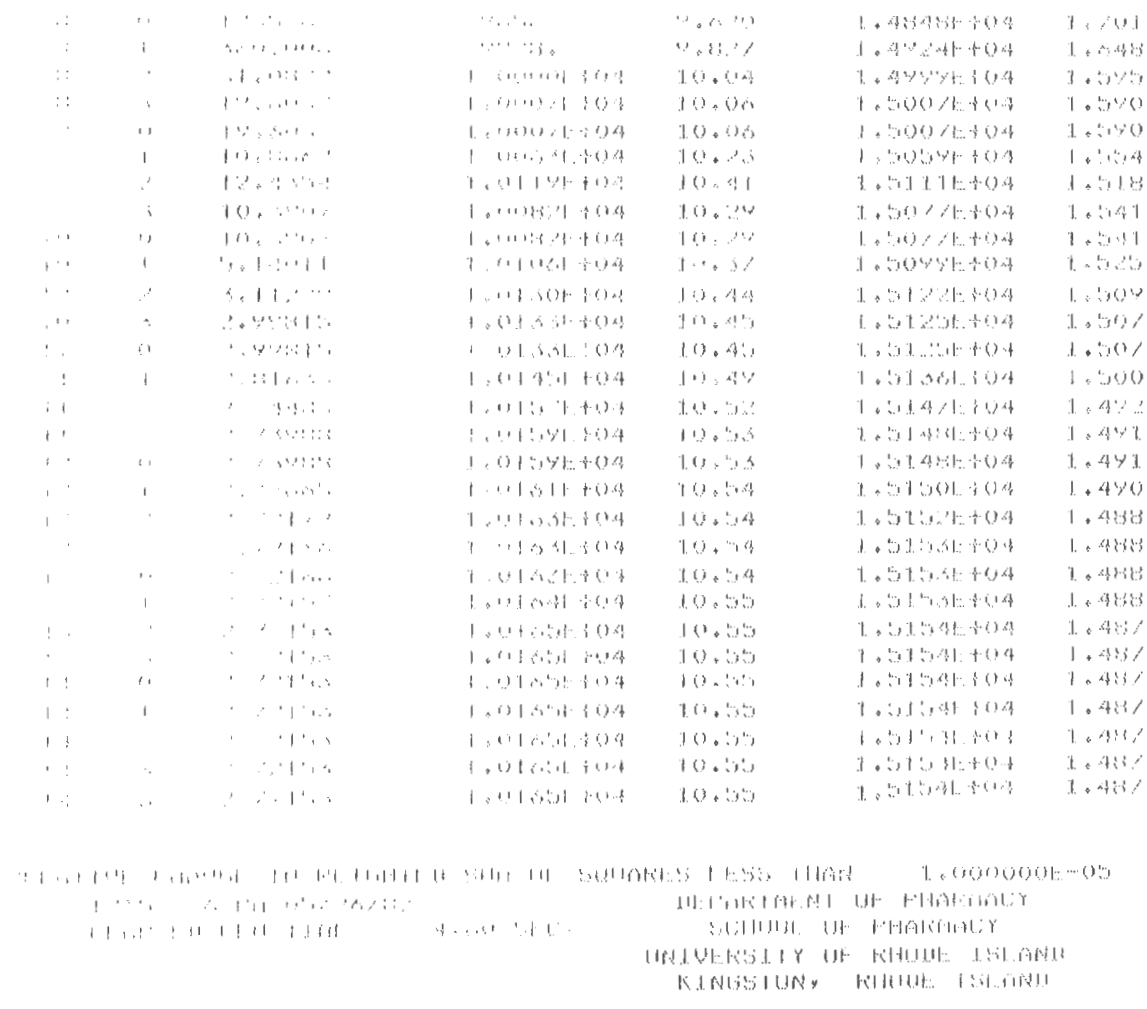


$=\quad 0=00 \%=0 \%$

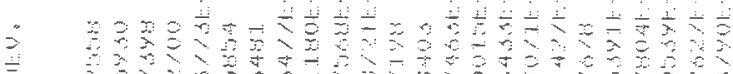

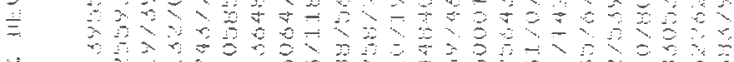

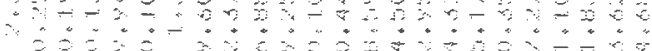

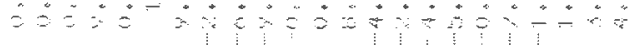

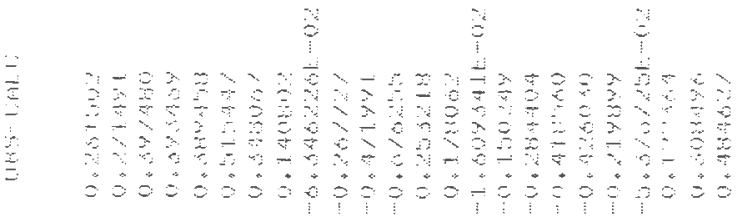

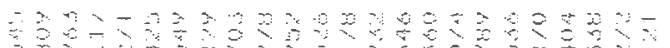

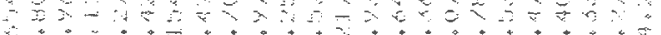

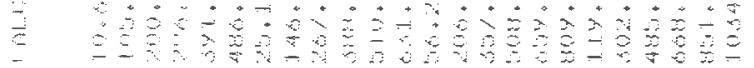

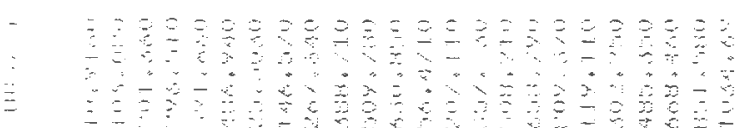

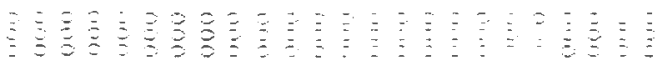

30
0
0

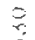

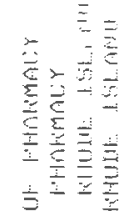

然

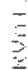

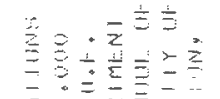$$
\begin{aligned}
& \overline{5}=5 \equiv= \\
& 5-5=0 \\
& 3= \pm
\end{aligned}
$$

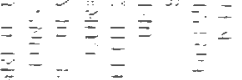

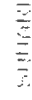$$
\equiv
$$

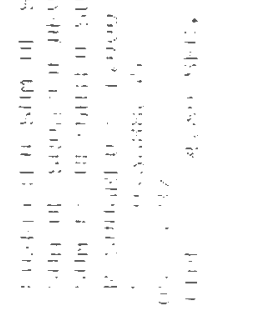

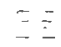




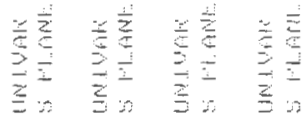
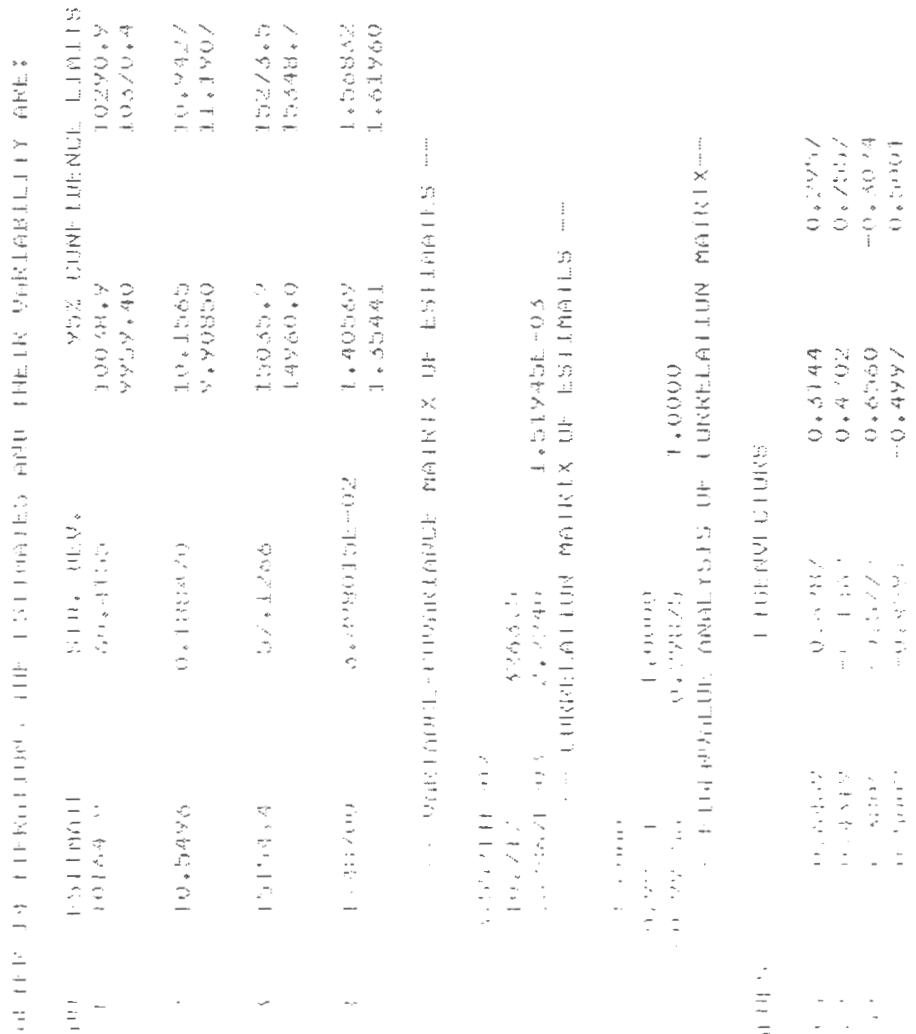
APPENDIX G 


\title{
SASGRAPH: PROGRAMS AND RESULTS
}

\begin{abstract}
The data of drug solubility as a function of cyclodextrin concentration and temperature were plotted using a SASGRAPH program. An example of the programs used is shown in this section for each of the drugs studied: phenytoin, ibuprofen, diazepam and hydrochlorothiazide. The results of the three-dimensional plots are then shown in the following order:
\end{abstract}

1. Phenytoin: $\beta \mathrm{CD}$ : $\mathrm{pH} 5,7,8$ and 9

2. Ibuprofen: $\beta \mathrm{CD}$ : $\mathrm{pH} 2,4,5$ and 6

3. Diazepam: $\quad \beta C D: p H 2,3,4$ and 6

4. Hydrochlorothiazide: $\beta \mathrm{CD}: \mathrm{pH} 5,8$ and 9 


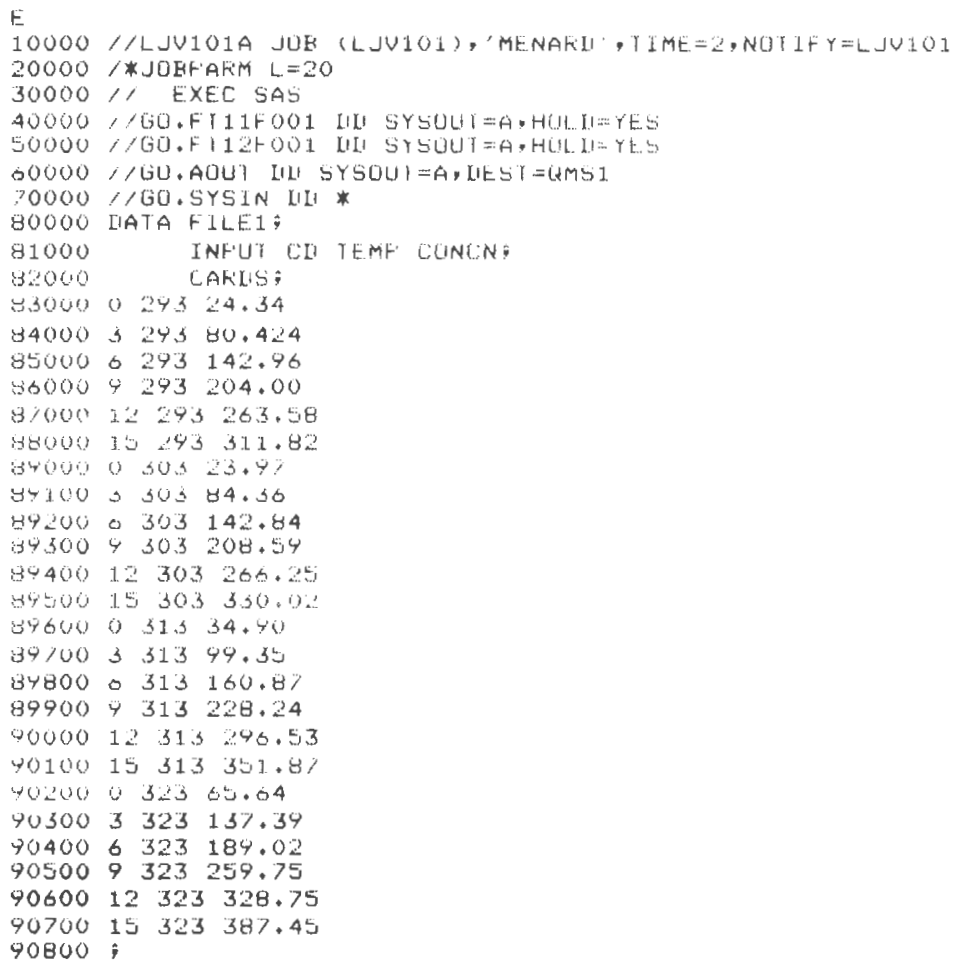




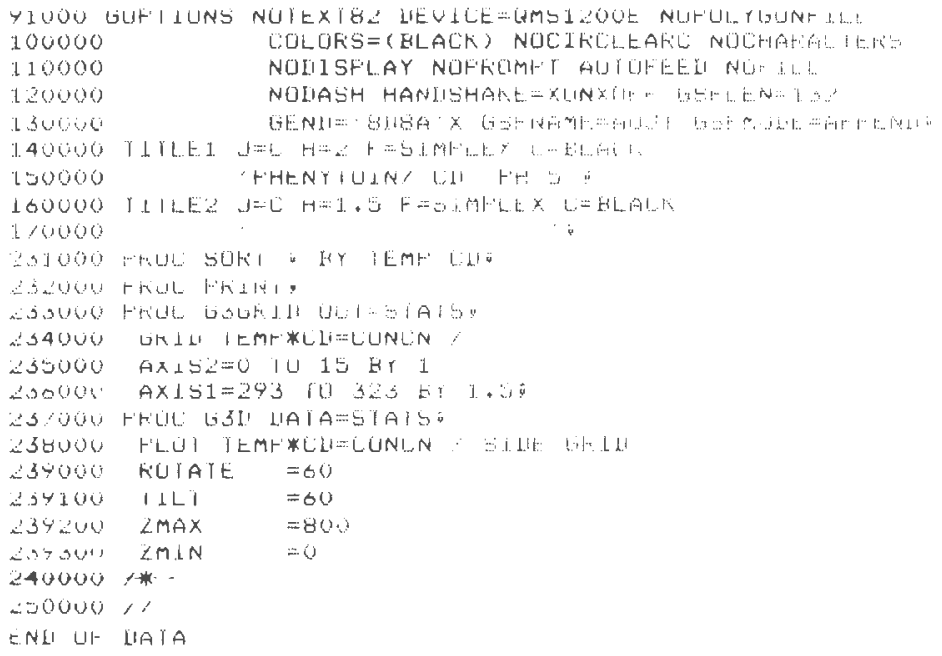




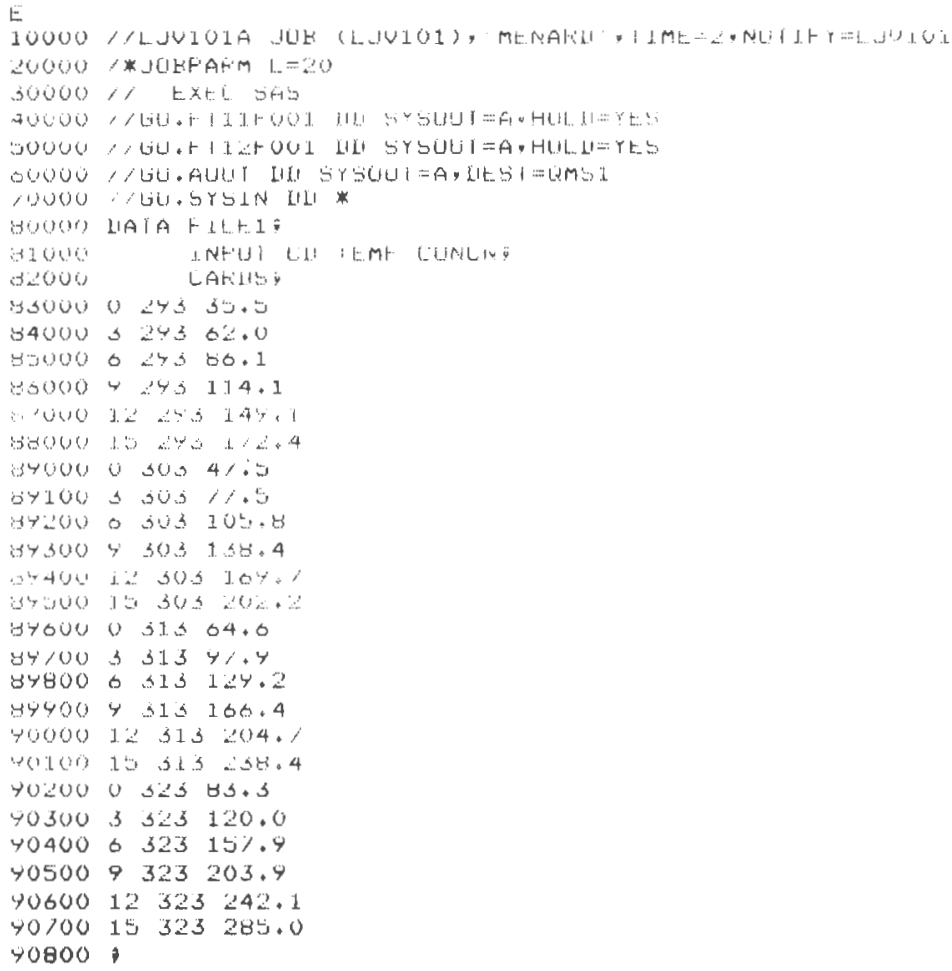




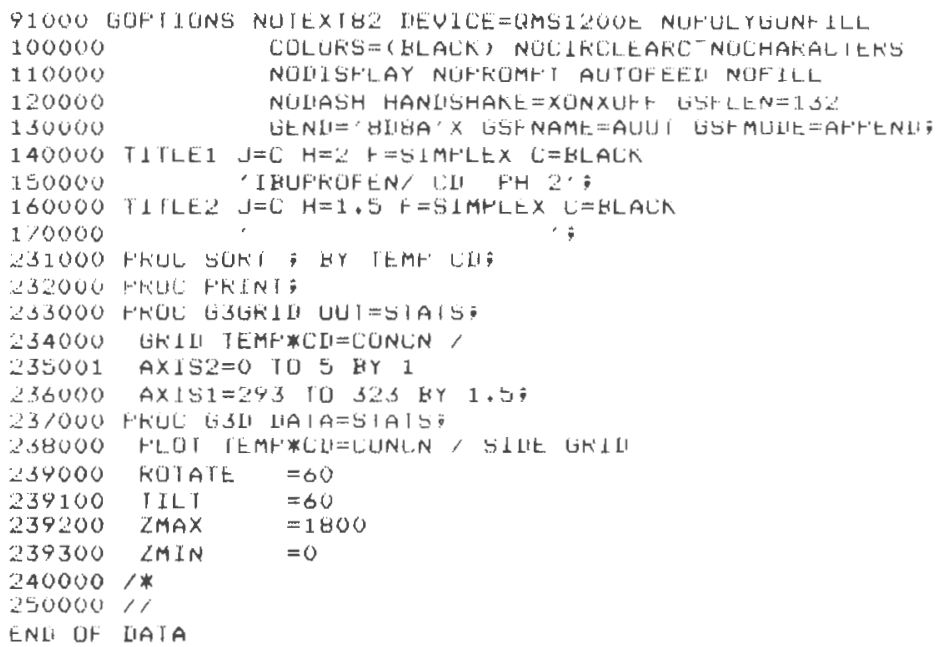




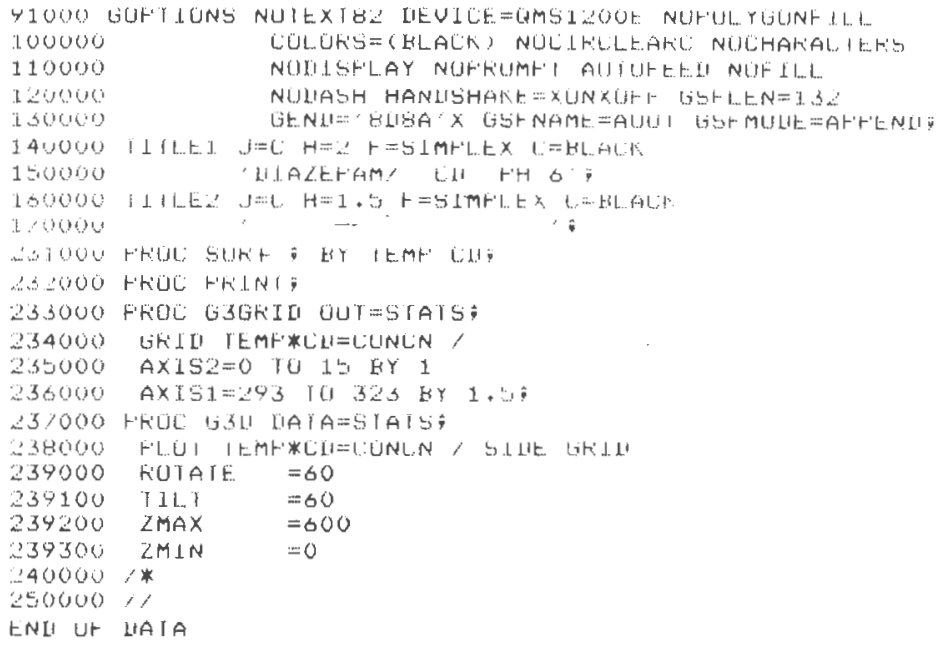




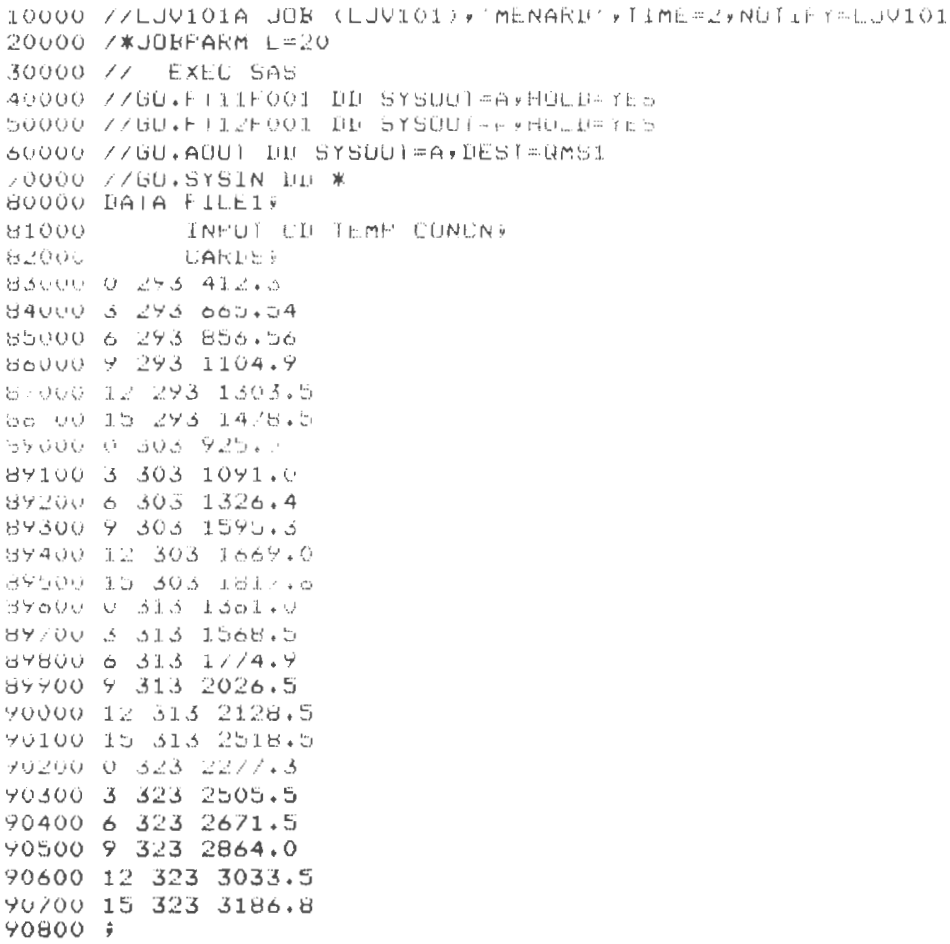




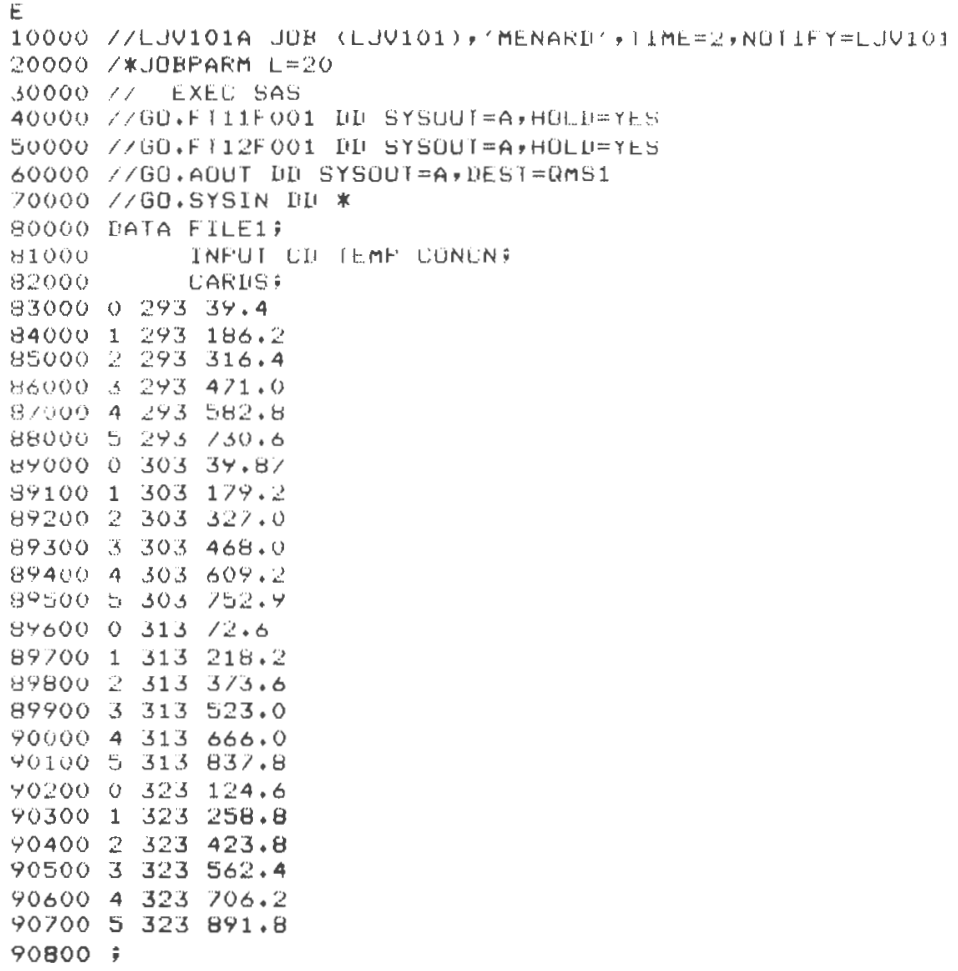




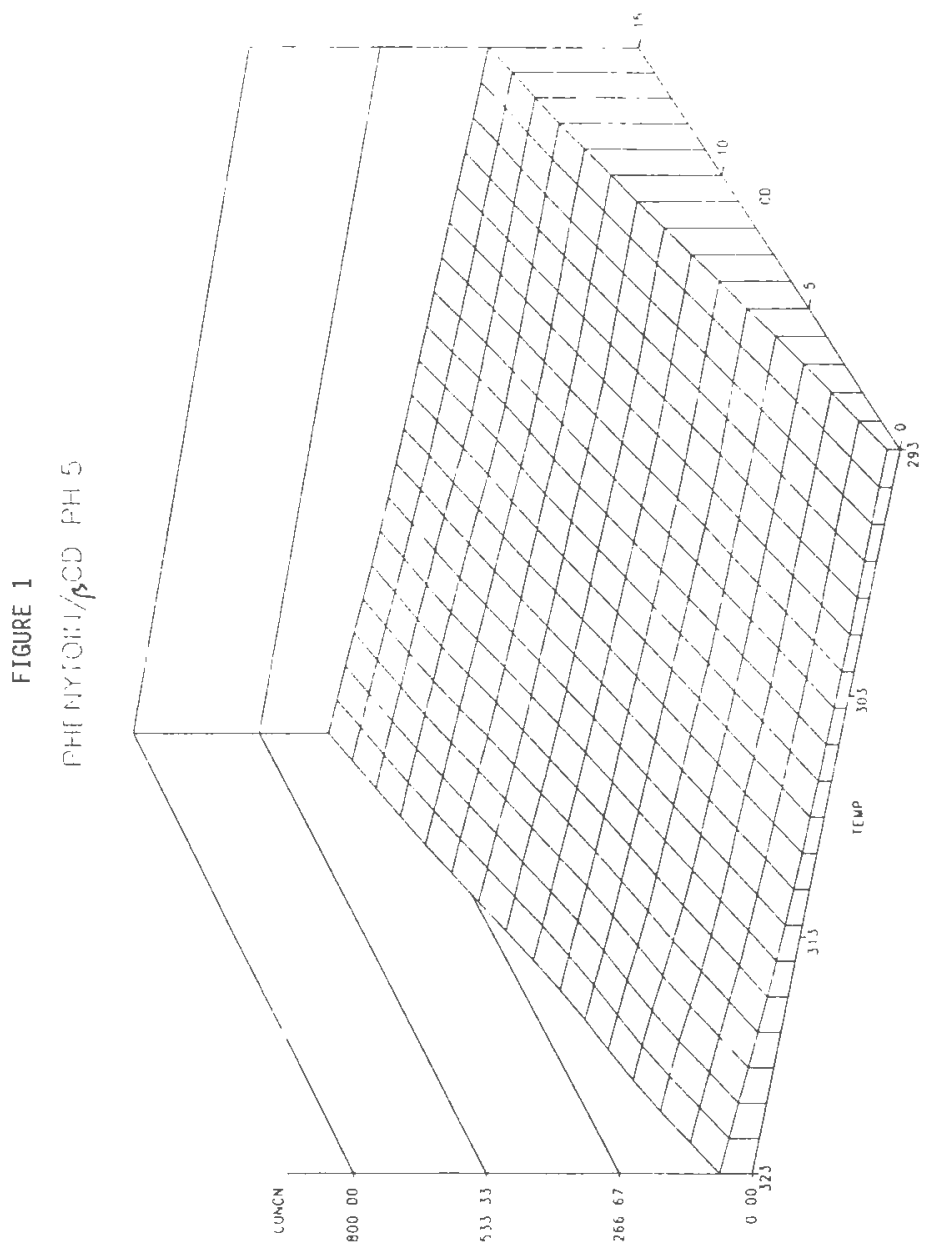




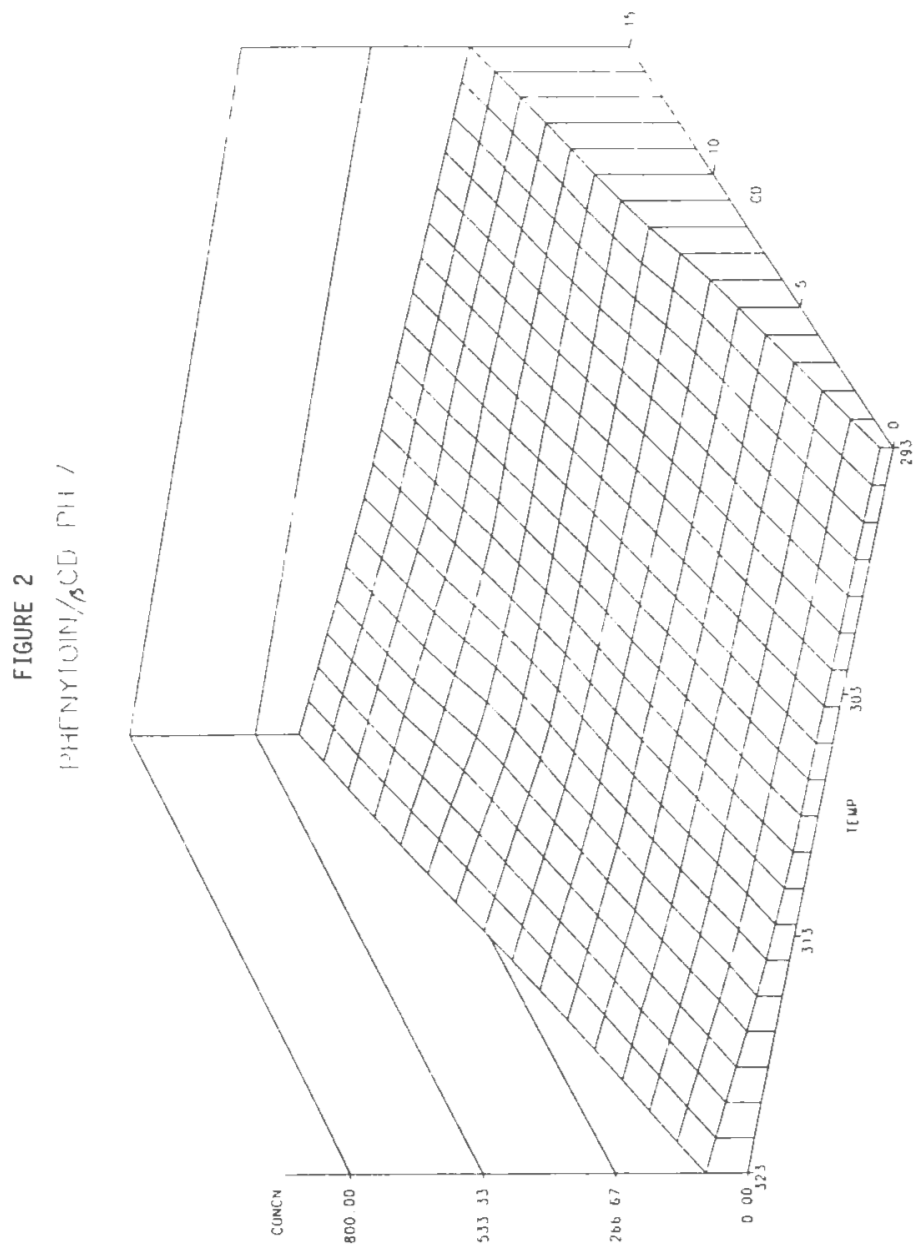




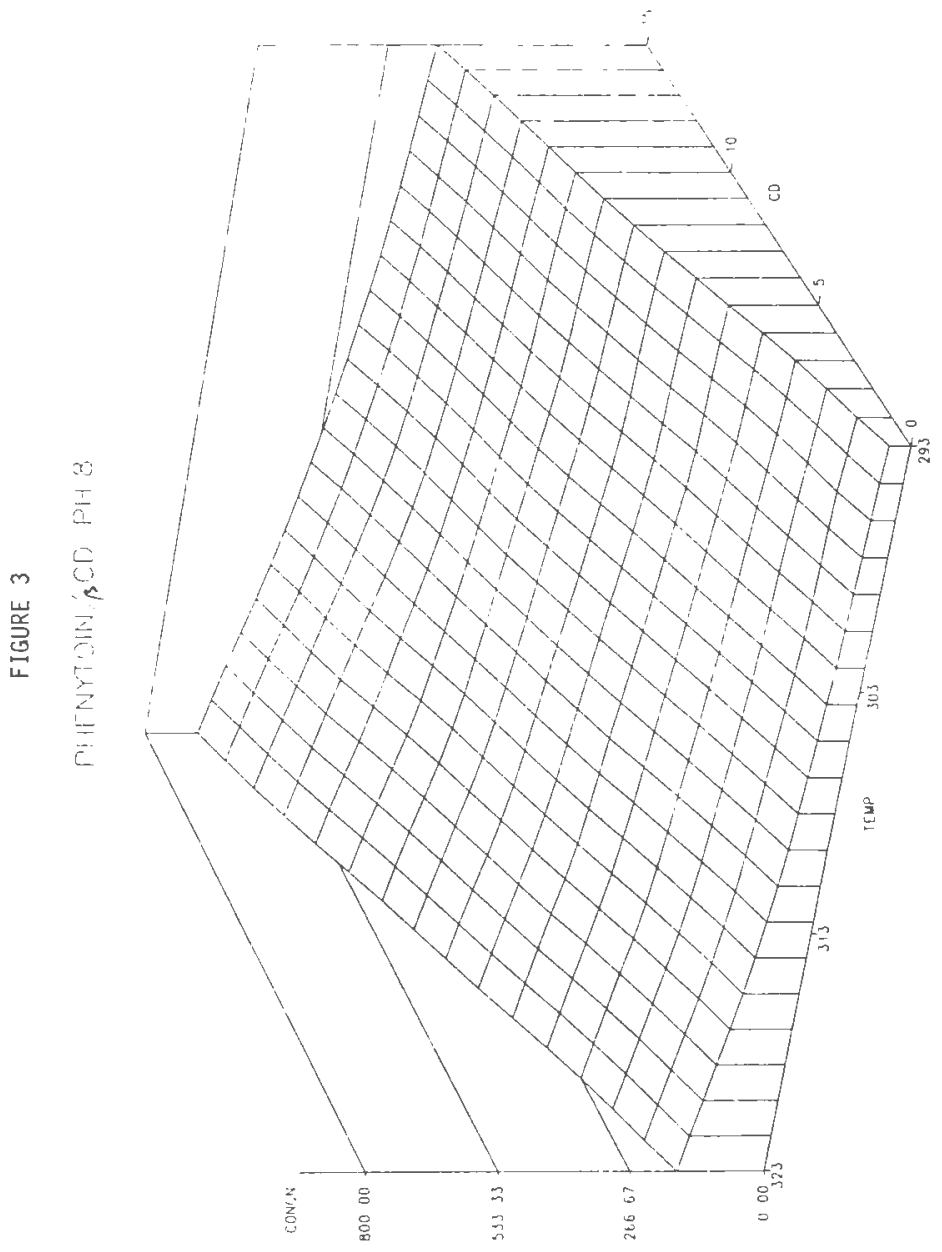




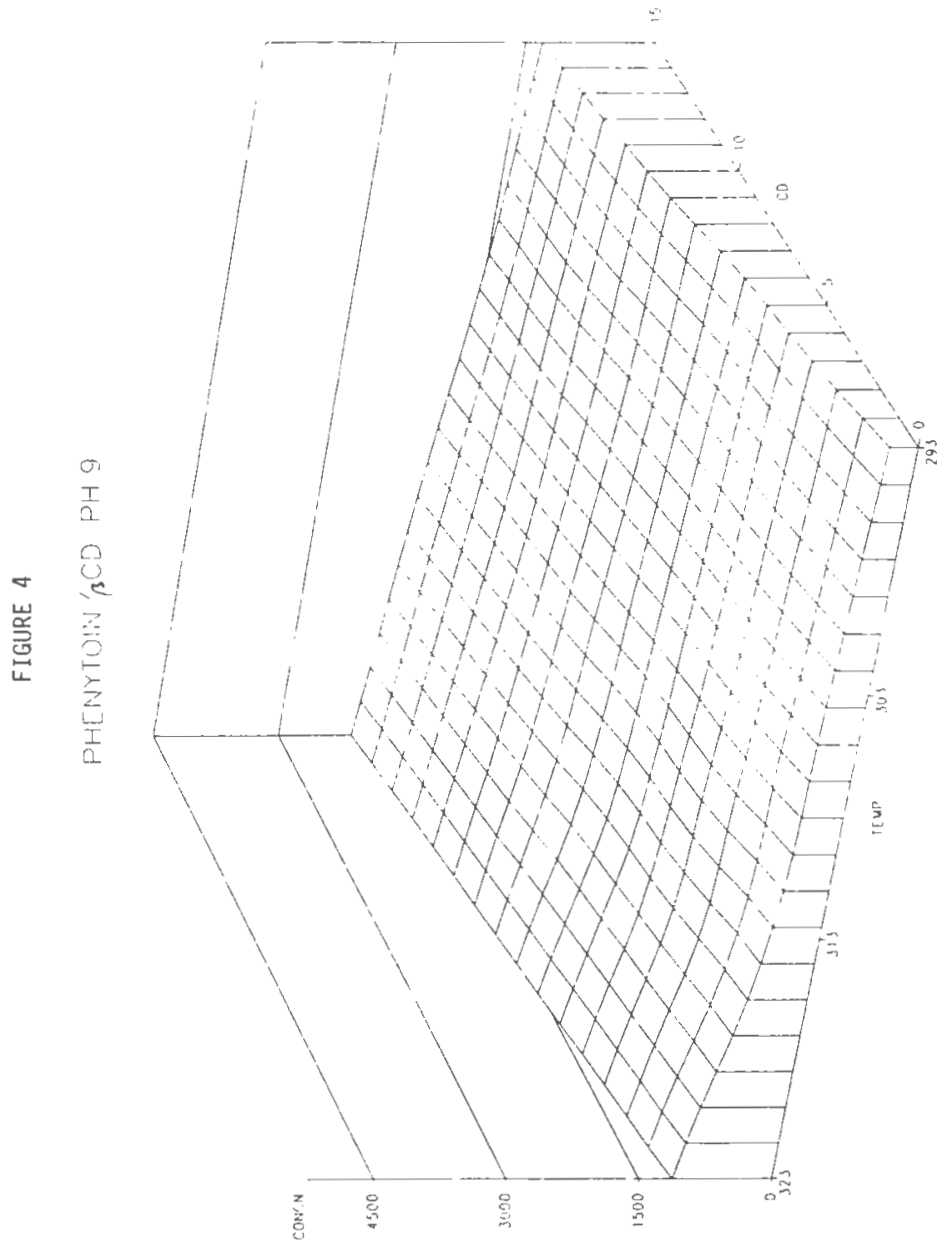




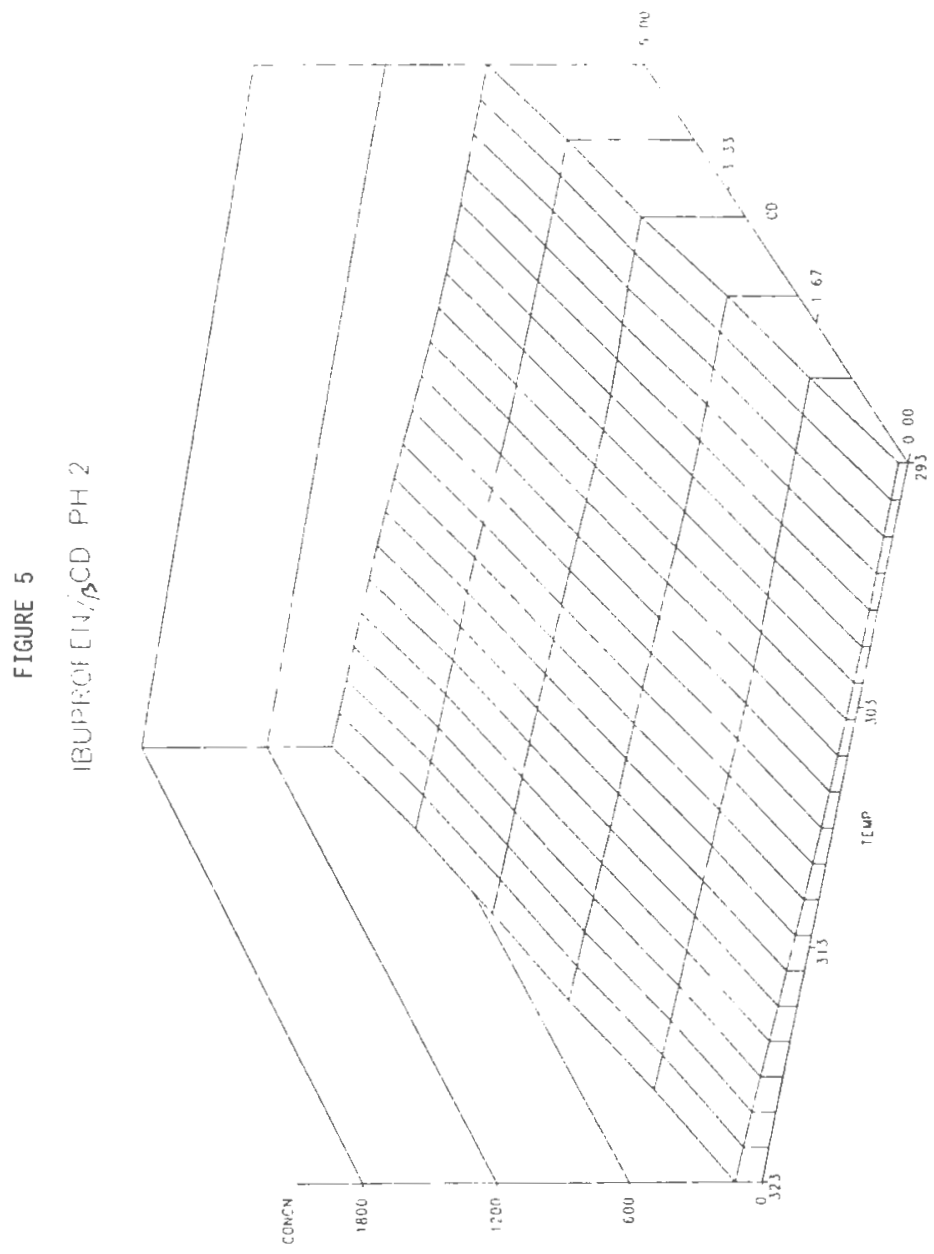




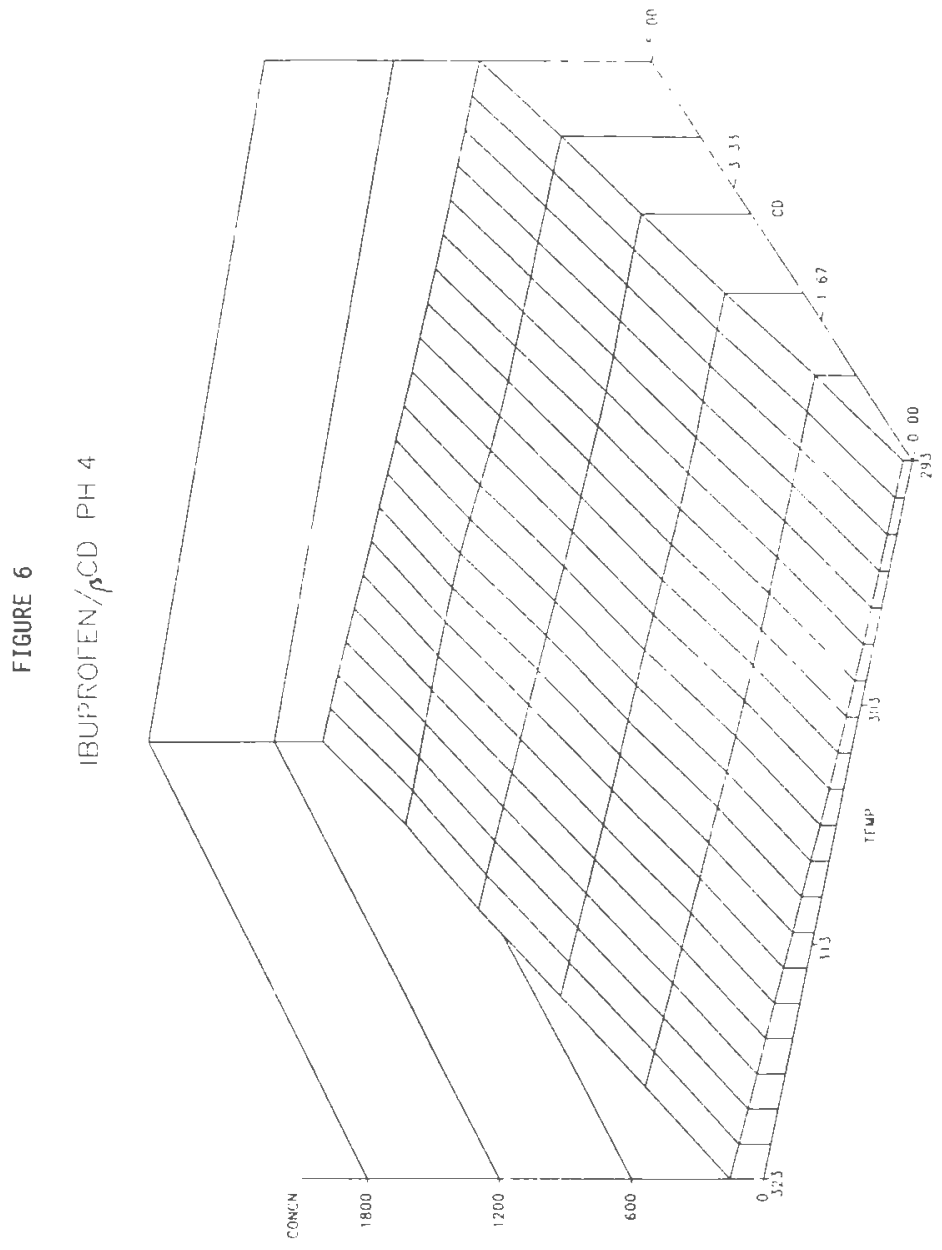




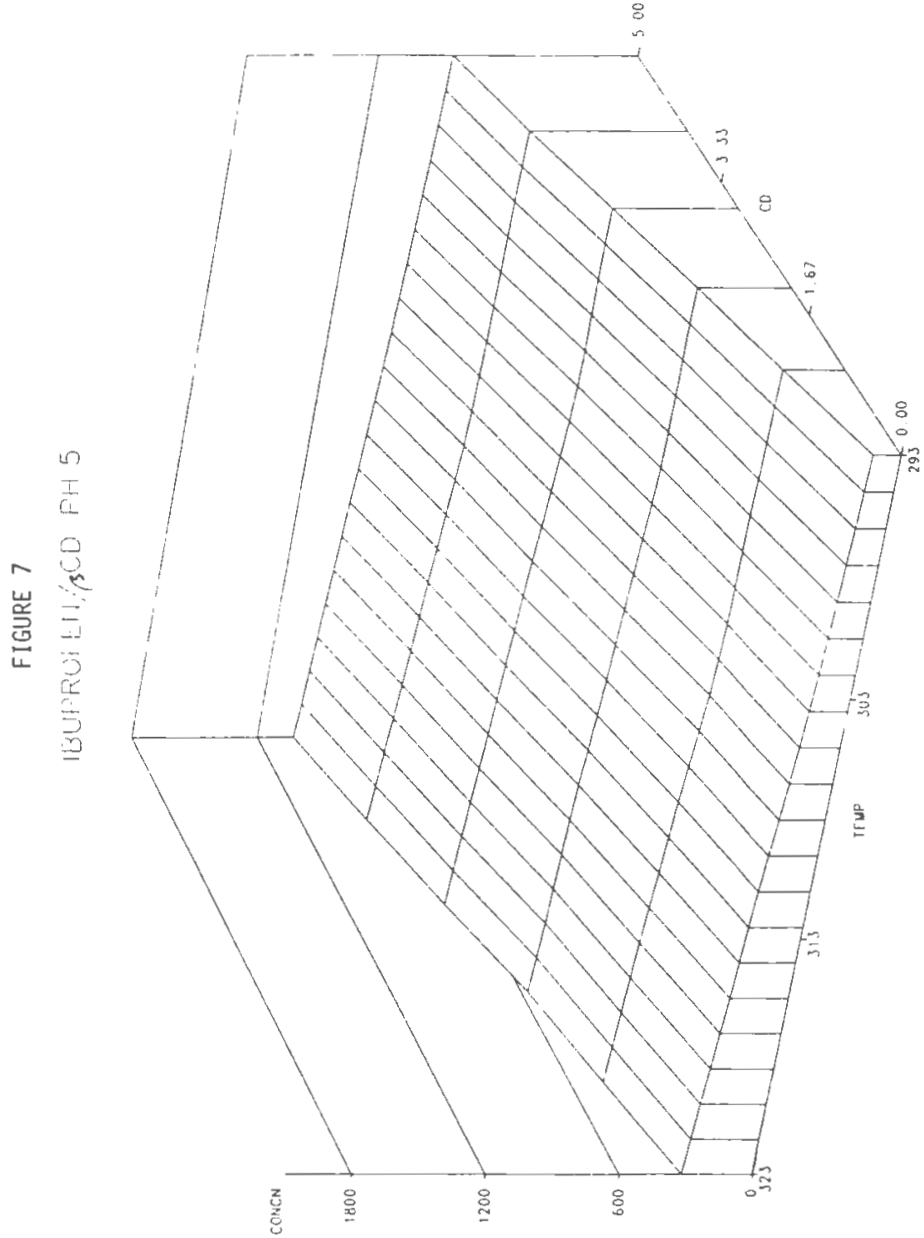




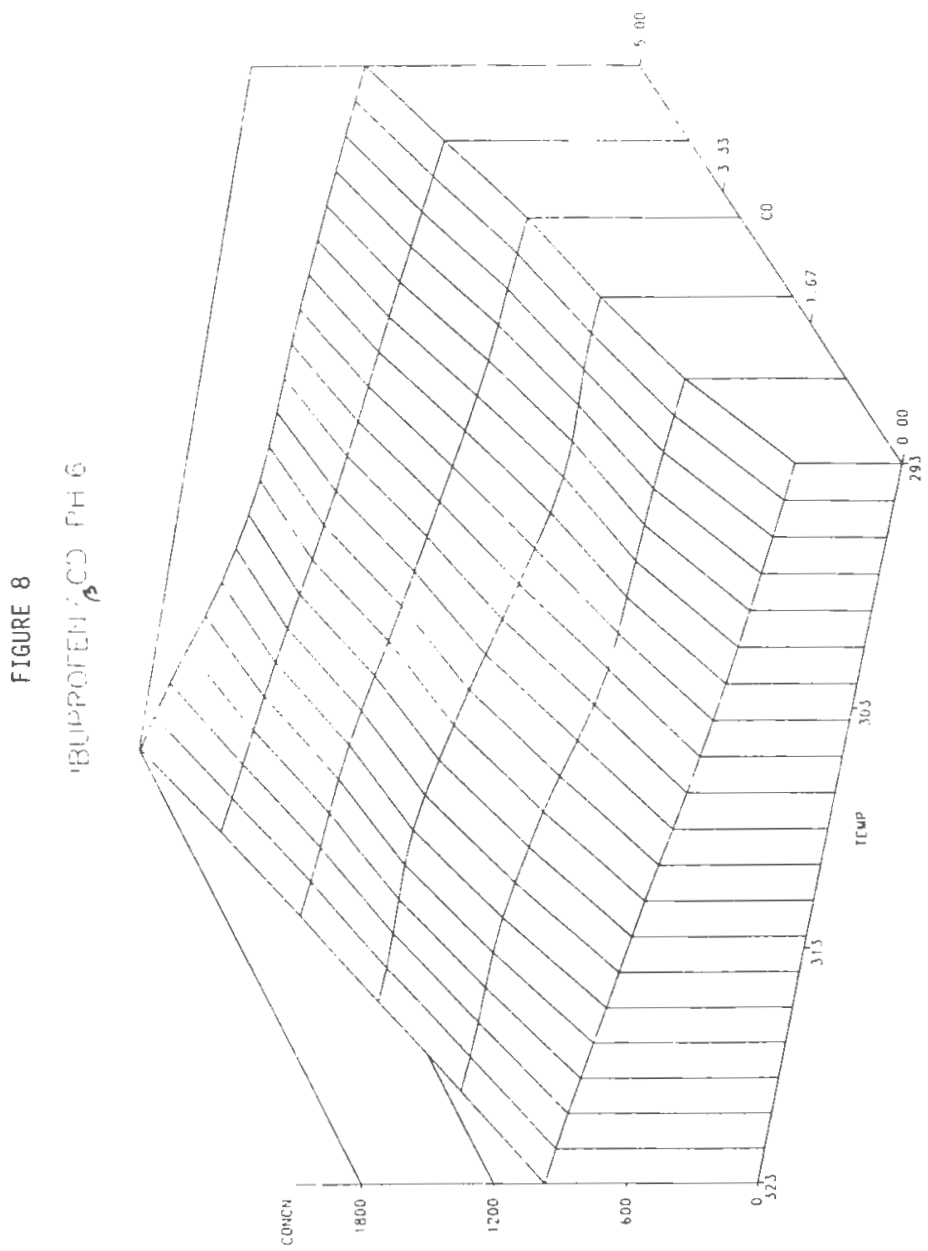




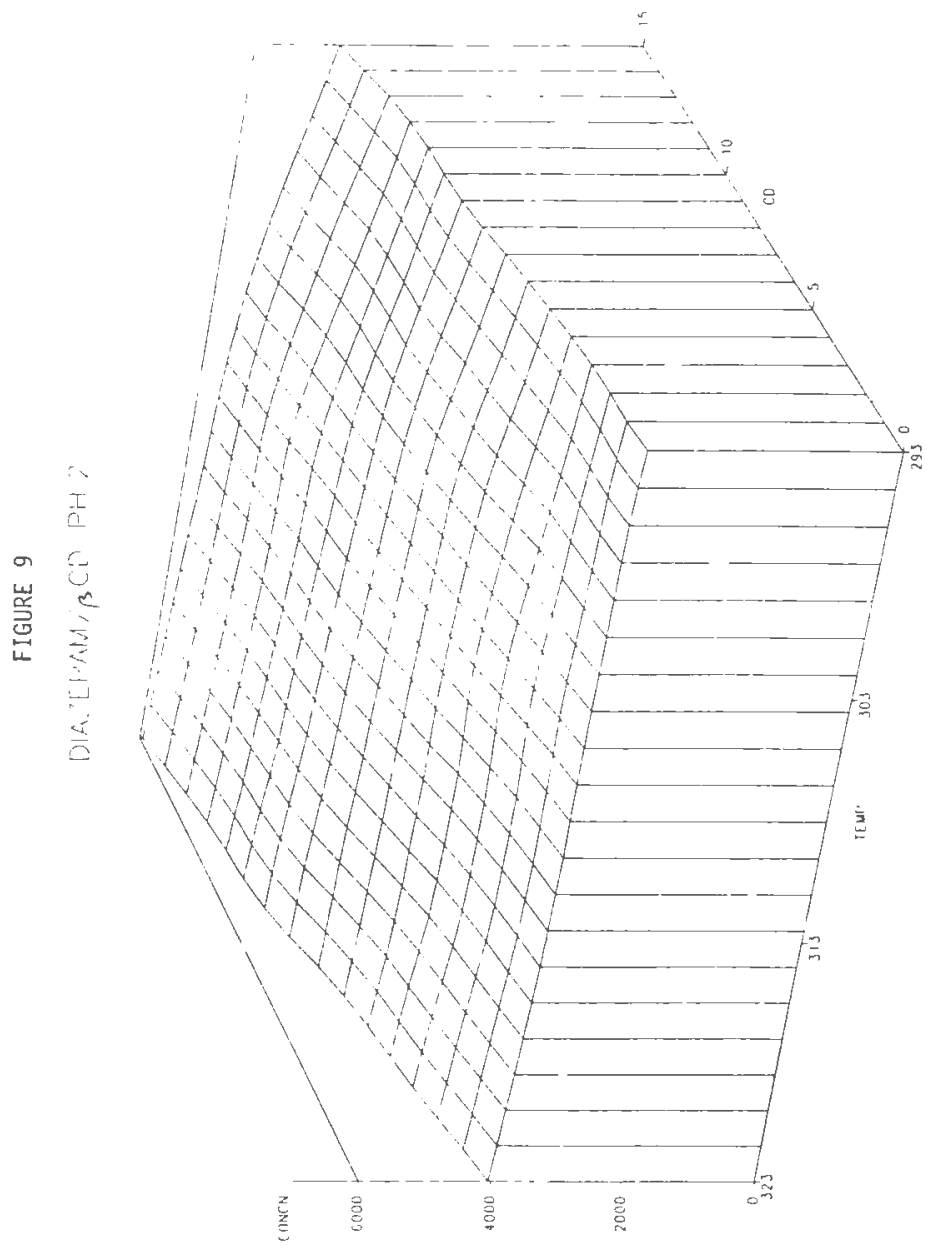




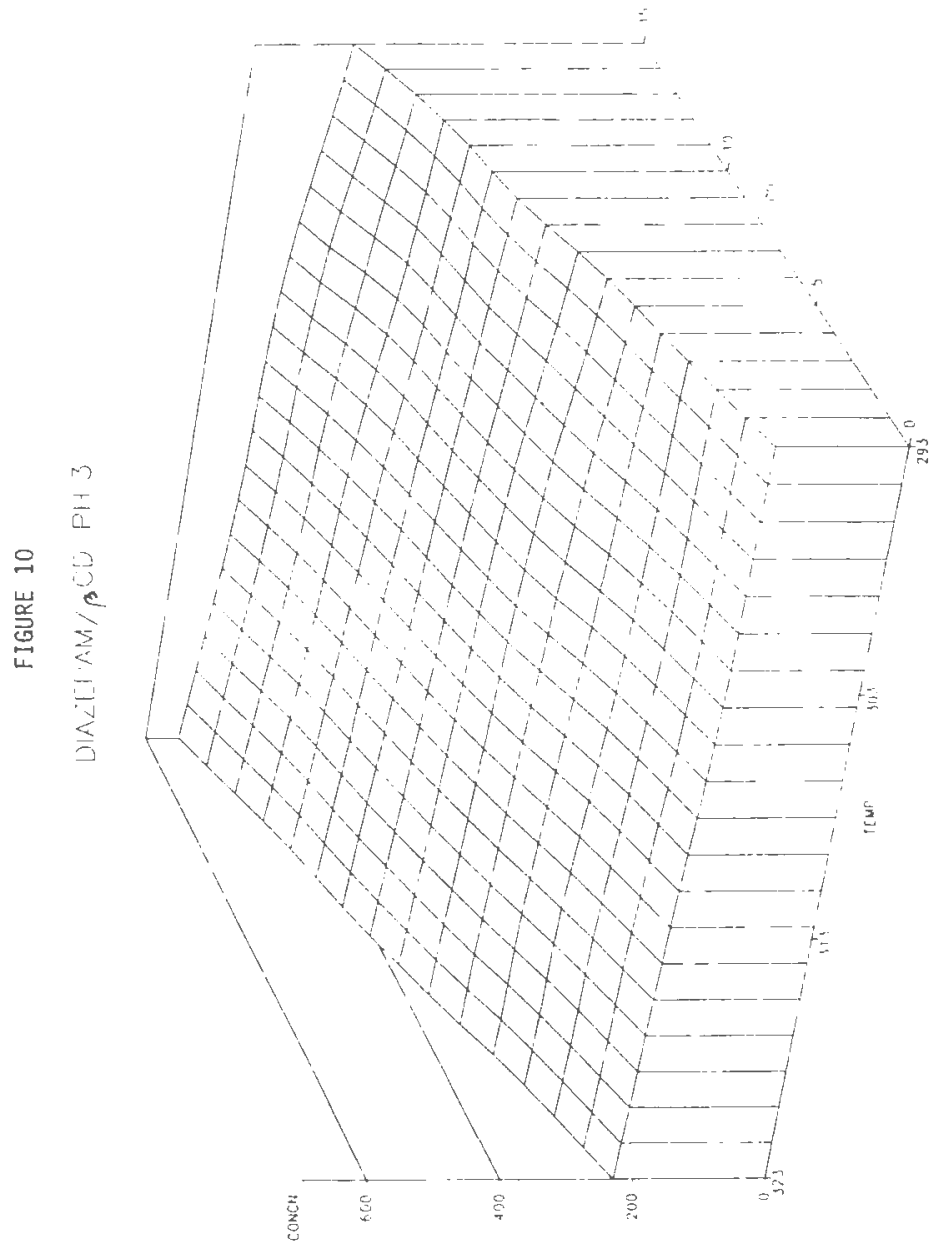




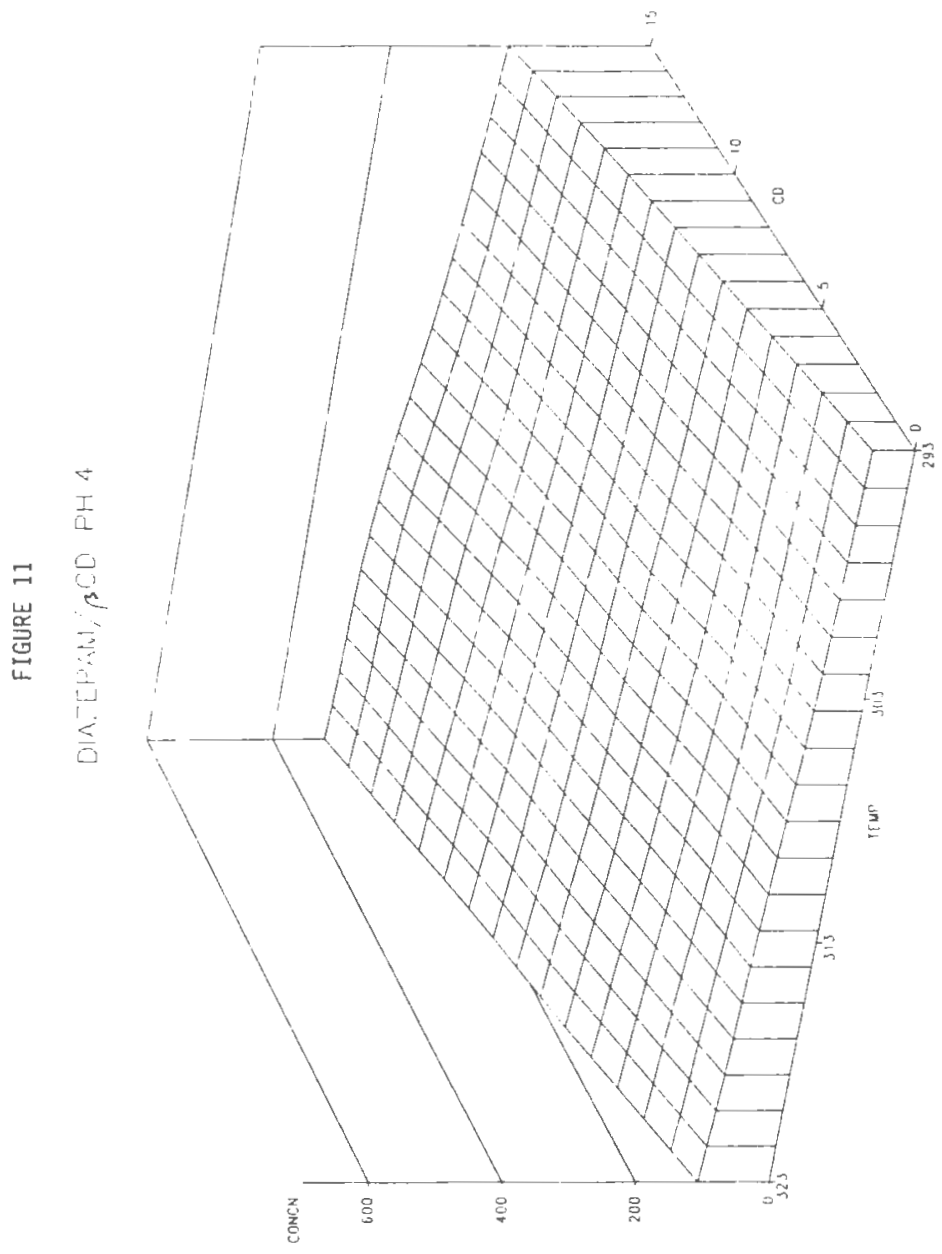




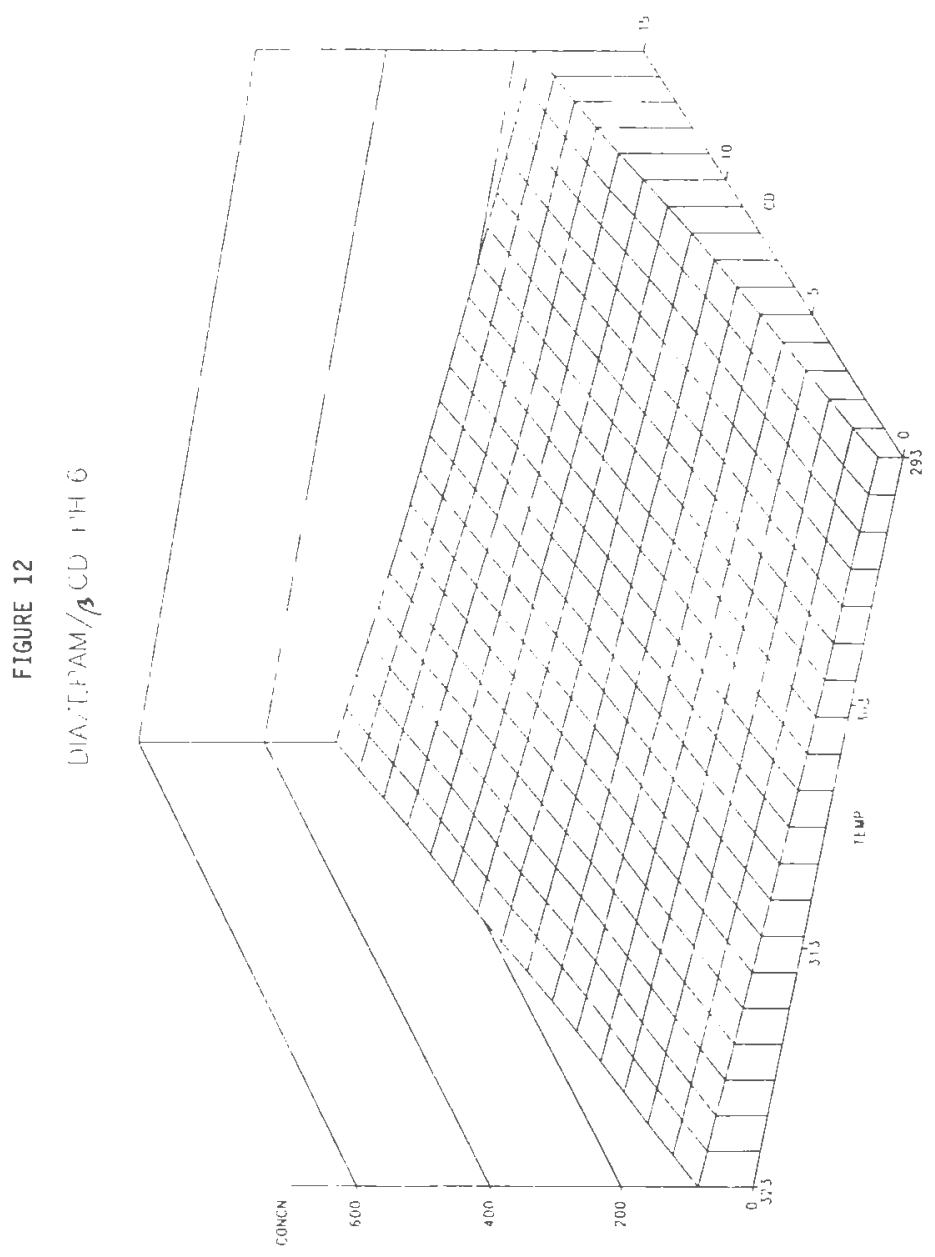




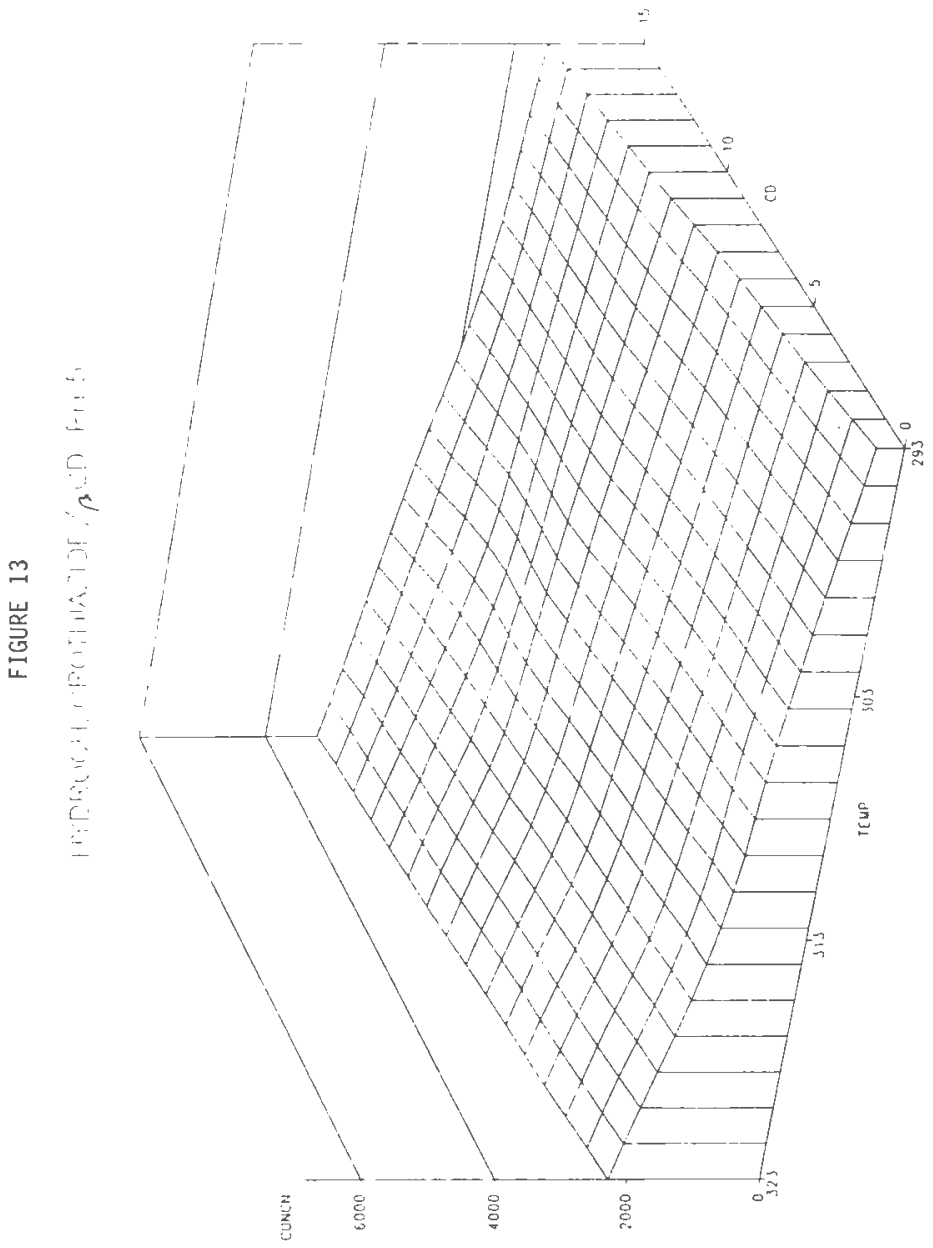




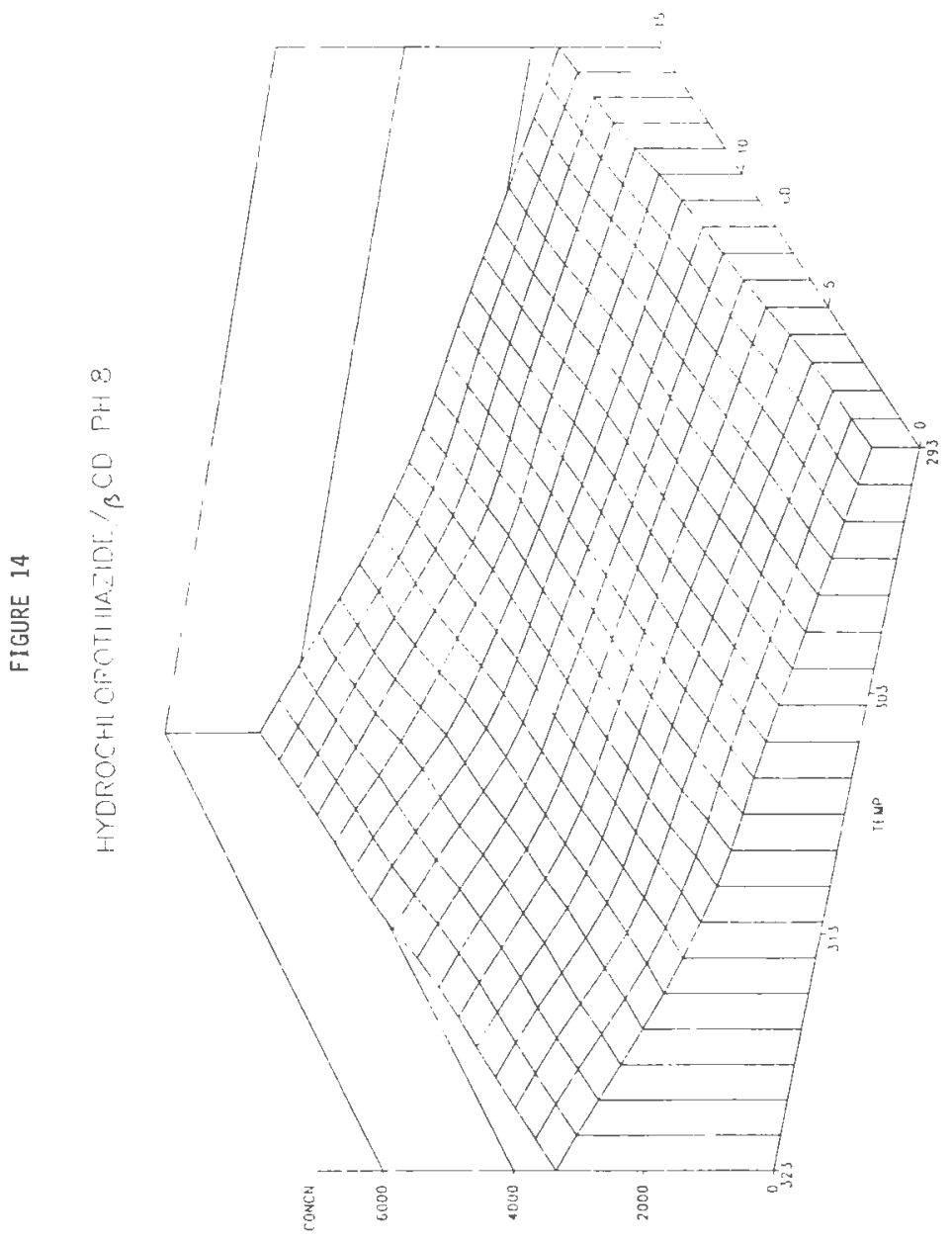




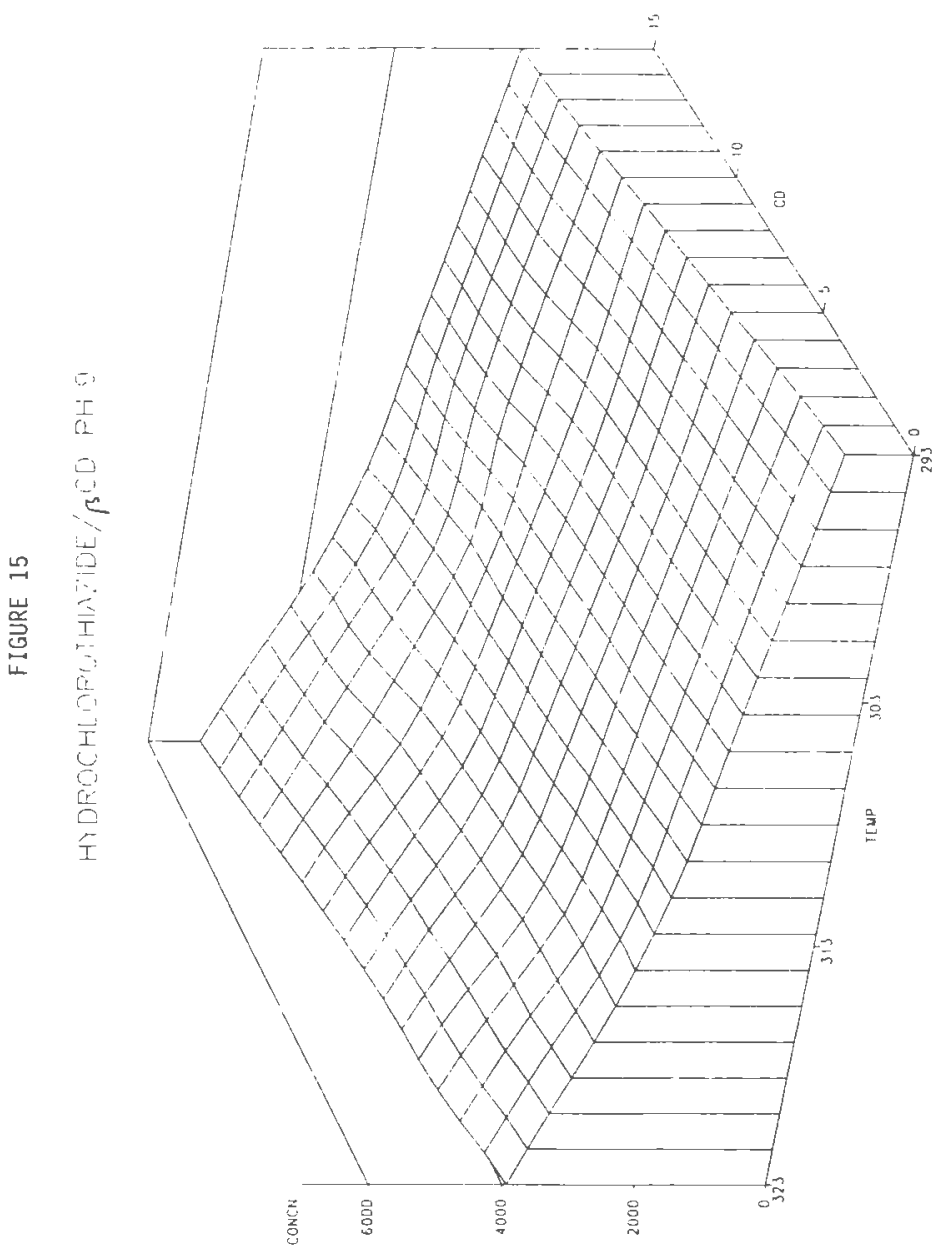


APPENDIX H 
BIBLIOGRAPHY

S.P. Agarwal and M.I. Blake. J. Pharm. Sci., 57 (8), 1434-1435 (1968).

K.S. Alexander, J.W. Mauger, H. Petersen and A.N. Paruta J. Pharm. Sci., 67, 625-627 (1978).

M.L. Bender and M. Kornigama, Cyclodextrin Chemistry, Berlin Heidelberg, NY (1978).

R.J. Bergeron, Inclusion Compounds: Atwood, Daries and MacNickol, Academic Press (1984).

R. J. Bergeron, M.A. Charming, and K.A. McGovern, J. Am. Chem. Soc., 100 (9), 2878-2883 (1978).

D.W. Block and P.P. Speiser, Pharm. Acta Helv., 62 (1), $23-27$ (1987).

G.K. Bolhuis, G. Reichman, C.F. Clerk, H.V. Vankamp and K. Zuurman, Drug Dev. Ind. Pharm., 11 (8), 1657-1681 (1985).

R. Breslow, Biomimet. Bioorg. Chem., 1-15 (1980).

R.N. Chilamkurti, C.T. Rhodes and J.B. Scwartz, Drug Dev. Ind. Pharm., 8, 63 (1982).

W.L. Chiou and S. Riegelman, J. Pharm. Sci., 60 (9), 1376-1380 (1971).

W.L. Chiou and S. Riegelman, J. Pharm. Sci., 60 (9), 281-302 (1971).

D.D. Chow and A.D. Kanara. Int. J. Pharmaceutics. 28, 95-101 (1986).

K.A. Connors and J.M. Lipari. J.Pharm.Sci. 65 (3), 379-383 (1976).

O.I. Corrigan and C.T. Stanley, J. Pharm. Pharmacol., $34,621-626(1984)$.

F. Cramer and F.M. Henglein, Chem. Ber., 90, 2561 (1957).

F. Cramer, W. Saenger and H.-Ch. Spatz, J. Am. Chem. Soc., 89 (1), 14-20 (1967).

Cyclodextrins and their industrial uses, Ed. de Sante, Paris (1987). 
Cyclodextrin News, 1 (10), 1 (1987).

D.S. Desai, C.T. Rhodes and J.L. Kanig, Proc. Pharm. Tech. Conf., 172 (1981).

D. Duchene, B. Debrueres and C. Vaution, STP Pharm., 1 (1), 37-43 (1985).

E. Fenyvesi, K. Takayama, J. Szejt1i and T. Nagai, Chem. Pharm. Bull., $32(20,670-677$ (1984).

D.J.W. Grant, M. Medhizadeh, A.H.-L. Chow and J.E. Fairbrother, Int. J. Pharm., 18, 25-38 (1984).

J.H. Greist, J.W. Jefferson and J. Marcetich, Behavioral Med., 12, 25 (1978).

K. Harata, K. Uekama, M. Otagiri and F. Hirayama, J. Incl. Phen., 1, 279-293 (1984).

G.E. Hardee, M. Otagiri and J.H. Perrin, Acta Pharm. Suec., 15, 199-199 (1978).

R.P. Hegde, Ph.D. Thesis, University of Rhode Island (1985).

R.P. Hegde and C.T. Rhodes, Pharm. Act. Helv., 6 (53), $(1985)$.

T. Higuchi, L.N. Elowe and L.W. Busse, J. Am. Pharm. Assoc., 43,685 (1954).

T. Higuchi and K.A. Connors, Adv. Anal. Chem. Instr., 4, $117-212$ (1965).

T. Higuchi and J.I. Lach. J. Am. Pharm. Assoc. 43, 349 (1954).

F. Hirayama and $K$. Uekama, Cyclodextrins and their industrial uses, ed. de Sante, Paris (1987).

F. Hirayama, M. Kurihara and K. Uekama, Chem. Pharm. Bull., 32, 4237-4240 (1984).

P. Hsyr, R.P. Hegde, B.K. Birmingham and C.T. Rhodes. Drug Dev. Ind. Pharm. 10 (4), 601-611 (1984).

K. Inaba, Personal communication (1986).

S.P. Jones, D.J.W. Grant, J. Hadgraft and G.D. Parr, Acta Pharm. Techn., 30, 213-223 (1984).

R.P. Jordan and C.T. Rhodes, Drug Dev. Ind. Pharm., 5, 151 (1979). 
M. Kata and L. Papp, Pharmazie, 42, 65-66 (1987).

K.A. Khan and C.T. Rhodes, J. Pharm. Sci., 66, 14 (1977).

S.P. King, M. Kung and H. Fung, J. Pharm. Sci., 73 (5), $657-662(1984)$.

M. Kirushi, F. Hirayama and K. Uekama, Chem. Pharm. Bul1., 35 (1), 315-319 (1987).

T.K. Korpela and J.-P. Himanen. J. Chromatogr. 290, 351-361 (1984).

M. Kurzumi, N. Nambu and T. Nagai, Chem. Pharm. Bull., 23,3062 (1975).

G. Levy, J.M. Antkowiak, J.A. Proknal and D.C. White, J. Pharm. Sci., 52, 1047 (1963).

S.Y. Lin and J.C. Yang, Drug Dev. Ind. Pharm., 13, $329-343(1987)$.

S.Y. Lin and J.C. Yang, Pharm. Weekblad Sc. Ed., 8, $223-228$ (1986).

R.H. Luecke and W.D. Wosilait, J. Pharmacokin. Biopharm., 14 (1), 65-78 (1986).

A.N. Martin, J. Swarbrick and A. Commarata, Physical Pharmacy, 3rd Edition, Lea and Febiger, Philadelphia (1983).

E. Martin, T.N. Tozer, L.B. Sheiner and S. Riegelman, J. Pharmacokin. Biopharm., 5 (6), 579-598 (1977).

Y. Matori, T. Niskioka and T. Fujita, Biometric. Bioorg. Chem., 128, 61-89 (1985).

Y. Matsui, T. Nishioka and T. Fujita, Biomet. Bioorg. Chem., 128, 61-89 (1985).

F.A. Menard, M.G. Dedhiya and C.T. Rhodes, submitted to Pharm. Act. Helv. (1987).

C.M. Metzler, Pharmac. Ther., 13, 543-553 (1981).

B.W. Muller and U. Brauns, Int. J. Pharm., 26, 77-88 (1985).

B.W. Muller and U. Brauns, Pharm. Res., 309-310 (1985).

Y. Nakamura and T. Sugama, Chem. Pharm. Bull., 32 , $4682-4685$ (1984). 
Y. Nakai, K. Yamamoto, K. Trada, H. Horibe and K. Ozawa, Chem. Pharm, Bu11., 31, 3745-3747 (1983).

Y. Nakai, Drug Dev. Ind. Pharm., 12 (7), 1017-1039 (1986).

Y. Nakai, K. Yamamoto, K. Terada and H. Horibe, Chem. Pharm. Bull., 30, 1796-1802 (1982).

G. Nemethy and H.A. Scheraga, J. Chem. Phys., 36 (2), $3401-3417(1962)$.

Y. Nozawa T. Mizumoto and F. Higashide, Pharm. Acta Helv., 61 (12), 337-341 (1986).

C. Nystrom, J. Mazur and J. Sjogren, Int. J. Pharm., 10, 209 $(1982)$.

C. Nystrom and M. Westerberg, J. Pharm. Pharmaco1., 38 , 161-165 (1986).

C. Ondari, Ph. D. Thesis, University of Rhode Island $(1984)$.

M. Otagiri, T. Imai, N. Matsuo and K. Uekama, Rcta Pharm. Suec., 20 (1), 1-10 (1983).

M. Otagiri, K. Uekama, T. Imai, T. Maeda, A. Takadate and S. Goya, Acta Pharm. Suec., 21, 357-366 (1984).

E. Parrott, Pharmaceutical Dosage Forms, Vol. II, Ed. H. Lieberman and L. Lachman, Marcel Dekker, New York $(1980)$.

C.C. Peck and I.Z. Benet. J.Pharm.Sci. 67 (1), 12-16 (1978).

J. Pitha, S.M. Harman and M.E. Michel, ,J. Pharm. Sci, $75,165-167(1986)$.

J. Pitha and J. Pitha, J. Pharm. Sci., 74, 987-990 (1987).

W.A. Ritschel and P. Parab, Drug Dev. Ind. Pharm., 11, 147 $(1985)$.

E. Rudnic et al., Drug Dev. Ind. Pharm,, 8, 87 (1982).

P.A. Schwartz and A.N. Paruta, J. Pharm. Sci., 65, 252-257(1976).

P.A. Schwartz, C.T. Rhodes and J.W. Cooper, Jr., J. Pharm. Sci., 66, 994-997 (1977). 
B. Sebille, Cyclodextrins and their industrial uses, Ed. de Sante, Paris (1987).

H. Sekikawa, N. Fukuda, M. Takada, K. Ohtani, T. Arita and M. Nakano, Chem. Pharm. Bull., 31 (4), 1350-1356 $(1983)$.

H. Seo, M. Tsuruokoa, T. Hashimoto, F. Fujinaga, M. Otagiri and $\mathrm{K}$. Uekama, Chem. Pharm. Bull., 31 (1), 286-291 (1983).

B. Siegel and R. Breslow. J.Am.Chem.Soc. 97 (23), 6869-6970 (1975).

H. Smith, C. Baker and J.W. Hood, J. Pharm. Pharmacol., 23, $536(1971)$.

E. Smolkova-Keulemansova and S. Krysl, J. Chromat., 184, 347-361 (1980).

S. Stavchansky and W.G. Gowan, J. Pharm. Sci., 73, 733 $(1984)$.

J. Szejtli, Cyclodextrins and their inclusion complexes, Akademiai Kiado, Budapest (1982).

J. Szejtli, J. Incl. Phen., 1, 135-150, (1983).

J. Szeman, H. Ueda, J. Szejtli, E. Fenyvesi, Y. Machida and T. Nagai, Chem. Pharm. Bul1., 35, 282-288 (1987).

I. Tabushi, Y. Kiyosuke, T. Sugimoto and K. Yamamura, J. Am. Chem. Soc., 100 (3), 916 (1978).

M. Tanaka, Y. Kawagushi, M. Nakae, Y. Mizobuchi and T. Shono, J. Chromat., 246, 207-214 (1982).

A.L. Thakkar, P.B. Kuehn, J.H. Perrin and W.L. Wilham, J. Pharm. Sci., 61, 1841-1843 (1972).

T. Tokumura et al., Chem. Pharm. Bull., 33 (7), 2962-2967 $(1985)$.

T. Tokunura et al., Chem. Pharm. Bull., 33 (5), 2079-2083 (1985).

T. Tokumura, Y. Tsushima, K. Tatsuishi, M. Kayano, Y. Machida and T. Nagai. Chem. Pharm.Bul1. 33 (7), 2962-2967 $(1985)$.

T. Tokumura, T. Tsushima, M. Kanayo, Y. Machida and T. Nagai, J. Pharm. Sci., 74 (4), 496-497 (1985). 
E.E. Tucker and S.D. Christian, J. Am. Chem. Soc., 106, 1942-1945 (1985).

K. Uekama, Pharm. Int., 3, 61-65 (1985).

$K$. Uekama and T. Erie, Cyclodextrins and their industrial uses, Editions de la Sante, Paris (1987).

K. Uekama and M. Otagiri, Cyclodextrin in drug carrier systems, CRC Press (1986).

K. Uekama, K. Udo, T. Irie, A. Yoshida and M. Otagiri, Acta Pharm. Suec., 24, 27-36 (1987).

K. Uekama, F. Hirayama, A. Fujise, M. Otagiri, K. Inaba and H. Saito. J. Pharm. Sci. 73 (3), 382-384 (1984).

K. Uekama and F. Hirayama, Chem. Pharm. Bull, 26 (4), 1195-1200 (1978).

K. Uekama, F. Fujinaga, F. Hirayama, M. Otagiri and M. Yamasaki, Int. J. Pharm., 10, 1-15 (1982).

K. Uekama, T. Fujinaga, M. Otagiri, N. Matsuo and $Y$. Matsuoka, Acta Pharm. Suec., 20, 287-294 (1983).

K. Uekama, N. Hirashima, Y. Horiuchi, F. Hirayama, T. Ijitsu and M. Ueno, J. Pharm. Sci., 76, 660-661 (1987).

K. Uekama, F. Hirayama, S. Nasu, N. Matsuo and T. Irie. Chem. Pharm. Bull. 26 (11), 3477-3484 (1978).

K. Uekama, T. Imai, T. Maeda, T. Irie, F. Hirayama and M. Otagiri, J. Pharm. Sci., 74, 841-845 (1985).

K. Uekama, N. Matsuo, F. Hirayama, T. Yamagushi, Y. Imamura and $\mathrm{H}$. Ichibagase, Chem. Pharm. Bull., 27 (2), 398-402 (1979).

K. Uekama, M. Otagiri, S. Sakai, T. Irie, N. Matsuo and Y. Matsuoka. J. Pharm. Pharmacol. 37 (8), 532-535 (1985).

R.L. Vanetten, J.F. Sebastian, G.A. Clowes and M.L. Bender. J. Am. Chem. Soc. 89 (13), 3242-3262 (1967).

B.P. Wall, J.E. Parkin, V.B. Sunderland and a. Zorbas, J. Pharm. Pharmacol., 34, 601 (1982).

B.P. Wall, J.E. Parkin and V.B. Sunderland, Austral. J. Pharm. Sci., 7, 57 (1978).

M.J. Waring, H. Sen, J.W. Eorrester and J.R. Salmon, Proc. 5th Pharm. Tech. Conf., 172 (1981). 
D.E. Wurster and P.W. Taylor, J. Pharm. Sci., 54, 169 (1965).

S. Yakou, S. Yamasaki, T. Sonobe, T. Nagai and M. Sugihara, Chem. Pharm. Bull., 34 (8), 3408-3414 (1986).

S. Yakou, S. Yamazaki, T. Sonobe, M. Sugihara, K. Fukumuro and T. Nagai, Chem. Pharm. Bull., 34 (10), $4400-4402$ (1986). 